\title{
GENE EXPRESSION IN HCV-ASSOCIATED HCC - IDENTIFICATION OF AN UP-REGULATED GENE ENCODING A PROTEIN RELATED TO UBIQUITIN CONJUGATING ENZYME
}

Thesis submitted to the Faculty of Medicine of the University of London for the degree of

Doctor of Philosophy

By

Ghada Maghawry Abdel-Latif El-Nady

Center for Hepatology, University Department of Medicine, Royal Free Campus, Royal Free and UCL Medical School, UCL

University of London 
ProQuest Number: U643755

All rights reserved

INFORMATION TO ALL USERS

The quality of this reproduction is dependent upon the quality of the copy submitted.

In the unlikely event that the author did not send a complete manuscript and there are missing pages, these will be noted. Also, if material had to be removed, a note will indicate the deletion.

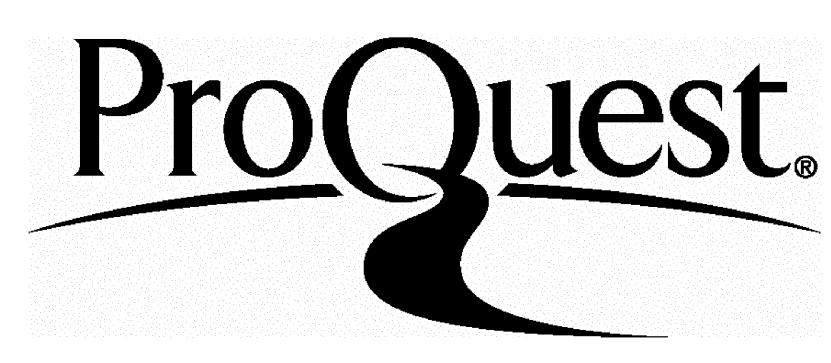

ProQuest U643755

Published by ProQuest LLC(2016). Copyright of the Dissertation is held by the Author.

All rights reserved.

This work is protected against unauthorized copying under Title 17, United States Code. Microform Edition @ ProQuest LLC.

ProQuest LLC

789 East Eisenhower Parkway

P.O. Box 1346

Ann Arbor, MI 48106-1346 


\section{Acknowledgement}

My thanks and praise go first of all to God who created us, taught us what we did not know, and showed us the right path to live, think, and thank him. No words can praise him the way he deserves.

I am extremely grateful to Dr Tim Harrison whose guidance and support were essential throughout all steps of this study. His valuable comments and critical reading helped me editing this thesis.

Thanks are also to Dr Vincent Emery for his encouragement and support.

I would like to acknowledge the generous help, advice and friendship of Dr Roger Ling who saw me through the whole study. His help is gratefully appreciated.

I would particularly like to acknowledge the help of Dr Kay Savage and Dr Alberto Quaglia, Histopathology Department, Royal Free Campus, UCL, and Dr Patrice Butler, Department of Surgery, Royal Free Campus, UCL, for providing me with liver tissues included in the study.

I would like to extend special thanks for my Professors in Medical Microbiology Department, Faculty of Medicine, Mansoura University, Egypt, for giving me the opportunity to carry out this study and lastly to the Egyptian Education Bureau, London, for funding this work. 


\begin{abstract}
Hepatocellular carcinoma is increasing in incidence throughout the world and the risk of developing hepatocellular carcinoma in chronic HCV infection has been estimated to be 100 times the risk in uninfected persons. To understand better the cellular changes in HCV-induced human hepatocellular carcinoma, differential display RT-PCR was used to compare levels of gene expression in tumour and non-tumour tissue from the same livers. Fifty two differentially expressed cDNA fragments were identified, 29 of them were cloned and sequenced and compared to the nucleotide sequence database.

Differential expression was confirmed using a ribonuclease protection assay (RPA) which confirmed reproducibly that one particular cDNA was up-regulated in the tumour cells. The relative expression levels of this candidate gene were studied in various normal tissues and some malignant cell lines using multiple tissue expression (MTE) array which revealed that this gene is expressed at high levels in various cell lines derived from human tumours. The expression level in $\mathrm{HCV}$-associated $\mathrm{HCC}$ was compared to other tumours using RPA which revealed that its expression levels in $\mathrm{HCV}$-associated $\mathrm{HCC}$ was higher than its level in other tumours. Further characterisation of the gene was carried out using nucleotide sequence analysis programmes and northern hybridisation was carried out to estimate the gene size. Investigation of this clone revealed that this novel gene lies on chromosome 17. It is about $2.7 \mathrm{~kb}$ in size and encodes a protein similar to ubiquitin conjugating enzyme suggesting that the ubiquitin system might be involved in $\mathrm{HCV}$ related hepatocarcinogenesis.
\end{abstract}




\section{Contents}

$\begin{array}{ll}\text { Title page } & 1\end{array}$

$\begin{array}{ll}\text { Acknowledgement } & 2\end{array}$

$\begin{array}{ll}\text { Abstract } & 3\end{array}$

Contents 4

$\begin{array}{ll}\text { List of figures } & 10\end{array}$

$\begin{array}{ll}\text { List of tables } & 11\end{array}$

Chapter 1: Tumours of the liver $\quad 12$

1.1. Benign tumours: $\quad 13$

1.1.1. Cavernous haemangioma. 13

1.1.2. Hepatocellular adenoma. 13

1.1.3. Focal nodular hyperplasia (FNH). 14

1.2 Hepatocellular carcinoma: $\quad 14$

1.2.1. Introduction. 14

1.2.2. Epidemiology. 15

1.2.3. Association with cirrhosis. 16

1.2.4. Risk factors: $\quad 17$

1.2.4.1. Hepatitis B virus (HBV) infection. $\quad 17$

1.2.4.2. Hepatitis $\mathrm{C}$ virus (HCV) infection. 22

$\begin{array}{ll}\text { 1.2.4.3. Aflatoxins. } & 27\end{array}$

1.2.4.4. Alcohol. $\quad 28$

1.2.4.5. Iron overload. $\quad 30$

1.2.4.6. Other factors. $\quad 31$

1.2.5. Pathogenesis of HCC. 31

1.2.6. Apoptosis and HCC. 33

1.2.7. Pathology of HCC: 35

1.2.7.1. Macroscopic Pathology. $\quad 35$

1.2.7.2. Microscopic pathology. $\quad 36$

1.2.8. Clinical features of HCC: 37 
1.2.8.1. Initial symptoms. $\quad 37$

1.2.8.2. Clinical manifestations. $\quad 37$

1.2.9. Diagnosis: $\quad 37$

1.2.9.1. Laboratory findings. $\quad 38$

1.2.9.2. Sonography (US). $\quad 39$

1.2.9.3. Colour Doppler US. 39

1.2.9.4. Computed tomography (CT). 39

1.2.9.5. Lipiodol Computed tomography. $\quad 40$

1.2.9.6. Magnetic resonance imaging (MRI). $\quad 40$

1.2.9.7. Digital Subtraction Angiography (DSA). $\quad 40$

1.2.10. Prognosis. 41

1.2.11. Prevention. $\quad 41$

1.2.12. Treatment: $\quad 44$

1.2.12.1. Surgical treatment. $\quad 44$

1.2.12.2. Percutaneous ethanol injection (PEI). $\quad 44$

1.2.12.3. Radio frequency (RF) ablation. 45

1.2.12.4. Transcatheter Arterial Chemoembolisation. $\quad 45$

1.2.12.5. Combined PEI and TACE. 46

1.2.12.6. Gene therapy for HCC. 46

1.3. Fibrolamellar carcinoma: $\quad 51$

1.3.1. Introduction. 51

1.3.2. Clinical features. 51

1.3.3. Pathology: $\quad 52$

1.3.3.1. Macroscopic appearance. $\quad 52$

1.3.3.2. Microscopic appearance. $\quad 53$

1.3.4. Diagnosis: $\quad 53$

1.3.4.1. Laboratory findings. $\quad 53$

1.3.4.2. Biopsy for diagnosis. $\quad 54$

1.3.4.3. Radiography. $\quad 54$

1.3.4.4. US. $\quad 54$

1.3.4.5. CT. $\quad 55$

1.3.4.6. MR Imaging. $\quad 55$

1.3.4.7. Angiography. $\quad 55$

1.3.5. Differential Diagnosis. 56

1.3.6. Prognosis and treatment. $\quad 56$

$\begin{array}{ll}\text { 1.4. Aims of the study. } & 57\end{array}$

Chapter 2: Analysis of differential gene expression 58

2.1. Introduction: $\quad 59$

2.1.1. History of gene expression detection. 59

2.1.2. Methods for detecting differential gene expression: $\quad 59$ 
2.1.2.1. Differential screening. $\quad 60$

2.1.2.2. Subtractive hybridisation. $\quad 60$

2.1.2.3. Enzymatic degrading subtraction (EDS). 61

2.1.2.4. Representational difference analysis (RDA). 62

2.1.2.5. Differential display. 63

\subsection{Materials and Methods: $\quad 68$}

2.2.1. Samples. $\quad 68$

2.2.2. mRNA extraction. 68

2.2.3. cDNA synthesis. 69

2.2.4. Differential Display Polymerase Chain Reaction 71

(DDRT-PCR):

2.2.4.1. Primers. $\quad 71$

2.2.4.2. PCR mix. $\quad 72$

2.2.4.3. Thermal cycler protocol. $\quad 73$

$\begin{array}{ll}\text { 2.2.5. Electrophoresis. } & 73\end{array}$

2.2.6. Reamplification. $\quad 74$

2.2.7. Cloning: 76

2.2.7.1. Blunt ended cloning. $\quad 76$

2.2.7.2. TA cloning. $\quad 79$

2.2.8. Sequencing: $\quad 80$

2.2.8.1. Chain termination sequencing. $\quad 80$

2.2.8.2. Cycle Sequencing. $\quad 82$

2.2.8.3. Gel electrophoresis. 83

2.2.9. Analysis of the sequences. 84

2.2.9.1. ORF finder. $\quad 84$

2.2.9.2. Sequence homology. $\quad 84$

2.3. Results: $\quad 85$

2.3.1. DDRT-PCR on HCV-associated HCC. 85

2.3.2. Cloning of DDRT-PCR bands. 87

2.3.3. Sequencing of DDRT-PCR clones. 87

2.3.4. Sequence analysis: $\quad 89$

2.3.4.1. ORF finder. $\quad 89$

2.3.4.2. Nucleotide sequence database search. 90

2.4. Discussion.

Chapter 3: Confirmation of differential expression 96

3.1. Introduction: $\quad 97$

3.1.1. Northern Hybridisation: 97

3.1.1.1. Introduction. 97 
3.1.1.2. Principles of northern hybridisation. 98

3.1.1.3. Hybridisation probes. $\quad 99$

3.1.2. Ribonuclease Protection Assay (RPA): $\quad 100$

3.1.2.1. Introduction. 100

3.1.2.2. Principles of RPA. 100

3.1.2.3. Advantages of RPA. 101

3.1.3. Quantitative PCR. 102

3.2. Materials and Methods: 103

3.2.1. Northern Hybridisation: 103

3.2.1.1. Sample preparation. 103

3.2.1.2. Agarose gel electrophoresis. 103

3.2.1.3. Hybridisation with RNA probe. 104

3.2.1.4. Hybridisation with a DNA Probe. 107

3.2.2. RPA: 108

3.2.2.1. Probe synthesis. 108

3.2.2.2. Hybridisation of Probe and Sample RNA. 113

3.2.2.3. RNase digestion of hybridised probe and $\quad 115$ sample RNA.

3.2.2.4. Separation of protected fragments. 116

3.3.2.5. Detection of results. 116

$\begin{array}{ll}\text { 3.3. Results: } & 117\end{array}$

3.3.1. Results of northern hybridisation. 117

3.3.2. Results of RPA: 117

$\begin{array}{ll}\text { 3.3.2.1. RPA 1. } & 119\end{array}$

3.3.2.2. RPA 2. 120

3.3.2.3. RPA 3. 121

3.3.2.4. RPA 4. 122

3.3.2.5. RPA 5. 123

3.3.2.6. Summary of RPA results. 124

3.4. Discussion. 125

Chapter 4: Characterisation of clone $397 \quad 128$

4.1 Introduction $\quad 129$

4.1.1. Historical backgrounds. 129

4.1.2. Computer analysis of newly identified cDNAs: 130

4.1.2.1. Basic Local Alignment Search Tool (BLAST). 130

4.1.2.2. NIX tool. 131

4.1.3. Amplification of complete cDNA molecules: 131

4.1.3.1. 5'-SMART RACE cDNA Amplification. 131

4.1.3.2. Inverse PCR. 132

4.1.4. Multiple tissue expression study. 132 
4.2.1. Computer analysis. 134

4.2.2. PCR amplification: $\quad 134$

4.2.2.1. 5'- end amplification. 135

4.2.2.2. Amplification of tailed cDNA. 142

4.2.2.3. "5'RACE system for rapid amplification of 142 cDNA Ends.

4.2.2.4. Inverse PCR. 146

4.2.2.5. Designing degenerate primer mixes. $\quad 150$

4.2.2.6. Amplification of predicted exons. 151

4.2.2.7. Amplification of full length gene. 153

4.2.3. Cloning and sequencing the full length gene. 153

4.2.4. Multiple tissue expression study. 154

4.2.4.1. Clone 397 probe. 154

$\begin{array}{ll}\text { 4.2.4.2. Control probe. } & 157\end{array}$

4.2.5. Northern hybridisation. 157

$\begin{array}{ll}\text { 4.2.6. RPA. } & 157\end{array}$

4.3. Results: $\quad 159$

4.3.1. Computer analysis: 159

$\begin{array}{lr}\text { 4.3.1.1. BLAST. } & 159\end{array}$

4.3.1.2. NIX. 159

4.3.2. PCR amplification: $\quad 161$

4.3.2.1. SMART RACE cDNA amplification kit, $\quad 161$ CLONTECH.

4.3.2.2. Amplification of tailed cDNA. 162

4.3.2.3. 5'RACE system for rapid amplification of $\quad 162$ cDNA Ends.

4.3.2.4. Inverse PCR. 163

4.3.2.5. Degenerate primer mixes. 163

4.3.2.5. Amplification of the 5 predicted exons. 163

4.3.2.6. Amplification of full length cDNA. 163

4.3.3. Sequencing of the full length clone. 165

4.3.4. MTE. 168

4.3.5. Northern blot analysis. 168

4.3.6. Gene expression analysis in various tumours. 171 
4.4. Discussion.

Chapter 5: General discussion.

References.

List of abbreviations.

229

Appendix I: Raw data of ribonuclease protection assays.

234

Appendix II: Constitution of buffers and solutions.

243

Appendix III: Abstract presented in the EASL 2001 meeting. 249 


\section{List of figures}

Figure 1.1 World-Wide Incidence of HCC. 15

$\begin{array}{lll}\text { Figure } 1.2 & \text { The JAK/STAT pathway. } & 21\end{array}$

Figure 1.3 Gene therapy with retroviral vector. 49

$\begin{array}{lll}\text { Figure 2.1 Steps of DDRT-PCR. } & 65\end{array}$

Figure 2.2 Different $\mathrm{MgCl}_{2}$ concentration in DDRT-PCR. 85

$\begin{array}{lll}\text { Figure 2.3 DDRT-PCR gels. } & 86\end{array}$

$\begin{array}{lll}\text { Figure 3.1 } & \text { Ribonuclease protection assay gel. } & 118\end{array}$

Figure 3.2 The optic density ratios of probes 383 and 403.

Figure 3.3 The optic density ratios of probes 333, 361 and $385 . \quad 120$

Figure 3.4 The optic density ratios of probes 299 and 373.

$\begin{array}{lll}\text { Figure 3.5 The optic density ratios of probes } 389 \text { and } 397 . & 122\end{array}$

Figure 3.6 The optic density ratios of probes 281, 287 and $311 . \quad 123$

$\begin{array}{lll}\text { Figure } 4.1 & 133\end{array}$

Figure 4.2 Display of NIX results. 160

$\begin{array}{lll}\text { Figure 4.3 Amplification of EST AA845421. } & 161\end{array}$

$\begin{array}{lll}\text { Figure 4.4 Amplification of EST AA845421. } & 162\end{array}$

Figure 4.5 Amplification of the predicted exons. 164

$\begin{array}{lll}\text { Figure 4.6 Amplification of the full length clone. } & 164\end{array}$

Figure 4.7 Sequencing the full length clone. 165

$\begin{array}{lll}\text { Figure } 4.8 & \text { Full length clone. } & 167\end{array}$

Figure 4.9 Probing the MTE array with clone 397 probe. 169

Figure 4.10 Probing the MTE array with HKG probe. 169

Figure 4.11 cDNA 397 expression levels in various tissues. 170

$\begin{array}{lll}\text { Figure 4.12 Northern blot analysis of cDNA } 397 . & 170\end{array}$

Figure 4.13 cDNA 397 expression levels in various tumour tissues. 171

$\begin{array}{lll}\text { Figure 5.1 } & \text { The ubiquitin pathway } & 179\end{array}$ 


\section{List of tables}

$\begin{array}{lll}\text { Table 2.1 Primers for DDRT-PCR. } & 71\end{array}$

$\begin{array}{lll}\text { Table } 2.2 & \text { Sequences of } 26 \text { clones. } & 88\end{array}$

$\begin{array}{lll}\text { Table } 2.3 & \text { BLAST search, October } 1999 . & 90\end{array}$

Table $2.4 \quad$ BLAST search, August 2001. 92

Table 3.1 Optic density ratios for probes 383 and $403 . \quad 119$

Table 3.2 Optic density ratios for probes 333, 361 and $385 . \quad 120$

Table 3.3 Optic density ratios for probes $299 \mathrm{~b}$ and $373 . \quad 121$

Table 3.4 Optic density ratios for probes 389 and $397 . \quad 122$

Table 3.5 Optic density ratios for probes 281, 287 and 311 . 123

$\begin{array}{lll}\text { Table } 3.6 & \text { Summary of RPA results. } & 124\end{array}$

$\begin{array}{lll}\text { Table 4.1 } & \text { Primers for 5' end amplification. } & 137\end{array}$

$\begin{array}{lll}\text { Table 4.2 Primers for sequence GS2073. } & 140\end{array}$

$\begin{array}{lll}\text { Table } 4.3 & \text { Primers for sequence AA845421. } & 141\end{array}$

Table 4.4 Primers for inverse PCR. 146

$\begin{array}{lll}\text { Table } 4.5 & \text { Primers for predicted exons. } & 152\end{array}$

Table 4.6 Sequencing primers for full length clone. 153

Table 4.7 Optic density ratios of cDNA 397 in various tumours. 172 
Chapter 1

Tumours of the liver 


\section{Tumours of the liver}

Tumours of the liver are either primary or metastatic. They are divided into benign or non-cancerous tumours, which remain localised in the liver, and malignant ones, which may spread to other parts of the body. This chapter will include some of the common neoplasms of the liver.

\subsection{Benign tumours:}

\subsubsection{Cavernous haemangioma:}

Cavernous haemangioma is the most common benign tumour of the liver. The incidence is around $2 \%$ of hepatic neoplasms. The aetiology of this tumour is unknown and most patients are asymptomatic. However, some patients present with abdominal mass, heart failure, coagulopathy or rupture. This tumour is usually detected by chance on imaging by ultrasound or computed tomography, which can usually diagnose the tumour accurately. Non-specific therapy is usually adequate unless the tumour is extremely large (Iqbal \& Saleem, 1997).

\subsubsection{Hepatocellular adenoma:}

The other common benign tumours of the liver are hepatocellular adenoma and focal nodular hyperplasia. Both of these two tumours are detected by chance. Hepatocellular adenoma has a risk of bleeding within the tumour mass itself or within the peritoneal cavity. Surgical resection of hepatic adenoma may be indicated sometimes to avoid the risk of bleeding or rupture (Grazioli et al., 2001) and malignant transformation (Terkivatan et al., 2001). 


\subsubsection{Focal nodular hyperplasia (FNH):}

FNH of the liver is another benign condition that usually reflects an abnormal hyperplastic response to a vascular abnormality (Wanless et al., 1989). It is more common in women than men and the role of endogenous oestrogens has been suggested as an explanation of the female predominance and its incidence during the child bearing period (Mathieu et al., 1998). Nime et al. (1979) suggested that high dose exogenous oestrogens enhance the growth and augment the vascular changes of FNH. As a result, patients with FNH were advised to discontinue oral contraceptives (Pain et al., 1991). However, Mathieu et al. (2000) reported that FNH development is independent of oral contraceptive use, whether the oral contraceptive was of low-dose estrogens, high-dose estrogens or progestogens. Furthermore, they found pregnancy not to be associated with FNH changes or complications. Being a benign condition, the treatment usually is conservative and therefore the differentiation from other malignant hepatocellular tumours is essential.

\subsection{Hepatocellular carcinoma $(H C C)$ :}

Hepatocellular carcinoma is a primary hepatic malignant neoplasm originating from epithelial tissue.

\subsubsection{Introduction:}

Hepatocellular carcinoma is a multiformed malignant tumour derived from hepatocytes. It is the predominant primary liver neoplasm and accounts for more than $80 \%$ of hepatic tumours (Molmenti et al., 1999). The remaining fraction comprises primary malignancies arising from other cell types such as cholangiocarcinoma and angiosarcoma (Stuver, 1998). HCC frequently is found on top of chronic liver disorders like cirrhosis, chronic hepatitis $\mathrm{B}(\mathrm{HBV})$ or $\mathrm{C}$ virus (HCV) infections, prolonged 
consumption of alcohol (Hardell et al., 1984) and exposure to aflatoxins (Ross et al., 1992a).

\subsubsection{Epidemiology:}

Hepatocellular carcinoma is increasing in incidence throughout the world. It is the fourth-most common tumour in the world (Scuric et al., 1998). It is a major cause of cancer death in Asia and Africa as a result of its high incidence and poor prognosis (Songsivilai et al., 1995).

The annual incidence of HCC varies from three to seven cases per 100,000 population in some parts of the world like North America and most of Europe, and up to 35 per 100,000 population in parts of sub-Saharan Africa, China and South-East Asia (Ogunbiyi, 2001), as shown in figure 1.1. A greater incidence has been found in black than white men in the United States (El Serag \& Mason, 1999). In Africa, the highest incidence has been found also in black Africans with the lowest incidence among the whites in north and south Africa (Ogunbiyi, 2001).

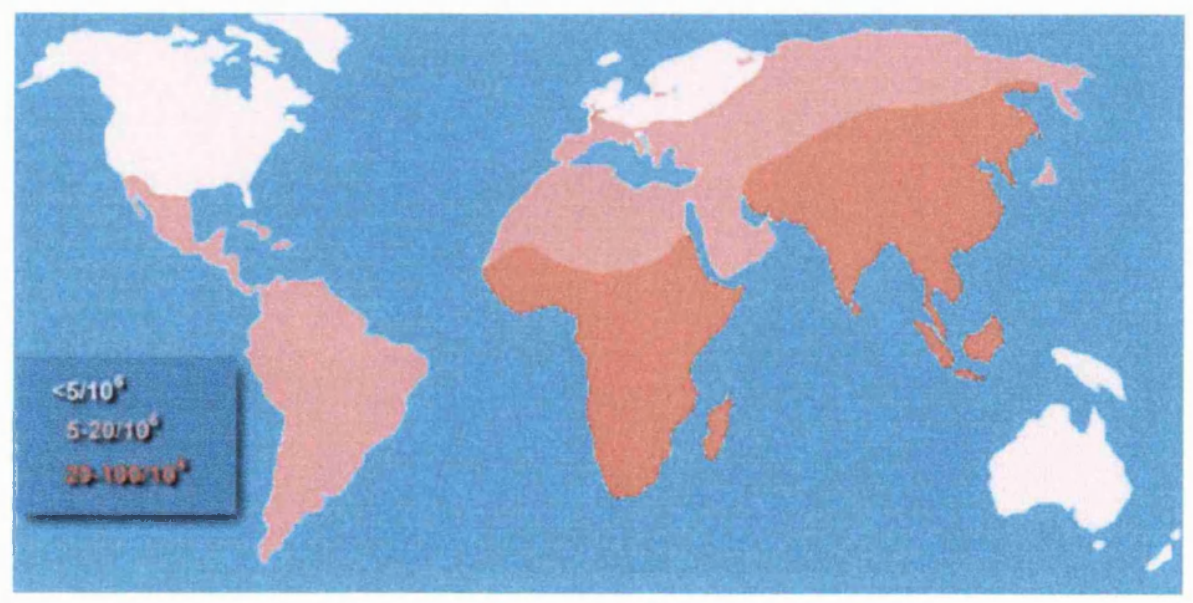

Figure 1.1

World-Wide Incidence of HCC 
Hepatocellular carcinoma is known to be more prevalent in males than females. The male: female ratio varies between $3: 1$ to $5: 1$ according to the geographic distribution (Ni et al., 1991). The male predominance was attributed to the association with HBV infection and the higher proportion of alcohol drinking and cirrhosis (Lai et al., 1987). The presence of androgen receptors in HCC cells have been suggested as another reason for the male predominance (Nagasue et al., 1986).

The incidence increases with age in most populations, with a peak in the fifth and sixth decades of life, then decreases in the elderly. In high incidence areas like Africa, the incidence shifts to the younger age groups with a peak in the third through the fifth decades. This early onset can be explained by infection with the hepatotropic viruses, $\mathrm{HBV}$ and $\mathrm{HCV}$, as well as exposure to aflatoxins early in life (Munoz \& Bosch, 1987).

\subsubsection{Association with cirrhosis:}

Up to $90 \%$ of cases of HCC develop on top of cirrhosis. The aetiology of this underlying cirrhosis is variable. In western countries, alcoholic cirrhosis is the commonest type while in the Far East, post hepatitis cirrhosis is more common (Molmenti et al., 1999). HCV has been implicated as a causative factor in as many as $80 \%$ of HCC cases in Japan (Tanaka et al., 2001).

It has been found that in high incidence areas, most of patients develop HCC on top of silent cirrhosis. This is explained by the fact that in these areas, patients develop cirrhosis in association with HBV infection. HBV related cirrhosis might present with an insidious course and fewer symptoms. On the other hand, in low incidence areas like the UK and northern Europe, about $50 \%$ of cirrhotic patients are alcoholic and seek medical attention for the other effects of excessive alcohol intake (Zaman et al., 1990). 


\subsubsection{Risk factors:}

\subsubsection{Hepatitis B virus (HBV) infection:}

There are estimated to be more than 400 million people worldwide chronically infected with HBV (Diao et al., 2001). Strong evidence indicates that persistent HBV infection is a major risk factor for the development of $\mathrm{HCC}$, as it has been implicated as a causative factor in as many as $80 \%$ of $\mathrm{HCC}$ cases in Chinese and black African populations (Arbuthnot \& Kew, 2001).

The distribution of hepatocellular carcinoma is correlated with the geographic distribution of chronic carriers of HBV. In endemic areas, such as Eastern Asia and subSaharan Africa, HBV infection commonly occurs at an early age and persists in adulthood (Szmuness, 1978).

Chronic HBV infection is associated with the development of macronodular cirrhosis. Long standing infection and the presence of cirrhosis in HBV-infected individuals increases the risk of developing HCC (Robinson, 1994).

\section{Pathogenesis:}

The oncogenic process associated with persistent $\mathrm{HBV}$ infection might be attributed to indirect oncogenicity starting with inflammation, increased cell turnover and cirrhosis. HBV-associated HCC usually develops in the regenerative nodules of infected livers where the HBV genome is integrated in the host cell chromosomes (Chen et al., 1986). Direct hepato-carcinogenecity might start with HBV-DNA integration into the hepatocyte chromosomes during HBV infection. The site of integration into the hepatocyte DNA becomes prone to deletions, translocations and rearrangements.

Ordered integration of viral DNA in cellular DNA has been described as an intrinsic part of retrovirus replication. This is not the case in hepadnavirus replication although 
sporadic viral integration takes place. Integrated viral DNA has been detected in cellular DNA of infected livers as well as HCC. Many HCCs have been found to contain viral integration with a clonal pattern, probably indicating that these tumours have arisen from clonal expansion of a cell containing this integration of the viral DNA (Dejean $e t$ al., 1984). So far, no preferential integration sites has been found in human HCCs. However, HBV integration in a few HCCs has been mapped for some cellular growth genes such as the cyclin A gene (Wang et al., 1992), the nuclear receptor gene (Dejean et al., 1986) and the mevalonate kinase gene (Graef et al., 1994). On the other hand, woodchuck hepatitis virus DNA was found to integrate near the c-myc oncogene and to activate its expression (Hsu et al., 1988).

In human HCCs, the sequences of these integrants are variable. Some consist of contiguous linear sequences of HBV DNA without rearrangement, others might consist of multiple viral genomes at one site due to post-integration rearrangement and recombination of different integrants (Matsubara \& Tokino, 1990). Integrations involving the surface antigen gene have been found to be present in the greatest number, whilst these of the core antigen gene were underrepresented (Chen et al., 1988).

It has been found that HBV integrations are associated with various genetic changes in the cellular DNA. Microdeletions, of about $10 \mathrm{bp}$, have been reported in all the sites of integration suggesting that it is an integral part of the HBV integration mechanism (Matsubara \& Tokino, 1990). However, larger deletions have been also found in sporadic HCCs, probably as a result of a different mechanism to the microdeletions (Rogler et al., 1985). Translocations involving DNA from two different chromosomes joined together at the ends of the viral DNA have been also described (Moroy et al., 1986). Other forms of the common genetic rearrangements at the site of integration are inverted identical sequences of both the integrated viral sequences as well as the 
flanking cellular DNA. It has been thought that such structures originated from the amplification of the initial simple integrant, whereupon two copies underwent head-totail recombination. Head-to-tail repeats of the integrated viral DNA have been reported in some HCCs (Matsubara \& Tokino, 1990). Less common genetic changes include amplification of a segment of the cellular DNA at the site of integration (Hatada et al., 1988).

cis-activation of cellular genes:

HBV DNA integration may cause cis-activation of cellular genes via the insertion of viral promoters. However, viral integrants may contain other cis-acting sequences such as the enhancers and glucocorticoid-responsive element, that may activate or inactivate cellular genes by insertion or deletions (Rogler et al., 1985) or translocations (Hino et al., 1986). In addition, HBV-DNA has been reported into sequences homologous to the oncogene v-erbA and steroid receptor genes (Dejean et al., 1986) which were identified as a novel retinoic acid receptor gene (Brand et al., 1988). Changes in these receptors have been thought to activate the neoplastic process. Moreover, analysis of another integrant site revealed that the target site was an intron in a cyclin A gene (Wang et al., 1990). Cyclins are crucial regulators for cell division and disruption of the normal gene expression may result in abnormal cell growth.

\section{Transcriptional transactivation:}

Another possible mechanism of oncogenesis by HBV-DNA is oncogene transactivation by the X-gene product. The X ORF, located at the 3' end of the linearised pregenomic RNA, encodes the HBX protein. HBX is the smallest HBV protein and presumably required for the replication of HBV in vivo, as suggested in woodchucks (Chen et al., 1993). HBX protein activates transcription and increases the expression of growth- 
regulating genes involved in the malignant transformation of hepatocytes (Ince \& Wands, 1999). Many cellular genes have been found to be activated by HBX including cellular oncogenes c-myc (Balsano et al., 1991), c-fos (Avantaggiati et al., 1993) and cjun (Twu et al., 1993), as well as $\beta$-interferon (Twu \& Schloemer, 1987). This activation of gene expression may be important both for viral infection, as well as for disruption of cellular genes that regulate hepatocyte proliferation (Arbuthnot \& Kew, 2001).

HBX protein forms a complex with cellular proteins, which causes the activation of $\mathrm{p} 53$ tumour suppressor gene functions including apoptosis. The HBX protein can also bind to p53 or sequester it in the cytoplasm (Ueda et al., 1995) and inhibits its DNA binding and transcriptional activity (Wang et al., 1994). It may also inhibit p53 dependent apoptosis (Wang et al., 1996).

$\mathrm{HBX}$ protein also plays a major role in cell survival and transformation into $\mathrm{HCC}$ during HBV infection. It interacts with and stimulates some cellular kinases such as PCK, Jak /STAT, and MAP, which normally modulate transcriptional activity of various transcriptional factors involved in regulating cellular growth, differentiation and apoptosis (Lee \& Yun, 1998). The STAT family of genes is thought to have arisen from a single gene, via a series of gene duplications (Copeland et al., 1995). In the human genome, duplication and mutation have resulted in three clusters of genes: STATs 1 and 4 on $2 q$, STATs 2 and 6 on 12q and STATs 3, 5a and 5b on 17q. The initial step in the JAK-STAT pathway is the binding of a cytokine to its cognate cell-surface receptor, which then dimerizes and is transphosphorylated, on specific intracellular tyrosine residues in the receptor's cytoplasmic domain, in a reaction catalyzed by a receptorassociated JAK tyrosine kinase (figure 1.2). Latent cytoplasmic STAT proteins are then recruited to the activated receptor-kinase complex, via the STAT's COOH-terminal SH2 
(phosphotyrosine-binding) domain, and are phosphorylated on a COOH-terminal region tyrosine residue and, secondarily, on serine or threonine residues. The activated STATs then form homo- or heterodimers via mutual and complementary SH2-domain interactions and, within minutes, translocate to the nucleus, where they bind to specific promoter elements and transactivate their target genes (Leonard \& O'Shea, 1998). Activation of JAKISTAT signalling in the liver is associated with increased hepatocyte proliferation in response to stimulation by growth factors (Cressman et al., 1995).

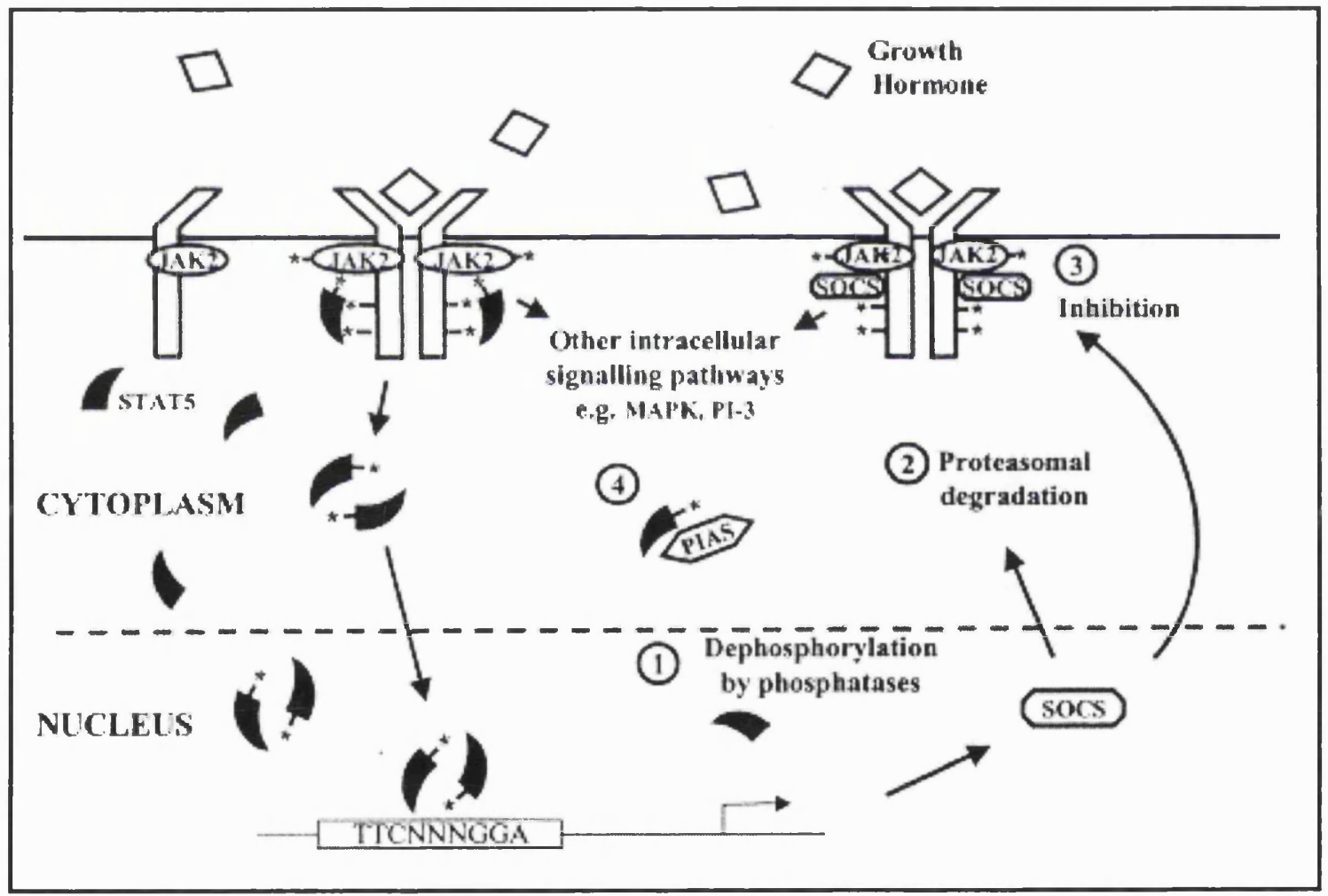

\section{Figure 1.2 The JAK/STAT pathway}

The growth hormone $(\mathrm{GH})$ JAK-STAT intracellular signaling pathway. GH binds to dimerized GH receptors, and the receptors and associated JAK2 phosphotyrosine kinases are phosphorylated $(*)$ and activated. Phosphorylated STAT5 proteins homo- or heterodimerize and translocate to the nucleus, where they bind to target DNA sequences. 


\subsubsection{Hepatitis $\mathrm{C}$ virus (HCV) infection:}

$\mathrm{HCV}$ is a member of the Flaviviridae and has a genome of $\sim 9.6 \mathrm{~kb}$. It is a small enveloped virus with a single strand positive sense RNA genome with no reverse transcriptase and does not integrate into the host genome (Tabor, 1992). The viral genome encodes a single large polyprotein. This polyprotein is cleaved by cellular and viral proteases into three structural (core, E1 and E2) and at least six non-structural (NS2, NS3, NS4a, NS4b, NS5a and NS5b) proteins (Grakoui et al., 1993). The core protein contains many basic amino acids presumably enabling RNA binding. The envelope proteins, E1 and E2, form the outer spikes in the viral membranes. Their functions include cell attachment, fusion to cell membranes and immune escape. Sequences in the NS2/NS3 comprise a metalloproteinase and require $\mathrm{Zn}^{2+}$ for cleavage of the NS2/NS3 boundary. After release of the NS3 amino terminus, the amino terminal third exhibits NS3 protease activity and the carboxy terminal two thirds exercise ATPase and RNA helicase activity. NS5B constitue the RNA-dependent RNA polymerase of the virus. The region encoding the polyprotein is flanked at both extremities by non-coding regions (NCR). The 5'NCR is highly conserved. It is 341 bases long and has weak similarity to the NCR of pestiviruses. It is folded into a complex set of stem loop structures which are essential for ribosome binding and translation of the large viral polyprotein. This region is known as the internal ribosomal entry site (IRES), and has an additional role in viral RNA replication. In contrast to the 5'NCR, the 3'NCR displays extreme heterogeneity. The first 23 to 66 nucleotides constitute the most heterogeneous sequence of the HCV genome. It was thought that a poly-(A) or more usually a poly-(U) sequence of variable length constituted the very 3 ' end of the HCV genome, but an additional sequence of 98 nucleotides downstream from the poly-(U) region was subsequently discovered. This region exhibits a higher level of 
conservation, as a conserved sequence at the 3' end of the genome may be required for initiation of RNA replication (Maertens et al., 1997).

$\mathrm{HCV}$ is a major cause of chronic hepatitis worldwide. It is usually transmitted parenterally in adults and about 80 percent of cases become chronic. Transfusion of blood products was a common mode of transmission before 1991. However, it has been found that about $50 \%$ of persons with chronic HCV infection have unknown routes of infection. In some parts of the world such as some towns in Japan, the prevalence of anti-HCV antibodies has been reported to exceed that in neighbouring towns. This has been thought to be due to unsanitary medical practice or to acupuncture (Takagi et al., 1998). A similar situation is present in Egypt where about $24 \%$ of the people are estimated to carry $\mathrm{HCV}$ and in some towns the anti-HCV positivity exceeds $50 \%$ in blood donors. These high rates are attributed to the parenteral antischistosomiasis therapy and prevention that was used in Egypt during 1918-1970 (Cohen, 1999).

The risk of developing hepatocellular carcinoma in chronic HCV infection is 100 times the risk in uninfected persons. Persistent infection with $\mathrm{HCV}$ is also an important risk factor for hepatocellular carcinoma (Molmenti et al., 1999). It has been found that a high percentage of patients with $\mathrm{HCC}$ have antibodies to $\mathrm{HCV}$, strongly supporting the correlation between HCV and HCC. This percentage has been estimated at about $51 \%$ in Japanese population (Tanaka et al., 1991a), $34.3 \%$ in China (Tsai et al., 1994), and about $30 \%$ among Egyptian HCC patients (Hassan et al., 2001). The known pathological changes associated with persistent $\mathrm{HCV}$ infection are, like persistent $\mathrm{HBV}$ infection, inflammation, cellular injury, regeneration, and cirrhosis which predispose to the carcinogenic process (Molmenti et al., 1999) but not integration of viral nucleic acid as $\mathrm{HCV}$ is an RNA virus with no reverse transcriptase.

\section{Pathogenesis:}


The natural history of $\mathrm{HCC}$ is heterogeneous and both the size and growth pattern are variable from one tumour to another. Encapsulated small tumours have been found to be frequent in HCV related HCC (Franco et al., 1990), while they were rare in HBV associated HCC (Anthony, 1973). HBV- tumours are more aggressive and grow by replacing the adjacent hepatic parenchyma (Colombo, 1999).

Chronic HCV infection causes long-lasting hepatic proliferation, cirrhosis and subsequently result in HCC. Although replicating HCV-RNA and virus specific protein expression have been detected in HCCs, the exact mechanism underlying the process of hepatocarcinogenesis in chronic $\mathrm{HCV}$ infection is still unclear. $\mathrm{HCV}$ is a ssRNA virus with no DNA intermediate and its integration into the host genome doesn't seem possible. However, the presence of patients who developed HCC on top of chronic HCV infection without the development of cirrhosis (el Refaie et al., 1996) suggests that HCV may be directly oncogenic. Although there is no evidence of activating protooncogenes or inactivating tumour suppressor genes (Sharara, 1997), the products of the virus might be involved in inducing liver cell proliferation.

\section{HCV core protein:}

\section{Properties:}

Recently, attention has been centred on the core protein and its properties. HCV core protein is derived from the cleavage of the $\mathrm{N}$-terminal 191 amino acids of the large precursor protein and is well conserved among all isolates (Bukh et al., 1994). This basic protein has RNA binding capacity and can form homomultimers. It can also bind to the viral E1 protein (Lo et al., 1996). It is found predominantly in the cytoplasm having granular distribution and related to the endoplasmic reticulum (McLauchlan, 2000) and a small amount has been found also in the nucleus. It has been described to associate with the endoplasmic reticulum, lipid droplets, apolipoprotein A II, 
lymphotoxin- $\beta$ receptor and tumour necrosis factor (TNF) receptor I (Jin et al., 2000).

\section{Function:}

It has become apparant that the main function of the core protein is the formation of the capsid shell of the virus. Recently, it seems apparent that the core protein can induce multiple effects on the cell. The effects of core protein on apoptosis have been studied intensely. Apoptosis, briefly, is programmed cell death that can be induced by a variety of stimuli. The stimulus exerts its effect via cell surface molecules which in turn activate a cascade of events and some enzymes called caspases inducing proteolytic activities (Thornberry, 1998). The best characterised cell surface molecules that trigger apoptosis are the tumour necrosis factor (TNF) and Fas receptor systems. Some studies have suggested that core protein is able to desensitise cells to Fas mediated apoptosis (Marusawa et al., 1999) and others have suggested that it increases TNF mediated apoptosis in HeLa, HepG2 and mouse fibrosarcoma cells (Zhu et al., 1998).

Studies in primary rat embryo fibroblasts have shown that core protein is only able to transform cells in combination with the cellular oncogene c-myc and H-ras.

Transformed cells displayed anchorage-independent growth, altered morphology and were able to induce tumours in nude mice (Ray et al., 1996a).

A recently described cellular protein, LZIP, has been identified as a direct core binding protein and cofactor in cellular transformation. LZIP presented activities consistent with that of a tumour suppressor. The transcriptional activities of this protein have been shown to be repressed by core protein. The core protein inactivates LZIP function through subcellular sequestration and loss of endogenous LZIP was correlated with abnormal cellular proliferation (Jin et al., 2000).

Moreover, Cho et al. (2001) studied the effects of HCV core protein on cyclin E in 
HCV core stable transfectant cell lines. Cyclins D, E and A are important factors for regulating the progression of a cell into G1 phase. Their data suggest that core protein promoted cell proliferation through the expression of cyclin $\mathrm{E}$ as well as increased kinase activities playing an important role in hepatocarcinogenesis.

Because cancer is a multistep process that requires a cumulative effect on changing cell regulators, inactivation of $\mathrm{p} 53$ has been considered an important event in human cancer. The p53 gene encodes a tumour suppressor protein that maintains the genetic integrity of the cell. As mentioned earlier, a large proportion of HCC patients are exposed to $\mathrm{HCV}$ and a p53 mutation has been found in a significant number of these patients. Mutational hotspots in p53 have been identified in HCV related HCC from Japanese patients. Most of these mutations were confined to exon 7, but none were found on codon 249 , as in the case of mutations induced by aflatoxin exposure. Instead, mutations were found in codons 245, 232 and 242. Mutations at exon 5 were also found on codons 146 and 159. Few cases displayed the $\mathrm{CGC}^{\mathrm{Arg}}$ to $\mathrm{CCC}^{\text {Pro }}$ polymorphism in codon 72 exon 4 (Wong et al., 2000). Moreover, Ray et al. (1997) found that the HCV core protein causes repression of $\mathrm{p} 53$ promoter activity and that the main core domain responsible for this repression is located between amino acid positions 80 and 122 . In addition to the data provided about the core protein, it has been suggested that other regions of the HCV genome may be potentially oncogenic. A truncated NS3 protease has been proven to transform murine fibroblasts and induced HCC in immunodeficient mice (Sakamuro et al., 1995).

It has been suggested that NS5A protein may have a role in the regulation of cell growth in a p53-dependent manner. This effect is mediated either through the down-regulation of the cell cycle regulatory gene $\mathrm{p} 21^{\mathrm{WAF} 1}$ or through a functional interaction between PKR protein kinase and $\mathrm{p} 53$. This interaction has a regulatory effect on gene expression 
at the transcriptional and translational level (Majumder et al., 2001). Moreover, De Mitri et al. (2002) showed that a significant majority of HCC patients had wild-type or a minimally mutated PKR-binding domain, suggesting that the inhibition of PKR activity by HCV may play a role in tumour development.

\subsubsection{Aflatoxins:}

Aflatoxins are hepatotoxins produced by Aspergillus flavus and Aspergillus parasiticus. Aflatoxins contaminate food supplies such as corn, peanuts, milo, sorghum, and rice in some regions of the world such as Qidong province of the Republic of China (Wang et al., 1999), sub-Saharan Africa and Mexico (Hussain \& Harris, 2000). Prolonged exposure to Aflatoxins has been reported to be associated with liver malignancies (Ross et al., 1992b). Aflatoxin B1 (AFB1) is considered one of the major risk factors for the development of HCC worldwide (Groopman et al., 1992).

The liver metabolises aflatoxins after ingestion into reactive intermediates that bind to guanine residues in the hepatocyte DNA (Ince \& Wands, 1999). To assess the exposure of AFB1, its metabolites could be measured in the urine or blood proteins and be used as biomarkers. However, these measurements have a limited role in the assessment of $\mathrm{AFB1}$ as a risk factor for the development of HCC. Ideally, these measures should be paired with other biomarkers that monitor long term exposure. It has been found that the somatic mutations that occur in the human hypoxanthine guanine phosphoribosyl transferase gene (HPRT) reflect the long-term exposure to DNA damaging agents and can be used as a biomarker (Cariello et al., 1994). Since mutation frequencies in human T-cells can be found elevated for years after the specific insult (Albertini et al., 1993), cumulative exposure to AFB1 can be measured (Wang et al., 1999). It has been found that the mutational site of AFB1 lies in exon 3 of the human HPRT gene in B lymphocytes and the hotspot has been characterised as a GC to TA transversion at base 
pair 209 (Cariello et al., 1994). Even though AFB1-albumin adducts indicate recent exposure, AFB1 measurements are still representative of exposure throughout life and HPRT mutant frequencies reflect AFB1 induced DNA damage. The final conclusion is that AFB1 exposure leads to AFB1-albumin adducts which in turn lead to DNA damage severe enough to be reported as HPRT gene mutations.

Aflatoxin B1 also induces a guanine-to-thymine point mutation in codon 249 of the p53 tumour-suppressor gene, which results in the amino acid substitution of serine for arginine. This mutation inactivates the $\mathrm{p} 53$ protein, causing uncontrolled cellular proliferation and predisposes to hepatocellular carcinoma. Furthermore, it has been found that there is a dose dependent relationship between dietary AFB1 intake and codon $249^{\text {ser }}$ of p53 gene (Harris, 1996). In vitro studies have shown that exposure of human liver cells to AFB1 produces $249^{\text {ser }}$ p53 mutations AGG to AGT in addition to other less common mutations (Aguilar et al., 1993). The $249^{\text {ser }}$ mutant p53 seems to be more effective than other p53 mutants $\left(143^{\text {ala }}, 175^{\text {his }}, 248^{\text {trp }}\right.$, and $\left.282^{\text {his }}\right)$ in inhibiting the wild type p53 transcriptional transactivating activity in human hepatocytes (Forrester et al., 1995). It is thought that AFB1 is activated to form the promutagenic N7dG adduct and the presence of chronic active hepatitis allows the fixation of the $\mathrm{G}$ : $\mathrm{C}$ to $\mathrm{T}$ : $\mathrm{A}$ transversion in codon 249 of the $\mathrm{p} 53$ gene leading to a selective clonal expansion of the cells with mutant p53 gene.

\subsubsection{Alcohol:}

Excessive alcohol intake has been known to cause hepatic injury promoting the development of cirrhosis and acting as a carcinogen (Yu et al., 1983). Prolonged alcohol ingestion stimulates hepatic oxygen consumption leading to a fatty liver, hepatomegaly, hepatic fibrosis and cirrhosis. The sequence of events leading to alcoholinduced hepatotoxicity is stimulated by an increase in endotoxin delivery, which in turn 
stimulates kupffer cells to produce some mediators. These mediators stimulate alcohol metabolism and result in a hepatic hypermetabolic state in parenchymal cells.

Subsequently, the pericentral regions of the liver lobule develop hypoxia and toxic free radicals form, resulting in cell death. The gut is involved in the above mentioned mechanism as alcohol alters the gut microflora with a subsequent increase in gram negative bacteria. As gram negative bacteria are the source of endotoxin, which is one of the components of the outer cell wall, the overall result is the increase in circulating endotoxin delivered to the liver causing hepatic tissue injury (Thurman, 1998).

A number of studied have demonstrated that alcohol administration increases the formation of lipid peroxidation products such as lipoperoxides, conjugated dienes and malonildialdehyde and decreases tissue levels of antioxidants (Nordmann et al., 1992). In addition, other studies have reported that a carbon-centered free radicle intermediate is produced by rat liver microsomes in the presence of alcohol and NADPH. Also, hydroxyethyl radical is generated during ethanol oxidation in human livers (Knecht et al., 1993). Hydroxyethyl radicals might cause alcohol-induced oxidative damage as these radicals react with glutathione and ascorbic acid and might contribute to the lowering of liver antioxidants (Albano et al., 1999).

In addition to the above described mechanisms, it has been found that alcoholic liver disease is associated with an antigen-driven immune response that targets hepatocytes. Such immune reactions involve lymphocyte-mediated reaction to alcoholic hyaline or liver autologous human hepatocytes as well as the development of circulating antibodies against epitopes present on the surface of hepatocytes that trigger antibody-dependent immunotoxicity (Albano et al., 1999).

\subsubsection{Iron overload:}

Iron has been found to influence the process of carcinogenesis of most neoplastic 
disorders in different ways. Iron has the ability to catalyse the formation of mutagenic hydroxyl radicals, suppresses the host defence system, and acts as a nutrient for proliferating tumour cells (Bergeron et al., 1985).

\section{Haemochromatosis:}

The risk of hepatocellular carcinoma has been estimated to be 200 times higher in patients with hemochromatosis with onset of cirrhosis, than non hemochromatosis patients. Point mutations resulting in amino acid substitution (Cys282Tyr) in the haemochromatosis genes (HFE) have been found to be homozygous in $83-100 \%$ of patients with hereditary haemochromatosis $(\mathrm{HH})$ strongly indicating that $\mathrm{HFE}$ is the primary $\mathrm{HH}$ locus. An additional point mutation causing amino acid substitution (His63Asp) has been described in the HFE gene and an increased frequency of heterozygotes for (Tyr282/Asp63) has been observed (Feder et al., 1996). Homozygotes for Asp63 is associated with a higher risk for haemochromatosis (Risch, 1997). The risk for hepatocellular carcinoma had been found to increase by about 200 times in patients with $\mathrm{HH}$ and liver cirrhosis (Niederau et al., 1996). Furthermore, heterozygosity seems to have an influence on carcinogenesis. $\mathrm{HH}$ patients have been found at higher risk of other malignancies including colorectal cancer, haematological malignancy, and gastric cancer (Nelson et al., 1995). Beckman et al. (1999) observed an interaction between HFE and transferrin receptor alleles which may increase the risk for various neoplasms.

\section{HCV and iron:}

Chronic HCV infection is sometimes associated with excess iron deposition in the liver which has been considered a negative prognostic factor for interferon therapy in chronic HCV infection (Piperno et al., 1996). However, there is mild to moderate elevation in serum iron indices in chronic $\mathrm{HCV}$, rarely reaching the haemochromatotic range (Fabris 
et al., 2001). Phlebotomy has been shown to improve serum aminotransferase levels (Burt \& Cooksley, 1998) suggesting that iron overload might have a role in hepatocyte injury in chronic $\mathrm{HCV}$ infection. In HCV infection, iron levels have been found to reflect the degree of hepatic inflammation and necrosis while ferritin levels reflect the extent of progressive deposition of iron in sites of scarring, contributing to the development of fibrosis (Pietrangelo, 1998).

Recently, iron has been found to enhance HCV replication in vitro, in an HCV-infected PH5CH8 cell culture system, suggesting that iron depletion may support other antiviral therapy and might be used in the treatment of chronic HCV (Kakizaki et al., 2000).

\subsubsection{Other factors:}

Some chemicals have been described as " hepatocarcinogens" like azodyes, aromatic amines and pesticides (Molmenti et al., 1999). For an unknown reason, the risk of hepatocellular carcinoma following cirrhosis associated with autoimmune hepatitis, Wilson's disease, primary biliary cirrhosis or alcohol abuse without a coexistent HCV infection, increases only by 2 to 5 times (Ince \& Wands, 1999).

\subsubsection{Pathogenesis of HCC:}

Carcinogenesis is a multi-step process involving a number of genetic changes. These changes might involve the activation and overexpression of oncogenes and or the inactivation of a tumour suppressor gene. Since hepatocytes have various metabolic functions that could be affected by many expressed genes, the process of hepatocarcinogenesis is expected to involve many complicated genetic changes (Okuda, 2000).

In 1992, Farshid \& Tabor found out that nine oncogenes; c-myc, H-ras, K-ras, N-ras, abl, rak, N-myc, fas and src, were expressed at higher levels in HCC and 
hepatoblastoma (HB) cell lines than in the control cells. However, certain oncogenes were expressed at different levels among different $\mathrm{HCC}$ and $\mathrm{HB}$ cell lines. The reason of this could be the different pathways of oncogene activation and tumour formation.

Furthermore, cell cycle regulators controlling the G1 phase progression have been thought to be involved in hepatocarcinogenesis, including the inactivation of p16INK4 and reduced p21 and p27Kip1 (Hui et al., 1998). Different genetic events might be responsible for different subtypes of HCC. For instance, mutations in c-met have been found associated with childhood $\mathrm{HCC}$, whereas mutations in the porphobilinogen deaminase gene have been detected in $\mathrm{HCC}$ with acute intermittent porphyria. More complicated genetic changes including DNA mutations and differential gene expressions have been observed in various HCCs. Nevertheless, none of these genetic alterations have been found in all HCCs suggesting a significant heterogeneity in HCC development (Xu et al., 2001).

However, the pathogenesis of HCC in patients with cirrhosis may differ from that in patients without cirrhosis. In cirrhotic livers a multistep process has been described. Cirrhotic livers have multiple regenerating nodules that progress to dysplastic nodules then to early HCC, which is usually multifocal. Another explanation for the presence of multifocal tumours in patients with cirrhosis is metastatic spread through the hepatic and portal veins since venous invasion is more common in cirrhotic patients than in patients without underlying liver disease (Winston et al., 1999).

\subsubsection{Apoptosis and HCC:}

Apoptosis is cell death characterised by an organised process of nuclear and cellular fragmentation. During apoptosis, the cell fragments into small membrane bound bodies with intact organelles and plasma membrane. The process is characterised by ordered 
DNA fragmentation in which endonucleases first cleave the DNA into large 50-300 kb pieces and then into smaller 180-200 bp fragments. This order is responsible for the classic ladder pattern usually found in apoptotic cells (Earnshaw, 1995). The apoptotic cells are then called apoptotic bodies and are removed by phagocytosis (Patel et al., 1998). In liver specimens, apoptotic cells are recognised as "Councilman bodies". Apoptotic cells are normally eliminated without causing an inflammatory response because intracellular constituents are contained in the apoptotic bodies. However, some intracellular enzymes have been detected in the liver during hepatocyte apoptosis indicating that the apoptotic process is not as silent as it has been thought. Furthermore, loss of tissue architecture may occur if the magnitude of apoptosis exceeds the normal process stimulating an inflammatory response (Feldmann, 1997).

In the final stages of apoptosis, a family of proteases called caspases disintegrate the cell (Cohen, 1997). Caspases are present in almost all the cells as zymogens in the cytosol. Caspases cleave proteins on the carboxyl side of aspartate moieties. It is thought that caspases themselves are activated by other caspases resulting in a caspase cascade similar to the coagulation cascade. Certain caspases $(-3,-6$, and -7$)$ are called effector caspases. Currently, two pathways have been described to activate these effector caspases (Green, 2000).

The first pathway involves the activation of death factors and death receptors. Death receptors are members of the TNF superfamily. Eight death receptors have been described of which TNF receptor-1 (TNF-R1) and Fas (CD95/APO-1) are the best characterised. Activation of these receptors recruits an intracellular death complex, which then activates a class of caspases, mostly caspase-8, activating the downstream effector caspases (Faubion \& Gores, 1999).

In the second pathway, cellular stress stimulates the release of cytochrome $\mathrm{c}$ from 
mitochondria as a result of permeability changes of the inner mitochondrial membrane known as mitochondrial permeability transition (MPT). Cytochrome $\mathrm{c}$ then results in the activation of caspase-9 leading to apoptosis (Green \& Kroemer, 1998). This in turn cleaves some of the important cellular target proteins, including poly (ADP-ribosome) polymerase and retinoblastoma protein leading to cell disassembly (An \& Dou, 1996).

\section{Role of apoptosis in HCC:}

In $\mathrm{HCC}$, the major determinant in hepatocarcinogenesis is insufficient apoptosis of DNA-damaged and malignant cells. It has been demonstrated that there is disruption of apoptosis during HCC development and some HCC might have partial or complete loss of Fas, which is normally expressed in hepatocytes (Strand et al., 1996). Furthermore, Fas expression has been found correlated to the degree of $\mathrm{HCC}$ differentiation as it was significantly reduced in poorly differentiated tumours (Ito et al., 1998). This observation suggests that loss of Fas expression helps the malignant cells to survive by escaping CTL cytotoxicity (Rust \& Gores, 2000). In addition, dysregulation of apoptosis by transforming growth factor (TGF)-beta 1 has been described as an important factor in the development of HCC. In normal hepatocytes, TGF-beta1 induces apoptosis involving two types of receptors, type 1 and type 2 receptors, which lead to the generation of downstream signals (Massague \& Weis-Garcia, 1996). In HCC, there is an impairment of apoptotic signalling as a result of reduced level of receptors (Sue et al., 1995). Another study suggested that the escape of TGF-beta 1 proliferation control might be related to a defect in type 2 receptor processing on the liver cell membrane (Bedossa et al., 1995). Finally, p53 has been found to have a role in regulating apoptosis in neoplastic liver disease. Protein p53 is a tumour suppressor gene that helps cells to repair the DNA damage. If DNA repair is not possible, p53 can induce apoptosis. Thus, a dysfunction of $\mathrm{p} 53$ can lead to escape of apoptosis and ends in 
neoplastic change (Rust \& Gores, 2000).

\subsubsection{Pathology of HCC:}

\subsubsection{Macroscopic Pathology:}

Hepatocellular carcinomas are variable. More frequently they arise in the right lobe rather than the left lobe. However, bilobar involvement has been seen (Tangkijvanich et al., 2000). The size ranges from a few millimetres to more than $30 \mathrm{~cm}$ in diameter. They can be single or multiple, and with or without a capsule. The colour is usually grey brown or yellow green with multiple foci of haemorrhage or necrosis. More recently, hepatocellular carcinomas have been classified according to the relationship with the surrounding healthy liver parenchyma. However, this relationship correlates poorly with the aetiology and prognosis. Extrahepatic metastasis occurs at late stages in 50 to $70 \%$ of cases and is higher in hepatocellular carcinomas without cirrhosis (Molmenti et al., 1999).

It has been shown that HCC in cirrhotic livers manifests as small lesions (Yamashita et $a l .$, 1993). In non cirrhotic livers, HCC are usually well circumscribed in most of the cases, about $57 \%$, and less frequently, in $33 \%$, manifest as multiple intrahepatic tumours without a dominant mass. In about $6 \%$ of cases, HCC presents with a dominant mass with smaller satellite lesions. A diffuse infiltrative pattern has been described in only $3 \%$ of cases (Smalley et al., 1988).

\subsubsection{Microscopic pathology:}

The histological pattern varies according to the degree of differentiation. The trabecular pattern that resembles the normal liver hepatic plates is present in almost all tumours. Sometimes a branching or papillary pattern is seen. A microglandular pattern that resembles the biliary ducts may be seen and often misdiagnosed as adenocarcinoma. 
The tumour cells are atypical and the DNA content as well as the proliferation indices correlate with the degree of differentiation (Ezaki et al., 1998). Small carcinomas tend to be more differentiated than large ones. At the interface with the adjacent healthy liver parenchyma the tumour is usually pushing and rarely infiltrating (Horigome et al., 2000).

The cytopathologic dictinction between primary $\mathrm{HCC}$ and other tumours as cholangiocarcinoma and metastatic carcinoma can be difficult especially in cases diagnosed with small fine-needle aspiration samples. To overcome these difficulties, immunohistochemical antibodies can be useful for the evaluation of liver tumours. (Wennerberg et al., 1993) developed a monoclonal antidoby designated as hepatocyte Paraffin 1 (HepPar1) and was specific for adult and foetal liver tissues. HepPar1 reacts with both normal and neoplastic hepatocytes. Bile ducts and nonparenchymatous liver cells were found to be negative for HepPar1 demonstrating its role in differentiating well differentiated HCC fron cholangiocarcinomas (Siddiqui et al., 2002). Other histochemical stains such as mucin and reticulin are also commonly used. Mucin is specific to adenocarcinoma and may be expressed in fibrolamellar carcinoma as well. Reticulin, on the other hand, is used to identify well differentiated HCC from normal liver tissue. Also, identifying endothelial cells with factor VIII usually indicates a tissue of hepatocellular origin, a feature not commonly reported in poorly differentiated HCC, and is used to identify well differentiated fron poorly differentiated HCCs (Zimmerman et al., 2002).

\subsubsection{Clinical features of HCC:}

\subsubsection{Initial symptoms:}

The most common presenting symptoms are general malaise, upper abdominal pain, 
anorexia, abdominal fullness, weight loss, ascites, palpable mass, nausea, vomiting, jaundice, and wasting. In the absence of cirrhosis, abdominal pain and a palpable abdominal mass are the most common initial complaints. Acute abdominal pain is almost always associated with hemoperitoneum caused by tumour rupture or bleeding (Cavallari et al., 1994).

\subsubsection{Clinical manifestations:}

The presence of a palpable mass is the most common presentation. An arterial bruit may rarely be heard on auscultation. The right diaphragm may be elevated. In addition, hepatomegaly, ascites, splenomegaly, jaundice, dilated abdominal veins, varices, gastrointestinal bleeding, fever, encephalopathy and rarely diarrhoea are other less common clinical manifestations (Bruix et al., 1990).

\subsubsection{Diagnosis:}

HCC may be detected by screening high risk patients or by chance on imaging study of the abdomen for another reason. The periodic screening with ultrasound and the blood tumour marker, $\alpha$-fetoprotein (AFP), may lead to early detection of hepatocellular carcinomas in high risk patients.

Percutaneous biopsy guided by ultrasonography or computed tomography is almost always possible and open biopsy is rarely necessary. A needle biopsy might be only indicated if it is not possible to diagnose HCC by other means, as laboratory tests and radiologic imaging, in these cases a single pass with a large needle (18 gauge) is preferable to multiple passes with smaller needles. However, the entire needle tract should be resected at surgery for the primary tumour to avoid local spread of the tumour along the tract (Schotman et al., 1999).

In cases with coagulopathy, biopsy results in severe complications and diagnosis is 
based on the presence of a cirrhotic liver, a space occupying lesion and laboratory findings.

\subsubsection{Laboratory findings:}

Laboratory diagnosis of $\mathrm{HCC}$ depends on the detection of some tumour markers. AFP is the most important marker used in the diagnosis of HCC. Most HCCs produce this marker at early stages that make early diagnosis possible depending on the AFP. However, a significant proportion of HCCs does not produce AFP or produce minimal amounts only, making early diagnosis difficult. Furthermore, AFP has been found to be elevated to equivocally high levels $(20-400 \mathrm{ng} / \mathrm{ml})$ in serum of cirrhotic patients (Okuda, 1997). Alternatively, Des- $\gamma$-carboxyprothrombin (DCP) (Fujiyama et al., 1988) or the protein induced by vitamin $\mathrm{K}$ absence or antagonist II (PIVKA-II) (Motohara et al., 1987) can be used as tumour markers in AFP negative cases. The two markers, AFP and DCP have no correlation with each other. DCP has been found to be more sensitive than AFP, as AFP negative cases have been found positive for DCP (Okuda et al., 1987). The early test kit developed for DCP was less sensitive than the AFP and most cases of small HCCs gave normal results (Okuda et al., 1991) while recently, the new kit for PIVKA-II has been improved with increased sensitivity and can be used to detect small HCCs (Okuda et al., 1999). Studying AFP molecules from HCC cases revealed that the molecules are heterogeneous and the fucosylation of the sugar chain is altered. These AFP subspecies from HCC patients have been found to have a high affinity for lectin and erythroagglutinating phytohemagglutinin (Okuda et al., 2000). An assay system was developed for L3 and P4+P5 fractions by (Taketa et al., 1989). Alternatively, Aoyagi et al. (1998) introduced a method for detecting the degree of fucosylation which has a diagnostic sensitivity of $66 \%$ with a high specificity. Elevation of these fractions is probably an early sign of detecting HCC now (Okuda et al., 2000). 


\subsubsection{Ultra Sonography (US):}

Regular screening with US has an important role in early detection of the HCC particularly in patients with cirrhosis or chronic hepatitis. US has gained popularity as an effective screening method for small $\mathrm{HCC}$ lesions particularly in patients with chronic liver disease (Oka et al., 1990). US is able to detect a nodular lesion in a cirrhotic liver. The tumour appears as a hyperechoic nodule. Needle biopsies are not indicated to confirm HCC in patients with solitary nodule who are suitable for liver transplantation (Schotman et al., 1999).

\subsubsection{Colour Doppler US}

Colour Doppler US can be used to analyse vascular lesions. During this analysis, the flow is colour coded, red indicates flow towards the transducer and blue away from it. Typical features in HCC are high velocity in tumour blood vessels and a pulsatile arterial flow. It can also demonstrate the presence of thrombi within the portal veins (Bolondi et al., 1992).

\subsubsection{Computed tomography (CT):}

Once HCC has been diagnosed on a histopathological basis, CT is needed to detect daughter nodules associated with the main tumour. It is the best method for detecting extrahepatic metastasis (Blaszczynska et al., 2000).

\subsubsection{Lipiodol Computed tomography:}

Hepatic artery catheterisation and injection of 2-10 $\mathrm{ml}$ of lipiodol, an oily contrast medium, is used to stain focal hepatic lesions. HCCs retain the lipiodol for months or years allowing small tumours to be demonstrated. Sequential CT scans are used to follow tumour growth or regression (Dick, 1998).

Dual-phase contrast-enhanced helical CT can provide useful information for the 
differential diagnosis of hepatic lesions by showing contrast enhancement features on scans obtained during the hepatic arterial phase and the portal venous phase. CT is performed to image the liver during the arterial and the venous phases of enhancement after a single bolus injection of iodinated contrast material (Choi et al., 1999).

\subsubsection{Magnetic resonance imaging (MRI):}

MR is the most accurate imaging method for the detection of a tumour capsule, which appears as a hypointense rim surrounding the tumour.

Classic MR imaging findings of HCC have predominantly been described in patients with cirrhosis in whom HBV is chronic. These changes include intratumoural fat, tumour encapsulation, portal or hepatic vein invasion, and arterial-portal venous shunting. While in non cirrhotic livers, a visible scar has been described more frequently. This scar was described in large, rather than small, lesions (Winston et al., 1999).

\subsubsection{Digital Subtraction Angiography (DSA):}

This invasive technique is required to detect daughter nodules smaller than $1 \mathrm{~cm}$ in diameter. DSA followed by the injection of iodised oil can detect the presence of other HCC deposits that contraindicate any surgical approach (Kudo et al., 1992).

\subsubsection{Prognosis:}

The identification of a capsule is an important factor in the prognosis as well as in therapy. Not only are encapsulated tumours associated with a better prognosis after hepatic resection, but also they are more amenable to percutaneous ethanol ablation than are unencapsulated lesions. This is because the capsule can retain ethanol for longer periods (Winston et al., 1999). However, the prognosis of HCC is extremely poor and the only potentially curative treatment, for an early HCC without extrahepatic spread, 
consists of hepatectomy, either partial or total, and orthotopic liver transplantation (Mazzaferro et al., 1996). This treatment is sometimes difficult to achieve as a result of the limited availability of liver donors. Furthermore, recurrent HCC has been observed, particularly with HCV associated cirrhosis (Takayasu et al., 1989). These facts attract the attention to the significance of prevention rather than treatment of $\mathrm{HCC}$.

\subsubsection{Prevention:}

The primary prevention of HCC is to avoid the exposure to different carcinogens particularly the infection with hepatitis viruses. This can be achieved with vaccination programs for $\mathrm{HBV}$ and prevention of the parenteral transmission of $\mathrm{HBV}$ and $\mathrm{HCV}$. In developed countries, prevention of transfusion associated transmission has been achieved via thorough testing of the blood and blood products.

The secondary prevention is to prevent viral hepatitis from progressing to cirrhosis through the treatment of hepatitis viruses with the appropriate antiviral therapy.

Until recently, Interferon (IFN)- $\alpha$ has been the only available therapy for chronic HBV infection. However, favourable response to IFN is dependent on a number of predictive factors, including the presence of high pre-treatment serum liver enzyme levels indicating immune response by the host. A further predictive factor of favourable response to IFN is a low pre-treatment level of HBV DNA. This observation lead to the combination of IFN with other agents, nucleoside analogues, which can suppress viral replication (Clarke \& Darby, 1997). Lamivudine is a potent nucleoside analogue, that inhibits the $\mathrm{HBV}$ reverse transcriptase activity, that has been introduced recently as an alternative to IFN, showing at least similar efficacy and without the adverse effects (Regev \& Schiff, 2001). Lamivudine, however, has to be given on a long term basis since the clinical trials show that the majority of patients have a rebound of the HBV 
DNA on cessation of therapy. Suppression of viral replication only is insufficient and there must be a corresponding decline in the number of productively infected hepatocytes. The endpoint for cessation of therapy should be the complete eradication of HBV and the disappearance of HBsAg and HBV DNA from the serum and liver (Lai \& Wu P.C., 1997). Mutations in the YMDD motif of the C domain of the polymerase gene of $\mathrm{HBV}$ is responsible for Lamivudine resistance through less efficient incorporation of Lamivudine in the proviral hepatitis B strand (Severini et al., 1995). It has been observed that patients with less favourable response to Lamivudine may develop variant virus. Also baseline levels of HBV DNA and ALT are two independent predictors for development of Lamivudine resistance (Tillmann et al., 1999). In contrast, a decrease in CD4 cell count results in a faster development of HBV mutations (Wolters et al., 2002).

The development of antiviral compounds against $\mathrm{HCV}$ has been more difficult than for $\mathrm{HBV}$ and in the same time urgent, as there is no current vaccine available for $\mathrm{HCV}$. IFN- $\alpha 2$ b was first used for the treatment of chronic HCV in 1986 (Hoofnagle et al., 1986). As a result of low sustained response rates, about $10-20 \%$, with IFN monotherapy, ribavirin was used in combination with IFN. It is evident that the addition of ribavirin to IFN increases sustained viral clearance (Davis et al., 1998) and cure rates of $80-90 \%$ can be achieved with combination therapy (Gow \& Mutimer, 2001).

The HCV genotype in an important factor in deciding whether to treat for 24 weeks, for genotypes 2 and 3, or 48 weeks, for types 1,4,5 and 6. HCV RNA testing should be performed at week 24 to determine whether to continue or stop combination therapy (Pianko \& McHutchison, 2000). The role of pegylated, long acting, IFN (PEG-IFN) is currently being evaluated whether in IFN monotherapy or in combination with ribavirin. There are two types of PEG-IFN available, PEG-IFN- $\alpha 2 b$ and PEG-IFN- $\alpha 2 a$. PEG- 
IFN- $\alpha 2 b$ leads to a sustained response rate of $20-25 \%$, compared to $12-17 \%$ achieved with recombinant IFN- $\alpha 2 b$. The efficacy of PEG-IFN- $\alpha 2 a$ is at least twice that of recombinant IFN- $\alpha 2 a$. PEG-IFN has also been evaluated in combination with ribavirin and the combination has proved to be superior to IFN- $\alpha 2$ a monotherapy (Carreno, 2002).

The tertiary prevention is called "chemoprevention" which is to prevent the cirrhotic liver from developing HCC. Chemoprevention can be applied to cirrhotic patients who have not yet developed HCC. The first approach would be to control the cause of cirrhosis as in patients with alcoholic cirrhosis, by alcohol abstinance. The second approach is chemoprevention of viral cirrhosis. With regard to HBV-related cirrhosis, no decrease in the rate of $\mathrm{HCC}$ has been observed with the administration of IFN. With regard to $\mathrm{HCV}$-related cirrhosis, a reduction in $\mathrm{HCC}$ incidence has been demonstrated. The benefit is most marked in sustained biochemical responders. This means that antiviral treatment should aim at inducing a sustained biochemical response. This response is rarely obtained by means of IFN alone and improved results have been obtained with pegylated IFN alone or in combination with ribavirin (Valla \& Degos, 2001).

\subsubsection{Treatment:}

\subsubsection{Surgical treatment:}

Planning the treatment depends largely on the size of the tumour. Masses larger than 5 $\mathrm{cm}$ in diameter usually are associated with a poor prognosis after hepatic resection while patients with small lesions may benefit from percutaneous ethanol ablation (Winston et al., 1999).

Surgical resection is the treatment of choice for patients with favourable prognostic 
factors. These factors are young age, a solitary mass, no portal invasion, compensated cirrhosis and low AFP level (Rose et al., 1998). In the noncirrhotic liver, resection can extend up to two thirds of the functional parenchyma with a good recovery expected, and the 5-year survival is more than $30 \%$ of patients (Little \& Fong, 2001). It is still the treatment of choice for contiguous multinodular $\mathrm{HCC}$ as a result of the unsatisfactory results of percutaneous ethanol injection or radiofrequency ablation in this tumour type. Multicentric tumours that are confined to one lobe are resectable although these patients have a worse prognosis after resection than do patients with a solitary nodule (Winston et al., 1999).

\subsubsection{Percutaneous ethanol injection (PEI):}

In cases with a small tumour, less than $3 \mathrm{~cm}$ in diameter, percutaneous ethanol ablation is the treatment of choice. Not only because it has relatively comparable results with those of surgery but because it has other advantages being relatively simple, has a low cost, and is safe. Results have shown that in about $70 \%-80 \%$ of cases, complete tumour necrosis has been achieved, without adverse effects on the adjacent noncancerous parenchyma (Shiina et al., 1990).

Ethanol is usually injected in a dose of 1-4 $\mathrm{ml}$ per session. The amount depends on the distribution of ethanol, patient compliance, and lesion size. The ethanol is injected slowly with the diffusion checked by real-time US in which the perfused area is seen as hyperechoic focus. If most of the ethanol diffuses outside the tumour, injection should be stopped and repeated. Treatment is ended after total perfusion of the neoplastic tissue. One treatment cycle usually includes two to six sessions, depending on the size of the lesion (Livraghi et al., 1998).

The greatest drawback of PEI is the difficulty to treat large tumours, in which, alcohol diffusion is incomplete. Alcohol diffusion is mostly impeded by the texture of the 
tumour or by the presence of septa, leaving residual viable neoplastic tissue (Shiina et al., 1991).

\subsubsection{Radio frequency (RF) ablation:}

In an attempt to improve results obtained with PEI and still maintain the same advantages over surgery, other percutaneous techniques have been developed. These include thermal methods such as the use of radio frequency (RF), laser, or microwaves.

$\mathrm{RF}$ ablation can induce complete tumour necrosis in more patients than does percutaneous ethanol injection. RF energy is delivered via a cooled-tip RF electrode with a $2-3 \mathrm{~cm}$ long metallic tip. The electrode is then attached to a $500-\mathrm{kHz} \mathrm{RF}$ generator capable of producing $150 \mathrm{~W}$ of power. Normal saline at $0^{\circ} \mathrm{C}$ is injected into a cooling lumen of the electrode via a pump to maintain the tip temperature at $20^{\circ}-25^{\circ} \mathrm{C}$.

For each treatment session, a single RF electrode should be positioned at the centre of the tumour. RF is usually applied for 10-12 minutes and one application is usually enough for each tumour (Livraghi et al., 1999).

\subsubsection{Transcatheter Arterial Chemoembolisation (TACE):}

TACE is mostly performed by injecting an infusion of antineoplastic agents mixed with iodised oil (Lipiodol R) intra-arterially (Hashimoto et al., 1989). Recently, the therapeutic efficacy of TACE has been improved with mixing the iodised oil with cytotoxic agents such as doxorubicin and Mitomycin- $\mathrm{C}$ followed by the administration of gelatine sponge particles. This technique has raised the 1-year survival in patients with unresectable HCC (Poyanli et al., 2001). Although this method has been used in the treatment of large tumours, it has been found mostly successful in nodules smaller than $4 \mathrm{~cm}$ in diameter with a thick capsule. This is due to the fact that small tumours are almost completely supplied by hepatic arterial blood. On the contrary, in the absence of 
the capsule or in the presence of extracapsular neoplastic invasion, TACE usually fails to induce complete necrosis (Kuroda et al., 1991).

\subsubsection{Combined PEI and TACE:}

Large HCC tumours can be more effectively treated with combined PEI and TACE.

Firstly, TACE induces necrotic changes then alcohol diffusion is more efficient allowing the intranodular injection of larger amounts of ethanol (Tanaka et al., 1991b). In addition, after embolisation, the normal process of wash-out in the tumour area is more difficult, resulting in longer retention of the injected ethanol. The combined PEI and TACE is a highly effective method of treatment, not only for large HCC but also in the association of daughter nodules with the main tumour. The presence of a tumour capsule is essential for the success of this method of treatment (Lencioni et al., 1994). Moreover, patients with small HCC lesions, less than $3 \mathrm{~cm}$ in the greatest dimension, that received combination of TACE and PEI had lower detection rates for local residual disease, low recurrence rates and higher survival rates (Koda et al., 2001).

\subsubsection{Gene therapy for HCC:}

Gene therapy is a new concept in the treatment of many human diseases. It is based on introducing genetic material into the cells of the patient with the aim of producing some therapeutic effects (Miller et al., 1992). The liver is a natural target for this new therapy being involved in many inborn errors of metabolism as well as due to the lack of effective treatment against diseases such as viral hepatitis, cirrhosis, and HCC (Ledley, 1993).

The two major elements in gene therapy are the genetic material, which might be nucleic acid based or protein based, and the vector to transmit this material into the cell. The nucleic acid materials used in this strategy could be antisense DNA and RNA or 
ribozymes. The therapeutic effect is achieved via blocking gene expression or function. In protein-based gene therapy, the biological effect is achieved via a protein synthesised by the genetic material. Genes are defined as pieces of DNA containing all the elements required for the synthesis of mRNA, which will be translated into protein. Genes used for this purpose could be either natural genes or chimeric genes (Ruiz et al., 1999). The other component of gene therapy is the gene transfer vector, which is either viral or nonviral. Transfer vectors are responsible for the introduction of these genes into target cells.

The problem of how to deliver a gene of interest to a target cell, however, remains a major obstacle. Traditional approaches to this problem have included inducing transient changes in the cellular membrane of a target cell to allow passive influx of foreign DNA by either electrical current or chemicals (Wigler et al., 1978). However, these methods are quite inefficient allowing less than 1 in $10^{4}$ to $10^{6}$ cells to take up the DNA. Direct microinjection of DNA has also been used to introduce genes into target cells (Stacey \& Allfrey, 1976). This technique is hampered by the frequent acquisition by the target cells of multiple tandem repeats of the microinjected gene in target cells. Furthermore, this technique is only useful for introducing foreign DNA into a few cells at a time. Viral vectors such as the papillomavirus, adenovirus, and herpes viruses have been used to carry the foreign gene into target cells (Grassmann et al., 1989). However, these vectors are large and difficult to manipulate genetically. In addition, they carry with them many of their own viral genes. Another problem with these vectors is that many of them are maintained episomally and therefore are not integrated into cellular DNA. Thus, the heterologous gene may not be subject to the same transcriptional controls active on endogenous genes. Retroviral-based vectors, however, can potentially overcome all of these problems. 
Retroviruses are efficient at infecting multiple cells simultaneously and integrating a single copy of genetic information into the target cell genome (figure 1.3). In addition, the host range of these viruses can be targeted to a particular cell type by changing the type of envelope on the virion (pseudotyping). Despite the success in using retroviral vectors, the development of clinically useful retroviral vectors will have to address several key problems. One such problem is the generation of helper or wild-type viruses, which occurs through recombination between homologous areas of the vector and the structural gene expressors, such that a replication-competent genome with sufficient packaging signals for virion incorporation is generated. This problem has been largely eliminated by placing the different structural genes on different expressors, thus requiring multiple recombination events to correctly occur for the generation of wild-type virus. Another problem with many retroviral vectors is that in vivo gene expression does not always parallel in vitro expression. A final major problem associated with the potential clinical usefulness of retroviral vectors relates to their ability to carry only one or a few genes. These vectors, therefore, hold immediate clinical promise only for diseases caused by loss of function of a single gene.

Unfortunately, most diseases, like cancer, are the result of a pathogenic process involving multiple genetic perturbations. Thus, for cancer therapy, retroviral vectors hold most promise not for reversing the malignant phenotype, but for delivering a gene that would inhibit the growth (or accelerate the destruction) of the neoplastic cells (Kufe et al., 2000). 


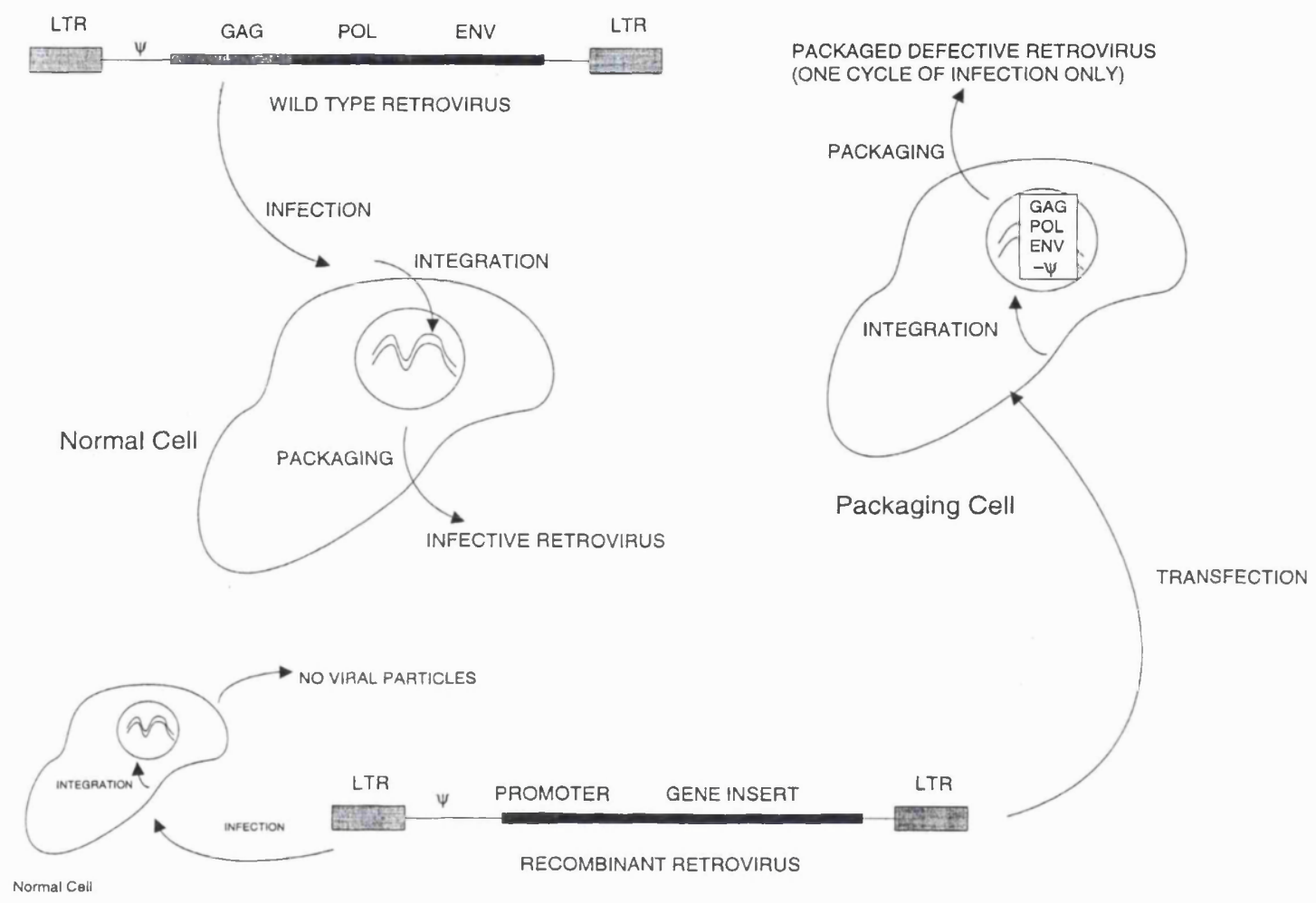

Figure 1.3 Gene therapy with retroviral vector

Retroviruses bind to specific cellular receptors on the target cell surface and are internalized by receptor-mediated endocytosis. Following entry, the retroviral RNA genome is removed from its capsid coat and is reverse transcribed by viral reverse transcriptase into DNA that is transported to the nucleus, where integration into the host genome occurs. In wild-type virus, the life cycle is completed by the synthesis of viral proteins and RNA by the host cell, packaging the retroviral particle that is released by budding from the cell surface. Recombinant viruses containing the therapeutic gene or cDNA are replication incompetent, with the insert taking the place of the viral genes GAG, POL, and ENV. "Packaging" lines produce these retroviral genes in vitro, allowing encapsulation of virus and production of the infectious virions. The "packaged" recombinant virus contains an RNA copy of the therapeutic gene insert that can be used to infect target cells. The organization of the genome of wild-type and recombinant retroviral vectors is depicted. 


\section{Gene therapy targeting for HCC:}

One approach of gene therapy for $\mathrm{HCC}$ was carried out using a retroviral vector that carries a suicide gene such as the herpes simplex virus thymidine kinase (HSV-tk) gene. Retroviruses can integrate their genes into proliferating cells but not into quiescent cells. The killing effect of the suicidal gene, HSV-tk, product on the infected cells can be only seen in proliferating cells. HSV-tk can phosphorylate some antivirals, nucleoside analogues, in the viral infected cells in which the phosphorylated products act as chain terminator of DNA and induce cell death (Ido et al., 1995).

The next modification was to induce selective ablation of tumour cells. It has been found that many tumours reexpress foetal genes, and AFP gene is reexpressed in HCC. To improve the selectivity of gene therapy to tumour cells, several studies have tried to use AFP 5'-flanking sequences that include the gene enhancers (Wills et al., 1995). Ido et al. (1995) tried a hepatoma specific gene therapy using an AFP promoter only to target AFP producing hepatoma cells. However, this approach provided cytotoxicity in high AFP producing human hepatoma cells only with little effect on the low AFP producing cells.

HCC is considered to be a hypervascular tumour and vascular endothelial growth factor (VEGF) has been detected at higher levels in HCC. Ido et al. (2001) constructed a hybrid promoter consisting of the hypoxia induced enhancer of the human VEGF gene. This hybrid promoter was linked to AFP promoter and was transduced in low and nonAFP producing hepatoma cells. This approach resulted in sufficient and specific expression of the transfected genes. This selectivity of antitumour effect has been thought to be vital to maintain the hepatic reserve in $\mathrm{HCC}$ patients. 


\subsection{Fibrolamellar carcinoma:}

\subsubsection{Introduction:}

Fibrolamellar carcinoma is an uncommon variant of HCC initially described by (Edmonson, 1956). However, this tumour was not considered as a specific tumour for 20 years and was referred to as hepatocellular carcinoma with laminar fibrosis, hepatocellular carcinoma with polygonal cell type and fibrous stroma, oncocytic hepatocellular carcinoma, eosinophilic hepatocellular carcinoma with lamellar fibrosis, and finally fibrolamellar carcinoma.

In 1980, Craig et al. demonstrated the clinical aspect of establishing the diagnosis of this tumour. They reported that patients with fibrolamellar carcinoma were different from patients with hepatocellular carcinoma in age, predisposing factors, positivity of tumour markers and prognosis. Fibrolamellar carcinoma is relatively uncommon among cases of hepatocellular carcinoma (Pinna et al., 1997) but its clinical significance lies in its relative abundance among $\mathrm{HCC}$ cases under 50 years of age with a noncirrhotic liver (McLarney et al., 1999).

\subsubsection{Clinical features:}

Fibrolamellar carcinoma accounts for $1-9 \%$ of $\mathrm{HCC}$ cases and occurs in young adults. Most patients present in their second or third decade of life. No sex predilection has been observed, in contrast with $\mathrm{HCC}$ which has a male predilection and FNH which has a female predilection (Pinna et al., 1997).

No specific risk factors have been described for fibrolamellar carcinoma. Hepatitis and liver cirrhosis are not known to predispose to this malignancy and most patients do not have an underlying liver disease (McLarney et al., 1999). 
Patients with fibrolamellar carcinoma usually present with pain, hepatomegaly, palpable right upper abdominal mass and cachexia (Craig et al., 1980). Symptoms usually are present for 3-12 months before diagnosis. Uncommon symptoms include metastatic manifestations, pain and fever that simulate a liver abscess, venous thrombosis (Duvoux et al., 1992) or gynaecomastia in men. Gynaecomastia is rare and results from direct conversion of circulating androgens into estrogens by the enzyme aromatase released by the malignant cells of fibrolamellar carcinoma (Agarwal et al., 1998) rather than resulting from liver failure as observed in alcoholic cirrhosis. Jaundice is rare, present in $5 \%$ of cases and results from direct compression on the biliary ducts by tumour invasion, or mass compression rather than due to liver failure (Soyer et al., 1991).

\subsubsection{Pathology:}

\subsubsection{Macroscopic appearance:}

Fibrolamellar carcinoma usually presents as a large solitary intrahepatic mass. It is frequently well demarcated, lobulated, and nonencapsulated. Cut sections are brown or brownish green with streaks of white fibrous tissue. The fibrous tissue infiltrates throughout the tumour and sometimes may divide the tumour into smaller compartments. It may coalesce to form a central scar. Less frequently, the tumour may appear as a mass with satellite lesions, a bilobed mass, and rarely as diffuse multifocal masses. Lesions are typically intrahepatic, although less frequently, they may be pedunculated. The average size is $13 \mathrm{~cm}$. Encapsulation of the tumour is rare, unlike the $\mathrm{HCC}$, and the lesions are usually well demarcated from the liver parenchyma. Haemorrhage and necrosis manifest in about a third of cases (Friedman et al., 1985). Rarely, multicystic appearance may result from massive haemorrhage and necrosis simulating a cystic hepatic neoplasm (Pombo et al., 1993). 


\subsubsection{Microscopic appearance:}

Fibrolamellar carcinoma consists of sheets of large eosinophilic, polygonal neoplastic cells. Sometimes may be arranged in cords or trabeculae separated by parallel sheets of fibrous tissue lamellae. The cells are well differentiated and have granular cytoplasm with large nuclei and prominent nucleoli. The lamellae consist of hypercellular vascular connective tissue and collagen (Berman et al., 1980). The deposition of collagen and the formation of lamellae may result in the compartmentalised appearance if infiltrative or result in a central fibrous scar if coalescent. Calcification has been detected in $35-55 \%$ of tumours. Calcifications may be punctuate, nodular, or stellate and are found within the scar. Rarely, they may be found in the tumour parenchyma or the capsule (Stevens et al., 1995). In contrast with HCC, vascular invasion is uncommon in fibrolamellar carcinoma (Friedman et al., 1985).

It has been found that the liver parenchyma surrounding the tumour may contain some foci of nodular hyperplasia which is thought to be a regenerative response to the liver injury. It has been known that vascular tumour such as fibrolamellar carcinoma may cause a vascular steal from the surrounding liver parenchyma resulting in relative ischaemia leading to hepatic regeneration or nodular hyperplasia. This usually causes a misdiagnosis of nodular hyperplasia or even FNH (Saxena et al., 1994).

\subsubsection{Diagnosis:}

\subsubsection{Laboratory findings:}

Tumour markers such as $\alpha$-fetoprotein usually are not elevated. Levels usually are normal, unlike the high levels found in patients with HCC. However, in $10 \%$ of cases, mild elevation may occur (less than $200 \mathrm{ng} / \mathrm{ml}$ ).

Serum transaminase levels are frequently mildly elevated (less than $100 \mathrm{IU} / \mathrm{L}$ ), and in 
very rare cases more elevations (100-400 IU/L) may occur (Craig et al., 1980).

Various other tumour markers may be detectable, including vitamin B12 binding capacity (Berman et al., 1988), neurotensin (Collier et al., 1984), and carcinoembryonic antigen. Although all these markers are non-specific to fibrolamellar carcinoma, they can be useful to monitor the response to therapy and follow up.

However, hepatitis markers might be detected in rare cases, but hepatitis and cirrhosis are thought to be incidental and not causative of fibrolamellar carcinoma (McLarney et al., 1999).

\subsubsection{Biopsy for diagnosis:}

Pathological diagnosis is sometimes needed if there is diagnostic uncertainty about the radiological findings. In these situations, percutaneous biopsy is indicated. Core biopsy is preferred rather than the fine needle aspiration which aspirates only the malignant hepatocytes resulting in the misdiagnosis as hepatocellular carcinoma.

In multiple core specimen biopsy, fibrolamellar carcinoma may contain areas with variable differentiation and cell types (Stevens et al., 1995). Biopsy materials are better obtained from the middle rather than the periphery of the tumour as the areas of the liver parenchyma adjacent to the tumour may demonstrate nodular hyperplastic changes and simulate FNH resulting in misdiagnosis (Saxena et al., 1994).

\subsubsection{Radiography:}

Abdominal radiography is not particularly helpful in the diagnosis of fibrolamellar carcinoma. The tumour usually appears as a liver mass or as hepatic calcifications which are usually nodular, or stellate (Friedman et al., 1985).

\subsubsection{US:}

Fibrolamellar carcinoma appears as a solitary, well-defined, lobulated mass with 
variable echotexture. Mixed echogenecity is common. The central scar appears as a central area of hyperechogenicity (Friedman et al., 1985). US can detect regional lymphadenopathy and may reveal calcification within the central scar (McLarney et al., 1999).

\subsubsection{CT:}

Non-enhanced CT scans show the fibrolamellar carcinoma as a solitary mass with well defined lobulated margins. During the dynamic enhanced CT, the non-scar portion enhances prominently. The scar may be visualised on non-enhanced CT scans and best seen on delayed CT scans. The liver adjacent to the tumour may be compressed forming a pseudocapsule which may demonstrate a delayed enhancement (Buetow et al., 1996).

Retraction of the liver capsule adjacent to the tumour has been described with fibrolamellar carcinoma in $10 \%$ of cases. Although this is not specific to fibrolamellar carcinoma, it is characteristic to malignant liver neoplasms and may be useful in distinguishing fibrolamellar carcinoma from FNH when present (Soyer et al., 1994).

\subsubsection{MR Imaging:}

AT MR imaging, fibrolamellar carcinoma appears as a large lobulated mass. The majority of cases are hypointense relative to the liver, fewer cases are isointense. The fibrous scar, if present, is usually isointense on all MR images.

\subsubsection{Angiography:}

Angiography is useful for preoperative assessment of arterial and portal anatomy, and help to define vascular invasion. Occasionally, it can display intrahepatic tumours not visualised by other means. However, its role is limited in diagnosis of fibrolamellar carcinoma (McLarney et al., 1999). 


\subsubsection{Differential Diagnosis:}

Fibrolamellar carcinoma should be distinguished from all hepatic tumours that have a scar, including FNH, hepatocellular carcinoma, intrahepatic cholangiocarcinoma, giant haemangioma, and hypervascular metastasis (Buetow et al., 1996). It is particularly important to distinguish fibrolamellar carcinoma from FNH because both are seen in young adults without an evident risk factor, and because both have a central scar at imaging. Most importantly FNH requires no treatment. It is of utmost importance in biopsy specimen examination to detect the presence of tumour reticuloendothelial activity (Kupffer cells) which is an indication of a benign lesion, FNH or hepatocellular adenoma, and allows the exclusion of fibrolamellar carcinoma (Beets-Tan et al., 1998). Radio-isotope scanning of the liver is used to diagnose different lesions. About $15 \%$ of the liver cells are reticuloendothelial or Kupffer cells. These cells remove colloids from the blood and the liver can be scanned after intravenous injection of ${ }^{99 \mathrm{~m}} \mathrm{Tc}$-colloid particles. Any lesion that does not contain reticuloendothelial cells creates a localised defect making these liver scans more reliable in detecting metastasis and diagnose neoplastic lesions as primary neoplasm of the liver, lymphoma and angioma which create a localised defect (Dick, 1998).

\subsubsection{Prognosis and treatment:}

Patients with fibrolamellar carcinoma have a better prognosis than patients with hepatocellular carcinoma. Even in limited metastasis, aggressive surgical resection is usually needed and liver transplantation sometimes indicated (Pinna et al., 1997).

Curative surgical resection, subtotal hepatectomy or liver transplantation, is required in the majority of cases even in cases with extensive liver involvement (Stevens et al., 1995). In advanced cases, or in the presence of involvement of the main portal vein or 
the hepatic artery, the patients may benefit from adjuvant chemotherapy either systemic or intraarterial (Stauber et al., 1993).

Fibrolamellar carcinoma is recurrent. Thus, follow-up imaging studies are needed to detect early recurrence. Resection of recurrent lymphadenopathy and of recurrent masses, prolongs survival and may be curative in a few cases (Stevens et al., 1995).

\subsection{Aims of the study:}

The aim of this study was to investigate gene expression in HCV-associated human hepatocellular carcinomas by identifying up- or down-regulated genes.

Clearly, tumour formation in $\mathrm{HCV}$ infection involves complex molecular mechanisms and studying differential cellular gene expression may help elucidate these processes. Differential display-reverse transcription PCR (DDRT-PCR) was used to compare transcription in $\mathrm{HCV}$-associated HCCs and non-tumorous tissue from the same livers. Because differential display can generate misleading data, a ribonuclease protection assay (RPA) was used as a sensitive method to confirm the up- or down-regulation of selected cDNAs. Further analysis was carried out on one particular cDNA, which was found to be upregulated in HCC and shown subsequently to encode a protein related to ubiquitin conjugating enzyme. 


\section{Chapter 2}

2. Analysis of differential gene expression 


\subsection{Introduction:}

\subsubsection{History of gene expression detection:}

The concept of gene expression dates back to 1961 when messenger RNA was discovered and the genetic code as well as genetic regulation of protein synthesis were described (Jacob, 1961). In the mid-1970s, the first attempts at gene expression detection were undertaken. The first experiments were studies of the hybridisation of mRNA pools with radioactively labelled cDNA. These experiments provided information about the presence of "house keeping" genes necessary for the structural and functional integrity of all cell types, and the existence of cell type-specific genes (Bishop \& Smith, 1974). During the 1980s, interest in gene expression increased steadily. During the 1990s, the need to analyse changes in gene expression increased. This need stimulated the search for suitable methods to identify the actual differences between two well-defined biological situations. Gene expression patterns change in response to developmental or physiological factors, mutations, or simply transfection of particular genes. For a long time, the only methods of distinguishing differentially expressed mRNAs were laborious.

\subsubsection{Methods for detecting differential gene expression}

Differential gene expression separates cells into different types. Determining the differences existing in the mRNA between closely related cell groups provides information for understanding the biochemical complexity of metabolic events (Hubank \& Schatz, 1994).

Various methods are currently available to isolate genes associated with certain biological situations. Examples of these methods are the following: 


\subsubsection{Differential screening:}

This method starts with constructing a cDNA library which is then plated on agar. The selected library is chosen that is expected to contain the expressed genes of interest. Plating the library should be performed at a density low enough to visualise isolated plaques ( 200-500/ $150 \mathrm{~cm}^{2}$ plate). Duplicate "lifts" or imprints of the agar-plated cDNAs are made onto nitrocellulose membranes. Two different radiolabelled probe mixtures are prepared, which are ${ }^{32} \mathrm{P}$-labelled cDNAs derived from the two related, but still different, cell populations by RT of their mRNAs in the presence of ${ }^{32} \mathrm{P}-\mathrm{dATP}$ (Linzer \& Nathans, 1983). Duplicate lifts are then screened with one of the probe mixtures. However, this method is relatively insensitive and low-abundance clones are undetectable because of the low copy number of the corresponding radiolabelled cDNAs in the heterogeneous reverse-transcribed probe pool. The differential screening method is also laborious often involving screening of hundreds of duplicate lifts of a cDNA library with radiolabelled cDNA probes. Although technically straightforward, it is time consuming to screen thousands of isolated plaques or colonies in order to compare the duplicate lifts and identify cDNAs more strongly expressed in one of the two sequence pools. Such differential screening can be limited by variation in signal intensity and high background, because the lifts can contain variable quantities of a mixture of vector DNA and protein (Sunday, 1995).

\subsubsection{Subtractive hybridisation:}

This method involves hybridisation of cDNA or cDNA libraries with mRNA. A large amount of total RNA from the control cells, referred to as the "driver", is biotinylated. Then a smaller amount of single-stranded cDNA is prepared by RT of mRNA from the selected cell population, referred to as the "tester". The driver is then hybridised with the tester. The biotinylated mRNA: cDNA hybrids that form represent shared sequences 
expressed by both of the cell populations. The next step involves separation of the biotinylated double stranded hybrids by the addition of the large protein streptavidin, which binds to biotin. The biotinylated sequences can be separated by phenolchloroform extraction, in which the sequences bound to avidin are displayed to the interface between the aqueous and organic phases. Non-biotinylated single-stranded cDNAs from the tester, present in the aqueous phase, can then be isolated and inserted into a vector to make a subtracted library. The subtracted library is enriched for both low-abundance and high-abundance mRNAs.

This method is technically difficult, time consuming and unreliable (Wieland et al., 1990). One limitation is that residual non- induced clones sometimes are present (Sunday, 1995). In general, due to the high complexity of the human genome, subtractive hybridisation techniques do not achieve sufficient enrichment of the sequences that occur only in the tester. This complexity prevents complete hybridisation. The "target" sequences are enriched only 100 to 1000 times, which is insufficient for more common situations in which the magnitude of enrichment required is $10^{6}$ (Lisitsyn et al., 1993). However, including PCR to allow multiple cycles of selection with limited starting material (Cecchini et al., 1993) has increased the power of this method. Nevertheless, difficulties still exist with this method. First, the biotinylation reaction is usually incomplete. Second, the methods used for separating the modified from unmodified molecules are troublesome. As a result of these problems, the subtracted tester is usually contaminated with driver cDNA, which is present initially in excess (Zeng et al., 1994).

\subsubsection{Enzymatic degrading subtraction (EDS):}

Zeng et al. (1994) described a method called EDS for differential library construction and gene cloning. In order to overcome the problems noted with subtractive 
hybridisation library, they developed a single enzymatic method. This method is capable of differentiation between the tester and the driver cDNAs. It also can remove tester-driver heterohybrid and driver-driver homohybrid molecules.

The method involves the incorporation of thionucleotides into the tester rather than biotinylating the driver. This enzymatic modification is more reliable and uniform due to the slow and synchronous excision activity and the high processive activity of Klenow polymerase enzyme. It is more economical since it modifies a small amount of DNA. The most important feature is the removal of the hybrid molecule enzymatically rather than using a physical partitioning method.

\subsubsection{Representational difference analysis (RDA):}

RDA is a method introduced for finding small differences between the sequences of two DNA populations. It is a process of subtraction coupled to amplification. The method builds upon subtractive hybridisation and kinetic enrichment.

In RDA, the DNA complexity of both tester and driver genomes is lowered by preparing a representative portion of each genome a "representation" by six-cutting restriction enzyme digestion. If one restriction fragment is amplifiable (the target) and exists in one representation (the tester) but absent from another (the driver), this target can be enriched by subtractive hybridisation of the tester in the presence of excess of the driver followed by PCR amplification. It has been found that high proportions of the digested fragments do not fall into the amplifiable range, $150-1000$ base pairs. As a result, the final representation contains only $2-10 \%$ of the total genome (Lisitsyn et al., 1993). Assuming that sufficiently few sequences are present in cDNA that RDA can be applied without reducing the genome's complexity, restricted cDNA with a four-cutting enzyme, for instance DpnII, would help to generate the representations. This enzyme cutting resulted in a mean cutting length of about 260 base pairs, which ensures that 
most of cDNA species would have at least one amplifiable fragment. This fragment would be sufficient to identify a gene (Hubank \& Schatz, 1994).

RDA was used to clone sequences of two viruses (GBV-A and GBV-B) from the serum of a tamarin infected with the GB hepatitis agent (Simons et al., 1995), and in the isolation of a genome related to GBV-C from a chimpanzee (Birkenmeyer et al., 1998). In 1997, TTV was detected using RDA in the serum of a petient with posttransfusion hepatitis unrelated to known hepatitis viruses (Nishizawa et al., 1997).

\subsubsection{Differential display}

\section{Introduction:}

In 1992, Liang \& Pardee described a new approach to identify genes expressed differentially in a subset of two or more cell populations. It was called differential display (DD) or according to the PCR nomenclature, DDRT-PCR (Bauer et al., 1993). The method is based on random primed amplification of a subfraction of mRNA from two cell populations of interest followed by running the amplicons side by side in adjacent lanes on polyacrylamide gels and isolating bands, which are expressed at different levels. The method of DDRT-PCR is illustrated in figure 2.1.

\section{Method strategy:}

The method starts with equal quantities of mRNA and uses two distinct types of PCR primers. The first set contains three different anchored 3' oligo- (dT) primers. These primers generate fragments that originate mostly from the poly (A) tail and extend about 50-600 nucleotides upstream (Liang \& Pardee, 1992). The second set contains 5' random 10-mer primers of arbitrary sequence, previously used for DNA fingerprinting (Welsh \& McClelland, 1990). They hybridise with complementary sequences located at varying distances from the 3' end of each newly synthesised cDNA strand during the ${ }^{35}$ S-labelled PCR reaction. The primer pairs are defined to yield $\sim 100-200$ bands on a 2- 
3 hours run of a standard sequencing gel. Differential expression is determined by visual inspection of autoradiographs to identify bands present in only a subset of the cell populations. The bands of interest can then be cut out of the dried gels, eluted, reamplified and utilised as probes for northern blot analyses to confirm the desired differential expression and to provide information about the molecular weight of the identified transcripts. The same cDNA probes, generally between 100 and 500 base pairs in length, can be used to screen directly an appropriate cDNA library. In addition, the amplified cDNAs can be screened rapidly by sequencing to determine whether the genes are known entities or represent novel genes, whether there are valid open reading frames, and what sequence similarities exist in the nucleotide sequence database (Sunday, 1995). 


\section{DDRT-PCR}

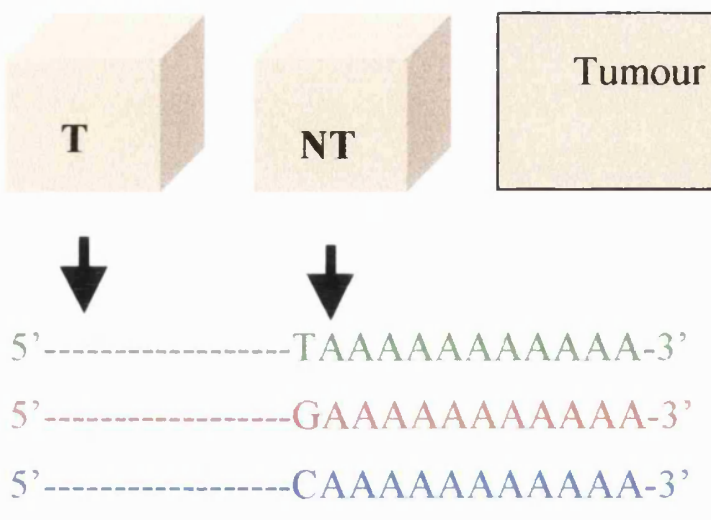

mRNA extraction parallel

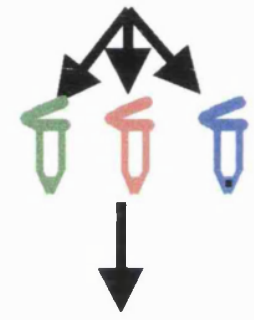

cDNA synthesis with

TTTTTTTTTTTA

TTTTTTTTTTTC

TTTTTITTTTTG

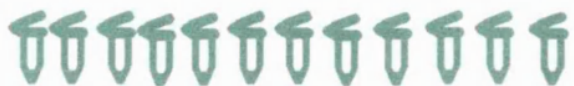 \\ PCR with 24 upstream primers making 72 reactions/ cell type}

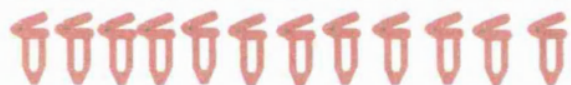

24 upstream primers

TACAACGAGG

TGGATTGGTC

CTTTCTACCC

TTTTGGCTCC

GGAACCAATC

AAACTCCGTC

TCGATACAGG

TGGTAAAGGG

TCGGTCATAG

GGTACTAAGG

TACCTAAGCG

CTGCTTGATG

GTTTTCGCAG

GATCAAGTCC

GATCCAGTAC

GATCACGTAC

GATCTGACAC

GATCTCAGAC

GATCATAGCC

GATCAATCGC

GATCTAACCG

GATCGCATTG

GATCTGACTG

GATCATGGTC 


\section{Theoretical Considerations:}

If one assumes 15,000 genes being expressed in a cell, it would be expected to see the same number of bands on a gel. Liang and Pardee (1992) subdivided the total mRNA into 12 fractions by performing the reverse transcription with oligo-dT primers having two additional nucleotides in all possible combinations at their $3^{\prime}$ end. In each of the 12 fractions one would expect approximately 1250 individual mRNA species to be present. On one lane of a sequencing gel one can easily detect some 150 individual bands if not uniformly distributed. This means that one PCR incubation should result in about this number of bands corresponding to individual cDNA species. Provided suitable primers are used, 10 to $12 \mathrm{PCR}$ incubations of one $\mathrm{mRNA} / \mathrm{cDNA}$ fraction would be sufficient to generate this number of bands. To simplify the screening of an entire mRNA pool, four 3' primers, T12MA, T12MC, T12MG, and T12MT, where $\mathrm{M}$ is a degenerate mixture of $\mathrm{dA}, \mathrm{dG}$, and $\mathrm{dC}$, can be used in both the $\mathrm{RT}$ and subsequent PCR reactions (Liang et al., 1993). These four 3' primers divide the expected 10,000-15,000 different mRNAs into four groups and anchor the PCR products to the 3' end of the mRNAs. Alternatively, three one-base anchored oligo (dt) primers can be used for excellent selectivity in subdividing mRNAs into three populations. A restriction site for Hind $\mathrm{III}$ can be incorporated at the 5' end of the anchored primers for more efficient amplification of the cDNA due to the longer primers used (Liang et al., 1994).

\section{Choosing suitable upstream PCR primers:}

On the basis of their theoretical considerations, Bauer et al. (1993) selected 26 oligonucleotide primers from a list of 50 arbitrary sequences generated by the computer and tested them empirically. These primers were selected to have GC-contents of $50 \%$. Among these, primers exhibiting uninterrupted self-complementarity between more than two nucleotides were disregarded. Thirteen of the primers were chosen to have an 
identical 5' end with sequence GATC in order to find out if this would affect the randomness in the selection of target sequences. After testing 50 potentially suitable primers in amplifying known genes, 26 were selected (Table 1).

\section{Applications:}

Only the original differential display technique is able to generate a largely complete pattern of all mRNAs expressed in a particular cell, using a reasonable number of primer pairs (Bauer et al., 1993). It has been used to distinguish altered gene expression in various situations such as between normal and cancer cells (Liang et al., 1992), normal and senescent cells (Linskens et al., 1995) and normal and injured nerve cells (Kiryu et al., 1995). It has been also applied to study differential gene expression in developing Xenopus embryos (Adati et al., 1995), in developing neonatal rats (Mou et al., 1994), following treatment with psychomotor stimulants (Douglass et al., 1995), hormones (Nitsche et al., 1996) and dietary supplements (Wang et al., 1996). 


\subsection{Materials and Methods:}

In this study the following steps were followed:

\subsubsection{Samples:}

The starting material was liver tissue obtained from an explanted liver. The patient underwent liver transplantation after being diagnosed of having HCC. The patient was $\mathrm{HCV}$ positive, genotype 1 , and $\mathrm{HBV}$ sAg negative and no other risk factors for the development of HCC were diagnosed. Two blocks were obtained from the explanted liver, one was dissected from the tumour and the other was excised from the surrounding non-tumourous cirrhotic liver tissue. These tissues were immediately frozen in liquid nitrogen then stored at $-70^{\circ} \mathrm{C}$ until further use.

\subsection{2. mRNA extraction}

Liver tissue was ground using a mortar and pestle under liquid nitrogen. Liquid nitrogen was allowed to evaporate then $15 \mathrm{ml}$ lysis buffer $(15 \mathrm{ml}$ stock buffer $+300 \mu \mathrm{l}$ Rase protein degrader, Invitrogen mRNA extraction kit) were added. The fluid was allowed to thaw and then was homogenised by pulling up and down until a clear fluid forms, 10 to 12 times, using a homogeniser. The lysate was passed through a sterile plastic syringe fitted with an 18-21 gauge needle, 2-4 times, to shear high molecular weight DNA. The fluid was incubated at $45^{\circ} \mathrm{C}$ for 60 minutes in a slow shaker water bath then centrifuged at $4000 \mathrm{xg}$ for 5 minutes. The supernatant was transferred to a new tube and the $\mathrm{NaCl}$ concentration was adjusted to $0.5 \mathrm{M}$ solution by adding $0.95 \mathrm{ml} 5 \mathrm{M} \mathrm{NaCl} / 15 \mathrm{ml}$ lysate. The lysate was mixed and passed through a sterile syringe fitted with 21 gauge needle 3-4 times to shear DNA. One oligo (dt) cellulose tablet was added to the lysate, the tube was sealed and left for two minutes to allow swelling of the tablet then rocked by hand 
to allow dispersion. The tube was rocked at room temperature for 60 minutes. Oligo (dt) cellulose was pelleted at room temperature at $2000-4000 \mathrm{xg}$ for 5 minutes then the supernatant was aspirated. The pellet was resuspended in $20 \mathrm{ml}$ binding buffer, pelleted and the supernatant was aspirated. The pellet was resuspended in $10 \mathrm{ml}$ binding buffer, $10 \mathrm{ml}$ low salt wash buffer twice. The oligo (dt) cellulose was resuspended in low salt wash buffer at a final volume not exceeding $0.8 \mathrm{ml}$. The sample was pipetted into a spincolumn and centrifuged for 10 seconds at $2,000-5,000 \mathrm{xg}$. The fluid was discarded and the centrifugation was repeated until the whole cellulose was transferred into the spincolumn. The column was washed by filling it to the top with low salt wash buffer then spinning for 10 seconds. The wash was repeated three times. The spin column was placed into a new microfuge tube then $200 \mu 1$ elution buffer were added, mixed into the cellulose bed with a pipette tip and centrifuged for 10 seconds. The process was repeated using another $200 \mu 1$ elution buffer. The column was removed from the tube. The RNA in the tube was precipitated with 0.15 volume $2 \mathrm{M}$ sodium acetate and 2.5 volume $100 \%$ ethanol. The RNA eluate was stored at $-70^{\circ} \mathrm{C}$ until solid.

\subsection{3. cDNA synthesis}

The first strand of cDNA was synthesised using a set of three, one base anchored primers, P1 (T11A), P2 (T11C) and P3 (T11G). The total amount of mRNA of each tissue type was fractionated into three fractions and by using one of these primers for each fraction three subfractions of cDNA were generated. Each tube contained $20 \mu 1$ reaction and was prepared as follows: 


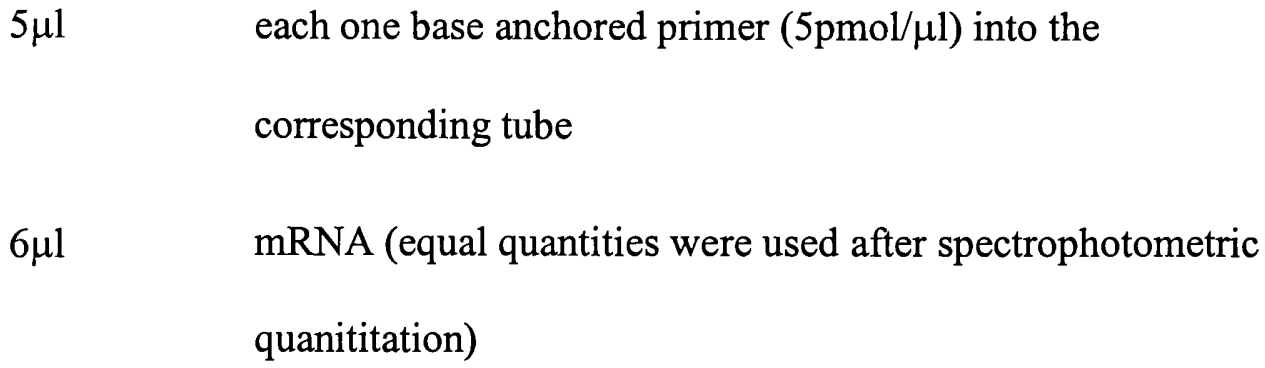

The tubes were left 2 minutes at room temperature then transferred to ice for a few minutes and the following reagents were added:

$\begin{array}{ll}4 \mu \mathrm{l} & 5 \mathrm{x} \text { first strand buffer } \\ 2 \mu \mathrm{l} & 0.1 \mathrm{M} \text { DTT } \\ 1 \mu \mathrm{l} & \text { dNTPs mix (10mM). } \\ 1 \mu \mathrm{l} & \text { Rnasin }\end{array}$

The mixture was added to each RNA/Primer tube and left 2 minutes at room temperature then $1 \mu l$ of superscript reverse transcriptase enzyme was added, making $20 \mu 1$ reaction.

The tubes were stored 8 minutes at room temperature followed by 1 hour at $37^{\circ} \mathrm{C}$ then heated for 5 minutes at $95^{\circ} \mathrm{C}$.

In later experiments, the one base anchored primers were modified by adding a Hind III restriction site (AAGCTT) at the 5' end of P1: AAGCTTTTTTTTTTTG,

\section{P2: P3: AAGCTTTTTTTTTTTA}

and these were used at a concentration of $5 \mathrm{pmol} / \mu \mathrm{l}$. 


\subsubsection{Differential Display Polymerase Chain Reaction (DDRT-PCR):}

\subsubsection{Primers:}

PCR procedures were carried out to analyse three cDNA subfractions from each tissue type using a combination of three downstream primers and 24 upstream primers as shown in Table 1. The concentration of the upstream primers was adjusted to $2.5 \mathrm{pmol} / \mu \mathrm{l}$. The downstream primers were adjusted to $10 \mathrm{pmol} / \mu \mathrm{l}$.

\begin{tabular}{|c|l|}
\hline Primer & \multicolumn{1}{|c|}{ Sequence 5' to 3' } \\
\hline Downstream & \\
P4 & AAGCTTTTTTTTTTG \\
P5 & AAGCTTTTTTTTTTC \\
PAGCTTTTTTTTTTA \\
\hline Upstream & TACAACGAGG \\
DD1 & TGGATTGGTC \\
DD2 & CTTTCTACCC \\
DD3 & TTTTGGCTCC \\
DD45 & GGAACCAATC \\
DD6 & AAACTCCGTC \\
DD7 & TCGATACAGG \\
DD8 & TGGTAAAGGG \\
DD9 & TCGGTCATAG \\
DD10 & GGTACTAAGG \\
DD11 & TACCTAAGCG \\
DD12 & CTGCTTGATG \\
DD13 & GTTTTCGCAG \\
DD14 & GATCAAGTCC \\
DD15 & GATCCAGTAC \\
DD16 & GATCACGTAC \\
DD17 & GATCTGACAC \\
DD18 & GATCTCAGAC \\
DD19 & GATCATAGCC \\
DD20 & GATCAATCGC \\
DD21 & GATCTAACCG \\
DD22 & GATCGCATTG \\
DD23 & GATCTGACTG \\
DD24 & GATCATGGTC \\
\hline
\end{tabular}

Table 2.1 Primers used in differential display (DDRT-PCR).

3 downstream primers used for cDNA synthesis and in PCR together with 24 upstream primers. The underlined bald sequences in the downstream primers are Hind III restriction sites. The sequence GATC in primers DD14 to DD24 was selected in the DDRT primers to see if this would affect the randomness in the selection of target sequences. 


\subsubsection{PCR mix:}

A $20 \mu 1$ PCR reaction was carried out as follows:

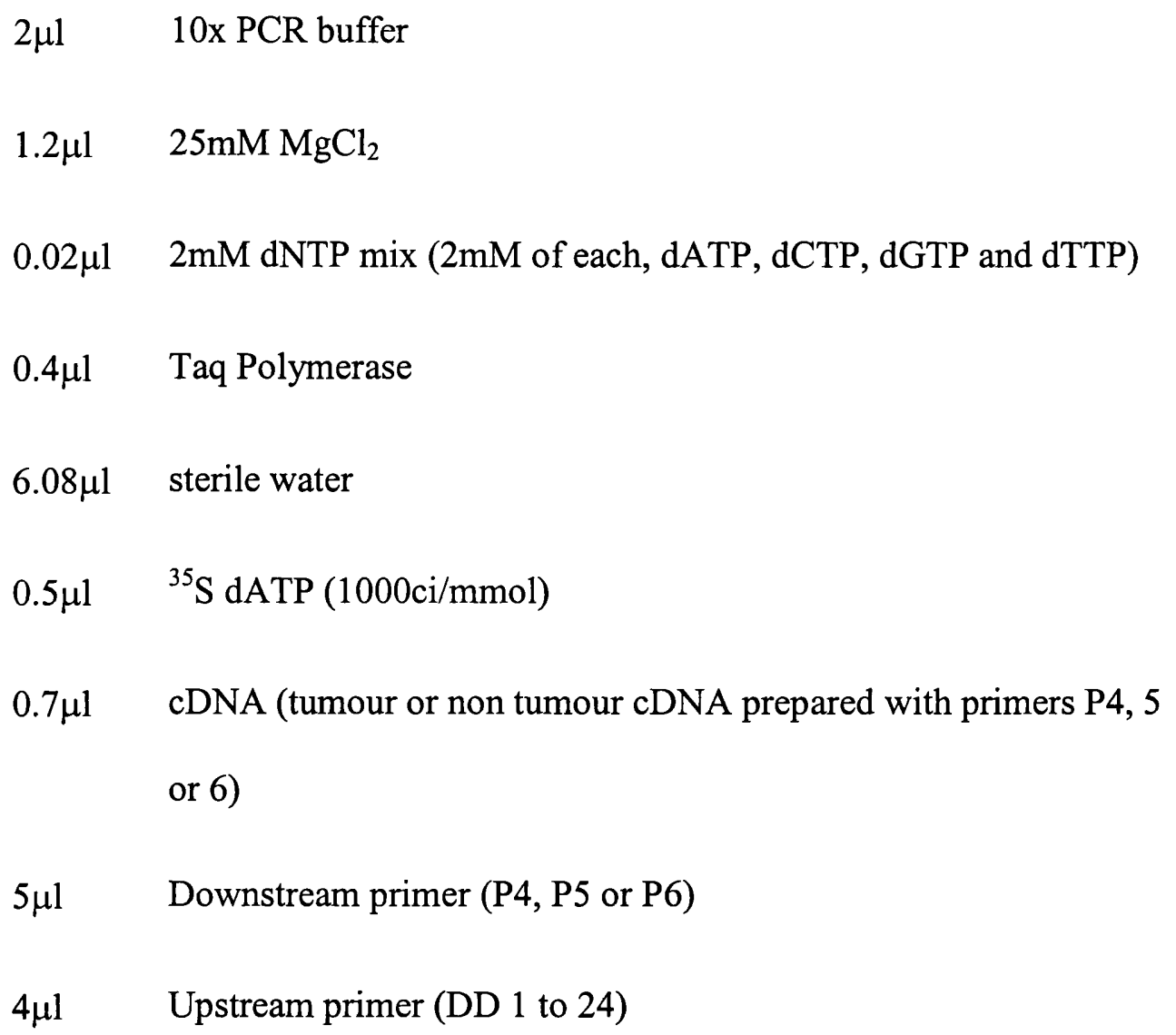

36 PCR tubes were prepared at a time amplifying 6 subfractions of cDNA, tumour or non-tumour synthesised by P4, P5 or P6. A master mix for 50 tubes was prepared including the PCR buffer, $25 \mathrm{mM} \mathrm{MgCl}_{2}, 2 \mathrm{mM}$ dNTP mix, Taq Polymerase, ${ }^{35} \mathrm{~S}$ dATP $(1000 \mathrm{ci} / \mathrm{mmol})$ and sterile water.

An additional 6 master tubes were labelled $A$ to $F$ in which tumour cDNA synthesised by $\mathrm{P} 4$ was aliquoted in tube $\mathrm{A}$, non tumour cDNA synthesised by $\mathrm{P} 4$ in tube $\mathrm{B}$, tumour cDNA synthesised by P5 in tube C, non tumour cDNA synthesised by P5 in tube D, tumour cDNA synthesised by P6 in tube E, non tumour cDNA synthesised by P6 in 
tube F), to each a 7x PCR mix was aliquoted, from the 50x mix, dowstream primers and the correspoding cDNA.

The 36 PCR tubes were labelled A1 to A6, B1 to B6 until F1 to F6.

A $20 \mu 1$ PCR reaction was set as follows:

$16 \mu \mathrm{l} \quad$ master tube mix in sets $\mathrm{A}$ to $\mathrm{F}$ was aliquoted into the corresponding tubes

$4 \mu 1 \quad$ upstream primer (each into its corresponding tube number) i.e. DD1 in $\mathrm{A} 1, \mathrm{~B} 1$ to $\mathrm{F} 1$.

A drop of mineral oil was added to each PCR reaction.

\subsubsection{Thermal cycler protocol:}

Tubes were amplified using a thermal cycler (Techne PHC-3) at these temperatures:

$\begin{array}{lll}\text { For the first } 5 \text { cycles: } & 50 \text { seconds } & 94^{\circ} \mathrm{C} \\ & 60 \text { seconds } & 40^{\circ} \mathrm{C} \\ & 60 \text { seconds } & 72^{\circ} \mathrm{C} \\ \text { For a further } 35 \text { cycles: } & 50 \text { seconds } & 94^{\circ} \mathrm{C} \\ & 60 \text { seconds } & 45^{\circ} \mathrm{C} \\ & & \\ & 60 \text { seconds } & 72^{\circ} \mathrm{C}\end{array}$

\subsubsection{Electrophoresis:}

Buffer: 20x TTE 
Sequencing gel solution was prepared as follows:

$\begin{array}{ll}50 \mathrm{ml} & \text { water } \\ 18.0 \mathrm{ml} & \text { acrylamide/bisacrylamide 19:1 } \\ 6 \mathrm{ml} & 20 \times \text { TTE buffer } \\ 50.4 \mathrm{gm} & \text { Urea }\end{array}$

After dissolving the urea, the solution was made up to $120 \mathrm{ml}$ with water then the following reagents were added:

$\begin{array}{ll}252 \mu 1 & 25 \% \text { ammonium persulphate } \\ 112 \mu 1 & \text { TEMED }\end{array}$

The gel solution was poured between two glass plates and left for 2 hours to set. Half of the DDRT-PCR mixture $(10 \mu \mathrm{l})$ was concentrated under vacuum and heat to $2 \mu \mathrm{l}$ and then $2 \mu$ l Differential Display loading dye were added (refer to appendix II).

$2 \mu 1$ were loaded onto the gel and run in TTE buffer at 80 watts. The run was stopped when the bromophenol blue run out of the gel. The gel was fixed in $2 \mathrm{~L}$ of $10 \%$ acetic acid for 45- 60 minutes then dried for 1 hour on a filter paper and exposed to an X-ray film overnight.

\subsubsection{Reamplification:}

The bands of interest, those differing in intensity between the tumour and the nontumour cells, were cut from the filter paper and transferred to microfuge tubes. 
DNA was extracted using QIAEX II polyacrylamide extraction kit (according to the manufacturer instructions).

\section{Reamplification PCR:}

$\begin{array}{ll}1 \mu \mathrm{l} & \text { extracted DNA } \\ 2 \mu \mathrm{l} & \text { PCR buffer } \\ 2 \mu 1 & 2 \mathrm{mM} \text { dNTP mix } \\ 4 \mu \mathrm{l} & \text { upstream primer }(2.5 \mathrm{pmol} / \mu \mathrm{l}) \\ 5 \mu 1 & \text { downstream primer }(10 \mathrm{pmol} / \mu \mathrm{l}) \\ 0.4 \mu \mathrm{l} & \text { advantage DNA Polymerase mix } \\ 5.6 \mu 1 & \quad \text { water }\end{array}$

Both primers were those used to generate the original PCR product.

Amplification was carried out using Touch Down PCR:

annealing temperature $48^{\circ} \mathrm{C}$ for 60 seconds 2 cycles

annealing temperature $47^{\circ} \mathrm{C}$ for 60 seconds $\quad 2$ cycles

annealing temperature $46^{\circ} \mathrm{C}$ for 60 seconds $\quad 2$ cycles

annealing temperature $45^{\circ} \mathrm{C}$ for 60 seconds 29 cycles

The reaction mixture was run on a $1.5 \%$ agarose gel and stained with ethidium bromide to check the size under UV. Bands corresponding to the predicted size were excised and 
DNA was extracted using a QIAEX II agarose gel extraction kit (according to the manufacturers instruction).

\subsubsection{Cloning:}

As mentioned before the DDRT-PCR bands were amplified with the advantage polymerase and there were no 'A overhangs'at the end of these fragments. For this reason blunt ended cloning was carried out to clone the cuccessfully amplified gel bands.

\subsubsection{Blunt ended cloning:}

\section{BLUNT ENDING THE FRAGMENT:}

The selected bands were treated with $\mathrm{T} 4$ polymerase enzyme as follows. The purified DNA was eluted in a final volume of $35 \mu l$ and to each tube the following reagents were added:

$$
\begin{array}{ll}
16 \mu \mathrm{l} & 5 \mathrm{x} \text { forward kinase buffer } \\
8 \mu \mathrm{l} & 1 \mathrm{mM} \text { dNTPs } \\
8 \mu \mathrm{l} & \text { BSA }(100 \mu \mathrm{g} / \mathrm{ml}) \\
2.5 \mu \mathrm{l} & \text { T4 DNA polymerase }(5 \mathrm{u} / \mu \mathrm{l})
\end{array}
$$

The mixtures were incubated for 30 minutes at $15^{\circ} \mathrm{C}$ then 15 minutes at $65^{\circ} \mathrm{C}$.

\section{PHOSPHORYLATING THE FRAGMENTS:}

The DNA was then phosphorylated as follows:

$$
\begin{array}{ll}
8 \mu \mathrm{l} & 10 \mathrm{mM} \text { ATP } \\
2.5 \mu \mathrm{l} & \text { T4 kinase enzyme }(10 \mathrm{u} / \mu \mathrm{l})
\end{array}
$$

The reaction tubes were incubated for 30 minutes at $37^{\circ} \mathrm{C}$ then 15 minutes at $65^{\circ} \mathrm{C}$. 


\section{BLUNT ENDING THE VECTOR:}

The plasmid vector pUC19 was blunt ended in the following reaction mixture:

$\begin{array}{ll}10 \mu \mathrm{l} & \mathrm{pUC19}(1 \mu \mathrm{g} / \mu \mathrm{l}) \\ 25 \mu \mathrm{l} & \text { water } \\ 5 \mu \mathrm{l} & \text { React } 4 \\ 5 \mu \mathrm{l} & \mathrm{BSA}(1 \mu \mathrm{g} / \mu \mathrm{l}) \\ 5 \mu \mathrm{l} & \mathrm{SmaI}(10 \mathrm{u} / \mu \mathrm{l})\end{array}$

The reaction tubes were incubated for 4 hours at $28^{\circ} \mathrm{C}$ then 15 minutes at $65^{\circ} \mathrm{C}$.

\section{DEPHOSPHORYLATING THE VECTOR:}

The vector ends were dephosphorylated in order to prevent recircularisation using the following reaction:

$\begin{array}{ll}40 \mu \mathrm{l} & \text { water } \\ 50 \mu \mathrm{l} & \mathrm{pUC} / \mathrm{Sma} \\ 5 \mu \mathrm{l} & 10 \mathrm{x} \text { Shrimp alkaline phosphatase (SAP) buffer } \\ 5 \mu 1 & \operatorname{SAP}(1 \mathrm{u} / \mu 1)\end{array}$

The reaction mixtures were incubated for 30 minutes at $37^{\circ} \mathrm{C}$ then 15 minutes at $65^{\circ} \mathrm{C}$.

\section{LIGATION REACTION:}

$\begin{array}{ll}2 \mu 1 & \text { pUC/Sma/SAP } \\ 8 \mu 1 & \text { phosphorylated fragment } \\ 7 \mu 1 & \text { water } \\ 2 \mu 1 & 10 x \text { ligation buffer }\end{array}$




$$
1 \mu \mathrm{l} \quad \text { T4 DNA polymerase }(4 \mathrm{u} / \mu \mathrm{l})
$$

The mixtures were incubated at $15^{\circ} \mathrm{C}$ overnight.

\section{TRANSFORMATION:}

Transformation was done using One shot $\mathrm{INV} \alpha \mathrm{F}^{\prime} \mathrm{E}$-coli, Invitrogen (according to the manufacturer's instruction).

$200 \mu 1$ of transformed cells were cultured on the surface of ampicillin agar plates (appendix II) after spreading $70 \mu \mathrm{l}$ of X-gal.

6 white colonies were picked from each cloned fragment and plasmid mini-preparations were made using a QIA prep spin plasmid kit (according to the manufacturers instruction).

Plasmids were cut with PvuII using the following reaction:

$\begin{array}{ll}5.5 \mu \mathrm{l} & \text { water } \\ 1 \mu \mathrm{l} & \text { React } 6 \\ 1 \mu \mathrm{l} & \text { BSA }(100 \mu \mathrm{g} / \mathrm{ml}) \\ 0.5 \mu \mathrm{l} & \text { PvuII }(10 \mathrm{u} / \mu \mathrm{l}) \\ 2 \mu \mathrm{l} & \text { plasmid DNA }\end{array}$

The reaction tubes were incubated for 2 hours at $37^{\circ} \mathrm{C}$ then electrophoresed on $1.5 \%$ agarose gel to check for the insert size. 


\subsubsection{TA cloning:}

Some fragments were difficult to clone. Since these fragments did not have 'A overhangs', they were A-tailed followed by cloning into pCR2.1, TA cloning kit, Invitrogen, as follows:

\section{A-TAILING THE PURIFIED FRAGMENT DNA:}

Before ligation, $5 \mu 1$ of PCR DNA was incubated for 15 minutes at $72^{\circ} \mathrm{C}$ with $2 \mu 12 \mathrm{mM}$ dATP, $2 \mu 1$ Taq polymerase buffer, $1.2 \mu 125 \mathrm{mM} \mathrm{MgCl} 2$, and $0.5 \mu 1$ Taq DNA polymerase, Promega.

LIGATION REACTION:

$\begin{array}{ll}3 \mu \mathrm{l} & \text { water } \\ 3 \mu \mathrm{l} & \text { A-tailed fragment } \\ 1 \mu \mathrm{l} & 10 \mathrm{x} \text { ligation buffer } \\ 2 \mu \mathrm{l} & \text { pCR } 2.1 \mathrm{DNA}(25 \mu \mathrm{g} / \mu \mathrm{l}) \\ 1 \mu \mathrm{l} & \text { T4 DNA ligase }(4 \mathrm{u} / \mu \mathrm{l})\end{array}$

The reaction mixtures were incubated at $14^{\circ} \mathrm{C}$ overnight.

Plasmids were cut with EcoRI as follows:

$\begin{array}{ll}5.5 \mu \mathrm{l} & \text { water } \\ 1 \mu \mathrm{l} & \text { React } 3 \\ 1 \mu \mathrm{l} & \text { BSA } \\ 0.5 \mu \mathrm{l} & \text { EcoRI }(10 \mathrm{u} / \mu \mathrm{l})\end{array}$




$$
2 \mu l \quad \text { plasmid DNA }
$$

The reaction tubes were incubated for 2 hours at $37^{\circ} \mathrm{C}$ then electrophoresed on $1.5 \%$ agarose gel to check for the insert size.

\subsubsection{Sequencing:}

\subsubsection{Chain termination sequencing:}

The following protocol was followed using Sequenase v2.0 kit, Amersham:

\section{Termination tubes:}

Four tubes were labelled for termination with each primer and were labelled as follows; green-capped for ddGTP, red-capped for ddATP, blue-capped for ddTTP and blackcapped for ddCTP.

\section{Alkali denaturation:}

Denaturation of double stranded DNA was done as follows:

Primer/NaOH mix: the following reagents were added and mixed:

$$
\begin{array}{ll}
0.5 \mu \mathrm{l} & 1 \mathrm{M} \mathrm{NaOH} \\
1 \mu \mathrm{l} & \text { Primer (either forward or reverse at } 10 \mathrm{pmol} / \mu \mathrm{l} \text { ) }
\end{array}
$$

Denaturation: one tube was labelled for each sample and the following were added and mixed by pipetting then incubated at $37^{\circ} \mathrm{C}$ for 40 minutes:

$1.5 \mu \mathrm{l} \quad$ primer $/ \mathrm{NaOH}$ mix

$$
2.5 \mu 1 \quad \text { DNA }
$$


Neutralisation: Neutralising solution was prepared by adding $25 \mu 1$ of $5 \mathrm{x}$ sequence buffer, $12.5 \mu 1$ of $1 \mathrm{M}$ Tris (pH 7.5) and $12.5 \mu \mathrm{l}$ of $1 \mathrm{M} \mathrm{HCl}$.

$2 \mu \mathrm{l}$ of this neutralising solution were added to each DNA/Primer tube, mixed by pipetting and incubated at $37^{\circ} \mathrm{C}$ for $25 \mathrm{~min}$.

\section{Labelling reaction:}

The following reagents were added, mixed and put on ice:

$$
\begin{array}{ll}
0.4 \mu \mathrm{l} & \text { labelling mix } \\
1.6 \mu \mathrm{l} & \text { water } \\
0.5 \mu \mathrm{l} & 0.1 \mathrm{M} \text { DTT } \\
0.25 \mu \mathrm{l} & 35 \mathrm{~S} \text { dATP }(1000 \mathrm{ci} / \mathrm{mmol}) \\
0.875 \mu \mathrm{l} & \text { Sequenase dilution buffer } \\
0.125 \mu \mathrm{l} & \text { Sequenase version } 2.0
\end{array}
$$

\section{Termination reaction:}

$1.25 \mu 1$ of each termination mixture $(\mathrm{G}, \mathrm{A}, \mathrm{T}$ and $\mathrm{C})$ were aliquotted into each termination tube then capped and incubated at $37^{\circ} \mathrm{C}$ in a heat block for a few minutes.

$2.75 \mu \mathrm{l}$ of labelling solution were added to each DNA/primer mix and incubated 2.5 minutes at room temperature then $1.75 \mu$ l of these tubes were added to each termination tube and incubated 5 minutes at a temperature between 37 and $42^{\circ} \mathrm{C}$.

\section{Stop reaction:}

$2 \mu \mathrm{l}$ of a stop mix was added to each tube. Followed by heating the samples to $80^{\circ} \mathrm{C}$ for 3 minutes then $2-3 \mu 1$ was loaded in each lane on denaturing sequencing gel. 


\subsubsection{Cycle Sequencing:}

ThermoSequenase cycle sequencing kit, Amersham, was used for sequencing the remainder of the clones as follows:

\section{Termination mixes:}

$2 \mu \mathrm{l}$ of the termination master dITP $(7.5 \mu \mathrm{M}$ dATP, dCTP, dTTP, $37.5 \mu \mathrm{M}$ dITP) was mixed with $0.5 \mu \mathrm{l} \alpha-{ }^{33} \mathrm{P}$ ddNTP (tubes were labelled G for ddGTP, A for ddATP, T for ddTTP and C for ddCTP).

\section{Reaction mixture:}

A $20 \mu 1$ reaction was prepared for forward reaction and another for reverse reaction as follows:

$$
\begin{array}{ll}
2 \mu 1 & \text { Reaction buffer } \\
2 \mu 1 & \text { DNA } \\
1 \mu 1 & \text { forward or reverse primer at } 2.5 \mathrm{pmol} / \mu \mathrm{l} \\
13 \mu 1 & \text { water } \\
2 \mu 1 & \text { Thermo Sequenase DNA polymerase }(4 \mathrm{u} / \mu \mathrm{l})
\end{array}
$$

\section{Cycling termination reactions:}

$4.5 \mu$ of reaction mixture was added to each termination tube G,A,C, or T, mixed well then cycled for 30 cycles as follows:

$$
\begin{aligned}
& 95^{\circ} \mathrm{C} \quad 30 \text { seconds } \\
& 50^{\circ} \mathrm{C} \quad 30 \text { seconds } \\
& 60^{\circ} \mathrm{C} \quad 6 \text { minutes (recommended for reading beyond } 200 \text { bases) }
\end{aligned}
$$




\subsubsection{Gel electrophoresis:}

Under optimal conditions, 300 or more bases can be read starting from the bottom of the gel. Many factors can reduce this resolution. Among these are the quality of reagents used, the polymerisation, the temperature of the gel during electrophoresis, and improper drying of the gel after running. Both denaturing and non denaturing gels were used in this study.

Buffer: 20X TTE.

Non-denaturing gel solution was prepared by adding the following reagents:

10.5ml Acrylamide/Bis-acrylamide 19:1

$3.5 \mathrm{ml} \quad 20 \mathrm{x}$ TTE buffer

$56 \mathrm{ml} \quad$ water

$153 \mu \mathrm{l} \quad 25 \%$ ammonium persulphate

$65.6 \mu 1 \quad$ TEMED

6\% urea gels were prepared by mixing the following reagents:

18ml $40 \%$ Acrylamide/Bis-acrylamide 19:1
$6 \mathrm{ml}$ 20X TTE buffer

$50.4 \mathrm{gm} \quad$ Urea

$50 \mathrm{ml} \quad$ water

The volume was adjusted up to $120 \mathrm{ml}$ with water then the following reagents were added and mixed: 


\section{$252 \mu 1 \quad 25 \%$ ammonium persulfate \\ $112 \mu \mathrm{l} \quad$ TEMED}

Gels were prepared one night prior to use and were pre-run for 30 minutes.

After running, gels were soaked in $10 \%$ acetic acid for 60 minutes to remove the urea then dried at $80^{\circ} \mathrm{C}$ to preserve resolution.

The dried gels were exposed to an x-ray film.

\subsubsection{Analysis of the sequences:}

\subsubsection{Open reading frame finder:}

The ORF finder web site (http://www.ncbi.nlm.nih.gov/gorf/orfg.cgi) was used to analyse the obtained sequences and to search for open reading frames (ORF). The ORF finder is a graphical analysis tool, which finds all open reading, frames of a selected user's sequence or in a sequence already in the database. It identifies all ORF using the standard or alternative genetic codes.

\subsubsection{Sequence homology:}

The nucleotide sequence database was searched for homologous sequences to each DDRT-PCR clone. BLAST program was used in the HGMP-UK and NCBI websites. 


\subsection{RESULTS:}

\subsubsection{DDRT-PCR on HCV-associated HCC:}

The methods described above include several modifications and are different from the standard methods described by Liang and Pardee. Some modifications of the DDRTPCR conditions were applied including the following changes:

1) Lowering the annealing temperature to $30^{\circ} \mathrm{C}$. This allows annealing of the primers in the presence of few mismatches.

2) Using different $\mathrm{MgCl}_{2}$ concentration of $25 \mathrm{mM}, 18.75 \mathrm{mM}, 17.5 \mathrm{mM}, 15.0 \mathrm{mM}$, $12.5 \mathrm{mM}, 10.0 \mathrm{mM}, 7.5 \mathrm{mM}, 5.0 \mathrm{mM}, 2.5 \mathrm{mM}$ and $0.0 \mathrm{mM}$.

Results were best with a $\mathrm{MgCl}_{2}$ concentration of $7.5 \mathrm{mM}$ to $12.5 \mathrm{mM}$ in the first experiment (figure 2.2) then results were not the same with subsequent reactions using other liver tissues.

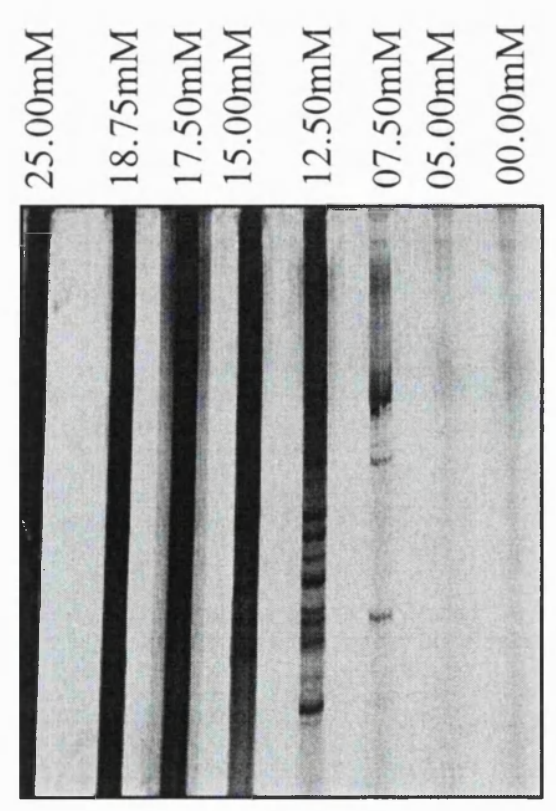

Figure 2.2

Different $\mathrm{MgCl}_{2}$ concentration in DDRT-PCR 
The final modification was to use Advantage DNA Polymerase mix without additional $\mathrm{MgCl}_{2}$.

Electrophoresis was tried initially on non-denaturing polyacrylamide gels. Results of these gels showed low resolution and very hazy bands so denaturing urea gels were used. Because the use of tapered spacers, 'wedge' gels, improves overall resolution (Ansorge \& Labeit, 1984), wedge urea gels were used subsequently.

Comparing the intensities of the different bands in every two adjacent lanes, tumour and non-tumour, showed that 52 bands appeared to be up-regulated in one and not the other tissue (figure 2.3).

5 were upregulated in the non-tumourous tissue and 47 in the tumour. These bands were excised from the gels, purified and reamplified as described above. 42 were successfully reamplified.

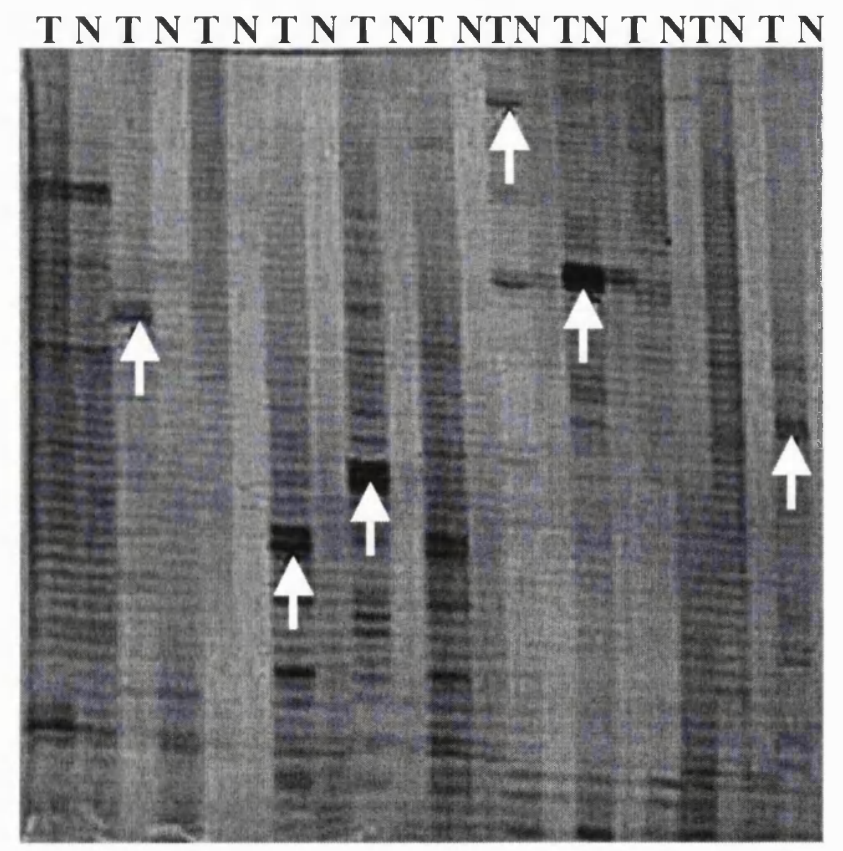

Figure 2.3 DDRT-PCR gel.

A section of one of the DDRT-PCR gels ( $\mathrm{T}=$ tumour- $\mathrm{N}=$ non-tumour).

The products were separated on $6 \%$ denaturing polyacrylamide gels and the arrows indicate differentially expressed bands in the tumour tissue. 


\subsubsection{Cloning of DDRT-PCR bands:}

21 sequences were successfully cloned into pUC 19 using the blunt ended cloning method and 7 in pCR2.1 using the TA cloning kit.

\subsubsection{Sequencing of DDRT-PCR clones:}

Six clones were successfully sequenced using Sequenase kit, and 22 using Cycle

Sequencing kit. Two clones, designated 263 and 265, proved to be primer dimers and the other 26 bands were designated as shown in table 2.2:

\begin{tabular}{|c|c|}
\hline Number & Sequence \\
\hline 271 & $\begin{array}{l}\text { 3'-CAACTTAGTA TTAAGTTTAT CAAATAGTAT TACCACCAGA TGGTATCTAC CAGTAGTAGA } \\
\text { ACCACTGTGG TACATCACCA AGCATCAGCA ATTATCATTT CAT-5' }\end{array}$ \\
\hline 272 & $\begin{array}{l}\text { 5'-CACTAAAAAA ATTACAAGGT ATCAGTTGGA AGGGATCAAA TGAGCTTTTT GTTGGTCTTG } \\
\text { GCACTTTTAA AGATTTAACA GACAGCCTTT TTCCTCTTCT CTTCTTTTT-3' }\end{array}$ \\
\hline 281 & 3'-TTTNGGATCC TACTTGCTCC CGGAAGAAAA GCCTTAAACG GT-5' \\
\hline 287 & $\begin{array}{l}\text { 5'-AATACAGTTC TGTTCACATA ATACGCATGT TCAGAATCTT TCGATATTTT AGGTTAGCCA } \\
\text { ACTTAAGTAT TCCACAAGAA TTATATTCAG AACAAGTTTA CTGAAAAGTA TTTCCTAAC } \\
\text { AAGAAACAAT ACTGAAATT CAAAACTATG AAAATAACTA GCACACTTGT-3' }\end{array}$ \\
\hline 289 & $\begin{array}{l}\text { 5'-TTTTNNCAAA TTCACCATAC AGCCATGACT CCAGCTAGCT CCCCCTCAGA TTCGGGTACC } \\
\text { GAGATCCTCG AANNGATCTA ATCATGTCAT AGCTGCTTTN CCTGTGTGAA ACTTGACTTA } \\
\text { CTATCGATCG ATCCACAATT CNATCGATCA ACATATG-3' }\end{array}$ \\
\hline 294 & $\begin{array}{l}\text { 5'-CAAAATATGG ATATATTTTA ATTTACTCAA ATGgGAACTA CTGATAAGCA GTTCTTATTT } \\
\text { TTCCAGCATA AGCAAGGCTA CAATAAATAT CTTTGAATA-3' }\end{array}$ \\
\hline $299 a$ & $\begin{array}{l}\text { 5'-GGAGTTAGTC CTTGACCACT AGTTTGATGC ATCTCCATTT TGGGTGACTG TTTACAGCAG } \\
\text { CTGTTACTCT-3' }\end{array}$ \\
\hline $299 b$ & $\begin{array}{l}\text { 5'-CTAGTGACCC ATGCTCAGAA TCCCAGCATT ATCTTAGACT CTTTGCTCTC TATGTTCCTT } \\
\text { ACATTTGTTT TCTCTTGT-3' }\end{array}$ \\
\hline 311 & $\begin{array}{l}\text { 5'-TTAATATAAA GATATATTCC ATAAAAGAGT TTGGCAGTCA AAGAGAAGCA TCACACTTCC } \\
\text { GAAAAACACA AGCATTCTTC TCCTAGTCTA CAGAGAGTTG TG-3' }\end{array}$ \\
\hline 329 & $\begin{array}{l}\text { 5'-AATAAAAGTA CTTTAAGCAC GAATACTTTT AATTTACCTT TCTATATTTT AATTTTGTTG } \\
\text { AAGGCTATTG GGATTTCCAT GTTCTTATTA AAAATCTAAC AAATC-3' }\end{array}$ \\
\hline 330 & $\begin{array}{l}\text { 5'-GAAGTCATTT ATTTACATAT TATATGCTCC GATATATAAT GTGTAGATAA ATGTATACTG } \\
\text { CAGTGAAAGC TGACCACTCT ACTGAACTGT ACAGCACATT ATAGGACAAA TTATTGGCCA } \\
\text { AGCTTTTCAT CTACTACTGG TATCTTTTAC AT-3' }\end{array}$ \\
\hline
\end{tabular}




\begin{tabular}{|c|c|}
\hline $333 a$ & $\begin{array}{l}\text { 5'-GAGACGGAGT CACGCTCTGT CGCCCAGGCT GGAGTGCAGT GGGGCAGAGA CAATGAGCGG } \\
\text { AAGAAATGAA ACAGACTTCA CTAGTGCTTT AAGATCCTAT GTCTTCTCCC AGTATTATTC } \\
\text { GTCCAGCATA CCAGAA-3' }\end{array}$ \\
\hline $333 b$ & 5'-TCTGCTTGAT GCACTGTTGG AAATGTGATT AATTTAATCA TNCAGATAAA CC-3' \\
\hline 335 & $\begin{array}{l}\text { 5'-TCCTCTATAT AGTCNGACCT GNNAGCATGC TAANCTTNCA CTNNNCTCTT TTTACTAACN } \\
\text { TNNTTACTNN-3' }\end{array}$ \\
\hline 339 & $\begin{array}{l}\text { 5'-CTGATAAGAA TTCTTTTATG TTATTCCAAT AAAAAATACA TTCATACAGA AATATAACAA } \\
\text { TCTTGCAAAA AACAATTTCA AATAAAATCT TGTAAAACAA AATTTTACAA AAATCTTACA } \\
\text { AAGATTCTT AGATAACAGG TGCTTC-3' }\end{array}$ \\
\hline 353 & $\begin{array}{l}\text { 5'-ATGAAATAAG GATAGGATAG GATAGAGTTG AAAATNCCAG ACTGCATNNN ATGTAGCAAG } \\
\text { AATGACAGTT GATTCATGAA AATGTTGTNN CAGGTGTGTA TGTACGTGAG TCGTCACGTN } \\
\text { CTAGCAACTT CAT-3' }\end{array}$ \\
\hline $359 d$ & 5'-AGTCTATTAT TGAAAATCGA CATTTCCCAT TTATTATATA TTGAGAGCAT-3' \\
\hline 361 & 5'-TATGTGTGTG TTTTAAAATA AACTTCTGGA AACATGTTTG-3' \\
\hline $367 \mathrm{~b}$ & $\begin{array}{l}\text { 5'-AAGCCCAAAT TGAGGATTCT ACAAAAGAAT TGCAAAATAA CTGGCCTGTA GTCTTCAAAA } \\
\text { ATGTTAAGGC CAT-3' }\end{array}$ \\
\hline 373 & 5'-AGAAAATACT GATGTTCACT TAAAGATATT TAGCAATTAA AATGTTAAAA CTT-3, \\
\hline $383 b$ & $\begin{array}{l}\text { 5'-GGAGTTAGTC CTTGACCACT AGTTTGATGC CATCTCCATT TTGGGTGACC TGTTTCACCA } \\
\text { GCAGGCCTGT TACTCTCCAT GACTAACTGT GTAAGTGCTT AAAATGGAAT AAATTGCTTT } \\
\text { TCTACA-3' }\end{array}$ \\
\hline $385 \mathrm{a}$ & $\begin{array}{l}\text { 5'-TAGTCTATGA CCAATCACAC TTATCTTTAA AAGAATACAA AAAATATTCC ACCAAAACAA } \\
\text { TGACATGTAG TCAAGCTCTT GTCTGTTATC TCTGTAATTT TAAGAACGTT GTT-3' }\end{array}$ \\
\hline $385 b$ & 5'-TAATTTGTCT GACTTATGAG TATAAAATTG TCATATTTTC TTGATAACTT TTTAAATGG-3' \\
\hline $389 a$ & $\begin{array}{l}\text { 5'-GGGGATCCTC TAGAGTCGAC CTGCAGGCAT GCAAGCTTGG CACTGGCCGT CGTTTTACAA } \\
\text { CGTCGTGACT GGGAAAACCC TGGCGTTACC CAACTTAATC GCCTTGCAGC ACATCCCCCT } \\
\text { TTCGCCAGCT GGCGTAATAG CGAAGAGCCC GCACCGATCG CCCTTCCCAA CAGTTGCGCA G- } \\
\text { 3, }\end{array}$ \\
\hline 397 & $\begin{array}{l}\text { 5'-TGCCAAAACA AATTTATTGC ACCAAAAAGG AAAACAAAAA AAACAAAAAA ACTTCATTTA } \\
\text { 'TATA-3' }\end{array}$ \\
\hline 403 & 5'-TGGGGCTTGA GGAAGATGAG TTTGTTGATT TAAATAAAGA ATTTGTCATT-3' \\
\hline
\end{tabular}

Table 2.2

Designation and sequence of the DDRT-PCR clones obtained.

$\mathrm{N}=$ unknown nucleotide. 


\subsubsection{Computer analysis of DDRT-PCR sequences:}

\subsubsection{ORF finder}

Some of the sequences had ORFs as follows:

One ORF on the plus strand was found for sequence 272. It started from position 3 to 108 , with a length of $107 \mathrm{nt}$. The amino acid length is 35 :

\section{LKKLQGISWKGSNELFVGLGTFKDLTDSLFPLLFF}

In sequence 289 , one ORF started from position 35 to 154 , with a length of $120 \mathrm{nt}$ on the minus strand. The amino acid length is 39 :

\section{MLIDXIVDRSIVSQVSHRXSSYDMIRSXRGSRYPNLRGS}

In sequence 330 , one ORF was found, from position 20 to 130 , on the minus strand. The amino acid length was 36: MKSLANNLSYNVLYSSVEWSAFTAVYIYLHIIYRSI

In sequence $333 \mathrm{a}$, one ORF started from position 17 to 135 , with a length of 120 nt on the plus strand. The amino acid length is 39 :

\section{LSPRLECSGAETMSGRNETDFTSALRSYVFSQYYSSSIPE}

Sequence 389a has 3 ORF. One on the minus strand and started from position 1 to 173 , with a length of $173 \mathrm{nt}$. The amino acid sequence was 57 :

\section{LLGRAIGAGSSLLRQLAKGGCAARRLSWVTPGFSQSRRCKTTASAKLACLQVD}

\section{SRGS}

And two on the plus strand, the first one started from position 29 to 180 with a length of 153 , and the second from position 37 to 180 with a length of 144 . The amino acid length was 50aa:

MQAWHWPSFYNVVTGKTLALPNLIALQHIPLSPAGVIAKSPHRSPFPTVAQ

And 47: 


\section{LALAVVLQRRDWENPGVTQLNRLAAHPPFASWRNSEEPAPIALPNSCA}

\subsubsection{Nucleotide sequence database search:}

Searching the nucleotide sequence database using the BLAST program at the HGMP-

UK and NCBI websites revealed that 7 sequences shared homology with known human genes as in table 2.2. These searches were carried out between September, 1998 and October, 1999.

\begin{tabular}{|ll}
\hline DDRT sequences & homologous known genes \\
\hline 333 & gene for K-channel enzyme \\
361 & TEL oncogene \\
367 & Di-OH-acetone phosphate acyl transferase \\
373 & carcino-embryonic antigen gene \\
383 & Apolipoprotein gene \\
403 & Retinoblastoma-binding protein gene (RbAp48) \\
\end{tabular}

Table 2.3. BLAST search in October 1999.

Homologous known genes with 7 DDRT-PCR clones, BLAST searched in October 1999. Similarity of more than $90 \%$ was considered. Expect value was 10, Cutoff score is calculated from the expect value. 
A more recent search was carried out, in August 2001, using the same BLAST programs in the same websites. The increased size of the nucleotide sequence database presented more results as shown in table 2.3.

\begin{tabular}{|c|c|c|}
\hline $\begin{array}{l}\text { DDRT } \\
\text { sequences }\end{array}$ & Homologous ESTs \& genes & Accession number \\
\hline 271 & Human EST & AB011399 \\
\hline 272 & Pseudogene similar to adenylate kinase & AL035411 \\
\hline 281 & A novel gene similar to a tumour protein & AL118506 \\
\hline 287 & Human EST from foetal liver & AI038405 \\
\hline 289 & Weak similarity to a human EST & AW972174 \\
\hline 294 & Human EST from foetal liver & AA704268 \\
\hline $299 \mathrm{a}$ & HS retinoblastoma-binding protein 4 & NM005610 \\
\hline $299 b$ & Weak similarity to a human EST & $\mathrm{AC} 053540$ \\
\hline 311 & Human EST from foetal liver & H79690 \\
\hline 329 & Human zinc finger protein mRNA & AF251039 and XM033573 \\
\hline \multirow[t]{2}{*}{330} & EST from parathyroid tumour & $\mathrm{AI} 032793$ \\
\hline & and from lung carcinoma & AA629918 \\
\hline $333 a$ & Human EST on chromosome 11 & AP002812 \\
\hline $333 b$ & Homo sapiens mRNA for KIAA0572 ptn & $\mathrm{AB} 011144$ \\
\hline 335 & No significant hits & \\
\hline 339 & Weak similarity to a human EST & AW304371 \\
\hline 359 & HS amyloid beta $\left(\mathrm{A}_{4}\right)$ precursor-like ptn & XM050726.1 \\
\hline
\end{tabular}




\begin{tabular}{|lll|}
\hline 361 & Glyceronephosphate O-acyltransferase & XM001982.4 \\
367 & Zinc finger protein Pseudogene & AL359511 \\
373 & Keratin 18 Pseudogene & AL121869 \\
383 & HS retinoblastoma-binding protein 4 & AR097319 and NM005610 \\
$385 \mathrm{a}$ & Weak similarity to a human EST & AL356109 \\
$385 \mathrm{~b}$ & Weak similarity to a human EST & AL359694 \\
389 & Rat aflatoxin-B1 mutated DNA & M28262 \\
397 & Human EST from parathyroid tumour & AA844472 \\
& DNA sequence on chromosome 17 & \\
403 & HS transgelin 2 mRNA & XM001274 \\
\hline
\end{tabular}

Table 2.4. BLAST search in August 2001.

Homologous sequences in the nucleotide databases, identified by searching with the sequences of differentially expressed cDNAs (searched in August 2001).

HS stands for Homo sapiens. EST stands for expressed sequence tag. ESTs 272 and 294 represent down-regulated clones, while the rest of ESTs represent up-regulated ones. 


\subsection{Discussion:}

Differential Display PCR is one of the most competitive methods for studying differential gene expression currently available and has been applied successfully by several groups. It has the advantage of studying gene expression in a relatively limited time, requiring low amounts of starting material. Despite the fact that DDRT-PCR has proven successful in isolating differentially expressed genes, it has some intrinsic disadvantages.

One of the main disadvantages is that it restricts the analysis to the 3' end of the cDNAs. This means that differences at the 5' side of cDNAs, like the variants of alternatively spliced genes, will not be detected (von Stein et al., 1997).

Another significant problem is the large number of false positive clones picked up using this technique, i.e. genes that are not differentially expressed (Linskens et al., 1995). Some of these result from contaminating cDNAs in the differentially expressed band of interest and can be minimised by rescreening cDNA clones by hybridisation selection (Callard et al., 1994) or by using single stranded conformation polymorphism gels in conjunction with DDRT-PCR to enhance positive clone selection (Mathieu-Daude $e t$ al., 1996). However, in this study duplicate reactions were not prtformed because of the limited availability of tumour tissue.

Since differential display relies on comparing the banding patterns of two different mRNA populations, small differences between mRNA quality or concentration can also lead to false positive clones (Sompayrac et al., 1995). Sung \& Denman (1997) found that small differences between RNA populations can result in significantly different banding patterns and that duplicate sampling of the same RNAs using two different reverse transcriptases minimises false-positive results. 
Bertioli et al. (1995) discovered that DDRT-PCR is biased toward high copy number genes, which makes it difficult to isolate rare transcripts that are differentially expressed. Haag \& Raman (1994) found alterations in differential display banding patterns using different sources of Taq DNA polymerase. Poirier et al. (1997) combined differential screening with the use of amplified RNA (aRNA) generated from $5 \mu \mathrm{g}$ total RNA according to Eberwine (1996).

In this study, the preliminary results of DDRT-PCR revealed that 52 bands appeared differentially expressed, 47 were up-regulated while 5 were down-regulated in the tumour tissue. After cloning and sequencing, 26 candidate sequences were available for further investigation.

Database searching analysis revealed that one of the clones, designated 281, was homologous with a known tumour protein. The latest search showed that 3 other clones were homologous with known Homo sapiens ESTs isolated from foetal livers. This might indicate the activation of foetal genes in carcinogenesis in general or, more specifically, in hepatocarcinogenesis. The two clones, 299a and 383, were found to be homologous with human retinoblastoma-binding protein 4 . Retinoblastoma binding proteins have been found to interfere with the normal function of retinoblastoma protein which is a critical step in the transformation process (Woitach et al., 1998). The sequence of clone 330 was significantly similar to human ESTs isolated from parathyroid and lung cancers. In addition, clone 397 was also found homologous with some human ESTs isolated from malignant cell lines and tissues like parathyroid tumour. This might indicate that these candidate genes might be related to malignant transformation. The two clones 329 and 367 were found homologous with a human “zinc finger" protein. Zinc finger proteins have been found to be expressed at higher levels in a variety of actively proliferating cells and tumour tissues. Furthermore, they 
have been studied in liver cells and found expressed at higher levels in hepatocytes of the regenerating cirrhotic nodules and even at higher levels in well-differentiated hepatocellular carcinoma (Ganger et al., 2001).

As, in general, differential display can generate many false positives it therefore requires a method for the verification of the truly differentially expressed cDNAs before relating any of the identified clones to $\mathrm{HCV}$-associated $\mathrm{HCC}$.

Screening methods such as northern assay, RNase protection assay, quantitative PCR, differential screening and in situ hybridisation are required to confirm the DDRT-PCR results but they are sometimes not optimal for large scale screening because of the large amounts of RNA required. However, northern hybridisation and RNase protection assay will be used in the next step of the study to confirm the differential expression of the identified DDRT-PCR clones. 
Chapter 3

Confirmation of Differential Expression 


\subsection{Introduction:}

To confirm differential regulation of individual candidate sequences, various methods can be used for the quantification of mRNA. There are three techniques available for this purpose. The first and most extensively used, is northern blotting. A second method is the ribonuclease protection assay, which offers improved sensitivity. The third method utilises the reverse transcriptase polymerase chain reaction; this provides considerable increases in sensitivity over northern blotting and RNase protection assay, and may be useful for measuring very low levels of a mRNA in a tissue.

\subsubsection{Northern Hybridisation:}

\subsubsection{Introduction:}

In 1977, a new technique for the analysis of RNA sequences known as northern blotting, was developed by Alwine et al. (1977). In this technique, RNA is fractionated, immobilised on a membrane, and hybridised to a probe. Since RNA present in a given cell represents the portion of the genome that is expressed in that cell, northern analysis was considered a powerful tool for studying gene expression and measurement of a specific mRNA (Sabelli \& Shewry, 1995). Nucleic acid hybridisation can be used to determine the concentration and the rate of synthesis of an individual RNA species in a complex situation (Williams, 1985). It is important to measure mRNA for two main reasons. The first reason is to determine which tissues express a particular gene. The second reason is to determine the factors which regulate the expression of a given gene (Trayhurn, 1996). 


\subsubsection{Principles of northern hybridisation:}

The underlying principle of northern hybridisation is RNA separation by size. RNA is detected on a membrane using a hybridisation probe with a base sequence complementary to all, or a part, of the sequence of the target mRNA.

The initial step in northern hybridisation is to extract total RNA from a tissue. In some cases, a separate step for the isolation of mRNA from total RNA may be included giving improved sensitivity. The extracted RNA species, whether total RNA or poly-A+ tail selected, are then separated on the basis of molecular size by agarose-gel electrophoresis under denaturing conditions. A number of methods of denaturation are in common use, for example, the use of glyoxal (McMaster \& Carmichael, 1977), formaldehyde (Lehrach et al., 1977) and methyl mercuric hydroxide (Bailey \& Davidson, 1976). Glyoxal procedure has been found to be as effective as the other two techniques, both of which involve the use of toxic compounds. In this method, the RNA is denatured by incubation at $50^{\circ} \mathrm{C}$ with glyoxal and dimethylsulphoxide (DMSO). The high temperature and DMSO combine to disrupt hydrogen bonding, which allows glyoxal to interact with the RNA. Glyoxal modifies guanine residues to form a covalent adduct which is stable at neutral or acidic $\mathrm{pH}$. Because glyoxal interacts with proteins, it is important to remove all proteins as this can cause nucleic acids to become stuck at the top of the gel (Thomas, 1983).

Blotting onto a membrane is the next step in northern hybridisation. In the first northern transfer experiments, RNA was bound to diazotised paper (Alwine et al., 1977). Thomas (1980) has shown that denatured RNA will bind very efficiently to nitrocellulose at high ionic strength. The higher binding capacity of nitrocellulose achieved greater sensitivity and as little as 1 pg of specific RNA could be detected. 
Two main alternatives are available for blotting, either capillary or vacuum. The traditional approach is to employ capillary blotting, this requiring no special equipment. However, vacuum blotting offers advantages in terms of speed (1-2h vs.4-18h) and reproducibility.

Following blotting, RNA must be immobilised on the membrane either by baking in an oven or by exposure to UV light. This results in covalent linkage of RNA to the membrane, which prevents the nucleic acid from being washed away during the subsequent processing.

\subsubsection{Hybridisation probes:}

Nucleic acid hybridisation requires that a probe is complementary to all, or part, of the sequence of the mRNA of interest. The minimum size of a probe to ensure specificity is approximately twenty-five bases, providing that there is a complete match between the probe sequence and the sequence of the target mRNA (Trayhurn, 1996). With a probe of thirty bases in length, the probability that the same sequence occurs in the mammalian genome by chance is of the order of one in billion (Sambrook et al., 1989).

There are two main forms of hybridisation probes, a complementary DNA (cDNA), or anti-sense oligonucleotides (generally thirty or forty bases in length). Oligonucleotides offer simplicity and reduced hybridisation times. Riboprobes based on RNA can also be employed. Riboprobes may increase sensitivity but are less stable being subject to breakdown by RNases (Trayhurn, 1996).

Hybridisation of the probe with the membrane must be followed by post-hybridisation stringency washes, which ensure that the probe is bound specifically to the target 
mRNA and that there is negligible non-specific binding to other mRNA or the membrane itself.

Detection is achieved either through the use of radioactivity or by non-radioactive methods. Most laboratories employ radioactivity, probes being labelled with ${ }^{32} \mathrm{P}$ or ${ }^{33} \mathrm{P}$. The procedures of using radioactivity are well established and have a high level of sensitivity. However the disadvantages of radioisotopes include safety, instability of the probe (reflecting the short half-life of the isotopes used), and difficulties with the disposal of waste. Colour dyes may be employed in non-radioactive detection.

Detection may be based on chemiluminescence or fluorescence. X-ray film is the usual means by which hybridisation signals are detected. This can be used with both radioactivity and chemiluminescence. Quantification might be achieved by densitometry (Trayhurn, 1996).

\subsubsection{Ribonuclease Protection Assay (RPA):}

\subsubsection{Introduction:}

The ribonuclease protection assay is a sensitive method used for quantitation of specific RNAs in solution. This assay can be performed on total cellular RNA or poly (A)mRNA.

\subsubsection{Principles of RPA:}

To perform the RPA, an excess of one or more anti-sense RNA probe, which is radiolabelled to high specific activity, are hybridised in solution with the target RNA. In hybridisation reaction, it has been found that RNA transcripts offer more sensitivity than the DNA probes because RNA-RNA and RNA-DNA hybrids are more stable than DNA-DNA hybrids. T3 and T7 phage RNA polymerase are used for synthesis of RNA 
transcripts in vitro from DNA templates. These phage RNA polymerases have a high specificity for their promoters, which allows the transcription of one strand of the template with no "cross-talk" from the promoter on the other strand.

After hybridisation, usually overnight, the mixture is treated with ribonuclease (RNase) to degrade all unhybridised, single stranded RNA. Only the hybridised portion of the probe will be protected from RNA digestion and can be visualised by autoradiography after electrophoresis on a denaturing polyacrylamide gel.

\subsubsection{Advantages of RPAs:}

\section{High Sensitivity:}

In northern hybridisation, a fraction of the target RNA that is transferred to the nylon or nitrocellulose filter becomes inaccessible to hybridisation while in RPA, $100 \%$ of the target RNA is available to probe hybridisation since in solution (Fabian et al., 1993). A second factor increasing the sensitivity of RPA is the lower background levels compared to northern hybridisation. In the RPA, any non-specific hybrids are digested into small fragments that are separated from the protected fragments during the electrophoresis step. Hybridising the probe at molar excess with respect to the target RNA results in a signal that is directly proportional to the amount of complementary RNA in the sample.

\section{Simultaneous detection of multiple targets:}

In RPA, multiple mRNA targets can be assessed simultaneously, using multiple probes in a single hybridisation reaction. It is essential that the probes have different sizes such that they can be separated on polyacrylamide gel electrophoresis (Hobbs et al., 1993). 


\section{Tolerance of partially degraded RNA:}

Since the probes used in the RPA are significantly shorter than the mRNA targets, breaks in the mRNA that occur outside the hybridisation region have no effect on the assay. Normally, this results in loss of signal in northern hybridisation.

\subsubsection{Quantitative PCR:}

Quantitative PCR is an efficient technique used for analysing very low amounts of mRNA derived from cells or tissues (Ylikoski et al., 1999). Quantification by PCR is based on using different calibrators. The first method used external calibrators (Syvanen et al., 1988). This approach was based on measuring the amount of the amplification product produced in the exponential phase by reference to the dilution of the external calibrator. However, this quantitation was inaccurate due to variability in the sample preparation as well as in the amplification reaction in which minor variations in the reaction conditions can be magnified. Chelly et al., (1988) normalised these variations by coamplifying an internal standard (IS) with the template in the same reaction tube. For accurate results, the IS and the target should be amplified with the same efficiency and have similar sized amplification products. Ideally, both the IS and the target must have a shared sequence in order to be coamplified with the same primers. Moreover, there should be a small difference between their sequences enough to distinguish the IS from the target. This method uses a serial dilution of the sample or the IS. For quantification of one sample, multiple tubes are required and the amplification signal of the target is compared with that obtained from various known amounts of IS (Lundeberg et al., 1991). For more accurate quantification of mRNA copies, an IS mRNA is added into the studied sample at the beginning of the RNA extraction step to avoid variations in the reverse transcription step (Ylikoski et al., 1999). 


\subsection{Materials and Methods:}

In this study, northern blotting and RPA were carried out as follows:

\subsubsection{Northern Hybridisation:}

\subsubsection{Sample preparation:}

All glassware was baked overnight and electrophoresis tank was treated with RNase away solution to inactivate the RNases. The glyoxal method was used as follows:

RNA samples (RNA ladder, HepG2 cells mRNA, and HCV-HCC mRNA) for the blot were mixed with the following reagents in separate tubes
$2.7 \mu 1$
$6 \mathrm{M}$ glyoxal
$8.0 \mu 1$
DMSO
$1.6 \mu 1$
$0.1 \mathrm{M} \mathrm{Na} \mathrm{H}_{2} \mathrm{PO}_{4} \mathrm{pH} 7.0$
$3.7 \mu 1$
RNA (up to $20 \mu \mathrm{g}$ )

Samples were incubated at $50^{\circ} \mathrm{C}$ for 60 minutes.

\subsubsection{Agarose gel electrophoresis:}

\section{Agarose gel:}

The samples were size separated on $1 \%$ agarose gels. The gel was prepared by mixing 1 gm agarose with a $100 \mathrm{ml}$ solution made with $10 \mathrm{ml} \mathrm{Na} \mathrm{H}_{2} \mathrm{PO}_{4}$ and $90 \mathrm{ml}$ DEPC treated water. The agarose was melted at high temperature and cooled down before it was poured into the tray. 


\section{Buffer:}

The buffer used for electrophoresis was $0.01 \mathrm{M} \mathrm{Na} \mathrm{H}_{2} \mathrm{PO}_{4} \mathrm{pH}$ 7.0. It was prepared by adding $900 \mathrm{ml}$ DEPC treated water to $100 \mathrm{ml} 0.1 \mathrm{M} \mathrm{Na} \mathrm{H}_{2} \mathrm{PO}_{4}$.

\section{Electrophoresis:}

RNA samples were cooled down to $20^{\circ} \mathrm{C}$ and loaded into the gel after adding $4 \mu 1$ sterile glyoxal gel loading dye (refer to appendix II). The gel was run at $100 \mathrm{~V}$, about 3-4 $\mathrm{V} / \mathrm{cm}$. At the end of the run the gel was stained with Ethidium bromide, $0.5 \mu \mathrm{g} / \mathrm{ml}$. Capillary blotting was carried out using 20x SSC overnight onto a nylon membrane, Hybond N (Amersham). The membrane was marked for orientation and then was baked at $80^{\circ} \mathrm{C}$ for 2 hours. After baking, the membrane was washed with $20 \mathrm{mM}$ Tris- $\mathrm{Cl}(\mathrm{pH}$ 8.0) at $65^{\circ} \mathrm{C}$ to remove glyoxal from the RNA.

\subsubsection{Hybridisation with RNA probe:}

\section{Probe synthesis:}

To synthesise RNA probes, the sequences of $\mathrm{T} 3$ and $\mathrm{T} 7$ promoters were introduced to the selected sequences via PCR reaction using primers with added 23 nucleotide promoters; T7-40 (GTA ATA CGA CTC ACT ATA GGG TTT TCC CAG TCA CGA C) and T3RP (GAA ATT AAC CCT CAC TAA AGG GAG CGG ATA ACA ATT TCA CAC).

Labeled RNA probes were synthesised using Maxiscript, Ambion. This method uses relatively low nucleotide concentrations $(0.5 \mathrm{mM}$ each). Higher nucleotide concentrations are not necessary since, in these reactions, the low concentration of radiolabeled or modified nucleotide present effectively limits the total yield of the reaction. The total concentration of the limiting nucleotide (labeled/modified) should be at least $3 \mu \mathrm{M}$ for efficient synthesis of full length RNA transcripts of less than $400 \mathrm{nt}$ (more will be needed to synthesize longer transcripts). To make very high specific 
activity or extensively modified transcripts one should limit or omit any unlabeled limiting nucleotide present. Starting with PCR template of bands 271 and 330 the following reaction was followed:

$\begin{array}{ll}8.5 \mu 1 & \text { water } \\ 2.0 \mu 1 & \text { DNA (PCR template) } \\ 2.0 \mu 1 & 10 \mathrm{x} \text { Transcription buffer } \\ 1.0 \mu 1 & 10 \mathrm{mM} \text { rATP (ribonucleotide) } \\ 1.0 \mu 1 & 2 \mathrm{mM} \text { modified rCTP (provided) } \\ 1.0 \mu 1 & 10 \mathrm{mM} \mathrm{rGTP} \\ 2.5 \mu 1 & { }^{32} \mathrm{P} \mathrm{rUTP} \\ 2.0 \mu 1 & \text { T7 or T3 RNA polymerase }\end{array}$

The transcription reaction was incubated at $37^{\circ} \mathrm{C}$ for 1 hour.

DNA was inactivated by adding $1 \mu 1 \mathrm{DNase} I$. The contents of the tube were mixed and incubated at $37^{\circ} \mathrm{C}$ for 15 minutes.

Each probe was diluted up to $100 \mu$ l with DEPC treated water.

Purification was done with Sephadex G50 columns as before.

\section{Prehybridisation:}

$10 \mathrm{ml}$ solution was prepared for a small northern hybridisation as follows:

$\begin{array}{ll}3.6 \mathrm{ml} & \text { DEPC treated } \mathrm{H} 2 \mathrm{O} \\ 10 \mathrm{ml} & \text { Formamide }\end{array}$




$\begin{array}{ll}5.0 \mathrm{ml} & 20 \mathrm{x} \text { SSPE } \\ 0.8 \mathrm{ml} & 50 \mathrm{x} \text { Denhardt's reagent } \\ 0.2 \mathrm{ml} & 10 \% \text { SDS } \\ 0.4 \mathrm{ml} & \text { yeast RNA } 5000 \mu \mathrm{g} / \mathrm{ml}\end{array}$

The membrane was prehybridised at $65^{\circ} \mathrm{C}$ overnight.

\section{Hybridisation:}

One $\mu 1$ yeast RNA was mixed with the probe then added to the membrane after aspirating an equal volume of the prehybridisation fluid. The membrane was placed in an airtight sealed bag as before and left in a shaking water bath at $65^{\circ} \mathrm{C}$ overnight.

\section{Washing:}

The blot was washed twice in $500 \mathrm{ml} 2 \mathrm{x}$ SSPE for half an hour at $42^{\circ} \mathrm{C}$ in a shaking water bath. The membrane was wrapped in Saran wrap, exposed to an X-ray film and stored at $-70^{\circ} \mathrm{C}$ as before.

\section{Probe removal:}

Strip-EZ RNA strippable removal kit, Ambion, was used to remove the probe as follows:

$45 \mathrm{ml} 0.1 \%$ SDS in DEPC treated water was used for 3 washes, $15 \mathrm{ml}$ each.

First wash: $200 \mathrm{x}$ probe degradation buffer was diluted to $1 \mathrm{x}$ with $0.1 \%$ SDS making 15 $\mathrm{ml}$ solution. The blot was incubated in wash 1 solution for 10 minutes at $68^{\circ} \mathrm{C}$ then the solution was discarded.

Second wash: $100 \mathrm{x}$ Blot reconstitution buffer was diluted to $1 \mathrm{x}$ with $0.1 \%$ SDS making $15 \mathrm{ml}$. the blot was incubated for 10 minutes at $68^{\circ} \mathrm{C}$ then the solution was discarded. 
Third wash: This wash was carried out using the remaining $15 \mathrm{ml} 0.1 \%$ SDS for another 10 minutes at $68^{\circ} \mathrm{C}$. Then the blot was stored for future use.

\subsubsection{Hybridisation with DNA Probe:}

Seven candidate sequences were selected for probe synthesis, 333a, 353, 361, 367b, $373,383 \mathrm{~b}$ and 403 . The selection was based on their homology with known genes in the nucleotide sequence database (refer to chapter 2 table 2.3).

\section{Probe synthesis:}

The DNA template was a PCR product inserted into pCR2.1 plasmid and digested with EcoRI. The digested DNA was purified on low melting point agarose electrophoresis. The purified DNA was denatured by boiling for 5 minutes then quickly placed onto ice. The DNA probe was transcribed as follows:

$\begin{array}{ll}5.0 \mu 1 & \text { Oligonucleotide labelling buffer (OLB) } \\ 1.0 \mu 1 & \text { BSA }(10 \mathrm{mg} / \mathrm{ml}) \\ 16.0 \mu 1 & \text { Boiled DNA } \\ 2.5 \mu & { }^{32} \mathrm{P} \mathrm{dCTP} \\ 0.5 \mu 1 & \text { Klenow polymerase }\end{array}$

The tubes were left at room temperature overnight.

Each probe was diluted with $75 \mu 1$ TNE buffer (appendix II).

Each probe was purified through a Sephadex G50 columns equilibrated with TNE buffer, then $12.5 \mu$ l boiled single stranded DNA (salmon sperm DNA) were added and the tube was put onto ice. 


\section{Prehybridisation:}

The blot was prehybridised in $15 \mathrm{ml}$ prehybridisation solution prepared as follows:

$\begin{array}{ll}0.6 \mathrm{ml} & \text { water } \\ 4.5 \mathrm{ml} & 20 \mathrm{x} \mathrm{SSC} \\ 1.5 \mathrm{ml} & 50 \mathrm{x} \text { Denhardt's reagent } \\ 0.75 \mathrm{ml} & 10 \% \mathrm{SDS} \\ 7.5 \mathrm{ml} & \text { Formamide } \\ 0.15 \mathrm{ml} & \text { ss DNA } 10 \mathrm{mg} / \mathrm{ml} \text { (boiled for } 5 \text { minutes) }\end{array}$

The membrane and the fluid were put in an airtight sealed plastic bag and incubated in a shaking water bath at $42^{\circ} \mathrm{C}$ overnight.

\section{Hybridisation reaction:}

$2 \mathrm{ml}$ of the prehybridisation fluid were replaced with the radioactive probes. The plastic bag was again sealed airtight and incubated in a shaking water bath at $42^{\circ} \mathrm{C}$ overnight. The hybridisation fluid was aspirated then the membrane was washed twice in $2 \mathrm{x}$ SSC at $65^{\circ} \mathrm{C}$ for 30 minutes, then once with $0.1 \times$ SDS for another 30 minutes.

The membrane was wrapped in Saran wrap, labelled with RAD tapes for orientation and exposed to X-ray film at $-70^{\circ} \mathrm{C}$ overnight.

\subsubsection{RPA:}

\subsubsection{Probe synthesis:}

The following steps were followed in the synthesis of RNA probes: 


\section{Template DNA:}

Some selected sequences of the DDRT-PCR clones together with the house keeping genes, G3PDH and $\beta$-actin, were used as templates. The sequences of T3 and T7 promoters were introduced into the selected sequences via PCR reaction using primers with added 23 nucleotide promoters; T7-40 (GTA ATA CGA CTC ACT ATA GGG TTT TCC CAG TCA CGA C) and T3RP (GAA ATT AAC CCT CAC TAA AGG

GAG CGG ATA ACA ATT TCA CAC). A 50 $\mu 1$ PCR reaction contained the following:

$\begin{array}{ll}32.6 \mu \mathrm{l} & \text { water } \\ 5.0 \mu \mathrm{l} & 10 \mathrm{x} \text { advantage polymerase buffer } \\ 5.0 \mu \mathrm{l} & 2 \mathrm{mM} \text { dNTP mix } \\ 2.5 \mu \mathrm{l} & \mathrm{T} 7-40 \text { primer }(10 \mathrm{pM} / \mu \mathrm{l}) \\ 2.5 \mu \mathrm{l} & \text { T3RP primer }(10 \mathrm{pM} / \mu \mathrm{l}) \\ 1.0 \mu \mathrm{l} & \text { DNA } \\ 1.0 \mu \mathrm{l} & \text { Advantage polymerase mix }\end{array}$

The samples were amplified using the following PCR cycling conditions:

$\begin{array}{lll}\text { Denaturation } & 94^{\circ} \mathrm{C} & 5 \text { minutes } \\ 30 \text { cycles } & 94^{\circ} \mathrm{C} & 30 \text { seconds } \\ & 35^{\circ} \mathrm{C} & 30 \text { seconds } \\ & 72^{\circ} \mathrm{C} & 30 \text { seconds } \\ 1 \text { cycle } & 72^{\circ} \mathrm{C} & 1 \text { minute }\end{array}$


$5 \mu l$ of each PCR product was examined on agarose gel to verify that they are unique and of the expected size. The rest of the samples were purified by running on $1 \%$ Low Melting Point agarose. The selected bands were excised from the gel and DNA was purified using Wizard PCR preps DNA purification system (according to the manufacturers instruction).

\section{Labelled Nucleotide:}

${ }^{32} \mathrm{P}$ UTP was used at approximately $400-800 \mathrm{Ci} / \mathrm{mmol}$ and $10 \mathrm{mCi} / \mathrm{ml}$ for the synthesis of radioactive RNA probe. UTP is generally preferred rather than the other nucleotides as ATP is not incorporated efficiently and GTP is liable to decomposition during storage (Melton et al., 1984).

The labelled NTP, ${ }^{32} \mathrm{P}$ UTP, was used at a limiting concentration and was referred to as the 'limiting nucleotide'. When the target is expected to be abundant, for instance the house keeping genes, the specific activity of the probe was lowered. This was accomplished by including $1 \mu 1$ of the unlabeled limiting nucleotide in the reaction. For the test sequences, where less abundance is expected, a high specific activity probe was required and all the unlabeled UTP were omitted.

\section{Transcription reaction:}

All the reagents were thawed mixed well and microfuged briefly using MAXIscript In Vitro Transcription kit, Ambion. The thawed ribonucleotides and the RNA polymerase were kept on ice during the assembly of the reaction. In $1.5 \mathrm{ml}$ microfuge tubes a $20 \mu \mathrm{l}$ reaction was assembled at room temperature as follows:

\section{Selected test sequences:}

$5.5 \mu 1 \quad$ Nuclease free water

5.0 $\quad$ DNA template (maximum volume for PCR template) 


$\begin{array}{ll}2.0 \mu \mathrm{l} & 10 \mathrm{x} \text { transcription buffer } \\ 1.0 \mu \mathrm{l} & 10 \mathrm{mM} \text { ATP } \\ 1.0 \mu \mathrm{l} & 10 \mathrm{mM} \mathrm{GTP} \\ 1.0 \mu \mathrm{l} & 10 \mathrm{mM} \mathrm{CTP} \\ 2.5 \mu 1 & \text { labelled }{ }^{32} \mathrm{P} \text { UTP }(800 \mathrm{Ci} / \mathrm{mmol}) \\ 2 \mu 1 & \text { RNA polymerase T7 or T3 }(5 \mathrm{u} / \mu \mathrm{l})+\text { Ribonuclease inhibitor }(5 \mathrm{u} / \mu \mathrm{l}) .\end{array}$

\section{House keeping genes:}

Some of the unlabeled limiting nucleotide was used in the reaction as follows:

\section{G3PDH probe:}

$\begin{array}{ll}2.5 \mu \mathrm{l} & \text { nuclease free water } \\ 7 \mu \mathrm{l} & \text { DNA template }(1 \mu \mathrm{g}) \\ 2 \mu 1 & 10 \mathrm{x} \text { transcription buffer } \\ 1 \mu 1 & 10 \mathrm{mM} \mathrm{ATP} \\ 1 \mu 1 & 10 \mathrm{mM} \mathrm{GTP} \\ 1 \mu 1 & 10 \mathrm{mM} \mathrm{CTP} \\ 1 \mu 1 & 10 \mathrm{mM} \mathrm{UTP} \\ 2.5 \mu \mathrm{l} & 32 \mathrm{P} \mathrm{UTP} \\ 2.0 \mu \mathrm{l} & \text { RNA T7 polymerase }(5 \mathrm{u} / \mu \mathrm{l})+\text { Ribonuclease inhibitor }(5 \mathrm{u} / \mu \mathrm{l}) .\end{array}$




\section{$\beta$-actin probe:}

The same concentrations of both labeled and unlabeled nucleotides, and transcription buffer were used as in the G3PDH, together with
$7.5 \mu 1$
nuclease free water
$2.0 \mu 1$
DNA template $(1 \mu \mathrm{g})$ (Ambion)
$2.0 \mu 1$
RNA T3 polymerase $(5 \mathrm{u} / \mu \mathrm{l})+$ Ribonuclease inhibitor $(5 \mathrm{u} / \mu \mathrm{l})$.

\section{Incubation of the reaction:}

The contents of each tube were mixed and microfuged briefly and incubated at $37^{\circ} \mathrm{C}$ for 1 hour.

\section{Removal of template DNA:}

The DNA template in the reaction was removed by adding $1 \mu 1$ of RNase-free DNase 1 $(2 \mathrm{u} / \mu \mathrm{l})$ per tube then incubated at $37^{\circ} \mathrm{C}$ for 15 minutes.

\section{Gel purification of the probes:}

Gel purification separates full-length transcripts from prematurely terminated transcription products and from unincorporated nucleotides.

After DNase treatment, an equal volume, $21 \mu 1$, of Gel loading buffer II was added per reaction. The tube was heated for 5 minutes at $85-95^{\circ} \mathrm{C}$. One $\mu 1$ of this final reaction was removed and diluted for TCA precipitation, in order to calculate the incorporation percentage and the specific activity of each probe.

One $\mathrm{mm}$ thick $5 \%$ polyacrylamide $8 \mathrm{M}$ urea gel was prepared as follows:

17.5ml $20 \%$ acrylamide: bisacrylamide $19: 17 \mathrm{M}$ urea $1 \mathrm{x}$ TBE 


$\begin{array}{ll}52.5 \mathrm{ml} & 7 \mathrm{M} \text { urea } 1 \mathrm{x} \text { TBE } \\ 153 \mu 1 & 25 \% \text { ammonium persulphate } \\ 65.6 \mu 1 & \text { TEMED }\end{array}$

The gel was poured and left to set for one hour. Then the reaction was loaded and run until the bromophenol blue reached the bottom of the gel at 100 volts.

After electrophoresis, the gel was covered with plastic wrap, to prevent slipping, and three squares of ' $\mathrm{Rad}$ tape' were taped at three corners, for orientation of the film. The gel was exposed to X-ray film for 2 minutes. After exposure the film was developed and used to localise the area of the gel that contains the full-length labelled transcripts. The area of the gel was then excised with a clean scalpel, transferred with clean forceps to a microfuge tube, and submerged in $350 \mu$ l of elution buffer and incubated at $37^{\circ} \mathrm{C}$ overnight.

\subsubsection{Hybridisation of probe and sample RNA:}

The quantity of sample RNA required depends on the abundance of the target mRNA and on the specific activity of the probe. Since there is no lower limit to how much RNA can be used in RPAs, average 5-20 $\mu \mathrm{g}$ total RNA, $1 \mu \mathrm{g}$ mRNA of each sample was used.

The labelled probe should better be present in molar excess over the target mRNA. Ideally 3-10 fold molar excess of probe should be used. In the case of G3PDH and $\beta$ actin, as the abundance of the target mRNA is known, the amount of probe required can be calculated. It has been estimated that $150-600 \mathrm{pg}$ or $2-8 \times 10^{4} \mathrm{cpm}$ of high specific activity probe per $10 \mu \mathrm{g}$ total RNA is usually sufficient. 
This experiment included 10 different samples of RNA. Three tumour and their corresponding non-tumour RNAs, 3 non-viral cirrhotic livers, alcoholic hepatitis, fulminant hepatitis, primary biliary cirrhosis, as well as a normal liver. The non-viral and normal livers served as control samples. One $\mu \mathrm{g}$ of each sample mRNA was aliquotted in a separate, labelled 1.5 microfuge tube. Each tube was made up to $17 \mu 1$ with DEPC water. The samples were then DNase treated by adding $1 \mu 1$ of DNase 1 and $2 \mu l$ of $10 \mathrm{x}$ DNase buffer, then incubating the tubes at $37^{\circ} \mathrm{C}$ for 15 minutes. The following steps were then followed:

Mixing the sample RNA and the labelled probe: $6 \times 10^{4} \mathrm{cpm}$ of each probe was mixed per $1 \mu \mathrm{g}$ of mRNA of each sample in a $0.5 \mathrm{ml}$ microfuge tube.

Control tubes: 2 control tubes containing the same amounts of all the labelled probes were used in each assay. Each tube contained yeast RNA equivalent to $1 \mu \mathrm{g}$ of sample mRNA.

Co-precipitation: The concentration of NH4 OAc was adjusted to $0.5 \mathrm{M}$ by adding $10 \mu \mathrm{l}$ of $5 \mathrm{M}$ NH4 OAc. Then $2.5 \mathrm{vol}$. $(250 \mu \mathrm{l})$ of EtOH were added and mixed.

All tubes were incubated at $-20^{\circ} \mathrm{C}$ for 25 minutes.

RNAs were pelleted by centrifugation at $13,000 \mathrm{xg}$ for 15 minutes at $4^{\circ} \mathrm{C}$.

Pellets were dried by discarding the supernatant, avoiding dislodging the pellets. Tubes were spun briefly and more fluid was discarded. Pellets were left to dry for 5 minutes.

Resuspension in hybridisation buffer: $10 \mu$ l of hybridisation buffer were added to each pellet. Tubes were vortexed for 10 seconds, then microfuged for a few seconds to collect the fluid at the bottom of the tubes. 
RNA was denatured by incubation at $92^{\circ} \mathrm{C}$ for 4 minutes to help solubilisation. Tubes were vortexed, microfuged briefly to collect the contents in the bottom of the tubes.

Overnight incubation at $42^{\circ} \mathrm{C}$ was carried out to allow hybridisation of each probe to its complementary sample mRNA.

\subsubsection{RNase digestion of hybridised probe and Sample RNA:}

Diluting RNase: The buffer was thawed and vortexed well before use. RNase A/ RNase T1 mix (250 u/ml RNase A and 10,000 u/ml RNase T1) was diluted to 1:100 in RNase digestion III buffer (RPA III kit, Ambion).

RNase digestion: $150 \mu \mathrm{l}$ of the diluted RNase solution were added to each of the 10 samples and one of the yeast RNA controls. This tube was labelled (+). It served as a positive control to show if the probe is being protected in the absence of a homologous sequence, as yeast RNA.

To the remaining yeast RNA control tube, $150 \mu$ l RNase Digestion III buffer without RNase was added. This tube was labelled (-) and served as a control for probe integrity. It shows the gel migration of full-length probes giving different signals corresponding to the different probes used.

Tubes were incubation at $37^{\circ} \mathrm{C}$ for 30 minutes. During this incubation, RNase should digest all the unprotected single stranded RNA.

RNase inactivation: To each tube, $225 \mu$ l of RNase inactivation/ precipitation solution (RPA III kit, Ambion) were added together with $75 \mu 1$ of ethanol to help precipitation.

Tubes were incubated at $-20^{\circ} \mathrm{C}$ for 15 minutes.

Centrifugation and drying the pellets: Tubes were microfuged at $4^{\circ} \mathrm{C}$ for 15 minutes at $10,000 \times$ g to pellet the precipitated products. The supernatant was removed carefully 
avoiding losing the pellets. The tubes were re-centrifuged briefly and the rest of the supernatant was removed. Pellets were left to air-dry for 10 minutes.

\subsubsection{Separation of protected fragments:}

One mm thick $5 \%$ polyacrylamide gel was poured (the same gel and buffer conditions used for purification of the probes). Sequencing gel glass plates were used to separate the different sized probes.

Pellets were resuspended in $5 \mu 1$ gel loading buffer II. This volume makes about 2-3 mm layer in each well. The tubes were vortexed vigorously then microfuged briefly.

Tubes were incubated at $95^{\circ} \mathrm{C}$ for 3 minutes then chilled on ice. This incubation helps to denature RNA and solubilise it then chilled on ice to prevent reannealing. Tubes were then vortexed and microfuged briefly.

The wells of the gel were rinsed first to wash the urea out. All samples were loaded, $5 \mu 1$ each except the (-) control tube. Only $10 \%$ were loaded. The gels were run at 80 watts until the bromophenol blue dye reached near the bottom of the gel.

\subsubsection{Detection of results:}

Gels were fixed in $10 \%$ acetic acid for 30 minutes and dried for 1 hour then exposed to $\mathrm{X}$-ray film and stored at $-70^{\circ} \mathrm{C}$ for a few days, depending on the radioactivity of the gel. Several exposures were usually needed in each assay. The films were developed and the densities of the bands were analysed using a densitometer. The densitometer measures the intensity of each band. Different probes were compared to the density of a house keeping gene probe and the ratios were determined and compared in the tumour and non-tumour tissues of various samples. 


\subsection{Results:}

\subsubsection{Results of northern hybridisation:}

It seemed that the used RNA was partially degraded and northern blot probing was unsuccessful. The membrane showed only a smear without high molecular weight products.

\subsubsection{Results of RPA:}

Due to limitations in obtaining tumour tissue and having small quantities of RNA, only 7 assays were performed. The tested samples were 3 tumour and their corresponding non tumour tissue as well as 3 control livers selected from non-viral hepatic cirrhosis and a normal liver tissue. Each assay included 3 different sized probes selected from the cloned DDRT-PCR bands and 2 house keeping genes, G3PDH and $\beta$-actin. However the $\beta$-actin probe didn't show clear bands and was not suitable for densitometric analysis.

The intensity of each band, corresponding to a different probe, in each sample was compared to the intensity of the G3PDH band in the same sample (figure 3.1). In each assay, different exposures were required. A longer or a shorter exposure was needed depending on the intensity of the bands.

In some assays, probes were excluded when the fraction incorporation of the isotope was very low. In addition, there was a possibility of RNase contamination in RPA 6 and 7 resulting in very faint bands in all the samples. Therefore, analysis of the 6 probes used in these two assays was not possible. 


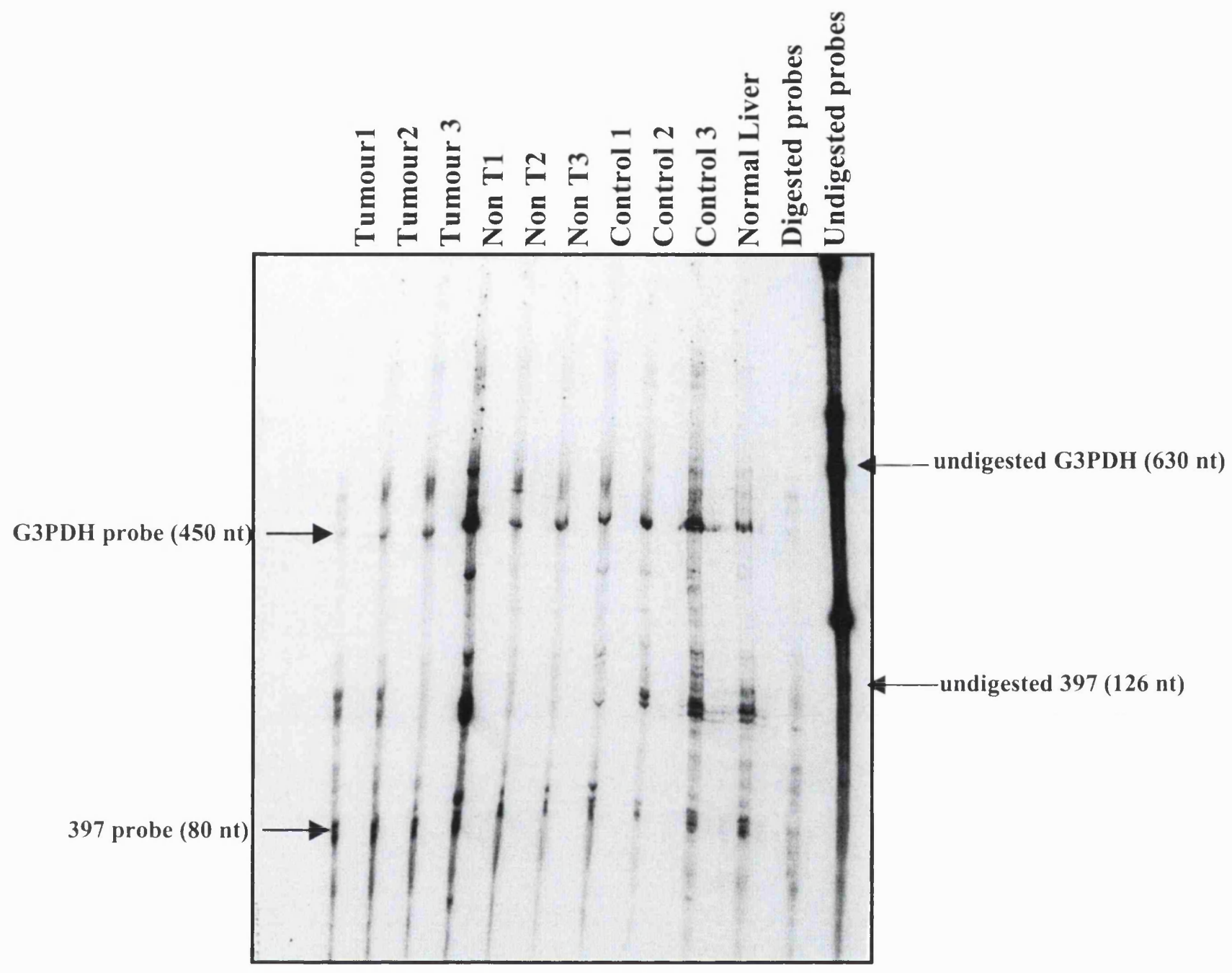

\section{Figure 3.1 RPA 4}

Analysis of clone 397 mRNA expression in 3 HCC tumours and their corresponding non tumour tissues using RPA. Overnight hybridisation was allowed between mRNA from the test samples and the ${ }^{32} \mathrm{P}-\mathrm{dUTP}$ labelled RNA probe 397 . The protected fragments were run on $1 \mathrm{~mm}$ thick $5 \%$ polyacrylamide gel. Control 1 is alcoholic cirrhosis, control 2 is fulminant hepatitis and control 3 is primary biliary cirrhosis. Undigested lane represents the unprotected fragments. 


\subsubsection{Results of RPA 1:}

In this assay, 4 probes were tested. G3PDH and 3 test probes designated 383,367 and 403. The sizes of the protected fragments were $450,150,100$, and 70 base pairs respectively. No clear bands were detected for probe 367 . The optical densities of protected probes are summarised in table 3.1 and illustrated in figure 3.2.

Analysis revealed higher expression levels of the tested sequence, 383 , in two of the tested tumours and no significant difference for sequence 403 . The raw data are listed in table RPA 1 (Appendix I).

\begin{tabular}{l|llllllllll}
\hline $\begin{array}{l}\text { OD } \\
\text { Ratio/G3PDH }\end{array}$ & T1 & T2 & T3 & NT1 & NT2 & NT3 & C1 & C2 & C3 & NL \\
\hline 383 & 0.89 & 2.83 & 1.07 & 12.93 & 1.35 & 0.87 & 0.50 & 0.90 & 0.30 & 0.20 \\
403 & 1.34 & 4.20 & 1.57 & 33.25 & 4.31 & 1.60 & 0.07 & 0.48 & 0.45 & 0.05 \\
\hline
\end{tabular}

Table 3.1. The ratios of optical densities of probes 383 and 403 to the house keeping gene probe.

$\mathrm{T} 1=$ Tumour $1, \mathrm{~T} 2=$ Tumour $2, \mathrm{~T} 3=$ Tumour $3, \mathrm{NT} 1=$ Non-tumour $1, \mathrm{NT} 2=$ Nontumour 2, NT3= Non-tumour 3, C1= Fulminant hepatitis, $\mathrm{C} 2=$ Alcoholic cirrhosis, $\mathrm{C} 3=$ Primary biliary cirrhosis, $\mathrm{NL}=$ Normal liver.

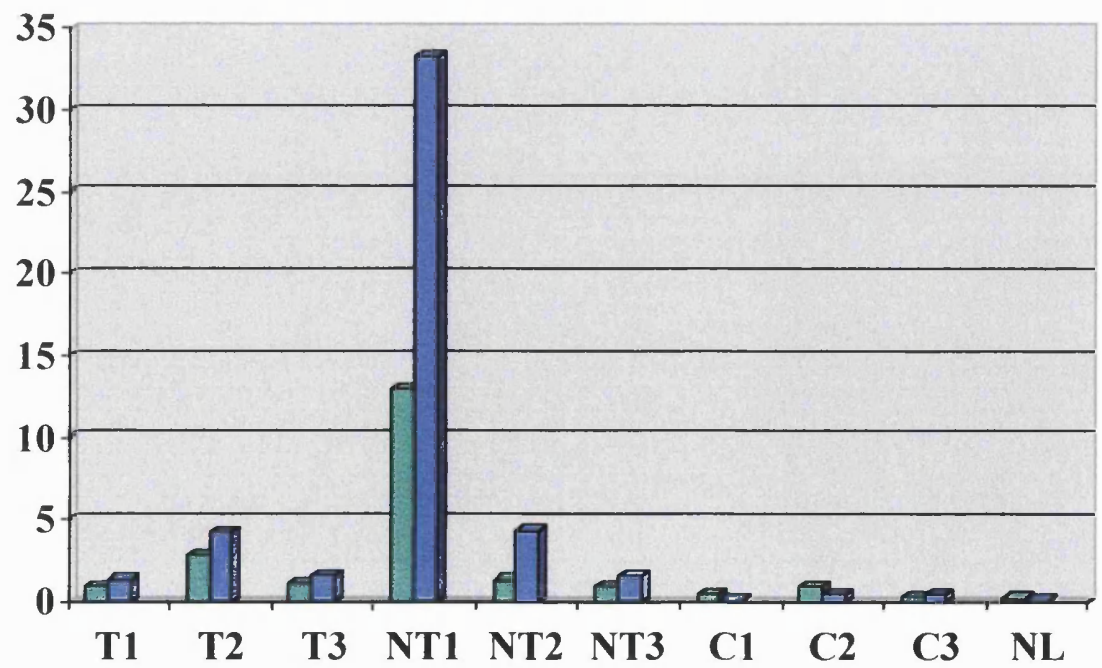

\section{Figure 3.2}

The OD ratios of probes 383 and 403 in various samples (as in table 3.1). 


\subsubsection{Results of RPA 2:}

In assay 2, the following probes were used: G3PDH (protected fragment of $450 \mathrm{bp}$ ), $\beta$ actin (127 bp), 333 (567 bp), 385 (297 bp) and 361 (233 bp). The optical densities of the different probes were compared as listed in Table 3.2 and illustrated in figure 3.3. The raw data are listed in tables RPA2a, b \& c (Appendix I).

Analysis revealed no significant difference in the expression levels of the tested sequences in the test tissues.

\begin{tabular}{l|llllllllll}
\hline $\begin{array}{l}\text { OD } \\
\text { Ratio/G3P } \\
\text { DH }\end{array}$ & T1 & T2 & T3 & NT1 & NT2 & NT3 & C1 & C2 & C3 & NL \\
333 & 0.06 & 0.61 & 0.03 & 2.46 & 0.08 & 0.47 & 0.50 & 0.41 & 0.36 & 0.34 \\
361 & 1.61 & 7.60 & 0.43 & 30.28 & 1.14 & 0.96 & 0.27 & 1.16 & 0.80 & 0.20 \\
385 & 0.89 & 5.32 & 0.30 & 12.30 & 0.15 & 0.10 & 0.06 & 1.66 & 0.58 & 0.32 \\
\hline
\end{tabular}

Table 3.2

The ratios of optical densities of probes 333,361 and 385 to the house keeping gene probe.

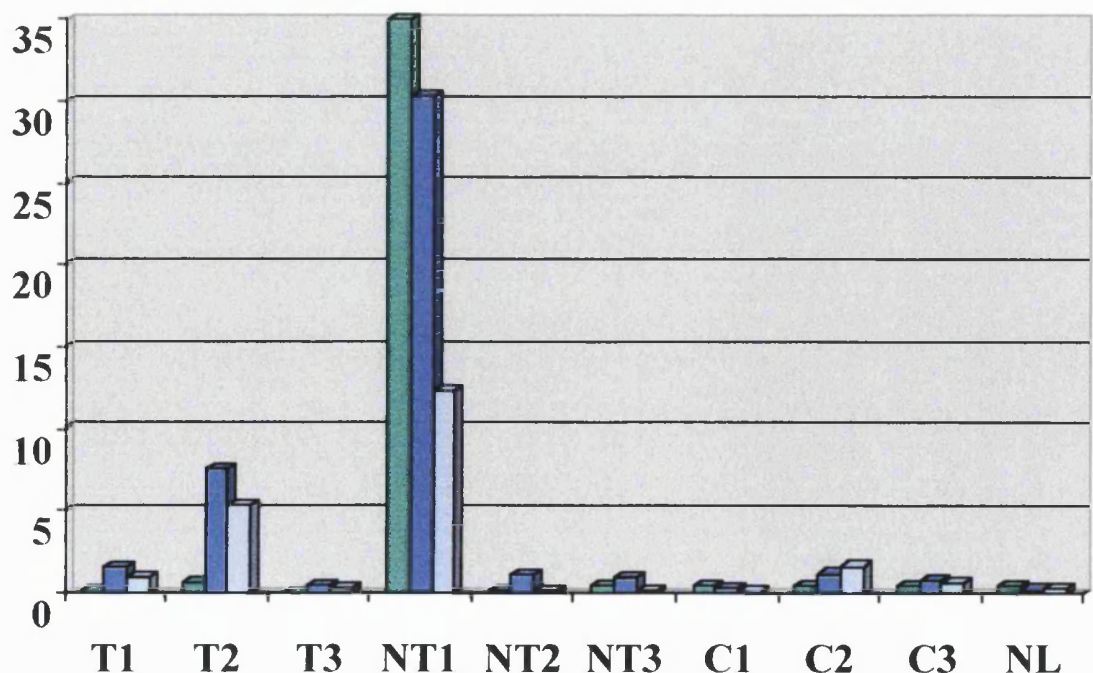

\section{Figure 3.3}

The OD ratios of probes 333,361 and 385 in various samples as in table 3.1. 


\subsubsection{Results of RPA 3:}

In RPA3, in addition to the house keeping genes, probe 299 (protected fragment of 300 bp), and probe 373 (100 bp) were tested. Another probe was excluded, 330, because the fraction incorporation of the isotope was very low. The results are summarised in table 3.3 and illustrated in figure 3.4. The raw data are listed in tables RPA $3 a \& b$ (Appendix I).

Analysis revealed no significant difference in the expression levels of the tested sequences, 373 , in the test tissues while sequence $299 \mathrm{~b}$ showed higher expression levels in two of the tested tumours.

\begin{tabular}{l|llllllllll}
\hline $\begin{array}{l}\text { OD } \\
\text { Ratio/G3PDH }\end{array}$ & T1 & T2 & T3 & NT1 & NT2 & NT3 & C1 & C2 & C3 & NL \\
\hline $299 \mathrm{~b}$ & 0.16 & 1.20 & 1.27 & 3.68 & 0.45 & 0.75 & 0.05 & 0.09 & 0.04 & 0.03 \\
373 & 0.5 & 0.70 & 0.33 & 0.53 & 0.13 & 0.31 & 0.39 & 0.39 & 0.55 & 0.70 \\
\hline
\end{tabular}

Table 3.3

The ratios of optical densities of probes $299 \mathrm{~b}$ and 373 to the house keeping gene probe.

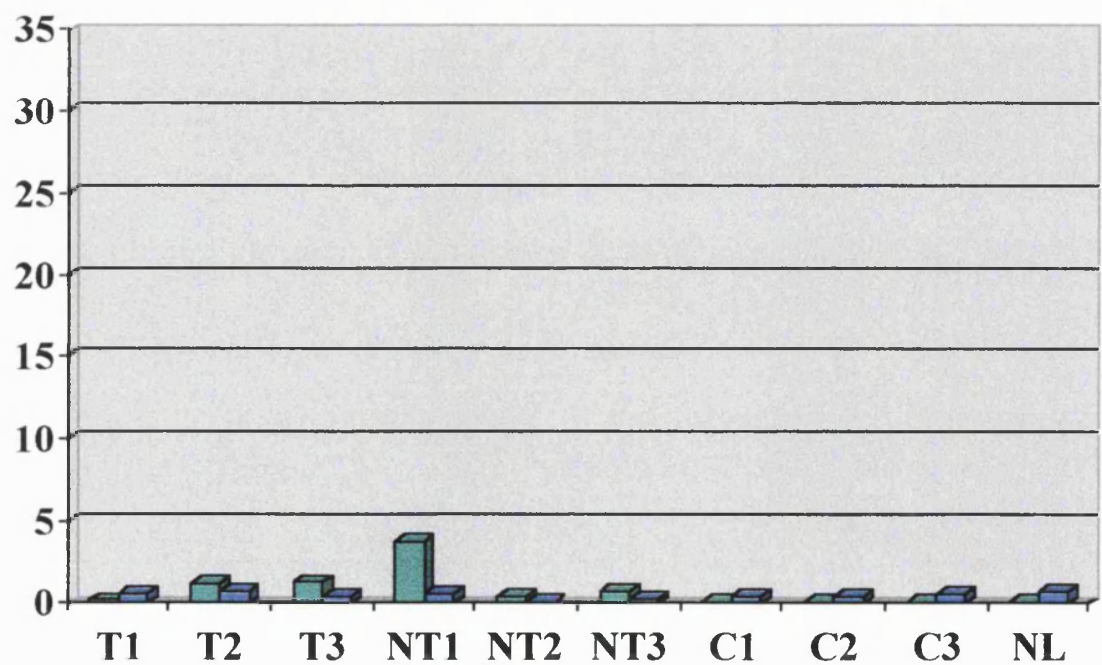

\section{Figure 3.4}

The OD ratios of probes $299 \mathrm{~b}$ and 373 in different samples as in table 3.1. 


\subsubsection{Results of RPA 4:}

In RPA4, probe 389 (protected fragment of $200 \mathrm{bp}$ ) and probe 397 (80 bp) were tested. Another probe, designated 289 , had a very low fraction incorporation of the isotope and was excluded from this assay. Results are summarised in table 3.4 and illustrated in figure 3.5. The raw data are listed in table RPA 4 (Appendix I).

Analysis revealed that probe 397 was expressed at higher levels in the tumour tissues as compared to the corresponding non tumour tissue, 14.3 vs. $0.97,5.08$ vs. $1.52 \& 2.05$ vs. 0.75 , as well as the control and the normal liver tissues.

\begin{tabular}{l|cccccccccc}
\hline $\begin{array}{l}\text { OD } \\
\text { Ratio/G3PDH }\end{array}$ & $T 1$ & $T 2$ & $T 3$ & $N T 1$ & $N T 2$ & $N T 3$ & $C 1$ & $C 2$ & $C 3$ & $N L$ \\
\hline 389 & 0.01 & 0.15 & 0.19 & 0.36 & 0.19 & 0.11 & 0.23 & 0.09 & 0.15 & 0.10 \\
397 & & & & & & & & & & \\
& $\mathbf{1 4 . 3 1}$ & $\mathbf{5 . 0 9}$ & $\mathbf{2 . 0 6}$ & 0.97 & 1.52 & 0.75 & 1.37 & 0.30 & 0.30 & 1.16 \\
\hline
\end{tabular}

Table 3.4

The ratios of optical densities of probes 389 and 397 to the house keeping gene probe.

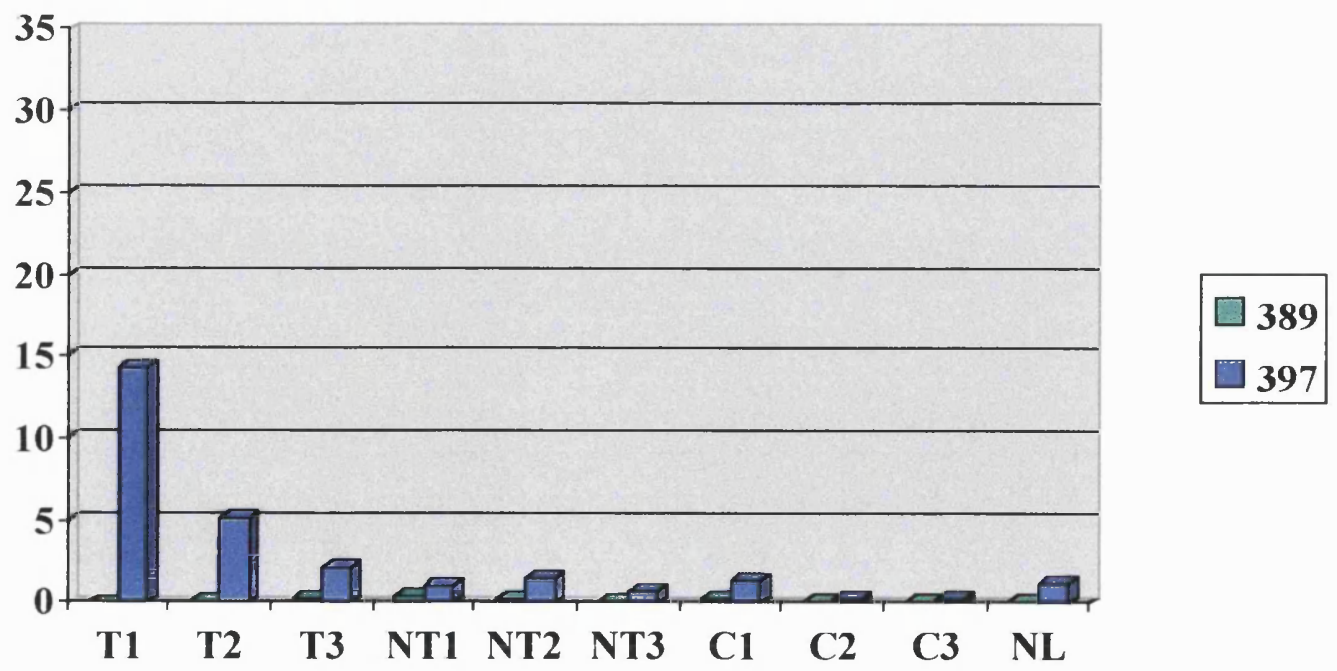

\section{Figure 3.5}

The OD ratios of probes 389 and 397 in various samples as in table 3.1. 


\subsubsection{Results of RPA 5:}

In RPA5, probe 281 (protected fragment of $50 \mathrm{bp}$ ), probe 287 (180bp), and probe $311(250 \mathrm{bp})$ were tested together with the house keeping genes. The ratios of the OD of the test probes to G3PDH are summarised in table 3.5 and illustrated in figure 3.6. Different exposures were required in this assay as the densities of the bands were variable. The raw data are listed in tables RPA5a, b \& c (Appendix I).

No significant difference in the expression levels of the tested sequences, 281 and 311 , was found in the test tissues while clone 287 had higher ratios in two of the tested tumours.

\begin{tabular}{l|llllllll}
\hline OD Ratio/G3PDH & T1 & T3 & NT1 & NT2 & NT3 & C1 & C2 & NL \\
\hline 281 & 4.94 & 2.40 & 0.32 & 1.16 & 3.33 & 0.20 & 0.38 & 2.44 \\
287 & 1.93 & 0.73 & 0.06 & 0.14 & 0.39 & 0.04 & 0.13 & 0.71 \\
311 & 0.05 & 0.07 & 0.19 & 0.02 & 0.02 & 0.02 & 0.04 & 0.00 \\
\hline
\end{tabular}

\section{Table 3.5}

The ratios of optical densities of probes 281,287 and 311 to the house keeping gene probe.
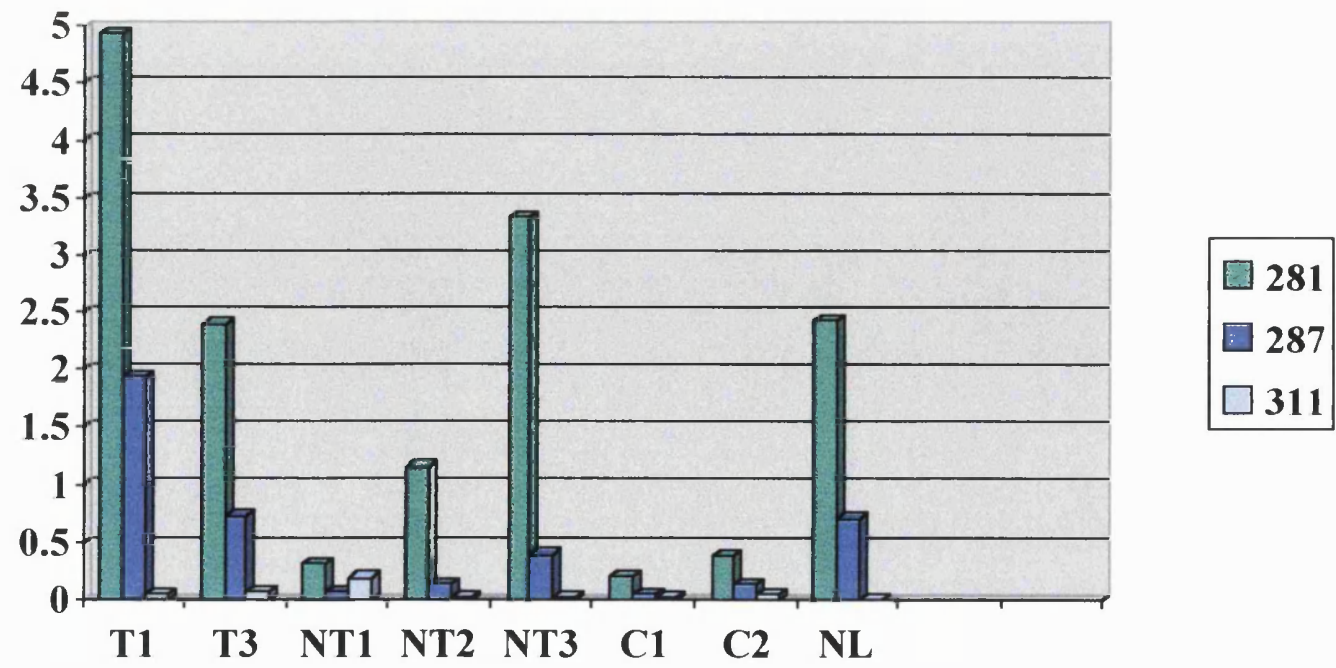

\section{Figure 3.6}

The OD ratios of probes 281,287 and 311 in various samples as in table 3.1. 


\subsubsection{Sammary of results:}

Use of RPA to confirm differential expression was limited to twelve clones because of the limited amounts of tumour tissue and mRNA available. Three probes were selected for each assay such that they had sizes different enough to be distinguished on the gels. The expression levels of the $12 \mathrm{cDNAs}$ were examined in three additional tumours and the corresponding non-tumorous tissues (Table 3.6). Expression of three of these cDNAs was up-regulated in two of these three tumours. One of the clones, designated 397 , was found to be expressed at higher levels in all three tumours than in the nontumorous and control liver tissues.

\begin{tabular}{|lllllllllll|}
\hline Probe & T1 & T2 & T3 & NT1 & NT2 & NT3 & C1 & C2 & C3 & C4 \\
287 & 1.93 & 0.73 & NA & 0.06 & 0.14 & 0.39 & 0.04 & 0.13 & NA & 0.17 \\
299 & 0.16 & 1.20 & 1.27 & 3.68 & 0.45 & 0.75 & 0.05 & 0.09 & 0.04 & 0.03 \\
383 & 0.89 & 2.83 & 1.07 & 12.93 & 1.35 & 0.87 & 0.50 & 0.90 & 0.30 & 0.20 \\
397 & 14.31 & 5.09 & 2.06 & 0.97 & 1.52 & 0.75 & 1.37 & 0.30 & 0.30 & 1.16 \\
\hline
\end{tabular}

Table 3.6 Summary of RPA results.

RPA Analysis: the ratios of optical densities of the test to the control G3PDH probe. 


\subsection{Discussion:}

Although northern blotting has been used extensively, it has some disadvantages. The most common problem is an unacceptable level of degradation of RNA. A low level of degradation that results in a 'shadow' migrating ahead of the intact RNA is quite common. In extreme cases all the RNA will migrate as diffuse smear of low molecular weight. This is frequently caused by inadequate de-ionisation of the glyoxal (Williams, 1985). Alternatively, it may arise from RNase contamination in one of the solutions. RNases are widely distributed in tissues, with fingers being a major source of contamination. The problem can be overcome by baking or sterilising glassware and solutions, and by employing specific RNase inhibitors such as diethyl pyrocarbonate (DEPC) (Trayhurn, 1996).

The other key problem is high background on membranes which can be minimised by careful adjustment of the post-hybridisation wash conditions.

RNA transfer and binding to the membrane, in northern hybridisation, may be inefficient. Once bound, some RNA molecules may be inaccessible for hybridisation. On the other hand, sample integrity influences the degree of signal localisation in a single band (Lee \& Costlow, 1987). For these reasons, the RPA is considered superior to northern blots for the detection and quantitation of low abundance RNAs.

On the other hand, quantitative PCR is extremely sensitive, less time consuming, and can be carried out with extremely low amounts of the starting material. Recently, it has been found that using DNA calibrators does not control the variations during reverse transcription. This problem can be overcome by adding internal standard mRNA to the test sample before RNA extraction. 
In this study, the confirmation methods were applied after the step of mRNA extraction, and using the IS mRNA was not possible. Furthermore, it might not be appropriate to confirm a PCR based method with another PCR method.

For these reasons, the RPA was selected as a confirmation method of the DDRT-PCR. In each RNA sample the ratio of expression level of the test probe, as represented by the density of the densitometry band, was compared to the expression level of the house keeping gene G3PDH and a ratio was obtained.

The analysis of the different bands, obtained by the densitometric analysis, in the different ribonuclease protection assays have shown that one sequence tag, designated 397 , has been confirmed to be up-regulated in the tumour tissue more than the nontumour and the control tissues. The ratios of this clone were $14.31 v s .0 .97$ in tumour vs. non tumour tissues of liver 1, $5.09 v s .1 .52$ in liver 2 and $2.06 v s .0 .75$ in liver 3 . The ratios in the three tumours were higher than the ratios in the control and the normal liver tissues. In only one non-tumour tissue. NT2, the ratio was higher than the control samples possibly reflecting early neoplastic changes.

Searching the nucleotide sequence database in October 1999, this sequence was found homologous with a sequence identified by the Human body map project designated GS 2073. No information was available on this sequence at that date.

RPA analysis of the other studied bands revealed that another clone, 383, was expressed in two of the studied tumours more than in their corresponding non-tumour tissues. The ratios were $2.83 v s .1 .35$ in sample 2 and $1.07 v s .0 .87$ in sample 3. Nevertheless, in liver sample 1 the ratios in the non-tumour tissues was much higher than in the tumour tissue, 12.93 vs. 0.89 . As searching the nucleotide sequence database at that time revealed 
homology with a retinoblastoma binding protein, the high expression levels of this candidate gene might indicate the involvement of this gene in the neoplastic process.

Two more clones were expressed at higher levels in two out of the three studied tumours. Clone 299b showed higher ratios in sample 2, 1.2 in T2 vs. 0.45 in NT2, and sample 3, 1.27 in T3 vs. 0.75 in NT3. Clone 287 also showed higher ratios in sample 1, 1.93 in T1 vs. 0.06 in NT1, and sample 3, 0.73 in T3 vs. 0.39 in NT3.

Because only clone 397 was consistently high in all the studied tumour tissues than their corresponding non-tumour as well as the control tissues, the next part of the study will include characterisation and more investigation of this candidate gene and testing the level of its expression in other tumour tissues. 
Chapter 4

4. Characterisation of clone 397 


\subsection{Introduction}

\subsubsection{Historical background:}

The discovery of DNA structure by Watson and Crick, 1953, lead to a revolution in the study of biology. The DNA discovery enabled us to decode the genomic information for life that is contained within every dividing cell. With the advances in computer technology we became able to store and process massive amounts of nucleotide sequence information. The combination of advances in biotechnology and bioinformatics has provided us with the ability to study the biology of thousands of genes at the same time. Unfortunately, sequencing billions of bases of DNA does not tell us the function of all genes, how cells work or what goes wrong in a disease (Lockhart \& Winzeler, 2000).

Expressed sequence tags (ESTs) are leading the way in gene discovery, and gene expression analysis. ESTs are partially sequenced cDNAs synthesised from randomly selected gene transcripts. Once created, the partially sequenced tags can be stored electronically and analysed. ESTs, once in hand, represent a sequence-based link from which each gene can be probed and monitored.

The importance of ESTs is derived from the fact that in any cell, only a subset of its genome is actively transcribed, known as the transcriptome. Isolating mRNA and constructing a cDNA library will make a collection of cDNA molecules that represent the subset of genes in use by that cell. A digital image of gene transcription levels for a particular cell line or tissue can be obtained by counting the number of ESTs in a random sampling that matched a given gene. Recently, with more sequence data obtained, the sequence database has emerged where sequence homology, gene function, and gene expression data are correlated (Zweiger \& Scott, 1997). 
The most fundamental application of EST databases is finding gene family members such as the chemokine family (Wells \& Peitsch, 1997) and the tumour necrosis factor alpha (TNF $\alpha$ ) receptor families (Wiley et al., 1995).

Other applications include detecting gene expression levels particularly genes whose expression levels change in diseased versus non-diseased tissues. With multiple transcripts obtained from a large set of tissues, statistically significant correlation may be obtained providing information about disease states, treatment outcome, or genotypes (Spanakis \& Brouty-Boye, 1997).

\subsubsection{Computer analysis of newly identified cDNAs:}

\subsubsection{Basic Local Alignment Search Tool (BLAST):}

BLAST is the search algorithm used by the programmes blastp, blastn, blastx, tblastn, and tblastx. The BLAST programmes are designed to search sequence similarity and identify homologues to a query sequence. Different BLAST programs can perform different tasks as follows:

blastn compares a nucleotide query sequence against a nucleotide sequence database.

blastp compares an amino acid query sequence against a protein sequence database. blastx compares the translation products of a nucleotide query sequence on both strands against a protein sequence database.

tblastn compares a protein query sequence against a nucleotide sequence database dynamically translated in all six reading frames on both strands.

tblastx compares the six-frame translations of a nucleotide query sequence against the six-frame translations of a nucleotide sequence database. 


\section{Search strategy:}

The unit of BLAST algorithm output is the High-scoring Segment Pair (HSP). HSP consists of two sequences, one from the query sequence and one from a database sequence, of arbitrary length whose alignment is maximal. Only matches that satisfy a threshold of significance are reported.

\subsubsection{NIX tool:}

NIX is a WWW tool used to analyse a chosen DNA sequence using many DNA programs including GRAIL, Fex, Hexon, MZEP, Genemark, Genefinder, Fgene, Blast, Polyah, RepeatMasker, and tRNAscan. NIX is designed to help the identification of genomic nucleic acid sequences and find predicted exons.

\subsubsection{Amplification of complete cDNA molecules:}

\subsubsection{5'-SMART RACE cDNA Amplification:}

The method of SMART RACE cDNA amplification performs both 5'- and 3'amplification of cDNA ends (RACE). The SMART (Switching Mechanism At 5' end of RNA Transcript) cDNA synthesis technology allows one to isolate the complete 5' sequence of the target transcript. It allows the use of first-strand cDNA directly in RACE PCR without the need for adaptor ligation. Full-length cDNAs can be generated in reverse transcription reaction by the joint action of the SMART oligonucleotide and MMLV reverse transcriptase (RT). Certain MMLV-RT exhibit a terminal transferase activity that adds 3-5 residues, predominantly $\mathrm{dC}$, to the 3 '- end of the first strand cDNA when they reach the end of an RNA template. The SMART oligo is a stretch of $\mathrm{dG}$ residues that anneal to the $\mathrm{dC}$ rich $\mathrm{cDNA}$ tail and serve as a template for $\mathrm{RT}$. A complete cDNA copy of the original RNA is thus synthesised with the addition of SMART sequence at the end. The $\mathrm{dC}$-tailing of $\mathrm{RT}$ is efficient only when the enzyme 
reaches the end of the RNA template, thus the SMART sequence is added only to complete first-strand cDNAs. The first-strand cDNA is then used directly in 5'- and 3'RACE PCR reactions without the need for second-strand synthesis.

The requirement for SMART RACE cDNA amplification is sequence information of about 23-28 nucleotides in order to design gene specific primers to be used with the universal primers. This limited requirement makes the method ideal for characterising genes identified through different methods including cDNA subtraction, differential display, RNA fingerprinting and library screening.

\subsubsection{Inverse PCR:}

The principle of this method is to generate a double stranded cDNA that starts with a known sequence followed by the unknown target sequence. The cDNA is then digested with a restriction enzyme which usually generates a 2-3 kb fragment containing a segment of the target sequence. The DNA fragment is then circularised by ligation. The circular DNA may be relinearised with a restriction enzyme that cleaves once within the target sequence. DNA is denatured and annealed with oligonucleotide primers that have been selected complementary to sequences at the 5'-end of target DNA followed by cycles of amplification in PCR (Ochman et al., 1988). The product of amplification reaction consists of a head-to-tail arrangement of the sequences that flanked the target region (figure 4.1).

\subsubsection{Multiple tissue expression study:}

One of the most powerful tools of studying sequence information is the use of highdensity arrays of oligonucleotides or cDNAs. Nucleic acid arrays work by hybridisation of labelled RNA or DNA to nucleic acid molecules attached onto a surface. 
Hybridisation of a chosen sample to an array simply means a search by each labelled molecule for a "matching partner" on the surface.

One of the most significant applications for arrays is studying the patterns of gene expression, mRNA abundance, in different disease situations and in different tissues.

This expression profile is a major determinant of cellular function as this profile changes with different situations.

Step 1) Restriction mapping of the target sequence

Step 2) Cutting with a restriction enzyme that doesn't cut within the target:

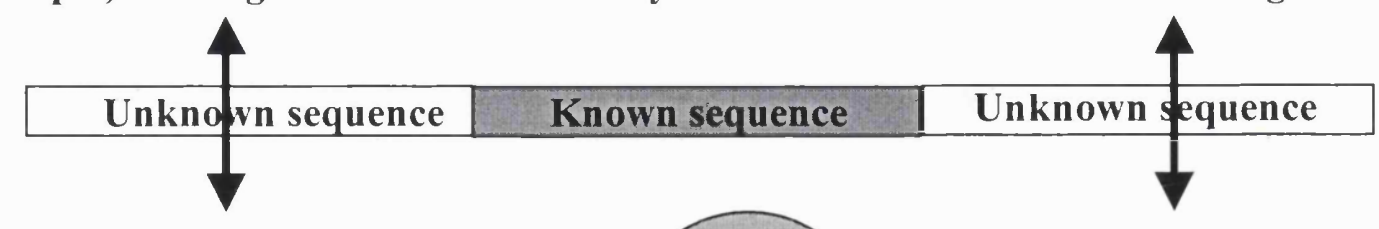

Step 3) Circularisation

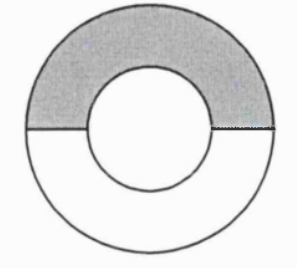

Step 4) PCR using primers from the known sequence

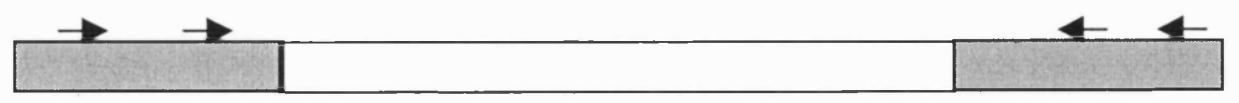

Figure 4.1 Inverse PCR

The small black arrows represent the selected primers from the known sequence. 


\subsection{Materials and Methods:}

\subsubsection{Computer analysis:}

In this study, in order to characterise our candidate clone 397 , sequence similarity was searched using the blastn program. This programme restricts the reported HSPs to the greatest statistically significant 50 .

The NIX program was used later to analyse some genomic sequences homologous with clone 397. NIX is a WWW tool to view the results of running many DNA analysis programs on a certain DNA sequence. The analysis programs run include: GRAIL, Fex, Hexon, MZEF, Genemark, Genefinder, FGene, BLAST (against many databases) Polyah, RepeatMasker, tRNAscan. NIX is intended as a tool to aid the identification of interesting regions in Genomic or transcribed nucleic acid sequences. The cut and paste field on the NIX input form can only transfer sequences of up to about $20 \mathrm{~Kb}$ (this is a limitation of HTML browsers). Many of the programs seem to loose sensitivity when analysing long sequences. Because many of the programs expect a sequence that is longer than 100 bases, the best length is probably 20 to $50 \mathrm{~Kb}$ or less. Results of NIX are displayed such as the sequence line is a central green line with "sequence' printed next to it. Everything above this line would be a feature found on the forward sense and everything below it is a feature found on the reverse sense. Some features are direction independent and so are duplicated on both strands.

\subsubsection{PCR amplification:}

Various amplification strategies were used in this study in an attempt to amplify the whole gene of clone 397 . 


\subsubsection{5'- end amplification:}

SMART RACE cDNA amplification kit, CLONTECH, was used to amplify the 5' end as follows:

Antisense gene-specific primers, GSP 397 and NGSP (table 4.1), were designed for a nested 5'-RACE PCR reactions together with the kit universal and nested universal primer mix. Gene specific primers (GSPs) were 23-28 nucleotides, having 50-70\% GC content, and having melting temperature between $65^{\circ} \mathrm{C}$ and $70^{\circ} \mathrm{C}$ to use touch down PCR. Self-complementary primer sequences were avoided. Primers complementary to the universal primer mix, particularly in their 3' end, were also avoided.

Various types of cDNAs and primers were used in several amplification methods.

\section{Method A:}

\section{cDNA synthesis:}

Two cDNAs were synthesised using normal liver mRNA one with the kit primer, 5' CDS, and one with the gene specific primer GSP 397.

\section{cDNA 1:}

mRNA was extracted from normal liver tissue using 'RNAgents total RNA Isolation system', Promega, followed by messenger RNA Isolation kit, STRATAGENE, according to the manufacturers instructions.

The SMART technology uses the joint action of a SMART II oligonucleotide and MMLV RT. Certain MMLV RTs add 3-5 residues, predominantly dC, to the 3' end of the first-strand cDNA when they reach the end of an RNA template. The stretch of dG residues in the SMART II oligo will anneal to the dC-rich cDNA tail and serve as an extended template for RT. First strand cDNA synthesis of the full-sized target 397 was performed as follows: 


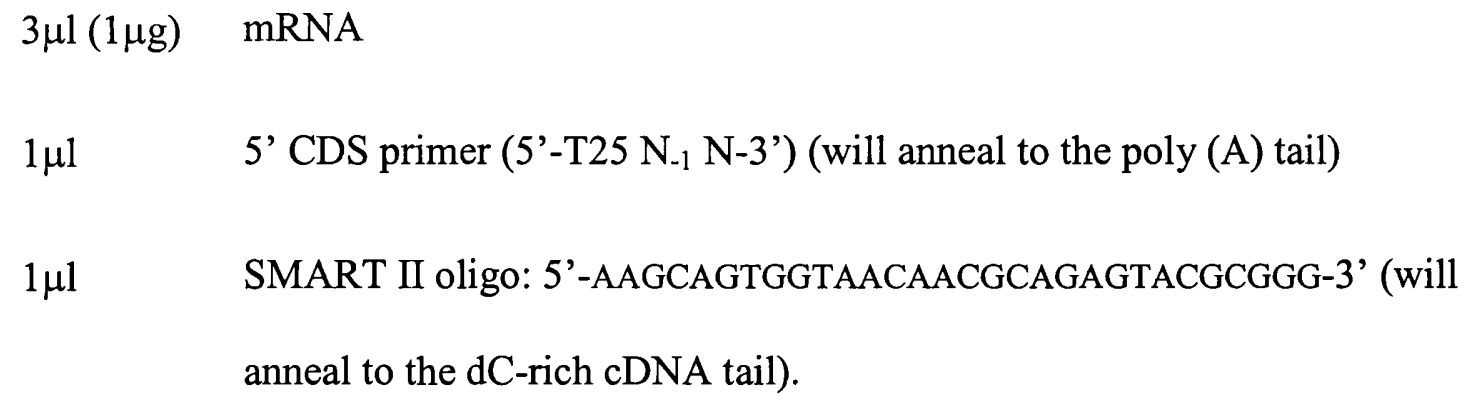

The reagents were mixed, briefly spun, and incubated at $70^{\circ} \mathrm{C}$ for 2 minutes then moved onto ice for another 2 minutes. The tube was briefly spun and the following reagents were added:

$\begin{array}{ll}2 \mu 1 & 5 x \text { first strand buffer } \\ 1 \mu 1 & \text { DTT (20mM) } \\ 1 \mu 1 & \text { 10mM dNTP mix } \\ 1 \mu \mathrm{l} & \text { SuperScript II (MMLV-RT) } 200 \mathrm{u} / \mu 1\end{array}$

\section{cDNA 2:}

Alternatively, cDNA was synthesised using the same protocol above replacing the 5' CDS primer with the gene specific primer GSP 397 (table 4.1).

\section{Termination reaction:}

The contents of the tube were mixed, spun, and incubated at $42^{\circ} \mathrm{C}$ for 1.5 hours to terminate the action of RT. $100 \mu$ l of Tricine-EDTA buffer was added and heated at $72^{\circ} \mathrm{C}$ for 7 minutes. 


\begin{tabular}{|ll|}
\hline Primer & Oligonucleotide 5 ' to 3, \\
\hline GSP 397 & GGAAAACAAAAAAAACAAAAAACTTCA \\
NGSP & TTCTAAGCCCTGGAGTAGCTCG \\
UPM & CTAATACGACTCACTATAGGGCAAGCAGTGGTAACAACGCAGAGT \\
NUPM & AAGCAGTGGTAACAACGCAGAGT \\
\hline
\end{tabular}

Table 4.1 Gene specific primers and universal primers used for 5' end PCR. Gene specific primers GSP 397 and the nested NGSP were designed from the known sequences, while the universal primer mix UPM and the nested NUPM were provided with the kit.

\section{PCR reactions:}

First round PCR was performed using the same primer used for cDNA 2 synthesis, GSP

397, as the outer primer together with the universal primer mix UPM (table 4.1):

A $50 \mu 1$ PCR reaction was set up as follows:

$2.5 \mu 1 \quad$ cDNA

$1.0 \mu \mathrm{l} \quad 10 \mathrm{mM} \mathrm{dNTP} \operatorname{mix}$

$5.0 \mu 1 \quad 10 \mathrm{x}$ advantage $2 \mathrm{PCR}$ buffer

$5.0 \mu 1 \quad 10 x \mathrm{UPM}$

$1.0 \mu 1 \quad$ GSP 397 at $10 \mathrm{pmol} / \mu \mathrm{l}$

$34.5 \mu 1 \quad$ Nuclease free water 


\section{0 $\quad$ Advantage 2 polymerase mix}

Perkin Elmer hot lid thermal cycler "Gene Amp System" was used, a touch down cycling protocol was used as follows:

5 cycles $\quad 94^{\circ} \mathrm{C} \quad 5$ seconds

$72^{\circ} \mathrm{C} \quad 3$ minutes

32 cycles $\quad 94^{\circ} \mathrm{C} \quad 5$ seconds

$72^{\circ} \mathrm{C} \quad 10$ seconds (Annealing temperature was decreased by $0.5^{\circ} \mathrm{C} /$ cycle)

$72^{\circ} \mathrm{C} \quad 3$ minutes

extension $\quad 72^{\circ} \mathrm{C} \quad 7$ minutes

Second round (nested) PCR was performed with the same protocol using the nested primers, NGSP and NUPM (table 4.1). NGSP was designed from the homologous EST TH C392255 from the TIGR Human Gene Index identified with BLAST search.

\section{Method B:}

This method used a modified PCR reaction using ELONGASE enzyme mix (advantage polymerase for long sequences) starting with the cDNAs synthesised in method A:

$\begin{array}{ll}2.5 \mu \mathrm{l} & \text { cDNA } \\ 5.0 \mu \mathrm{l} & 2 \mathrm{mM} \text { dNTP mix }\end{array}$


5.0 $10 \mathrm{x}$ advantage 2 PCR buffer

5.0 1 10x UPM (or NUPM in second round PCR)

2.0 $\mu 1$ GSP 397 at $10 \mathrm{pmol} / \mu \mathrm{l}$ (or NGSP in second round PCR)

$5.5 \mu \mathrm{l} \quad$ Nuclease free water

The following buffer mix was prepared separately and subsequently added to the reaction. It provides $\mathrm{MgCl}_{2}$ concentration of $7.8 \mathrm{~mol}$ :

$2 \mu 1 \quad$ Buffer A (provided with the Elongase enzyme)

$8 \mu \mathrm{l} \quad$ Buffer B (provided with the Elongase enzyme)

$2 \mu 1 \quad$ ELONGASE enzyme mix

$18 \mu 1 \quad$ water

The cycling protocol was:

5 cycles $\quad 94^{\circ} \mathrm{C} \quad 15$ seconds

$68^{\circ} \mathrm{C} \quad 7$ minutes

32 cycles $\quad 94^{\circ} \mathrm{C} \quad 15$ seconds

$68^{\circ} \mathrm{C} \quad 15$ seconds (Annealing temperature was decreased by $0.3^{\circ} \mathrm{C} /$ cycle)

$68^{\circ} \mathrm{C} \quad 7$ minutes

Extension $\quad 68^{\circ} \mathrm{C} \quad 7$ minutes 


\section{Modification of method B:}

\section{Method B1:}

The same protocol in method B was followed. PCR was performed to amplify a short homologous sequence, EST AA845421, using the specific primers:

GSP 397 and “5' outer" primers for first round PCR and “3' NESTED” and "5'

NESTED" primers for second round PCR (table 4.2).

\begin{tabular}{|l|l|}
\hline Primer & Oligonucleotide 5' to 3' \\
\hline GSP 397 & GGAAAACAAAAAAAACAAAAAACTTCA \\
5'NESTED & CTGTAGAGAAACTGAGGACAGTAT \\
5'NESTED & GATCGAAAAGGGACCCTGCTTC \\
\hline
\end{tabular}

\section{Table 4.2}

Gene specific primers used to amplify the homologous EST GS2073. 


\section{Method B2:}

The same protocol in method B was followed using different cDNAs. Two cDNAs were synthesised from total RNA extracted from 293 cells as well as HUH-7 cells. For each cDNA type two attempts of amplification were tried, once to amplify the whole gene and the other to amplify the known sequence EST AA845421.

\section{Method B3:}

In this experiment PCR was repeated using other GSPs designed from the homologous EST AA845421 (table 4.3).

\begin{tabular}{|l|l|}
\hline Primers & Oligonucleotide 5' to 3' \\
\hline G588IB (nested) & TAAGGGAGAGGATAGTGTGTAC \\
G588IE (nested) & TCCTCAACTCAAGATTAGGGCA \\
G588OE (outer) & ATATACAGTCAGATATAAAGACATCTC \\
G588OB (outer) & TCAGTCAGTGTCCAGCCATGCA \\
\hline
\end{tabular}

\section{Table 4.3}

Gene specific primers used to amplify the homologous EST AA845421.

G588OE and G588OB are outer primers while G588IE and G588IB are nested primers. 


\section{Method B4:}

This method was performed as method B3 but this time with UPM and NUPM in an attempt to amplify the 5'-end using the same conditions that amplified the shorter sequences.

\subsubsection{Amplification of tailed cDNA:}

Because tailing cDNA creates a binding site at the 3' end on cDNA, it was tried on our cDNA. Tailing is usually done with $\mathrm{dC}$ or $\mathrm{dG}$ as $\mathrm{C}: \mathrm{G}$ base pairs are more stable than A:T pairs.

In this method, two types of cDNA were synthesised from normal liver mRNA, once with the primer SMART II (as in 4.2.2.1.method A) and once with G588OE (table 4.2). cDNA was then purified and tailed with GGGGG.

First and second rounds of PCR were carried out using primers G588OE and G588IE (table 4.2) respectively together with C-prim.

\subsubsection{3. “5'RACE system for rapid amplification of cDNA Ends, version 2.0", Life} Technologies, was used:

This kit involves the degradation of the rest of RNA by RNase mix, a mixture of RNase $\mathrm{H}$ and RNase T1. Template RNA in the cDNA:RNA hybrid is degraded by the RNase $\mathrm{H}$ while the single stranded RNAs are degraded by the RNase T1. This step avoids the renaturation of RNA to cDNA which might inhibit tailing of the cDNA, if needed, and interfere with subsequent PCR of the cDNA (Pikaart \& Villeponteau, 1993).

\section{Method A:}

cDNA Synthesis:

$1 \mu \mathrm{l} \quad$ Gene specific primer (G588OE) at $2.5 \mathrm{pmol} / \mu \mathrm{l}$ 
$5 \mu \mathrm{l}(5 \mu \mathrm{g}) \quad$ HepG2 cells total RNA

$9.5 \mu \mathrm{D} \quad \mathrm{DEPC}$ treated water (final volume of $15.5 \mu \mathrm{l}$ )

The reaction was incubated at $70^{\circ} \mathrm{C}$ for 10 minutes then placed onto ice for 1 minute.

The tube was briefly spun and the following reagents were added in order:

$\begin{array}{ll}2.5 \mu \mathrm{l} & 10 \mathrm{x} \text { PCR buffer } \\ 2.5 \mu \mathrm{l} & 25 \mathrm{mM} \mathrm{MgCl}_{2} \\ 1.0 \mu \mathrm{l} & 10 \mathrm{mM} \mathrm{dNTP} \mathrm{mix} \\ 2.5 \mu \mathrm{l} & 0.1 \mathrm{M} \mathrm{DTT}\end{array}$

The reagents were mixed, spun, and incubated at $42^{\circ} \mathrm{C}$ for 1 minute then $1 \mu 1$

SuperScript II was added and incubated at $42^{\circ} \mathrm{C}$ for 50 minutes.

\section{Termination reaction:}

The tube was heated at $70^{\circ} \mathrm{C}$ for 15 minutes, spun for 20 seconds, then incubated at $37^{\circ} \mathrm{C}$.

$1 \mu \mathrm{l}$ of RNase mix was added and incubated at $37^{\circ} \mathrm{C}$ for 30 minutes. The tube was spun and put on ice.

\section{Purification of cDNA:}

“Glass Max DNA Isolation spin cartridge” was used for purification:

$120 \mu \mathrm{l}$ of binding solution, $6 \mathrm{M} \mathrm{NaCl}$, was added to the first strand reaction after equilibrating the spin cartridge at room temperature. 
cDNA/NaI solution was transferred to a "Glass Max Spin Cartridge" and centrifuged at $13,000 x$ for 20 seconds.

The cartridge was washed 3 times with $400 \mu$ l of $1 \mathrm{x}$ wash buffer (cooled to $4^{\circ} \mathrm{C}$ ), then twice with cold $400 \mu 170 \%$ ethanol.

The cartridge was centrifuged at $13,000 \mathrm{xg}$ for 1 minute then transferred to a fresh sample recovery tube.

$50 \mu \mathrm{l}$ preheated $\left(65^{\circ} \mathrm{C}\right)$ sterile, distilled water was then added to the spin cartridge and centrifuged at $13,000 \mathrm{xg}$ for 20 seconds to elute cDNA.

\section{Terminal deoxynucleotidyl transferase (TdT) tailing of cDNA:}

The following reagents were mixed together in a microfuge tube:

$\begin{array}{ll}6.5 \mu 1 & \text { DEPC treated water } \\ 5 \mu 1 & 5 \times \text { tailing buffer } \\ 2.5 \mu 1 & 2 \mathrm{mM} \mathrm{dGTP} \\ 10 \mu 1 & \text { purified cDNA }\end{array}$

The tube was incubated at $94^{\circ} \mathrm{C}$ for 2 minutes then chilled on ice for 1 minute and briefly spun again. $1 \mu \mathrm{TdT}$ was added to the reaction, mixed gently and incubated at $37^{\circ} \mathrm{C}$ for 10 minutes.

TdT was heat inactivated at $65^{\circ} \mathrm{C}$ for 10 minutes. The tube was microfuged and placed on ice. 


\section{First round PCR:}

$\begin{array}{ll}31.5 \mu \mathrm{l} & \text { sterile water } \\ 5 \mu \mathrm{l} & 10 \mathrm{x} \text { PCR buffer } \\ 3 \mu \mathrm{l} & 25 \mathrm{mM} \mathrm{MgCl}{ }_{2} \\ 1 \mu 1 & 10 \mathrm{mM} \mathrm{dNTP} \mathrm{mix} \\ 2 \mu 1 & \text { Primer "G588 OE" at } 10 \mathrm{p} \mathrm{mol} / \mu \mathrm{l} \\ 2 \mu 1 & \text { Abridged Anchor primer (provided) } \\ 5 \mu 1 & \text { dC-tailed cDNA } \\ 0.5 \mu 1 & \text { Taq DNA polymerase }\end{array}$

The cycling protocol was:

$\begin{array}{llll}\text { Preamplification } & \text { denaturation } & 94^{\circ} \mathrm{C} & 2 \text { minutes } \\ 35 \text { cycles } & \text { denaturation } & 94^{\circ} \mathrm{C} & 1 \text { minute } \\ & \text { annealing } & 55^{\circ} \mathrm{C} & 1 \text { minute } \\ & \text { primer extension } & 72^{\circ} \mathrm{C} & 7 \text { minutes } \\ & & & \\ \text { Final extension } & & 72^{\circ} \mathrm{C} & 7 \text { minutes }\end{array}$

\section{Second round PCR:}

The same protocol used in the first round PCR was followed replacing primer "G588 OE", used in the first round PCR, with the nested one, "G588IE". 


\section{Method B:}

Another PCR amplification was carried out to amplify the sequence of EST AA845421 using the gene specific primers; G588OB and G588OE for the first round and G588IE and G588IB for the second round PCR using the same conditions as above.

\subsubsection{Inverse PCR:}

Inverse PCR was attempted starting from the known sequence of clone 397 . Double stranded cDNA was synthesised then digested with two restriction enzymes that do not cut within the known sequence and expected to cut at intervals of $2-3 \mathrm{~kb}$. The selection of restriction enzymes, BsmI and NspI, was guided by the known sequence of a homologous contig on chromosome 17.

\section{Primers:}

Four primer sequences were selected from the known sequence for a nested PCR reaction (table 4.4).

\begin{tabular}{|l|l|}
\hline Primers & Oligonucleotide 5' to 3' \\
\hline Right Outer & GCAGGAAGCAAAGGAACTGGAC \\
Reft Outer & CCTCGAGCTACTCCAGGGCAATG \\
Left Inner & ACGTACCGACCTGTGACTGACT \\
\hline
\end{tabular}

Table 4.4 Inverse PCR primers.

Right inner and Left inner are the nested PCR primers. 


\section{Restriction mapping:}

Two restriction enzymes Bsm I and NspI were found to cut at intervals of about 2-3 kb in the adjacent sequence, and not in the known sequence, based on the homology with chromosome 17 contig.

Double strand cDNA was synthesised as follows:

$\begin{array}{ll}26.5 \mu \mathrm{l} & \text { RNA in DEPC water } \\ 2.5 \mu \mathrm{l} & \text { oligo dT }(1 \mathrm{mg} / \mathrm{ml})\end{array}$

The reaction was incubated at $70^{\circ} \mathrm{C}$ for 10 minutes then onto ice. The following reagents were added:

$\begin{array}{ll}10 \mu 1 & 5 x \text { first strand buffer } \\ 5 \mu 1 & 1 \text { M DTT } \\ 2.5 \mu 1 & 10 \mathrm{mM} \mathrm{dNTPs} \\ 1 \mu \mathrm{l} & \text { RNasin }\end{array}$

The reaction was incubated at $42^{\circ} \mathrm{C}$ for 2 minutes.

$2.5 \mu \mathrm{l}$ SuperScript II RT was added and the tube incubated at $42^{\circ} \mathrm{C}$ for 40 minutes.

Then the following reagents were added:
$70 \mu 1$
$10 \mathrm{mM} \mathrm{MgCl}_{2}$
$10 \mu 1$
$1 \mathrm{M}$ Tris $\mathrm{pH} 7.5$ 


$\begin{array}{ll}1.5 \mu \mathrm{l} & \text { 1M Ammonium Sulphate } \\ 0.5 \mu \mathrm{l} & \text { RNase H } 2 \mathrm{u} / \mu \mathrm{l} \\ 10 \mu \mathrm{l} & \text { E-coli DNA polymerase }(5 \mathrm{u} / \mu \mathrm{l})\end{array}$

The tube was incubated at $16^{\circ} \mathrm{C}$ for 4 hours then the following reagents were added:

$\begin{array}{ll}1 \mu \mathrm{l} & 50 \mathrm{mM} \text { NAD (nicotinamide adenine dinucleotide) } \\ 1 \mu \mathrm{l} & \text { E-coli DNA ligase }\end{array}$

The reaction was incubated at room temperature for 15 minutes.

\section{Phenol:Chloroform extraction of the dsDNA:}

$140 \mu \mathrm{l}$ phenol:chloroform was added to the sample, mixed well, and centrifuged at 13,000 r.p.m. for 20 seconds.

The aqueous phase, pure cDNA, was aspirated and put in another microfuged tube.

Chroma Spin 400 columns, CLONTECH, were used to purify the cDNA according to the manufacturers instructions after being equilibrated with $1 \times$ NE buffer and 100 $\mathrm{mg} / \mathrm{ml}$ BSA solution.

To $50 \mu 1$ of the eluate, $5 \mu 1 \mathrm{BsmI}$ enzyme was added and digested at $37^{\circ} \mathrm{C}$ for 2 hours. Phenol:chloroform extraction and purification, with the Chroma Spin 400 columns after equilibration with $1 \mathrm{x}$ T4 ligase buffer, was repeated.

$1 \mu 1$ of T4 ligase was added and incubated overnight at $16^{\circ} \mathrm{C}$. 


\section{First round PCR:}

First round PCR was carried out to the purified, and ligated ds CDNA using two different polymerases and the outer primers Right-O and Left-O at a concentration of 10 $\mathrm{pmol} / \mu \mathrm{l}$.

Advantage polymerase protocol for GC rich sequences:

$\begin{array}{ll}19 \mu 1 & \text { water } \\ 10 \mu 1 & 5 \times \text { GC (provided buffer) } \\ 5 \mu 1 & \text { GC melt buffer } \\ 5 \mu 1 & \text { 2mM dNTPs } \\ 2.5 \mu 1 & \text { primer Right-O } \\ 2.5 \mu 1 & \text { primer Left-O } \\ 1 \mu 1 & \text { Advantage GC rich polymerase } \\ 5 \mu 1 & \text { cDNA }\end{array}$

Standard Taq polymerase protocol:

$\begin{array}{ll}31.5 \mu \mathrm{l} & \text { water } \\ 10 \mu \mathrm{l} & 10 \times \mathrm{PCR} \text { buffer } \\ 5 \mu \mathrm{l} & 25 \mathrm{mM} \mathrm{MgCl}_{2} \\ 3 \mu \mathrm{l} & 10 \mathrm{mM} \text { dNTPs } \\ 2 \mu \mathrm{l} & \text { primer Right-O }\end{array}$




$\begin{array}{ll}2 \mu 1 & \text { primer Left-O } \\ 0.5 \mu l & \text { Taq polymerase } \\ 5 \mu 1 & \text { cDNA }\end{array}$

The cycling protocol was:

$\begin{array}{llll}\text { Preamplification } & \text { denaturation } & 94^{\circ} \mathrm{C} & 2 \text { minutes } \\ 35 \text { cycles } & \text { denaturation } & 94^{\circ} \mathrm{C} & 1 \text { minute } \\ & \text { annealing } & 55^{\circ} \mathrm{C} & 1 \text { minute } \\ & \text { primer extension } & 72^{\circ} \mathrm{C} & 3 \text { minutes } \\ & & & \\ \text { Final extension } & & 72^{\circ} \mathrm{C} & 10 \text { minutes }\end{array}$

\section{Second round PCR:}

The same protocols were tried using the nested primers Right-I and Left-I at $10 \mathrm{pmol} / \mu \mathrm{l}$.

\subsubsection{Designing degenerate primer mix:}

The known sequence of our candidate gene 397 was found to encode a protein with similarity to Ubiquitin conjugating enzyme (UBC). The conserved region of UBC was searched and 2 degenerate primer mixes were prepared:

Inner 1: GAG GAY TAY CCN WWY ARN CCN CCN CC

Inner 2: GGC ARN AUH UGY CUN RRY AUY YU

$(\mathrm{Y}=\mathrm{C}$ or $\mathrm{T}, \mathrm{W}=\mathrm{A}$ or $\mathrm{T}, \mathrm{R}=\mathrm{A}$ or $\mathrm{G}, \mathrm{N}=\mathrm{A}, \mathrm{T}, \mathrm{C}$ or $\mathrm{G})$ 
Two different cDNAs were used for amplification. One was synthesised from normal liver mRNA and the other from HepG2 cells total RNA with the same primer “GSP397”.

First round PCR:

$\begin{array}{ll}19 \mu \mathrm{l} & \text { water } \\ 10 \mu \mathrm{l} & 5 \times \mathrm{GC} \text { buffer } \\ 5 \mu \mathrm{l} & \text { GC melt } \\ 5 \mu \mathrm{l} & \text { 2mM dNTPs } \\ 2.5 \mu \mathrm{l} & \text { GSP 397 OR 1900-O at } 10 \mathrm{pmol} / \mu 1 \\ 2.5 \mu \mathrm{l} & \text { Inner 1 } \\ 1 \mu \mathrm{l} & \text { Advantage GC rich polymerase } \\ 5 \mu \mathrm{l} & \text { cDNA }\end{array}$

Second round PCR was set up using the corresponding nested primers; NGSP, or 1900-I and Inner 2.

Touch down PCR was used as referred to in 4.2.2.1. method A.

\subsubsection{Amplification of predicted exons:}

cDNA was synthesised using primer, 1900-O, designed at the end of EST THC392255.

10 sense primers were designed from the sequences of the predicted exons identified by the NIX tool to amplify these exons from our cDNA together with the antisense primers 1900-O and 1900-I (table 4.5). 
PCR was performed using the GC rich advantage polymerase in the first and second round of amplification as before in step 4.2.2.5.

Cycling conditions were as for the standard protocol used for inverse PCR.

\begin{tabular}{|ll|}
\hline Primer & Oligonucleotide 5' to 3' \\
\hline $1900-\mathrm{O}$ & ACGGGATGAATGGATGAACGAAG \\
Exon 1-O & ATACACAGTGCCTCTCCATC \\
Exon 1-N & AATGCAGAAATGGACTCTGATAGCA \\
Exon 2-O & TCATGGGAGCCTGAGGGTTTA \\
Exon 2-N & GACTTCTACGAGGTGGCCTGC \\
Exon 3-O & AAGATCGCCTGCACCTTCAAG \\
Exon 3-N & GCAAAAACTATAATGAATGTATCCGGC \\
Exon 4-O & TGTCCCTGTCCTGAACCCCT \\
Exon 4-N & CGTCCTGTTCGTGTTTCGGTGT \\
& CGGGTCAAACTGATGACAACG \\
\hline
\end{tabular}

Table 4.5 Primers for predicted exons

10 sense primers ( $\mathrm{O}$ is for outer primers and $\mathrm{N}$ is for nested ones). $1900-\mathrm{O}$ and $1900-\mathrm{N}$ are anti sense primers. 


\subsubsection{Amplification of full length gene:}

PCR was carried out to amplify the full length sequence as follows:

cDNA used was synthesised from normal liver mRNA with GSP 397.

Primers used were GSP 397 and Exon5-O for first round PCR and NGSP and Exon5-N for nested PCR reaction.

PCR was performed using the GC rich advantage polymerase as before (step 4.2.2.5) in the first and second rounds of amplification.

Cycling conditions were as for the standard protocol used for inverse PCR.

\subsubsection{Cloning and sequencing the full length gene:}

The PCR product was cloned using TOPO cloning reaction, Invitrogen, according to the manufacturers instructions.

The clone was sequenced with Thermosequenase radiolabelled terminator cycle sequencing kit, Amersham, and new sequencing primers were designed at about 250 base pair intervals and used with some of the predicted exons primers, Exon4-N, Exon3-O, Exon2-N,Exon1-N, until the whole clone was sequenced. A list of all sequencing primers is in table 4.6.

\begin{tabular}{|l|l|}
\hline Primer & Oligonucleotide 5' to 3' \\
\hline SP1 & GTTCATCCATTCATCCCGTATCAG \\
SP2 & CATTATTTCCCACAGGCCAGC \\
SP3 & ACAGGCAGCTGCTGTGTATATGG \\
SP4 & CCAGCTGCTCTTGTCACTGTCTC \\
\hline
\end{tabular}

\section{Table 4.6}

Sequencing primers for the full length clone. 


\subsubsection{Multiple tissue expression study:}

In this study, CLONTECH's Multiple Tissue Expression (MTE) was used to study the expression profile of our candidate gene, clone 397. MTE array is a positively charged nylon membrane to which mRNAs from different human tissues as well as malignant cell lines have been immobilised in separate dots after being normalised, along with some control samples. However, the mRNA used is not size fractionated on the array, thus it does not indicate the size of the transcript.

The following steps were followed:

\subsubsection{1. hybridisation with labelled clone 397 :}

\section{1) Probe synthesis:}

The DNA template was a PCR product of about 450 base pairs amplified with the specific primers to EST AA 845421 as before. Amplification was carried out with Elongase enzyme using touch down cycling conditions mentioned before in 4.2.2.1 method B.

DNA was quantitated to have $100 \mathrm{ng} / 1 \mu \mathrm{l}$ as compared to the ladder bands.

\section{Radiolabelling:}

$25 \mathrm{ng}$ DNA was diluted in water to a final volume of $19 \mu \mathrm{l}$ and heated to $100^{\circ} \mathrm{C}$ for 5 minutes then placed onto ice. The following reagents were added:

$\begin{array}{ll}5.0 \mu 1 & \text { OLB } \\ 16 \mu \mathrm{l} & \text { boiled DNA } \\ 0.5 \mu \mathrm{l} & \text { Klenow polymerase }(4 \mathrm{u} / \mu \mathrm{l}) \\ 2.5 \mu \mathrm{l} & { }^{32} \mathrm{P} \mathrm{dCTP}(800 \mathrm{Ci} / \mathrm{mmol})\end{array}$


$1 \mu \mathrm{BSA}(10 \mathrm{mg} / \mathrm{ml})$

The mixture was incubated at room temperature overnight.

\section{Probe Purification:}

Radio labelled probe was purified to remove unincorporated nucleotides using Sephadex G-50 columns after equilibration with $100 \mu 1 \mathrm{TNE}$.

The probe was diluted to $100 \mu$ l with nuclease free water.

The probe was added to the column and spun through and collected in an eppendorf tube.

The percentage of incorporation was estimated to be $70 \%$ with Geiger counter.

\section{2) Prehybridization of the membrane:}

A solution of ExcessHyb and sheared salmon testes DNA was prepared by mixing these two solutions together:

$15 \mathrm{ml}$ of ExcessHyb was prewarmed at $50-60^{\circ} \mathrm{C}$.

$1.5 \mathrm{mg}$ sheared salmon testes DNA was heated at $95-100^{\circ} \mathrm{C}$ for 5 minutes then chilled on ice.

$10 \mathrm{ml}$ of the solution prepared in the step above was added to the MTE array in a hybridisation container.

Prehybridisation was allowed for 30 minutes at $68^{\circ} \mathrm{C}$ with continuous agitation.

\section{3) Hybridisation:}

Labelled cDNA probe was mixed with $30 \mu \mathrm{l}(30 \mu \mathrm{g}) \mathrm{C}_{\mathrm{o}} \mathrm{t}-1$ DNA (a DNA enriched for repetitive DNA sequences to block hybridisation with these sequences if the probe 
contain repetitive sequences) $150 \mu 1$ sheared salmon testes DNA, and $50 \mu 120 x$ SSC in a total volume of $200 \mu \mathrm{l}$.

The mixture was heated at $95-100^{\circ} \mathrm{C}$ for 5 minutes then at $68^{\circ} \mathrm{C}$ for 30 minutes and chilled on ice.

The hybridisation mixture was added to the remaining $5 \mathrm{ml}$ of prehybridisation solution and mixed together thoroughly.

Prehybridisation solution was poured out and discarded then replaced with the hybridisation mixture.

Hybridisation was carried out overnight at $68^{\circ} \mathrm{C}$ with agitation.

\section{4) Washing and exposure of the membrane:}

The hybridisation solution was carefully removed and discarded then replaced with $200 \mathrm{ml}$ of wash solution 1 [ $2 x \mathrm{SSC}, 1 \% \mathrm{SDS}$ ].

The array was washed for 20 minutes at $65^{\circ} \mathrm{C}$ with continuous agitation.

The previous 2 steps were repeated 4 times.

Second wash was carried out twice with $200 \mathrm{ml}$ wash solution 2 [0.1x SSC, $0.5 \%$ SDS] at $55^{\circ} \mathrm{C}$ with continuous agitation for 20 minutes.

The MTE array was carefully removed from the container with a pair of forceps and immediately wrapped in a plastic wrap. Drying of the membrane was not allowed as subsequent probe removal would be difficult.

The plastic wrapped array was placed on an old X-ray film. A strip of Rad-tape was placed at the upper left hand side corner for orientation. The MTE array was exposed to an MS X-ray film at $-70^{\circ} \mathrm{C}$ with an intensifying screen. Several exposures for varying lengths of time were carried out. 


\section{5) Stripping the probe from the membrane:}

$250 \mathrm{ml}$ of $0.5 \%$ SUS solution was heated to boiling.

The array was removed from the plastic wrap and placed immediately in the boiling solution.

Boiling was continued for 10 minutes.

The array was removed from the boiling solution and measured for radioactivity with a Geiger counter. The counts were 3-5 cpm which was accepted.

The membrane was then stored in a plastic wrap at $-20^{\circ} \mathrm{C}$ until further use.

\subsubsection{2. hybridisation with the control probe:}

Human Ubiquitin control cDNA (provided with the MTE array) was used to label a probe as described above. Hybridisation, exposure, stripping and storage of the array were as described before in step 4.2.2, method (A).

\subsubsection{Northern hybridisation:}

As mentioned earlier, the MTE array does not indicate the size of the target. For this reason northern hybridisation was needed. The same steps carried out as before in chapter 3 were followed to prepare the northern blot. The gel was loaded with $3.5 \mu \mathrm{g}$ of mRNA extracted from HepG2 cells as well as the RNA ladder. The blot was probed with ${ }^{32} \mathrm{P}$ dCTP labelled probe prepared from the PCR template used in the MTE array.

\subsubsection{RPA:}

As a method of measuring mRNA, ribonuclease protection assay was performed as in chapter 3 of the study. Messenger RNA was extracted from the following samples: HepG2cells, HCV-HCC 1, HCV-HCC 2, alcoholic HCC, colon carcinoma and prostatic cancer with two kits; RNAgents total RNA Isolation system, Promega, followed by 
messenger RNA Isolation kit, STRATAGENE, according to the manufacturers ínstructions.

The DNA template was the same PCR product used in the MTE array experiment. The sequence of $\mathrm{T} 7$ promotor was introduced via a PCR reaction.

${ }^{32} \mathrm{P}$ dUTP labelled RNA probe was synthesised using T7 RNA polymerase. The house keeping gene used was $\beta$-actin with a protected fragment of 245 bases long. 


\subsection{Results:}

\subsubsection{Computer analysis:}

\subsubsection{BLAST:}

The BLAST program revealed some homologous ESTs in the nucleotide sequence databases. These ESTs were isolated from different malignant human cell lines such as parathyroid tumour and carcinoid tumour, as well as a larger sized EST THC392255. BLAST analysis also revealed that cDNA 397 sequence is homologous to one of the known contigs of chromosome 17.

\subsubsection{NIX:}

The NIX tool was used to analyse the genomic DNA sequence of chromosome 17 contig found homologous to clone 397 sequence.

Analysis revealed 5 predicted exons within the same contig. These exons showed similarity with "Ubiquitin Conjugating Enzyme" (UBC).The results were displayed as shown in Figure 4.2. 


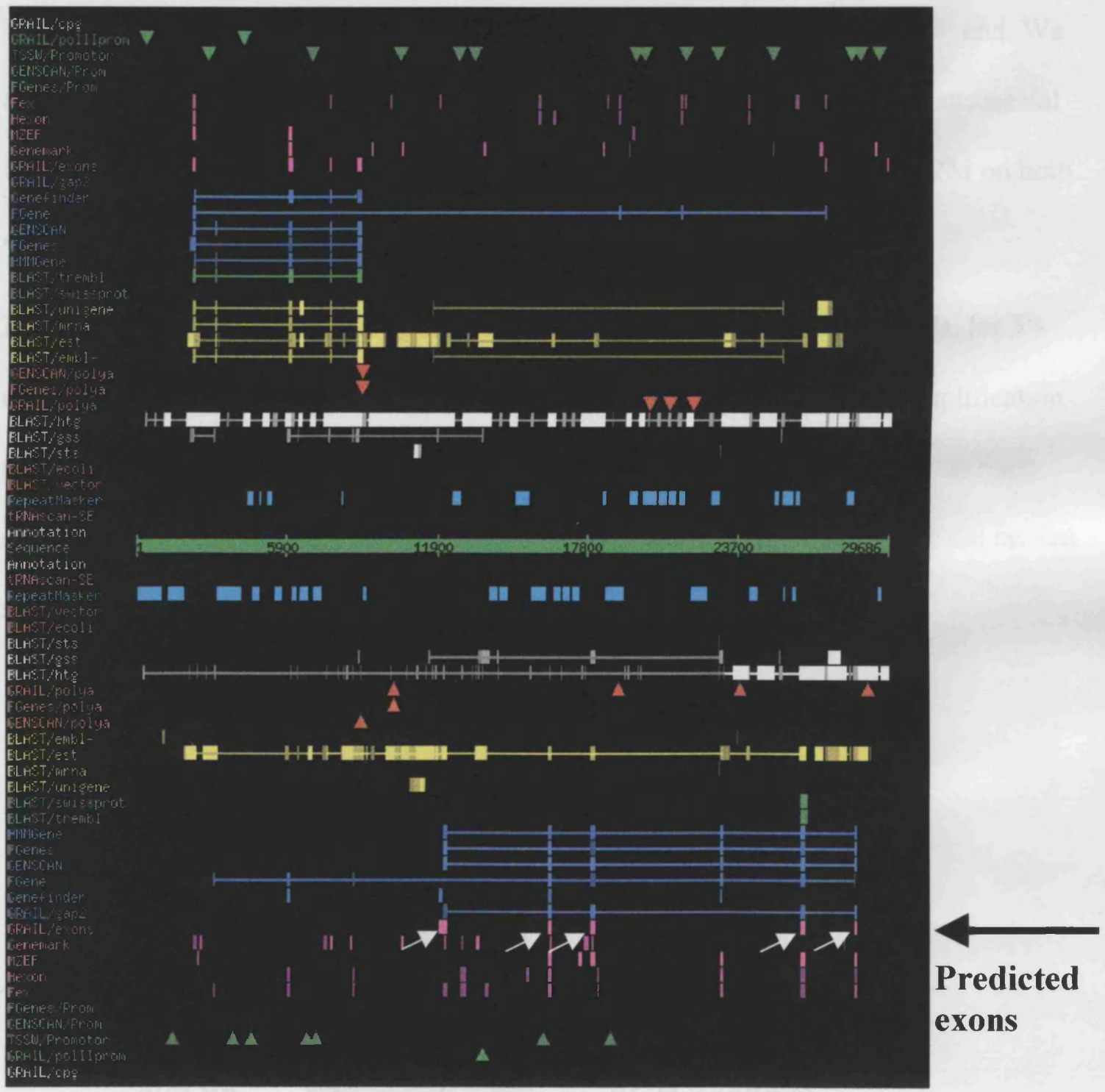

Figure 4.2 Display of NIX results.

NIX is a WWW tool to view the results of running many DNA analysis programs on a certain DNA sequence.

The sequence line is the central green line with "sequence' printed next to it. Everything above this line is a feature found on the forward sense and below it is a feature found on the reverse sense. The predicted exons lie opposite the white arrows. 


\subsubsection{PCR amplification}

\subsubsection{SMART RACE CDNA amplification kit, CLONTECH:}

To characterise the full sized gene of clone 397 we aimed at amplifying the 5' end. We applied the SMART RACE technology, however, methods A and B were unsuccessful as sequencing results showed that all the amplification products had the NUPM on both ends. It seemed that the gene specific primers were weaker than the NUPM.

Modification of method B was again unsuccessful, with NUPM on both ends, for 5'end amplification. Nevertheless, under the same amplification conditions amplification of the shorter known sequence EST AA845421 generated a PCR product of the right size, about 450 bp (Figure 4.3). Sequencing showed that it was identical with the known sequence.

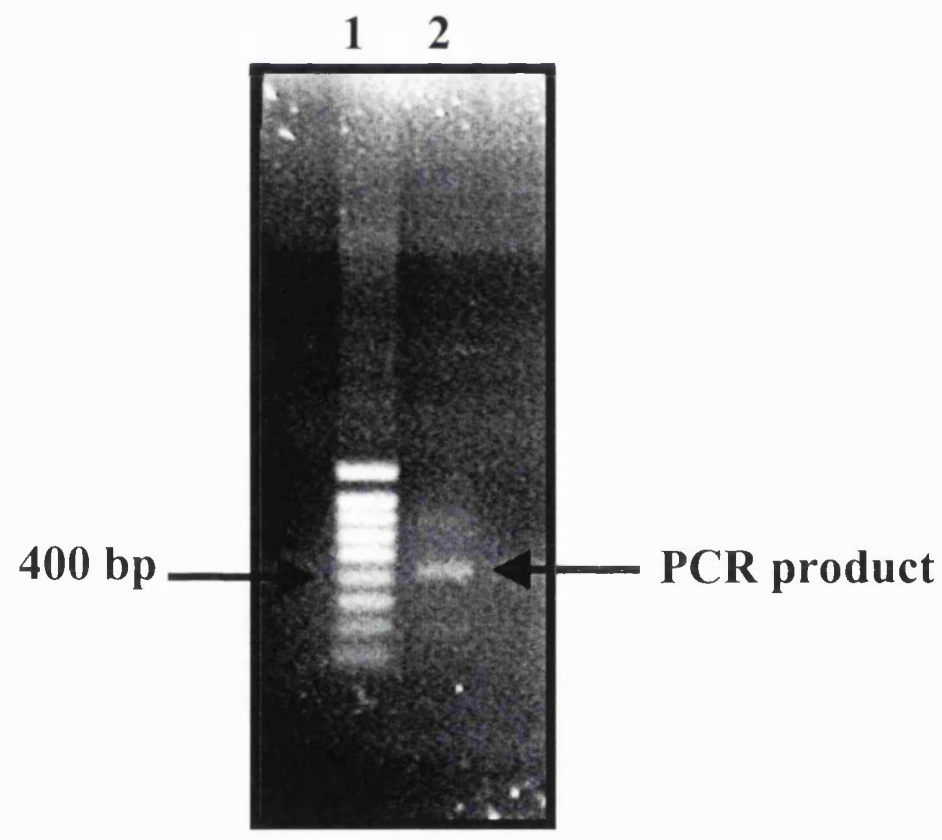

Figure 4.3 Amplification of EST AA845421.

Lane 1: $1 \mathrm{~kb}$ DNA ladder, Lane 2: Amplified cDNA. 


\subsubsection{Amplification of tailed cDNA:}

Tailing the cDNA with multiple GGG was carried out to create a binding site for the primer C-prim in PCR. However, amplification was unsuccessful and resulted in a smear on the gel.

\subsubsection{5'RACE system for rapid amplification of cDNA Ends, version 2.0, Life}

\section{Technologies:}

This kit involves the degradation of RNAs with RNase mix. This step might be important as the presence of RNA:cDNA hybrids might inhibit subsequent cDNA tailing. However, amplification of 5' end was negative with no amplification products on the gel. Again, amplification of the known shorter sequence of EST AA845421 with the specific primers using the 5' RACE system generated the right sized PCR product, $450 \mathrm{bp}$, as in figure 4.4 .

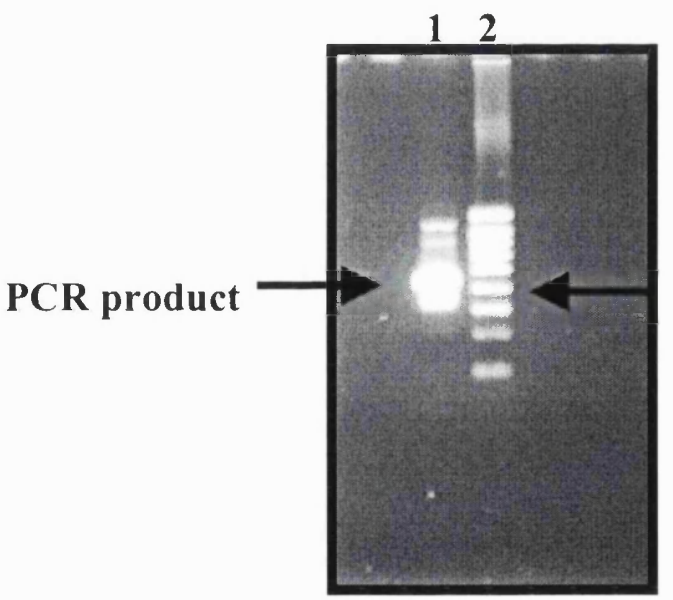

$400 \mathrm{bp}$

Figure 4.4 Amplification of EST AA845421 with specific primers.

Lane 1: amplified cDNA, Lane 2: 1 kb DNA ladder. 


\subsubsection{Inverse PCR}

In an attempt to amplify the unknown sequences adjacent with the known one, double stranded cDNA was synthesised and digested with two restriction enzymes. The two enzymes BsmI and NspI were found not to cut in the known sequences and were expected to cut at $2-3 \mathrm{~kb}$ intervals. However this experiment was unsuccessful and there was no amplification products on the gel.

\subsubsection{Degenerate primer mix:}

We performed this experiment after searching the nucleotide sequence databases suggested similarity of our sequence with UBC enzyme. The conserved region of all $\mathrm{UBC}$ enzymes in various species were searched and degenerate primer mixes were tried at the 3' end together with the UAP primer used before in step 4.2.2.3. However the amplification products showed the kit UAP on both ends.

\subsubsection{Amplification of the 5 predicted exons:}

In order to prove that the predicted exons identified by the NIX programme were part of our target, amplification was tried using specific primers selected from these exon sequences. This amplification attempt was positive and resulted in products of amplification that coincided with the expected exons sizes. Exon-1was $171 \mathrm{bp}$, Exon-2 was 91 bp, Exon-3 was 113 bp, Exon-4 was 188 bp and Exon-5 was 73 bp (Figure 4.5).

\subsubsection{Amplification of full length cDNA:}

Towards the goal of characterising the full length gene and sequence all the 3' untranslated region, amplification was tried using GSP 397 and NGSP as up-stream primers together with exon-5 outer and nested primers as down-stream primers in a nested PCR reaction. Amplification resulted in a PCR product of about $2.5 \mathrm{~Kb}$ (Figure 4.6). 
$\begin{array}{lllllll}0 & 1 & 2 & 3 & 4 & 5 & 6\end{array}$

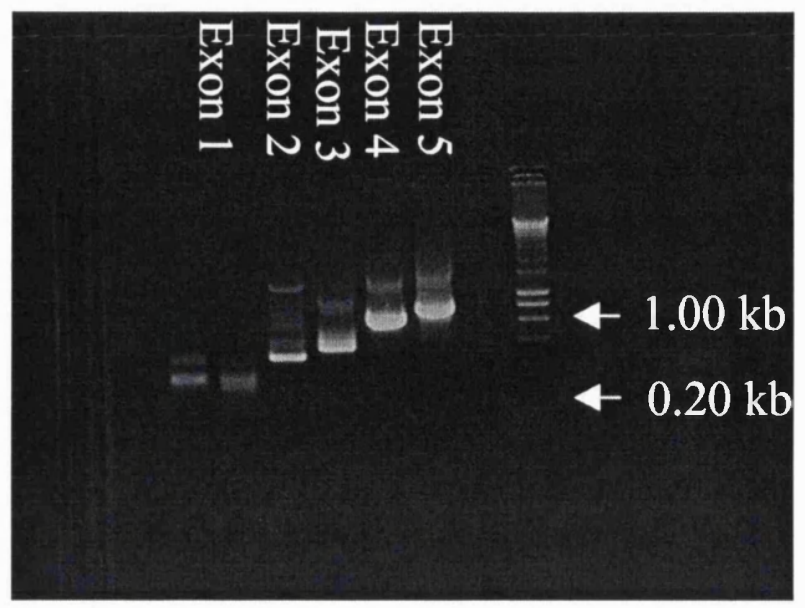

Figure 4.5 Amplification of the predicted exons.

Lanes 0 and 1: exon 1, Lanes 2 to 5: corresponding exons, Lane 6: $10 \mathrm{~kb}$ DNA ladder.

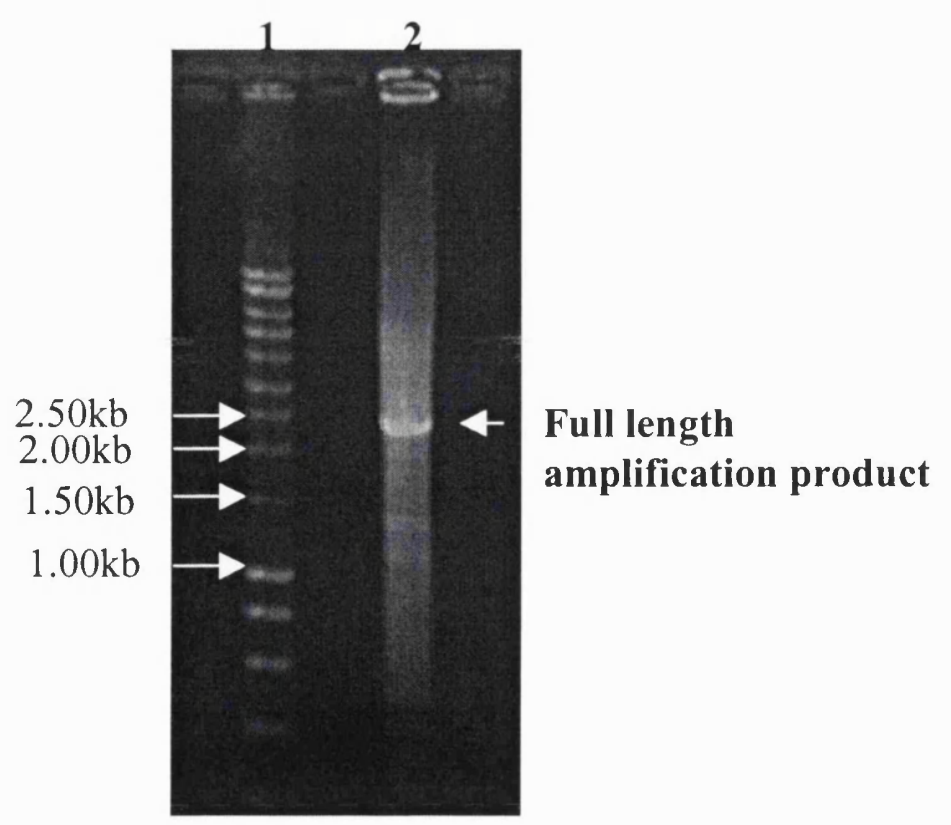

Figure 4.6 Amplification of the full length clone from Exon 5 to the poly A tail. Lane 1: $10 \mathrm{~kb}$ DNA ladder, Lane 2: PCR product. 


\subsubsection{Sequencing of the full length clone:}

To determine the sequence of our full length clone, sequencing was performed using sequence specific primers in the sequencing reaction and designing new sequencing primers at 200 to 250 nucleotide intervals, as illustrated in figure 4.7. Sequencing showed the predicted exons as well as the mRNA sequence as shown in figure 4.8. An open reading frame was found that spans nt 165 to 728 and extends for 187 aa.

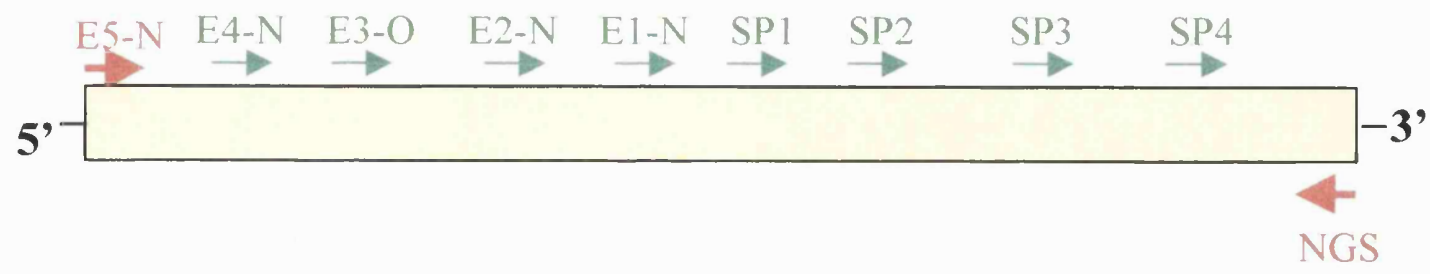

Figure 4.7 Sequencing the full length clone.

The red arrows represent the nested PCR primers. The green arrows and E5-N represent the sequencing primers. 


\begin{abstract}
EXON5-O EXON5-N
1 AGGAGCCTCC TCCAGGAATG TTCGTTGTAC CTGATACTGT CGACATGACT AAGATTCATG

61 CATTGATCAC AGGCCCATTT GACACTCCTT ATGAAGGGGG TTTCTTCCTG TTCGTGTTTC

EXON4-N

121 GGTGTCCGCC CGACTATCCC ATCCACCCAC CTCGGGTCAA ACTGATGACA ACGGGCAATA

181 ACACAGTGAG GTTTAACCCC AACTTCTACC GCAATGGGAA AGTCTGCTTG AGTATTCTAG

241 GTACATGGAC TGGACCTGCC TGGAGCCCAG CCCAGAGCAT CTCCTCAGTG CTCATCTCTA

301 TCCAGTCCCT GATGACTGAG AACCCCTATC ACAATGAGCC CGGCTTTGAA CAGGAGAGAC

361 ATCCAGGAGA CAGCAAAAAC TATAATGAAT GTATCCGGCA CGAGACCATC AGAGTTGCAG

421 TCTGTGACAT GATGGAAGGA AAGTGTCCCT GTCCTGAACC CCTACGAGGG GTGATGGAGA

481 AGTCCTTTCT GGAGTATTAC GACTTCTATG AGGTGGCCTG CAAAGATCGC CTGCACCTTC

541 AAGGCCAAAC TATGCAGGAC CCTTTTGGAG AGAAGCGGG CCACTTTGAC TACCAGTCCC

601 TCTTGATGCG CCTGGGACTG ATACGTCAGA AAGTGCTGGA GAGGCTCCAT AATGAGAATG

661 CAGAAATGGA CTCTGATAGC AGTCCATCTG GGACAGAGAC AGACCTTCAT GGGAGCCTGA

721 GGGTTTAGAC CCTGCTCCCA TCTCCCCTTC CCCCACTCAA GAGTCCCAGC AGAATCCCTT

781 CCCCCCACCC CAGGGATGGA GAGGCACTGT GTATCTCCCT CCAGACTCGA AGTCATCCTG

841 CAAGATGGCA AGAACCAAGC AAGCTCCGAT CCCAGGGTGT GGGAGTGGGG GCCTGTTCCC
\end{abstract} 901 GGTCTGACCT CCTTGGCACT GGAGCATCTG GGGCTTCGTT CATCCATTCA TCCCGTATCA 961 GgGgCCAAGg tacCTTTACA GgAGCACCTA GAgCGAGgGC CTTTGGCAAA AACAAAACAA 1021 CCAACACACC TCTCCACAGG GCCAGCTCCT TAGGGATAAG TGGAAGATGG AAATTGCAAT 1081 TCCAAGAGGg AGTGTGCCCA AATGATTTAT GGGGATACCT GGAAGGGAGC TTGGGGTGGG 1141 GGCTGTCTGT GACACTTAAG CAGTCTGGGT GGTTGTCTAT TTGTCTGTCT TCAGTCTTGA 1201 AGCAGGGCTT CCCAATGCCC TTTTCCTCCC TGCCTTCCTT CCCCCATTAT TTCCCACAGG 1261 CCAGCATAAT TTTGTTTTTC CTAATTTATA GTCACTGTTC TAGACAGACC AAAGAGAAgG 1321 AACAgTGGTG GAGTCTAGGC TGCTGATCAg tAAgCTTTAC CTAGCACCTG AGCACCTTTC 1381 TCCCCTCCCC TCTTTCCTCA CCCTTTTCTA GATGTAAGAC AGAAAGTAAA TGTGACTGGG 1441 ACTTAACCAA GGTCTTGGTA AAGCCTGCAT GGTACCGTAA GAAGCTGAAA ATACTGTTTG 1501 TTCCCGCAAT CATTGATTTG AAAAGTTCCC AACACAGGCA GCTGCTGTGT ATATGGGATT 1561 AgAGCCACTA CATAGAATAG TCTCTTACAg ATtTTCATAA ATACTAGTCA CAATAAGGGT 1621 ATTTTTCTTG GGGGTGGAGT AAGGGGGAGA CTGATGCTAG TCCTTGTTGT ATTTTGTTGG 1681 GCTGTCCTTG TGTATTTTCA CCCCAGCCTG TAGTCCTCCT CACTTCAACC CCAGGGATTT 1741 GTGGGGAGCA AGGGTAGCCA ATGGCAGAGg GGGTTGGGGC TGGGACTCTG GAGGCCCCTC 1801 CCCTTCTTTC TCCTCCTTCC GCCTCCCCCG TGCCCCCAGC TGCTCTTGTC ACTGTCTCTG 1861 ATGGGTGTTT GCCTGGCTTT GTTGCTTCTC TATCTGTATT TAGCTGCAGT GATCCTTTAG 1921 CTGGTTGGCT CAGAAAAAA AAAATGTGCT TTAGGTGTCC TGTAATCCTG GGCATCAAGg 1981 GAATCCATCC TTCCCCTTTT TGATATGTTC TCCCCGTACT TCCAGATTTA TTGTTATGGC 2041 TCCCAGTGGg TATTGGCGAT TCTTGTGATG CAGGGCCTCA GTCAGTGTCC AGCCATGCAT 2101 AAgGGAGAgg ATAGTGTGTA CCTGCCCTGC CCTCTGCTAT GAAGGTCTCT GCCTTGTGGA 2161 TCATGGGACT CCCCTTGGAG GATCTGTGCA AAGGGGGGT GGGCACAAAG GAGAATGTCC 2221 TATTTGGGAg GGCAGGAAGC AAAGGAACTG GACAGGGATT GGTGGGCTTG GGGAACGGAA 


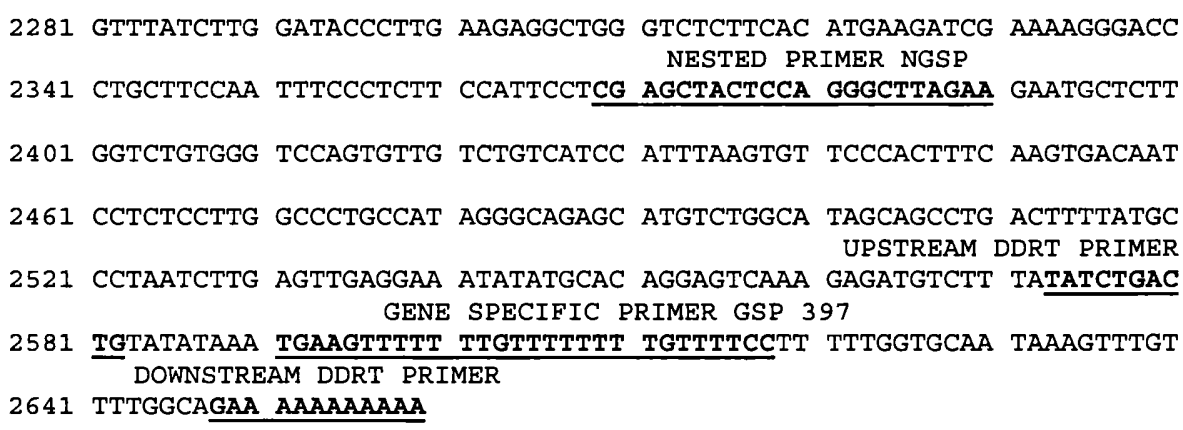

\section{Figure 4.8}

Sequence of the full-length clone 5' to 3', amplified by a nested PCR using primers with the sequences underlined at either end of the sequence (GSP 397, NGSP and Exon5-O, Exon5-N). Clone 397 is between the upstream and downstream DDRT primers. EST THC392255 spans nt 770 to the poly-(A) tail and EST AA 845421 spans nt 2078 to the poly-(A) tail. The predicted coding sequences are: exon 1 from nt 1 to nt 73, exon 2 (74260), exon 3 (373-485), exon 4 (486-576) and exon 5 (577- 747). The sequence between nt 261 and 372 was not predicted as an exon by analysis using the NIX programme. The sequencing primers are underlined and shown in italics. The homologous entries in the nucleotide sequence databases include approximately $300 \mathrm{nt}$ of additional 5', untranslated sequences. 


\subsubsection{MTE:}

To investigate the expression levels of this gene in various tissues and study its expression pattern, the MTE array, CLONTECH, was probed with a $450 \mathrm{bp}$ DNA probe starting from the 397 sequence (figure 4.9). One of the house keeping genes used for normalisation of the membrane, human ubiquitin cDNA probe, was used as a control probe (figure 4.10).

Each dot represented the expression level of this gene in this particular tissue. These dots were analysed with a densitometry and the ratios of optical densities of the 397 probe to the house keeping gene probe was determined.

We classified the various tissue types on the membrane into different systems and obtained the mean ratio of each system. Mann-Whitney U test was performed to test for the difference between malignant cell lines group and the other tissues group. The test showed statistically significant difference between the two groups $(p=<0.02)$ with an expression level higher in the malignant cell lines group.

The mean ratios were then blotted on a histogram to show that cDNA 397 was expressed at higher levels in the human malignant cell lines group as compared to the normal adult and foetal tissues (Figure 4.11).

\subsubsection{Northern blot analysis:}

In order to determine the size of this gene, northern blot analysis was carried out using mRNA from HCV-HCC 1 and HepG2 cells. Messenger RNA was extracted using mRNA isolation system, Invitrogen. The gel included $3.5 \mu \mathrm{g}$ mRNA as well as the RNA ladder. The results showed that this gene is about 2.5 to $3 \mathrm{~kb}$ in size. (Figure 4.12). 


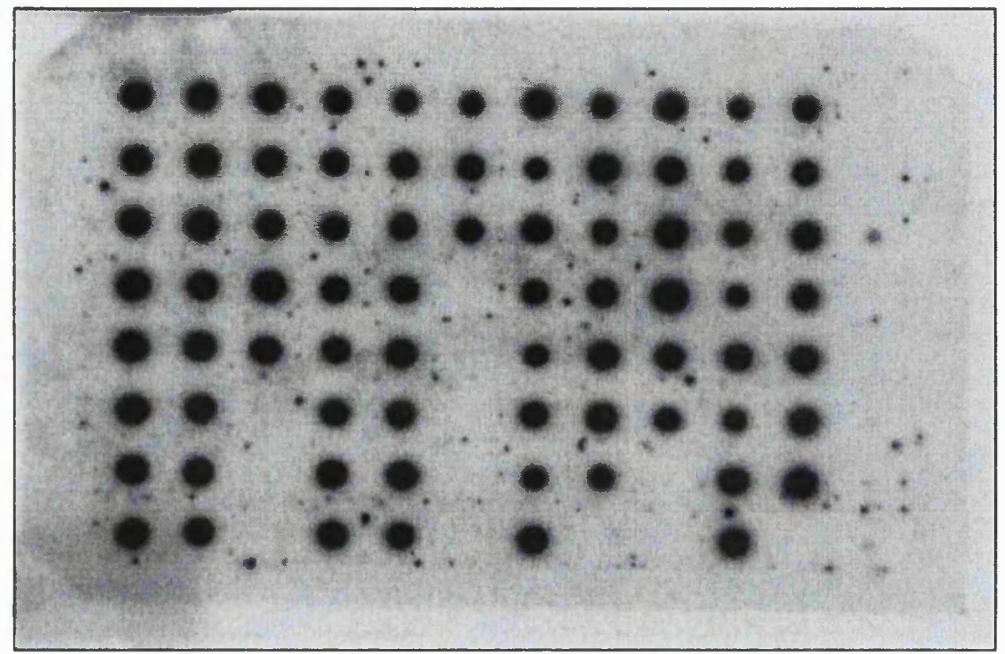

Figure 4.9 cDNA 397 probe.

Probing the MTE array with clone 397 probe.

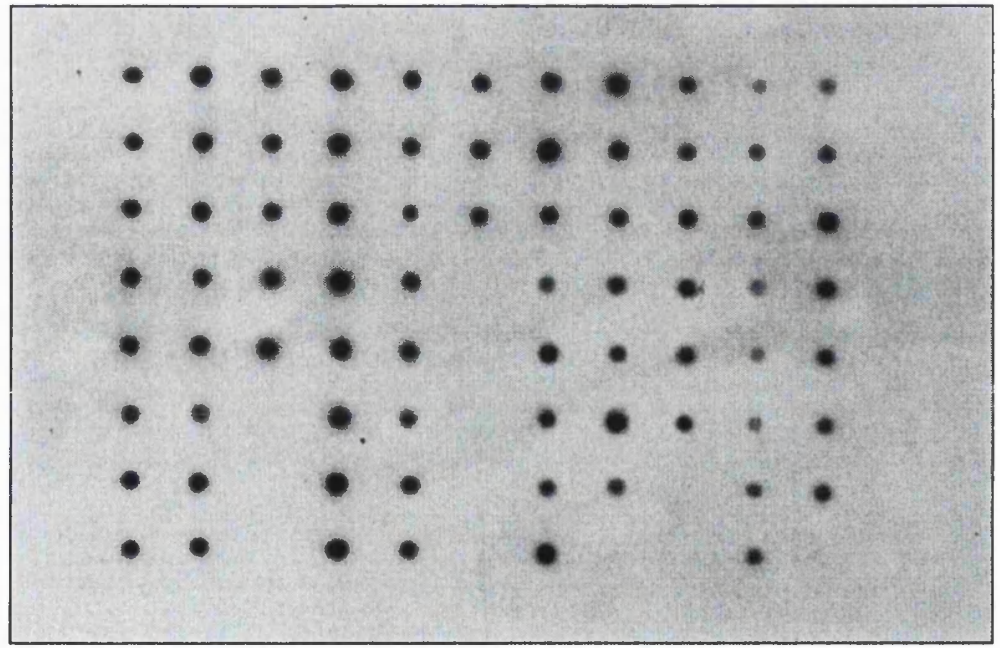

Figure 4 .10 Human ubiquitin cDNA probe.

Probing the MTE array with the house keeping gene probe. 


\section{Levels of CDNA 397 expression in various tissues}

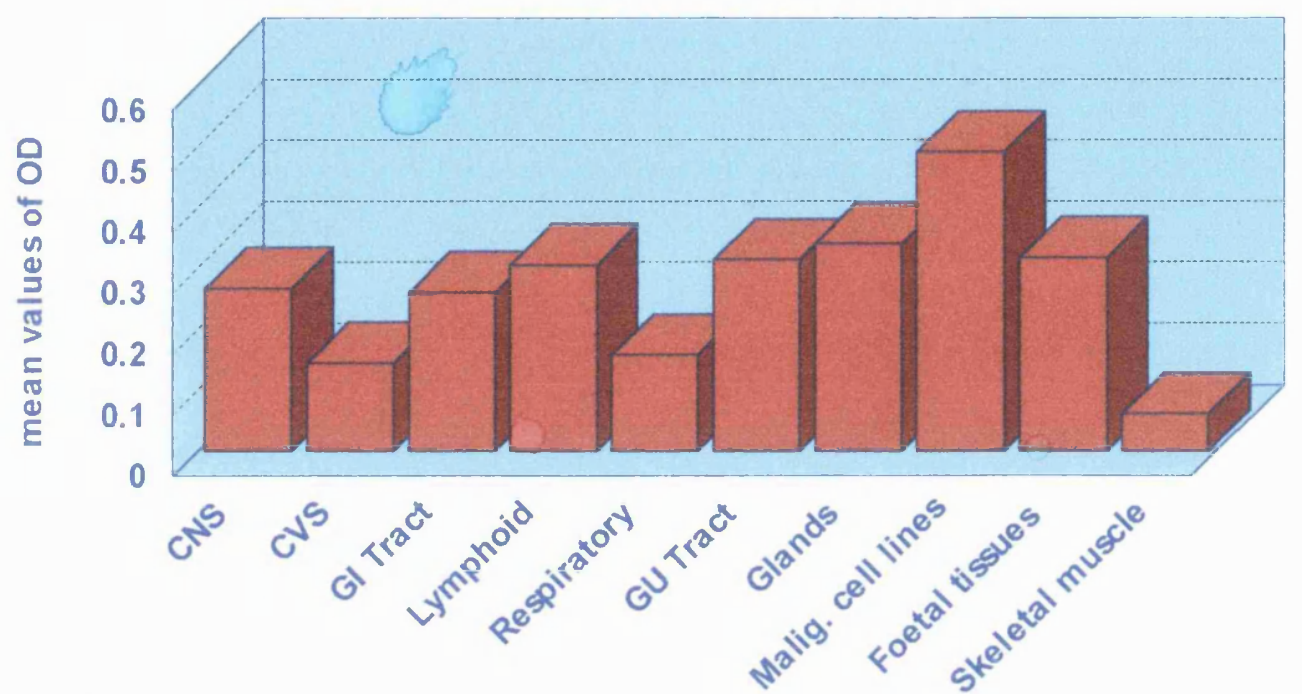

Figure 4.11

The mean ratios of cDNA 397 expression levels to the house keeping gene probe in various tissues.

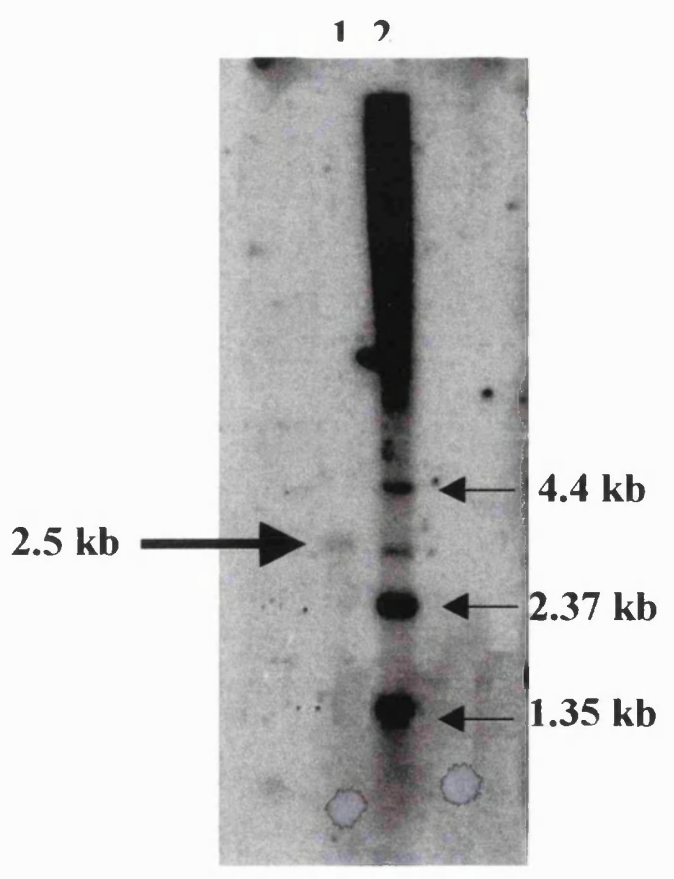

Figure 4.12 Northern blot.

Northern blot analysis of cDNA 397. mRNA was loaded on each lane of a $1 \%$ agarose gel, electrophoresed, blotted onto a nylon membrane and hybridised with the specific probe 397 . Lane 1 is HepG2 cells mRNA and Lane 2 is RNA ladder. Left arrow represents the size of full-length gene of clone $397(2.5 \mathrm{~kb})$ 


\subsubsection{Gene expression analysis in various tumours:}

In order to investigate our hypothesis and find out whether this gene is specific to HCV associated HCC, we needed to carry out an experiment to compare these tumours to other tumours both hepatic as well as non hepatic. RPA was carried out including HepG2 cells, $2 \mathrm{HCV}-\mathrm{HCC}$, non viral (alcoholic) HCC, prostatic tumour as well as colonic tumour. Results of RPA analysis showed that the candidate gene 397 was expressed at higher levels in HCV-HCC2 than in HepG2 cells and the other tumours included in the assay. HCV-HCC1 mRNA was degraded as no high molecular weight products were detected on the gel (Figure 4.13). Analysis was done by comparing the ratios of optical densities of the 397 probe to the house keeping gene probe (Table 4.7).

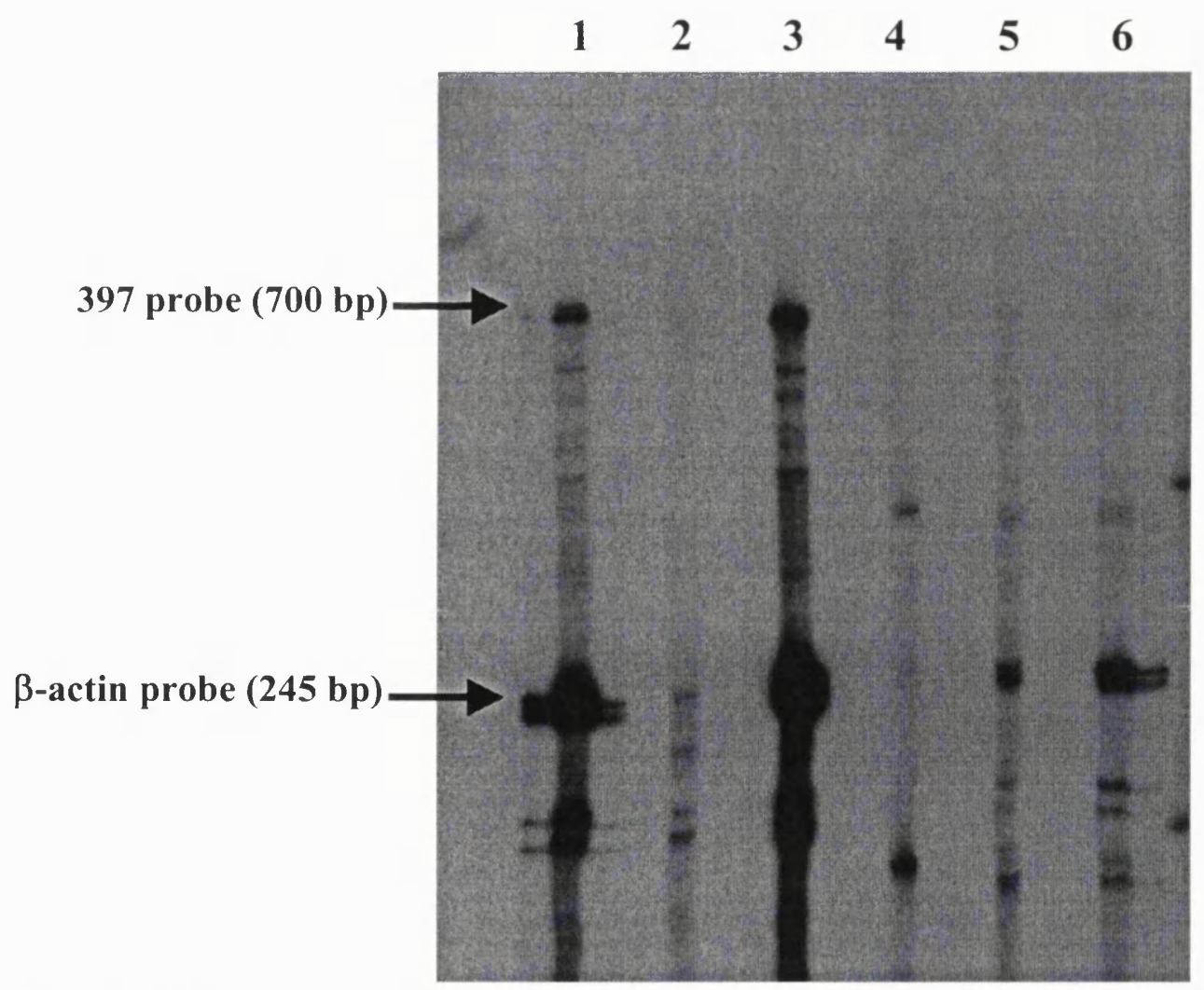

\section{Figure 4.13}

Analysis of clone 397 mRNA expression in various tumours using RPA. Overnight hybridisation was allowed between mRNA from the test samples and the ${ }^{32} \mathrm{P}$-dUTP labelled RNA probe 397. The protected fragments were run on $1 \mathrm{~mm}$ thick $5 \%$ polyacrylamide gel. Lane 1, HepG2 cells; Lane 2 and 3, HCV-associated HCCs; Lane 4, alcoholic HCC; Lane 5, colon carcinoma and Lane 6, prostate carcinoma. 


\begin{tabular}{l|ccccc}
\hline & HepG2 & HCV T2 & Alc HCC & Prostate T & Colon T \\
\hline$\beta$-actin & 127.1 & 94.0 & 11.9 & 12.8 & 43.0 \\
cDNA 397 & 16.1 & 29.1 & 1.3 & 1.6 & 2.1 \\
Ratio & 0.12 & $\mathbf{0 . 3}$ & 0.1 & 0.12 & 0.04 \\
\hline
\end{tabular}

\section{Table 4.7}

The ratio of optical densities of the cDNA 397 probe to the control $\beta$-actin probe in various tumours. 


\subsection{Discussion:}

In this part of the study, the aim was to investigate and characterise the full sized cDNA of clone 397 and try to understand its role in HCV-associated HCC. As mentioned before in chapter 3, sequence 397 was homologous with GS 2073 identified in the database "Human body map project" with no further information. In March, 2000, new homologous ESTs emerged in the nucleotide sequence databases like EST AA 845421 identified by BLAST HGMP UK website and THC 392255 from TIGR Human gene index. These sequences helped to design better nested primers and perform more efficient amplification. The sequence of AA 845421 was amplified successfully from the test samples.

Unfortunately, despite the different PCR protocols using ELONGASE enzyme mix which is designed for amplification of long templates and a "hot start" PCR technique to minimise non-specific annealing and extension of primers, all 5'- end amplification experiments were unsuccessful. However, efficient 5'-end amplification is dependent on complete cDNA synthesis. Therefore, if the RNA used is partially degraded it might result in all these experiments failing.

With more advances in the nucleotide sequence databases, more searching revealed homology with genomic sequence on chromosome 17. Unfortunately, up to the end of this study, chromosome 17 sequencing was unfinished and only 17 unordered pieces, separated by gaps of unknown length, were known. At this point, the NIX program was used to search for splicing sites on the contig of chromosome 17 that contained the homologous sequence to clone 397 . NIX analysis revealed 5 predicted exons within the same contig encoding a protein similar to ubiquitin conjugating enzyme (UBC). 
Specific primers were designed from these predicted sequences and successful amplification was carried out. The whole sequence was then amplified and sequenced.

Sequencing identified the unknown sequence between the last exon and the poly A tail. MTE array hybridisation showed that this gene was expressed at higher levels in the malignant cell lines included on the membrane than in the other normal human tissues. This came in agreement with our results earlier. However, as the RNA is not sizefractionated on the membrane the MTE array does not reveal mRNA transcript size. For this reason, northern hybridisation was required. Northern blot analysis showed a band of about $2.6 \mathrm{~kb}$ in size, which coincided with the size of the full length PCR product. Finally, the expression level of this gene was studied in HCV-associated HCC versus other hepatic, non-viral, as well as non-hepatic, tumours. RPA analysis showed that expression levels of this transcript were significantly higher in $\mathrm{HCV}$-associated $\mathrm{HCC}$ than in the other tumours studied. In this experiment, in order to avoid the problems of using a short probe and as a result of having a limited tumour material, a larger probe was used to ensure having better hybridisation results. Due to this reason, the house keeping gene G3PGH was avoided, having approximately the same test probe size, and $\beta$-actin was used instead. The ratios of the test probe, $\operatorname{cDNA} 397$, to the $\beta$-actin probe showed that the ratio was two to three folds higher in the tested HCV tumour, 0.3 , as compared to the ratios in the control tumours, 0.04-0.12, suggesting its role in HCVrelated oncogenesis.

Our results revealed that there seems to be a gene on chromosome 17 of about $2.6 \mathrm{~kb}$ in size encoding a protein, of about 187 aa length, with similarity to UBC enzyme, and that this gene is expressed at significantly higher levels in $\mathrm{HCV}-\mathrm{HCC}$ as compared to other normal, cirrhotic liver tissues as well as other tumours. 
Ubiquitin is a small, 76 residue protein found in eukaryotic cells. It functions in the cell in conjunction with a large intracellular protease, the $26 \mathrm{~S}$ proteasome. The ubiquitinproteasome system consists of the attachment of ubiquitin to proteins followed by proteolytic processing by the proteasome (Ciechanover, 1994). One of the ubiquitin targets is the tumour suppressor $\mathrm{p} 53$ protein whose accumulation has an important proapoptotic role (Lowe et al., 1993). There is evidence indicating that alterations in the ubiquitin system are related to tumour progression through escape from immune control, drug resistance, and alterations in cell cycle control (Oikawa et al., 1998).

Our data suggest that ubiquitin conjugating enzyme is expressed at high levels in HCV associated HCC and might be involved in this process of tumour formation. However, discovery of the correlation between HCV and the up-regulation of the ubiquitin conjugating enzyme needs further investigation. 


\section{Chapter 5}

\section{General Discussion}


$\mathrm{HCV}$ is the major known pathogen associated with parenterally transmitted non- $\mathrm{A}$, non$\mathrm{B}$ hepatitis and as many as $85 \%$ of cases become chronic. The virus may continue to replicate for decades, causing progressive liver disease which leads to cirrhosis or HCC in as many as $20 \%$ of infected cases (McLauchlan, 2000). The molecular events underlying $\mathrm{HCV}$-associated hepatocarcinogenesis are not yet fully understood, as there is no means of efficient propagation of the virus in vitro using tissue culture systems and the only available well characterised animal model is the chimpanzee. These obstacles have hampered progress in understanding HCV and the mechanisms of its associated tumour formation.

Recently, there has been a focus on the properties of the HCV core protein. Several studies on the core protein suggest that it is pleiotropic and can modulate several cellular processes including cellular transformation and apoptosis (McLauchlan, 2000). Several observations relate the HCV core to cellular transformation such as transformation of NIH 3T3 (Ray et al., 1996a) and Rat-1 cells (Chang et al., 1998). Other studies have suggested the co-operation of $\mathrm{HCV}$ core with $\mathrm{H}$-ras to transform BALB/3T3 A31-I-1 cells (Tsuchihara et al., 1999) and primary rat embryo fibroblasts (Ray et al., 1996a).

Effects of $\mathrm{HCV}$ core protein on apoptosis could include inducing apoptosis through modulation of anti-fas (Ruggieri et al., 1997), cisplatin plus c-myc (Ray et al., 1996b) and TNF- $\alpha$ (Ray et al., 1998) or inhibiting apoptosis through the inhibition of $\mathrm{p} 53$. In 1997, Ray et al. investigated the role of the HCV core gene product on the transcription of the human p53 gene. Their results suggested that the core protein inhibits p53 promoter activity in a dose-dependent manner and that the domain responsible for repression is located between amino acid positions 80 and 122. This inhibition of $\mathrm{p} 53$ 
by the HCV core protein may serve as a factor in the multi-step process of liver tumour formation (Ray et al., 1997).

$\mathrm{HCV}$ core protein has also been found to regulate the transcription of several viral and cellular genes with no evidence that it interacts directly with RNA polymerase II promoters (You et al., 1999).

More recent studies have suggested that the HCV core protein may be involved in hepatocarcinogenesis by disturbing the regulation of cellular proliferation. It has been found that cell cycle progression is activated by the sequential activation of cyclindependent kinases (Cdks), which are regulated by positive regulators called the cyclins as well as negative effectors as Cdk inhibitory protein and CKIs (Sherr, 1993). During the G1/S transition phase, cyclin $\mathrm{E}$ associates with Cdks and activates serine-threonine kinase shortly before entry into S phase. Thus, cyclin $\mathrm{E}$ has been suggested to have an important role in cell cycle progression (Koff et al., 1992). Cho et al. (2001) discovered that in $\mathrm{HCV}$ core stable transfectants, the HCV core has been found to promote cellular proliferation through the overexpression of cyclin $\mathrm{E}$ its increased kinase activities promoting the development of HCC.

Furthermore, Jin et al. (2000) identified a new human transcription factor designated LZIP that act as a core protein-binding and core protein-transforming cofactor. The expression of $\mathrm{HCV}$ core protein has been found to result in loss of LZIP function leading to growth of NIH 3T3 cells. This observation suggested that LZIP might be a new tumour suppression pathway that is relevant to HCV-related HCC.

It has also been thought that the core protein must have an effect on gene expression indirectly through protein-protein interactions (Jin et al., 2000). However, the mechanism by which HCV core exerts its functions has not been fully explored. 
Ultimately, the core protein may only target a limited number of cellular functions but this might have a wider effect on other cellular processes (McLauchlan, 2000).

Nevertheless, many of the available descriptive findings for HCV core protein have not been explained at a mechanistic level. For better understanding of the molecular mechanism of $\mathrm{HCV}$-associated hepatocarcinogenesis, differential gene expression in HCV-related tumours had to be studied.

In this study, DDRT-PCR has been chosen as a method of studying differential gene expression. As mentioned before, because this method can generate many false positive results, RPA analysis was used to confirm the preliminary results. Analysis revealed that one of the DDRT-PCR bands, designated 397, was homologous with genomic sequence of one contig on chromosome 17. Our data indicate that there seems to be a gene on chromosome 17 that has been found up-regulated in HCV-related HCC tissues. This gene is about $2.5 \mathrm{~kb}$ in size, consisting of 5 exons and encoding a protein similar to ubiquitin conjugating enzyme. An open reading frame was found that spans nt 165 to 728 and extends for 187 amino acids.

Ubiquitin conjugating enzymes constitute a part of the ubiquitin/proteasome system involved in the regulation of cellular processes in eukaryotes through protein degradation (fig 5.1). The degradation of intracellular proteins involves a large proteolytic complex, the $26 \mathrm{~S}$ proteasome, and a multistep pathway involving ubiquitin. Ubiquitin acts as a cofactor to provide selectivity and precise regulation. Within mammalian cells, all synthesised proteins are degraded into amino acids, but different proteins have variable half lives ranging from minutes to days. This process thus, has to be selective and accurately regulated. Specificity in this pathway is achieved by a group of enzymes that covalently modify the target protein by conjugating them to the small polypeptide ubiquitin to target them to the $26 \mathrm{~S}$ proteasome. Inside the proteasome, 
proteolysis is isolated within an internal compartment, the $20 \mathrm{~S}$ proteasome, to which access is tightly regulated to ensure that non-specific degradation of essential cell components does not take place (Goldberg, 2000)

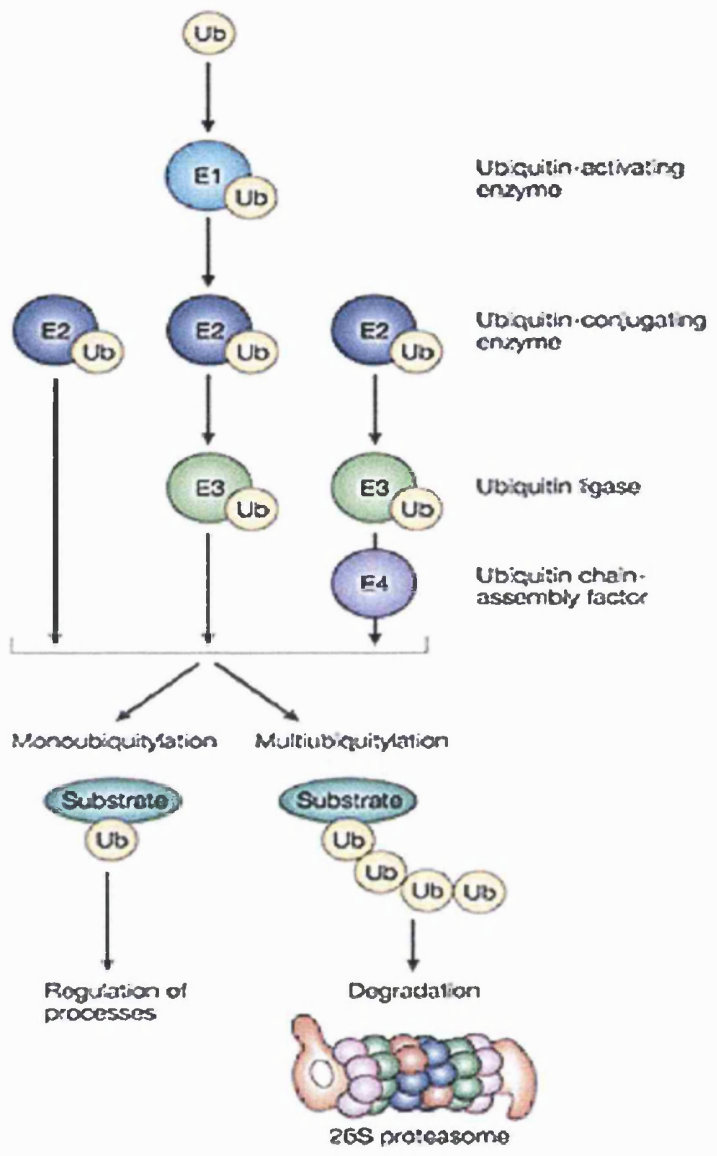

Figure 5.1 The ubiquitin pathway.

Free ubiquitin (Ub) is activated in an ATP-dependent manner by the activity of a ubiquitin-activating enzyme (E1), which hydrolyses ATP and forms a complex with ubiquitin. Subsequently, ubiquitin is transferred to one of many distinct ubiquitinconjugating enzymes (E2s). In some reactions, E2s can directly ubiquitylate substrates, whereas others require the help of ubiquitin ligases (E3s). Some E3s function catalytically, whereas other E3s support ubiquitylation by recruiting substrates to the ubiquitylating enzymes. Usually, several ubiquitin molecules are conjugated to a substrate, in the form of a multiubiquitin chain. This reaction sometimes requires a specific multiubiquitin chain-assembly factor (E4). Multiubiquitylation serves mainly, but not exclusively, to label the substrate for degradation. 
The first step in this process is ATP dependent activation of the carboxyl-terminal end of ubiquitin by the enzyme E1, ubiquitin activating enzyme. The resulting ubiquitin thiolester is then transferred to a ubiquitin carrier protein E2, ubiquitin conjugating enzyme, which transfers the ubiquitin to a lysine residue on the substrate with the help of E3, ubiquitin protein ligase. E3 then catalyses the attachment of a chain of ubiquitin molecules. Cells usually contain over a hundred different E3s which would ubiquitinate different protein groups in concert with a specific E2. In the yeast, Saccharomyces cervisiae, because the whole genome sequence is known, only one E1 has been identified, 11 E2s and an unknown large number of E3s (Kornitzer \& Ciechanover, 2000).

Known functions of these yeast E2s include DNA repair, cell cycle progression, sporulation and heat tolerance (Jentsch, 1992). Most of the identified E2s are small proteins with a conserved $16 \mathrm{kD}$ domain called the UBC domain (Jentsch et al., 1990). Some E2s consist only of this domain while others possess short COOH-terminal extensions. BRUCE (BIR repeat containing ubiquitin conjugating enzyme) is a ubiquitin conjugating enzyme from the mouse described by Hauser et al., (1998). BRUCE is a giant $528 \mathrm{kD}$ protein that also possesses a baculovirus inhibitor of apoptosis repeat (BIR) motif. The structural diversity of IAP- like proteins suggests that BRUCE may function through its ubiquitin conjugating activity inhibiting apoptosis.

The human homologue of BRUCE is called APOLLON gene. It has been found expressed in brain cancers and an ovarian cancer cell line (Chen et al., 1999). Furthermore, one of the recently cloned human ubiquitin conjugating enzymes (hUBC9) has been found to interact with a putative tumour suppressive gene, fragile histidine triad (FHIT) (Shi et al., 2000). Alterations in FHIT gene were found frequently in many 
cancer cell lines as well as in primary tumours, including those of lung, breast, thyroid, head and neck, stomach and oesophagus (Tanaka et al., 1998).

The level of ubiquitination of a substrate of the ubiquitin pathway seems to be the main determinant of its degradation by the proteasome. The process of ubiquitination provides the eukaryotic cells with the capacity to eliminate abnormal proteins as well as specific proteins under specific circumstances. In addition, the rate of proteolysis may vary in response to different physiological conditions and alter the rate of gene transcription and other cell processes (Schwartz \& Ciechanover, 1999). For example, the cell cyclins undergo a process of phosphorylation which triggers their ubiquitination and rapid destruction (Laney \& Hochstrasser, 1999), also the muscle wasting seen in cancers, AIDS, or nerve injury is mainly attributed to excessive proteasomal breakdown in muscle (Lecker et al., 1999). On the other hand, incorporation of a protein into a complex might mask the degradation signal and protect it. It has been found that the myogenic transcription factor $\mathrm{MyoD}$ can be ubiquitinated in vitro, while its binding to its specific DNA sequence protects it (Abu-Hattoum et al., 1998).

Inhibition of the proteasome system has profound therapeutic effects as proteasome inhibitors have anti-inflammatory and anti-cancer effects. However, more selective inhibition of this pathway could be achieved by blocking specific ubiquitin conjugating enzymes. As yet, no known inhibitors of E2s and E3s have been described (Goldberg, 2000).

In humans, aberrations in the ubiquitin system have been implicated in the pathogenesis of some malignancies. Tumour suppressor proteins as $\mathrm{p} 53$, protooncogenes such as cjun, c-fos, c-myc as well as cell cycle modulators, such as the cyclin dependent kinase, are targeted by this system. Indeed, accelerated degradation of $\mathrm{p} 53$ was induced by the human papillomavirus oncogene product E6 (Scheffner et al., 1993). The human 
papillomavirus was found to induce uterine cancers through triggering ubiquitination of the tumour suppressor protein $\mathrm{p} 53$. This interaction in the presence of the papilloma virus protein E6 accounts for the oncogenecity of the virus (Schwartz \& Ciechanover, 1999).

Increased level of ubiquitin conjugated proteins as well as increased expression of the ubiquitin genes were reported in various tumour cells (Nishibori et al., 1996). Moreover, inhibition of the proteasome was shown to induce apoptosis in neoplastic cells such as U937 myeloid leukemia cells (Imajoh-Ohmi et al., 1995), human leukemic (HL)-60 cells (Drexler, 1997) and B-CLL cells (Chandra et al., 1998). Masdehors et al. (2000) found that the level of ubiquitin conjugated proteins was higher in B-CLL compared with normal human lymphocytes and that alteration in the ubiquitinproteasome system in B-CLL was associated with modification of the proteolytic balance of $\mathrm{p} 53$. These data support our hypothesis of the involvement of this system in HCV related malignant transformation, as represented by clone 397 in this study. In addition to clone 397 , preliminary results of DDRT-PCR in this study revealed that two other clones, designated $383 \mathrm{~b}$ and $299 \mathrm{a}$, are up-regulated in $\mathrm{HCV}$-associated HCC tissues. The latest BLAST search in August, 2001 showed that these two sequences were homologous to retinoblastoma binding proteins.

The retinoblastoma gene is one of the tumour-supressor genes and loss of its function was found to be associated with uncontrolled cellular proliferation. Woitach et al. (1998) identified a protein homologous with other retinoblastoma-binding proteins. This protein was over expressed in primary human liver tumours. Furthermore, when this protein was over expressed in normal rat liver epithelial cells after being transplanted into nude mice, they formed hepatoblastoma-like tumours. These data suggest that the retinoblastoma-binding proteins may be important in the transforming process which 
come in agreement with our DDRT-PCR results. The differential expression of one of these two clones, 383, has been confirmed in two, out of three, of the tested HCV-HCCs in RPA. However, these sequences were not tested in other non-HCV liver tumours and their role in $\mathrm{HCV}$-induced oncogenesis cannot be suggested.

Two more DDRT-PCR sequences, 329 and 367, have been found to be homologous with "zinc finger" proteins. Although differential expression of these two clones has not been confirmed, as mentioned before, these preliminary results might be of importance. The zinc finger protein family is a large family of transcription factors. Members of this family, such as BCL-6, DPZF and $\mathrm{C} 2 \mathrm{H} 2$, have been found expressed in lymphoid neoplasms, especially in B-lymphoma, indicating that these transcription factors might be involved in haematopoiesis and oncogenesis (Zhang et al., 2001). Moreover, another zinc finger protein, human metallopanstimulin-1, have been studied in chronic hepatitis, cirrhosis and HCC. The level of expression was low in hepatocytes obtained from chronic hepatitis, while higher in the regenerating cirrhotic nodules and even higher in well differentiated HCC suggesting that this protein may be involved in progression towards malignancy and other steps in hepatocarcinogenesis (Ganger et al., 2001). In addition, some zinc chelators have been suggested to have a potential therapeutic role in controlling viral and proliferative diseases. This suggestion is based on the observation that zinc deficiency can induce apoptosis in virally transformed cells with no effect on the normal cells (Fernandez-Pol et al., 2001).

Bulimo et al. (2000) described an interaction between a retinoblastoma binding protein and a ubiquitin conjugating enzyme encoded by the African swine fever virus. Although UBC is present in the nucleus in most of the cells, it has been also found in the cytoplasm in some cells suggesting that UBC shuttles between the nucleus and the cytoplasm. 
The role of the ubiquitin-proteasome system has been described in the oncogenic effects of the human papilloma virus through the proteolysis of p53. Recent studies have showed that the oncoprotein E7 of the HPV caused proteolytic degradation of the tumour suppressor $\mathrm{Rb}$. This degradation has been found to be mediated through the ubiquitin-proteasome pathway as the levels of $\mathrm{Rb}$ increased with proteasome inhibitors (Wang et al., 2001).

Our data suggest that the ubiquitin-proteasome system might be involved in $\mathrm{HCV}$ induced hepatocarcinogenesis, possibly through inhibition of apoptosis. However, whether this effect is mediated via the inhibition of $\mathrm{Rb}$ gene, through the up-regulation of retinoblastoma binding proteins, as in HPV, remains unclear and needs further investigation. 
References

References 
1. Abu-Hattoum O., Gross-Mesilaty S., Breitschopf K., Hoffman A., Gonen H., Ciechanover A. and Bengal E. (1998) Degradation of myogenic transcription factor MyoD by the ubiquitin pathway in vivo and in vitro: regulation by apecific DNA binding. Mol.Cell Biol. 18, 5670-5677.

2. Adati N., Ito T., Koga C., Kito K., Sakaki Y. \& Shiokawa K. (1995) Differential display analysis of gene expression in developing embryos of Xenopus laevis. Biochim.Biophys.Acta 1262, 43-51.

3. Agarwal V.R., Takayama K., Van Wyk J.J., Sasano H., Simpson E.R. \& Bulun S.E. (1998) Molecular basis of severe gynecomastia associated with aromatase expression in a fibrolamellar hepatocellular carcinoma.

J.Clin.Endocrinol.Metab 83, 1797-1800.

4. Aguilar F., Hussain S.P. \& Cerutti P. (1993) Aflatoxin B1 induces the transversion of G-->T in codon 249 of the p53 tumor suppressor gene in human hepatocytes. Proc.Natl.Acad.Sci.U.S.A 90, 8586-8590.

5. Albano E., French S.W. \& Ingelman-Sundberg M. (1999) Hydroxyethyl radicals in ethanol hepatotoxicity. Front Biosci. 4, D533-D540

6. Albertini R.J., Nicklas J.A. \& O'neill J.P. (1993) Somatic cell gene mutations in humans: biomarkers for genotoxicity. Environ.Health Perspect. 101 Suppl 3, 193-201.

7. Alwine J.C., Kemp D.J. \& Stark G.R. (1977) Method for detection of specific RNAs in agarose gels by transfer to diazobenzyloxymethyl-paper and hybridization with DNA probes. Proc.Natl.Acad.Sci.U.S.A 74, 53505354. 
8. An B. \& Dou Q.P. (1996) Cleavage of retinoblastoma protein during apoptosis: an interleukin 1 beta-converting enzyme-like protease as candidate. Cancer Res. 56, 438-442.

9. Ansorge W. \& Labeit S. (1984) Field gradients improve resolution on DNA sequencing gels. J.Biochem.Biophys.Methods 10, 237-243.

10. Anthony P.P. (1973) Primary carcinoma of the liver: a study of 282 cases in Ugandan Africans. J.Pathol. 110, 37-48.

11. Aoyagi Y., Isokawa O., Suda T., Watanabe M., Suzuki Y. \& Asakura H. (1998) The fucosylation index of alpha-fetoprotein as a possible prognostic indicator for patients with hepatocellular carcinoma. Cancer 83, 2076-2082.

12. Arbuthnot P. \& Kew M. (2001) Hepatitis B virus and hepatocellular carcinoma. Int.J.Exp.Pathol. 82, 77-100.

13. Avantaggiati M.L., Natoli G., Balsano C., Chirillo P., Artini M., De Marzio E., Collepardo D. \& Levrero M. (1993) The hepatitis B virus (HBV) pX transactivates the $\mathrm{c}$-fos promoter through multiple cis-acting elements. Oncogene 8, 1567-1574.

14. Bailey J.M. \& Davidson N. (1976) Methylmercury as a reversible denaturing agent for agarose gel electrophoresis. Anal.Biochem. 70, 75-85.

15. Balsano C., Avantaggiati M.L., Natoli G., De Marzio E., Will H., Perricaudet M. \& Levrero M. (1991) Full-length and truncated versions of the hepatitis B virus (HBV) X protein ( $\mathrm{pX}$ ) transactivate the cmyc protooncogene at the transcriptional level. Biochem.Biophys.Res.Commun. 176, 985-992. 
16. Bauer D., Muller H., Reich J., Riedel H., Ahrenkiel V., Warthoe P. \& Strauss M. (1993) Identification of differentially expressed mRNA species by an improved display technique (DDRT-PCR). Nucleic Acids Res. 21, 42724280.

17. Beckman L.E., Van Landeghem G.F., Sikstrom C., Wahlin A., Markevarn B., Hallmans G., Lenner P., Athlin L., Stenling R. \& Beckman L. (1999) Interaction between haemochromatosis and transferrin receptor genes in different neoplastic disorders. Carcinogenesis 20, 1231-1233.

18. Bedossa P., Peltier E., Terris B., Franco D. \& Poynard T. (1995) Transforming growth factor-beta 1 (TGF-beta 1) and TGF-beta 1 receptors in normal, cirrhotic, and neoplastic human livers. Hepatology 21, 760-766.

19. Beets-Tan R.G., Van Engelshoven J.M. \& Greve J.W. (1998) Hepatic adenoma and focal nodular hyperplasia: MR findings with superparamagnetic iron oxide-enhanced MRI. Clin.Imaging 22, 211-215.

20. Bergeron R.J., Streiff R.R. \& Elliott G.T. (1985) Influence of iron on in vivo proliferation and lethality of L1210 cells. J.Nutr. 115, 369-374.

21. Berman M.A., Burnham J.A. \& Sheahan D.G. (1988) Fibrolamellar carcinoma of the liver: an immunohistochemical study of nineteen cases and a review of the literature. Hum.Pathol. 19, 784-794.

22. Berman M.M., Libbey N.P. \& Foster J.H. (1980) Hepatocellular carcinoma. Polygonal cell type with fibrous stroma--an atypical variant with a favorable prognosis. Cancer 46, 1448-1455. 
23. Bertioli D.J., Schlichter U.H., Adams M.J., Burrows P.R., Steinbiss H.H. \& Antoniw J.F. (1995) An analysis of differential display shows a strong bias towards high copy number mRNAs. Nucleic Acids Res. 23, 4520-4523.

24. Birkenmeyer L.G., Desai S.M., Muerhoff A.S., Leary T.P., Simons J.N., Montes C.C. \& Mushahwar I.K. (1998) Isolation of a GB virus-related genome from a chimpanzee. J.Med.Virol. 56, 44-51.

25. Bishop J.O. \& Smith G.P. (1974) The determination of RNA homogeneity by molecular hybridization. Cell 3, 341-346.

26. Blaszczynska M., Rybczynska E. \& Szaflarska M. (2000) [The outline of diagnostic procedures in the cases of focal lesions in liver]. Wiad.Lek. 53, 84-91.

27. Bolondi L., Gaiani S., Benzi G., Zironi G., Rigamonti A., Fusconi F. \& Barbara L. (1992) Ultrasonography and guided biopsy in the diagnosis of hepatocellular carcinoma. Ital.J.Gastroenterol. 24, 46-49.

28. Brand N., Petkovich M., Krust A., Chambon P., De The H., Marchio A., Tiollais P. \& Dejean A. (1988) Identification of a second human retinoic acid receptor. Nature 332, 850-853.

29. Bruix J., Castells A., Calvet X., Feu F., Bru C., Sole M., Bruguera M. \& Rodes J. (1990) Diarrhea as a presenting symptom of hepatocellular carcinoma. Dig.Dis.Sci. 35, 681-685.

30. Buetow P.C., Pantongrag-Brown L., Buck J.L., Ros P.R. \& Goodman Z.D. (1996) Focal nodular hyperplasia of the liver: radiologic-pathologic correlation. Radiographics 16, 369-388. 
31. Bukh J., Purcell R.H. \& Miller R.H. (1994) Sequence analysis of the core gene of 14 hepatitis C virus genotypes. Proc.Natl.Acad.Sci.U.S.A 91, 8239-8243.

32. Bulimo W.D., Miskin J.E. \& Dixon L.K. (2000) An ARID family protein binds to the African swine fever virus encoded ubiquitin conjugating enzyme, UBCv1. FEBS Lett. 471, 17-22.

33. Burt M.J. \& Cooksley W.G. (1998) The influence of iron on chronic hepatitis C. J.Gastroenterol.Hepatol. 13, 330-333.

34. Callard D., Lescure B. \& Mazzolini L. (1994) A method for the elimination of false positives generated by the mRNA differential display technique. Biotechniques 16, 1096-3.

35. Cariello N.F., Cui L. \& Skopek T.R. (1994) In vitro mutational spectrum of aflatoxin $\mathrm{B} 1$ in the human hypoxanthine guanine phosphoribosyltransferase gene. Cancer Res. 54, 4436-4441.

36. Carreno V. (2002) Present treatment expectations and risks of chronic hepatitis C. Clin.Microbiol.Infect. 8, 74-79.

37. Cavallari A., Vivarelli M., Bellusci R., De Raffaele E., Nardo B. \& Gozzetti G. (1994) [The intraperitoneal bleeding of hepatocellular carcinoma]. Chir Ital. $46,45-49$.

38. Cecchini E., Dominy P.J., Geri C., Kaiser K., Sentry J. \& Milner J.J. (1993) Identification of genes up-regulated in dedifferentiating Nicotania glauca pith tissue, using an improved method for constructing a subtractive cDNA library. Nucleic Acids Res. 21, 5742-5747. 
39. Chandra J., Niemer I., Gilbreath J., Kliche K.O., Andreeff M., Freireich E.J., Keating M. \& Mcconkey D.J. (1998) Proteasome inhibitors induce apoptosis in glucocorticoid-resistant chronic lymphocytic leukemic lymphocytes. Blood 92, 4220-4229.

40. Chang J., Yang S.H., Cho Y.G., Hwang S.B., Hahn Y.S. \& Sung Y.C. (1998) Hepatitis $\mathrm{C}$ virus core from two different genotypes has an oncogenic potential but is not sufficient for transforming primary rat embryo fibroblasts in cooperation with the H-ras oncogene. J.Virol. 72, 30603065.

41. Chelly J., Kaplan J.C., Maire P., Gautron S. \& Kahn A. (1988) Transcription of the dystrophin gene in human muscle and non-muscle tissue. Nature 333, $858-860$.

42. Chen H.S., Kaneko S., Girones R., Anderson R.W., Hornbuckle W.E., Tennant B.C., Cote P.J., Gerin J.L., Purcell R.H. \& Miller R.H. (1993) The woodchuck hepatitis virus $\mathrm{X}$ gene is important for establishment of virus infection in woodchucks. J.Virol. 67, 1218-1226.

43. Chen J.Y., Harrison T.J., Lee C.S., Chen D.S. \& Zuckerman A.J. (1986) Detection of hepatitis B virus DNA in hepatocellular carcinoma. Br.J.Exp.Pathol. $67,279-288$.

44. Chen J.Y., Harrison T.J., Lee C.S., Chen D.S. \& Zuckerman A.J. (1988) Detection of hepatitis B virus DNA in hepatocellular carcinoma: analysis by hybridization with subgenomic DNA fragments. Hepatology 8, 518-523. 
45. Chen Z., Naito M., Hori S., Mashima T., Yamori T. \& Tsuruo T. (1999) A human IAP-family gene, apollon, expressed in human brain cancer cells. Biochem.Biophys.Res.Commun. 264, 847-854.

46. Cho J.W., Baek W.K., Suh S.I., Yang S.H., Chang J., Sung Y.C. \& Suh M.H. (2001) Hepatitis $\mathrm{C}$ virus core protein promotes cell proliferation through the upregulation of cyclin E expression levels. Liver 21, 137-142.

47. Choi B.I., Chung J.W., Itai Y., Matsui O., Han J.K. \& Han M.C. (1999) Hepatic abnormalities related to blood flow: evaluation with dual-phase helical CT. Abdom.Imaging 24, 340-356.

48. Ciechanover A. (1994) The ubiquitin-proteasome proteolytic pathway. Cell 79, $13-$ 21.

49. Clarke B.E. \& Darby G.K. (1997) Development of antivirals against hepatitis B and $\mathrm{C}$ viruses. In The molecular medicine of viral hepatitis. Ed Tim J Harrison and Arie J Zuckerman. West Sussex, England: John Wiley \& Sons Ltd. pp. 235-248.

50. Cohen G.M. (1997) Caspases: the executioners of apoptosis. Biochem.J. 326 ( Pt 1), 1-16.

51. Cohen J. (1999) The scientific challenge of hepatitis C. Science 285, 26-30.

52. Collier N.A., Weinbren K., Bloom S.R., Lee Y.C., Hodgson H.J. \& Blumgart L.H. (1984) Neurotensin secretion by fibrolamellar carcinoma of the liver. Lancet 1, 538-540. 
53. Colombo M. (1999) Natural history and pathogenesis of hepatitis C virus related hepatocellular carcinoma. J.Hepatol. 31 Suppl 1, 25-30.

54. Copeland N.G., Gilbert D.J., Schindler C., Zhong Z., Wen Z., Darnell J.E., Jr., Mui A.L., Miyajima A., Quelle F.W., Thle J.N. \& . (1995) Distribution of the mammalian Stat gene family in mouse chromosomes. Genomics 29, 225228.

55. Craig J.R., Peters R.L., Edmondson H.A. \& Omata M. (1980) Fibrolamellar carcinoma of the liver: a tumor of adolescents and young adults with distinctive clinico-pathologic features. Cancer 46, 372-379.

56. Cressman D.E., Diamond R.H. \& Taub R. (1995) Rapid activation of the Stat3 transcription complex in liver regeneration. Hepatology 21, 1443-1449.

57. Davis G.L., Esteban-Mur R., Rustgi V., Hoefs J., Gordon S.C., Trepo C., Shiffman M.L., Zeuzem S., Craxi A., Ling M.H. \& Albrecht J. (1998) Interferon alfa-2b alone or in combination with ribavirin for the treatment of relapse of chronic hepatitis C. International Hepatitis Interventional Therapy Group. N.Engl.J.Med. 339, 1493-1499.

58. De Mitri M.S., Morsica G., Cassini R., Bagaglio S., Zoli M., Alberti A. \& Bernardi M. (2002) Prevalence of wild-type in NS5A-PKR protein kinase binding domain in HCV-related hepatocellular carcinoma. J.Hepatol. 36, 116-122.

59. Dejean A., Bougueleret L., Grzeschik K.H. \& Tiollais P. (1986) Hepatitis B virus DNA integration in a sequence homologous to v-erb-A and steroid receptor genes in a hepatocellular carcinoma. Nature 322, 70-72. 
60. Dejean A., Sonigo P., Wain-Hobson S. \& Tiollais P. (1984) Specific hepatitis B virus integration in hepatocellular carcinoma DNA through a viral 11base-pair direct repeat. Proc.Natl.Acad.Sci.U.S.A 81, 5350-5354.

61. Diao J., Garces R. \& Richardson C.D. (2001) X protein of hepatitis B virus modulates cytokine and growth factor related signal transduction pathways during the course of viral infections and hepatocarcinogenesis. Cytokine Growth Factor Rev. 12 , 189-205.

62. Douglass J., Mckinzie A.A. \& Couceyro P. (1995) PCR differential display identifies a rat brain mRNA that is transcriptionally regulated by cocaine and amphetamine. J.Neurosci. 15, 2471-2481.

63. Drexler H.C. (1997) Activation of the cell death program by inhibition of proteasome function. Proc.Natl.Acad.Sci.U.S.A 94, 855-860.

64. Duvoux C., Rahmouni A., Mathieu D. \& Dhumeaux D. (1992) Clinical symptomatology and radiological aspects of primary cancers of the liver. Rev.Prat. 42, 1628-1634.

65. Earnshaw W.C. (1995) Nuclear changes in apoptosis. Curr.Opin.Cell Biol. 7, 337343.

66. Eberwine J. (1996) Amplification of mRNA populations using aRNA generated from immobilized oligo(dT)-T7 primed cDNA. Biotechniques 20, 584591.

67. Edmonson Ha (1956) Differential diagnosis of tumors and tumor-like lesions of liver in infancy and childhood. Arch Dis Child 1, 168 
68. El Refaie A., Savage K., Bhattacharya S., Khakoo S., Harrison T.J., El Batanony M., Soliman E., Nasr S., Mokhtar N., Amer K., Scheuer P.J. \& Dhillon A.P. (1996) HCV-associated hepatocellular carcinoma without cirrhosis. J.Hepatol. 24, 277-285.

69. El Serag H.B. \& Mason A.C. (1999) Rising incidence of hepatocellular carcinoma in the United States. N.Engl.J.Med. 340, 745-750.

70. Ezaki T., Koyanagi N., Toyomasu T., Ikeda Y., Nakanishi N. \& Sugimachi K. (1998) Appraisal of a manual blunt dissection for an intraoperative diagnosis of extrahepatic cancer invasion. Hepatogastroenterology 45, $1837-1841$

71. Fabian J.R., Kane C.M., Abel K.J. \& Gross K.W. (1993) Expression of the mouse Ren-1 gene in the coagulating gland: localization and regulation. Biol.Reprod. 48, 1383-1394.

72. Fabris C., Toniutto P., Scott C.A., Falleti E., Avellini C., Del Forno M., Mattiuzzo M., Branca B. \& Pirisi M. (2001) Serum iron indices as a measure of iron deposits in chronic hepatitis C. Clin.Chim.Acta 304, 49-55.

73. Farshid M. \& Tabor E. (1992) Expression of oncogenes and tumor suppressor genes in human hepatocellular carcinoma and hepatoblastoma cell lines. J.Med.Virol. 38, 235-239.

74. Faubion W.A. \& Gores G.J. (1999) Death receptors in liver biology and pathobiology. Hepatology 29, 1-4. 
75. Feder J.N., Gnirke A., Thomas W., Tsuchihashi Z., Ruddy D.A., Basava A., Dormishian F., Domingo R., Jr., Ellis M.C., Fullan A., Hinton L.M., Jones N.L., Kimmel B.E., Kronmal G.S., Lauer P., Lee V.K., Loeb D.B., Mapa F.A., Mcclelland E., Meyer N.C., Mintier G.A., Moeller N., Moore T., Morikang E. \& Wolff R.K. (1996) A novel MHC class I-like gene is mutated in patients with hereditary haemochromatosis. Nat.Genet. 13, $399-408$.

76. Feldmann G. (1997) Liver apoptosis. J.Hepatol. 26 Suppl 2, 1-11.

77. Fernandez-Pol J.A., Hamilton P.D. \& Klos D.J. (2001) Essential viral and cellular zinc and iron containing metalloproteins as targets for novel antiviral and anticancer agents: implications for prevention and therapy of viral diseases and cancer. Anticancer Res. 21, 931-957.

78. Forrester K., Lupold S.E., Ott V.L., Chay C.H., Band V., Wang X.W. \& Harris C.C. (1995) Effects of p53 mutants on wild-type p53-mediated transactivation are cell type dependent. Oncogene 10, 2103-2111.

79. Franco D., Capussotti L., Smadja C., Bouzari H., Meakins J., Kemeny F., Grange D. \& Dellepiane M. (1990) Resection of hepatocellular carcinomas. Results in 72 European patients with cirrhosis. Gastroenterology 98, 733-738.

80. Friedman A.C., Lichtenstein J.E., Goodman Z., Fishman E.K., Siegelman S.S. \& Dachman A.H. (1985) Fibrolamellar hepatocellular carcinoma. Radiology $157,583-587$. 
81. Fujiyama S., Morishita T., Hashiguchi O. \& Sato T. (1988) Plasma abnormal prothrombin (des-gamma-carboxy prothrombin) as a marker of hepatocellular carcinoma. Cancer 61, 1621-1628.

82. Ganger D.R., Hamilton P.D., Klos D.J., Jakate S., Mcchesney L. \& Fernandez-Pol J.A. (2001) Differential expression of metallopanstimulin/S27 ribosomal protein in hepatic regeneration and neoplasia. Cancer Detect.Prev. 25, 231-236.

83. Goldberg A.L. (2000) Probing the proteasome pathway. Nat.Biotechnol. 18, 494496.

84. Gow P.J. \& Mutimer D. (2001) Treatment of chronic hepatitis. BMJ 323, 11641167.

85. Graef E., Caselmann W.H., Wells J. \& Koshy R. (1994) Insertional activation of mevalonate kinase by hepatitis B virus DNA in a human hepatoma cell line. Oncogene $9,81-87$.

86. Grakoui A., Wychowski C., Lin C., Feinstone S.M. \& Rice C.M. (1993) Expression and identification of hepatitis $\mathrm{C}$ virus polyprotein cleavage products. J.Virol. 67, 1385-1395.

87. Grassmann R., Dengler C., Muller-Fleckenstein I., Fleckenstein B., Mcguire K., Dokhelar M.C., Sodroski J.G. \& Haseltine W.A. (1989) Transformation to continuous growth of primary human $\mathrm{T}$ lymphocytes by human T-cell leukemia virus type I X-region genes transduced by a Herpesvirus saimiri vector. Proc.Nat1.Acad.Sci.U.S.A 86, 3351-3355. 
88. Grazioli L., Federle M.P., Brancatelli G., Ichikawa T., Olivetti L. \& Blachar A. (2001) Hepatic adenomas: imaging and pathologic findings. Radiographics 21, 877-892.

89. Green D. \& Kroemer G. (1998) The central executioners of apoptosis: caspases or mitochondria? Trends Cell Biol. 8, 267-271.

90. Green D.R. (2000) Apoptotic pathways: paper wraps stone blunts scissors. Cell $102,1-4$.

91. Groopman J.D., Hall A.J., Whittle H., Hudson G.J., Wogan G.N., Montesano R. \& Wild C.P. (1992) Molecular dosimetry of aflatoxin-N7-guanine in human urine obtained in The Gambia, West Africa. Cancer Epidemiol.Biomarkers Prev. 1, 221-227.

92. Haag E. \& Raman V. (1994) Effects of primer choice and source of Taq DNA polymerase on the banding patterns of differential display RT-PCR. Biotechniques 17, 226-228.

93. Hardell L., Bengtsson N.O., Jonsson U., Eriksson S. \& Larsson L.G. (1984) Aetiological aspects on primary liver cancer with special regard to alcohol, organic solvents and acute intermittent porphyria--an epidemiological investigation. Br.J.Cancer 50, 389-397.

94. Harris C.C. (1996) p53 tumor suppressor gene: at the crossroads of molecular carcinogenesis, molecular epidemiology, and cancer risk assessment. Environ.Health Perspect. 104 Suppl 3, 435-439. 
95. Hashimoto N., Kawai S., Mikuriya S., Oda T., Inoue J., Shimamura Y., Takahashi A., Masuzawa M., Yumoto Y. \& Makino M. (1989) Effects of transcatheter arterial chemoembolization with oral chemotherapy on hepatic neoplasms. Cancer Chemother.Pharmacol. 23 Suppl, S21-S25

96. Hassan M.M., Zaghloul A.S., El Serag H.B., Soliman O., Patt Y.Z., Chappell C.L., Beasley R.P. \& Hwang L.Y. (2001) The role of hepatitis C in hepatocellular carcinoma: a case control study among Egyptian patients. J.Clin.Gastroenterol. 33, 123-126.

97. Hatada I., Tokino T., Ochiya T. \& Matsubara K. (1988) Co-amplification of integrated hepatitis B virus DNA and transforming gene hst-1 in a hepatocellular carcinoma. Oncogene 3, 537-540.

98. Hauser H.P., Bardroff M., Pyrowolakis G. \& Jentsch S. (1998) A giant ubiquitinconjugating enzyme related to IAP apoptosis inhibitors. J.Cell Biol. 141, $1415-1422$.

99. Hino O., Shows T.B. \& Rogler C.E. (1986) Hepatitis B virus integration site in hepatocellular carcinoma at chromosome 17;18 translocation. Proc.Natl.Acad.Sci.U.S.A 83, 8338-8342.

100. Hobbs M.V., Weigle W.O., Noonan D.J., Torbett B.E., Mcevilly R.J., Koch R.J., Cardenas G.J. \& Ernst D.N. (1993) Patterns of cytokine gene expression by CD4+ T cells from young and old mice. J.Immunol. 150, 3602-3614.

101. Hoofnagle J.H., Mullen K.D., Jones D.B., Rustgi V., Di Bisceglie A., Peters M., Waggoner J.G., Park Y. \& Jones E.A. (1986) Treatment of chronic non- 
A,non-B hepatitis with recombinant human alpha interferon. A preliminary report. N.Engl.J.Med. 315, 1575-1578.

102. Horigome H., Nomura T., Saso K., Joh T., Ohara H., Akita S., Sobue S., Mizuno Y., Kato Y., Kanematsu T., Murasaki G. \& Itoh M. (2000) Diagnosis of small hepatocellular carcinoma--imaging diagnosis and significance of tumor biopsy. Hepatogastroenterology 47, 1659-1662.

103. Hsu T., Moroy T., Etiemble J., Louise A., Trepo C., Tiollais P. \& Buendia M.A. (1988) Activation of c-myc by woodchuck hepatitis virus insertion in hepatocellular carcinoma. Cell 55, 627-635.

104. Hubank M. \& Schatz D.G. (1994) Identifying differences in mRNA expression by representational difference analysis of cDNA. Nucleic Acids Res. 22, $5640-5648$.

105. Hui A.M., Sun L., Kanai Y., Sakamoto M. \& Hirohashi S. (1998) Reduced p27Kip1 expression in hepatocellular carcinomas. Cancer Lett. 132, 6773.

106. Hussain S.P. \& Harris C.C. (2000) Molecular epidemiology and carcinogenesis: endogenous and exogenous carcinogens. Mutat.Res. 462, 311-322.

107. Ido A., Nakata K., Kato Y., Nakao K., Murata K., Fujita M., Ishii N., Tamaoki T., Shiku H. \& Nagataki S. (1995) Gene therapy for hepatoma cells using a retrovirus vector carrying herpes simplex virus thymidine kinase gene under the control of human alpha-fetoprotein gene promoter. Cancer Res. $55,3105-3109$. 
108. Ido A., Uto H., Moriuchi A., Nagata K., Onaga Y., Onaga M., Hori T., Hirono S., Hayashi K., Tamaoki T. \& Tsubouchi H. (2001) Gene therapy targeting for hepatocellular carcinoma: selective and enhanced suicide gene expression regulated by a hypoxia-inducible enhancer linked to a human alphafetoprotein promoter. Cancer Res. 61, 3016-3021.

109. Imajoh-Ohmi S., Kawaguchi T., Sugiyama S., Tanaka K., Omura S. \& Kikuchi H. (1995) Lactacystin, a specific inhibitor of the proteasome, induces apoptosis in human monoblast U937 cells. Biochem.Biophys.Res.Commun. 217, 1070-1077.

110. Ince N. \& Wands J.R. (1999) The increasing incidence of hepatocellular carcinoma. N.Engl.J.Med. 340, 798-799.

111. Iqbal N. \& Saleem A. (1997) Hepatic hemangioma: a review. Tex.Med. 93, 48-50.

112. Ito Y., Takeda T., Umeshita K., Sakon M., Wakasa K., Matsuura N. \& Monden M. (1998) Fas antigen expression in hepatocellular carcinoma tissues. Oncol.Rep. 5, 41-44.

113. Jacob F.A.M.J. (1961) Genetic regulatory mechanisms in the synthesis of proteins. J.Mol.Biol 3, 318-356.

114. Jentsch S. (1992) The ubiquitin-conjugation system. Annu.Rev.Genet. 26, 179207.

115. Jentsch S., Seufert W., Sommer T. \& Reins H.A. (1990) Ubiquitin-conjugating enzymes: novel regulators of eukaryotic cells. Trends Biochem.Sci. 15, 195-198. 
116. Jin D.Y., Wang H.L., Zhou Y., Chun A.C., Kibler K.V., Hou Y.D., Kung H. \& Jeang K.T. (2000) Hepatitis C virus core protein-induced loss of LZIP function correlates with cellular transformation. EMBO J. 19, 729-740.

117. Kakizaki S., Takagi H., Ichikawa T., Abe T., Yamada T., Suzuki K., Kojima A., Takayama H., Takezawa J., Nagamine T. \& Mori M. (2000) Histological change after interferon therapy in chronic hepatitis $\mathrm{C}$ in view of iron deposition in the liver. Biol.Trace Elem.Res. 73, 151-162.

118. Kiryu S., Yao G.L., Morita N., Kato H. \& Kiyama H. (1995) Nerve injury enhances rat neuronal glutamate transporter expression: identification by differential display PCR. J.Neurosci. 15, 7872-7878.

119. Knecht K.T., Thurman R.G. \& Mason R.P. (1993) Role of superoxide and trace transition metals in the production of alpha-hydroxyethyl radical from ethanol by microsomes from alcohol dehydrogenase-deficient deermice. Arch.Biochem.Biophys. 303, 339-348.

120. Koda M., Murawaki Y., Mitsuda A., Oyama K., Okamoto K., Idobe Y., Suou T. \& Kawasaki H. (2001) Combination therapy with transcatheter arterial chemoembolization and percutaneous ethanol injection compared with percutaneous ethanol injection alone for patients with small hepatocellular carcinoma: a randomized control study. Cancer 92, 1516-1524.

121. Koff A., Giordano A., Desai D., Yamashita K., Harper J.W., Elledge S., Nishimoto T., Morgan D.O., Franza B.R. \& Roberts J.M. (1992) Formation and activation of a cyclin E-cdk2 complex during the G1 phase of the human cell cycle. Science 257, 1689-1694. 
122. Kornitzer D. \& Ciechanover A. (2000) Modes of regulation of ubiquitin-mediated protein degradation. J.Cell Physiol 182, 1-11.

123. Kudo M., Tomita S., Tochio H., Mimura J., Okabe Y., Kashida H., Hirasa M., Ibuki Y. \& Todo A. (1992) Small hepatocellular carcinoma: diagnosis with US angiography with intraarterial $\mathrm{CO} 2$ microbubbles. Radiology 182 , $155-160$.

124. Kufe D.W., Advani S. \& Weichselbaum R. (2000) Principles of gene therapy. In Cancer Medicine. Fifth Ed. Eds K.D.W.Bast R.C., Pollock R.E., Weichselbaum R., Holland J.F., Frei E. \& Gansler T.S.

125. Kuroda C., Sakurai M., Monden M., Marukawa T., Hosoki T., Tokunaga K., Wakasa K., Okamura J. \& Kozuka T. (1991) Limitation of transcatheter arterial chemoembolization using iodized oil for small hepatocellular carcinoma. A study in resected cases. Cancer 67, 81-86.

126. Lai C.L., Gregory P.B., Wu P.C., Lok A.S., Wong K.P. \& Ng M.M. (1987) Hepatocellular carcinoma in Chinese males and females. Possible causes for the male predominance. Cancer 60, 1107-1110.

127. Lai C.L.A. \& Wu P.C. (1997) Antiviral treatment for chronic hepatitis B. HKMJ 3, 289-296.

128. Laney J.D. \& Hochstrasser M. (1999) Substrate targeting in the ubiquitin system. Cell 97, 427-430. 
129. Lecker S.H., Solomon V., Mitch W.E. \& Goldberg A.L. (1999) Muscle protein breakdown and the critical role of the ubiquitin-proteasome pathway in normal and disease states. J.Nutr. 129, 227S-237S.

130. Ledley F.D. (1993) Hepatic gene therapy: present and future. Hepatology 18, 1263-1273.

131. Lee J.J. \& Costlow N.A. (1987) A molecular titration assay to measure transcript prevalence levels. Methods Enzymol. 152, 633-648.

132. Lee Y.H. \& Yun Y. (1998) HBx protein of hepatitis B virus activates Jak1-STAT signaling. J.Biol.Chem. 273, 25510-25515.

133. Lehrach H., Diamond D., Wozney J.M. \& Boedtker H. (1977) RNA molecular weight determinations by gel electrophoresis under denaturing conditions, a critical reexamination. Biochemistry $16,4743-4751$.

134. Lencioni R., Vignali C., Caramella D., Cioni R., Mazzeo S. \& Bartolozzi C. (1994) Transcatheter arterial embolization followed by percutaneous ethanol injection in the treatment of hepatocellular carcinoma. Cardiovasc.Intervent.Radiol. 17, 70-75.

135. Leonard W.J. \& O'shea J.J. (1998) Jaks and STATs: biological implications. Annu.Rev.Immunol. 16, 293-322.

136. Liang P., Averboukh L., Keyomarsi K., Sager R. \& Pardee A.B. (1992) Differential display and cloning of messenger RNAs from human breast cancer versus mammary epithelial cells. Cancer Res. 52, 6966-6968. 
137. Liang P., Averboukh L. \& Pardee A.B. (1993) Distribution and cloning of eukaryotic mRNAs by means of differential display: refinements and optimization. Nucleic Acids Res. 21, 3269-3275.

138. Liang P. \& Pardee A.B. (1992) Differential display of eukaryotic messenger RNA by means of the polymerase chain reaction. Science $257,967-971$.

139. Liang P., Zhu W., Zhang X., Guo Z., O'connell R.P., Averboukh L., Wang F. \& Pardee A.B. (1994) Differential display using one-base anchored oligo-dT primers. Nucleic Acids Res. 22, 5763-5764.

140. Linskens M.H., Feng J., Andrews W.H., Enlow B.E., Saati S.M., Tonkin L.A., Funk W.D. \& Villeponteau B. (1995) Cataloging altered gene expression in young and senescent cells using enhanced differential display. Nucleic Acids Res. 23, 3244-3251.

141. Linzer D.I. \& Nathans D. (1983) Growth-related changes in specific mRNAs of cultured mouse cells. Proc.Natl.Acad.Sci.U.S.A 80, 4271-4275.

142. Lisitsyn N., Lisitsyn N. \& Wigler M. (1993) Cloning the differences between two complex genomes. Science 259, 946-951.

143. Little S.A. \& Fong Y. (2001) Hepatocellular carcinoma: current surgical management. Semin.Oncol. 28, 474-486.

144. Livraghi T., Benedini V., Lazzaroni S., Meloni F., Torzilli G. \& Vettori C. (1998) Long term results of single session percutaneous ethanol injection in patients with large hepatocellular carcinoma. Cancer 83, 48-57. 
145. Livraghi T., Goldberg S.N., Lazzaroni S., Meloni F., Solbiati L. \& Gazelle G.S. (1999) Small hepatocellular carcinoma: treatment with radio-frequency ablation versus ethanol injection. Radiology 210, 655-661.

146. Lo S.Y., Selby M.J. \& Ou J.H. (1996) Interaction between hepatitis C virus core protein and E1 envelope protein. J.Virol. 70, 5177-5182.

147. Lockhart D.J. \& Winzeler E.A. (2000) Genomics, gene expression and DNA arrays. Nature 405, 827-836.

148. Lowe S.W., Ruley H.E., Jacks T. \& Housman D.E. (1993) p53-dependent apoptosis modulates the cytotoxicity of anticancer agents. Cell 74, 957967.

149. Lundeberg J., Wahlberg J. \& Uhlen M. (1991) Rapid colorimetric quantification of PCR-amplified DNA. Biotechniques 10,68-75.

150. Maertens G. \& Stuyver L. (1997) Genotypes and genetic variation of hepatitis C virus. In The molecular medicine of viral hepatitis. Ed T.J.a.Z.A.J.Harrison. John Wiley \& Sons. pp. 183-233.

151. Majumder M., Ghosh A.K., Steele R., Ray R. \& Ray R.B. (2001) Hepatitis C virus NS5A physically associates with p53 and regulates p21/wafl gene expression in a p53-dependent manner. J.Virol. 75, 1401-1407.

152. Marusawa H., Hijikata M., Chiba T. \& Shimotohno K. (1999) Hepatitis C virus core protein inhibits Fas- and tumor necrosis factor alpha-mediated apoptosis via NF-kappaB activation. J.Virol. 73, 4713-4720. 
153. Masdehors P., Merle-Beral H., Maloum K., Omura S., Magdelenat H. \& Delic J. (2000) Deregulation of the ubiquitin system and p53 proteolysis modify the apoptotic response in B-CLL lymphocytes. Blood 96, 269-274.

154. Massague J. \& Weis-Garcia F. (1996) Serine/threonine kinase receptors: mediators of transforming growth factor beta family signals. Cancer Surv. 27, 41-64.

155. Mathieu-Daude F., Cheng R., Welsh J. \& Mcclelland M. (1996) Screening of differentially amplified cDNA products from RNA arbitrarily primed PCR fingerprints using single strand conformation polymorphism (SSCP) gels. Nucleic Acids Res. 24, 1504-1507.

156. Mathieu D., Kobeiter H., Cherqui D., Rahmouni A. \& Dhumeaux D. (1998) Oral contraceptive intake in women with focal nodular hyperplasia of the liver. Lancet 352, 1679-1680.

157. Mathieu D., Kobeiter H., Maison P., Rahmouni A., Cherqui D., Zafrani E.S. \& Dhumeaux D. (2000) Oral contraceptive use and focal nodular hyperplasia of the liver. Gastroenterology 118, 560-564.

158. Matsubara K. \& Tokino T. (1990) Integration of hepatitis B virus DNA and its implications for hepatocarcinogenesis. Mol.Biol.Med. 7, 243-260.

159. Mazzaferro V., Regalia E., Doci R., Andreola S., Pulvirenti A., Bozzetti F., Montalto F., Ammatuna M., Morabito A. \& Gennari L. (1996) Liver transplantation for the treatment of small hepatocellular carcinomas in patients with cirrhosis. N.Engl.J.Med. 334, 693-699. 
160. Mclarney J.K., Rucker P.T., Bender G.N., Goodman Z.D., Kashitani N. \& Ros P.R. (1999) Fibrolamellar carcinoma of the liver: radiologic-pathologic correlation. Radiographics 19, 453-471.

161. Mclauchlan J. (2000) Properties of the hepatitis C virus core protein: a structural protein that modulates cellular processes. J.Viral Hepat. 7, 2-14.

162. Mcmaster G.K. \& Carmichael G.G. (1977) Analysis of si. Proc.Natl.Acad.Sci.U.S.A 74 , 4835-4838.

163. Melton D.A., Krieg P.A., Rebagliati M.R., Maniatis T., Zinn K. \& Green M.R (1984) Efficient in vitro synthesis of biologically active RNA and RNA hybridization probes from plasmids containing a bacteriophage SP6 promoter. Nucleic Acids Res 12, 7035-7056.

164. Miller A.R., Skotzko M.J., Rhoades K., Belldegrun A.S., Tso C.L., Kaboo R., Mcbride W.H., Jacobs E., Kohn D.B. \& Moen R. (1992) Simultaneous use of two retroviral vectors in human gene marking trials: feasibility and potential applications. Hum.Gene Ther. 3, 619-624.

165. Molmenti E.P., Marsh J.W., Dvorchik I., Oliver J.H., Iii, Madariaga J. \& Iwatsuki S. (1999) Hepatobiliary malignancies. Primary hepatic malignant neoplasms. Surg.Clin.North Am. 79, 43-57, viii.

166. Moroy T., Marchio A., Etiemble J., Trepo C., Tiollais P. \& Buendia M.A. (1986) Rearrangement and enhanced expression of c-myc in hepatocellular carcinoma of hepatitis virus infected woodchucks. Nature 324, 276-279. 
167. Motohara K., Endo F., Matsuda I. \& Iwamasa T. (1987) Acarboxy prothrombin (PIVKA-II) as a marker of hepatoblastoma in infants. J.Pediatr.Gastroenterol.Nutr. 6, 42-45.

168. Mou L., Miller H., Li J., Wang E. \& Chalifour L. (1994) Improvements to the differential display method for gene analysis. Biochem.Biophys.Res.Commun. 199, 564-569.

169. Munoz A \& Bosch F.X. (1987) Epidemiology of hepatocellular carcinoma. In Neoplams of the liver. Ed Okuda K.and Ishaki K.G. Tokyo: Springer. pp. 3-19.

170. Nagasue N., Yukaya H., Chang Y.C., Ogawa Y., Kohno H. \& Ito A. (1986) Active uptake of testosterone by androgen receptors of hepatocellular carcinoma in humans. Cancer 57, 2162-2167.

171. Nelson R.L., Davis F.G., Persky V. \& Becker E. (1995) Risk of neoplastic and other diseases among people with heterozygosity for hereditary hemochromatosis. Cancer 76, 875-879.

172. Ni Y.H., Chang M.H., Hsu H.Y., Hsu H.C., Chen C.C., Chen W.J. \& Lee C.Y. (1991) Hepatocellular carcinoma in childhood. Clinical manifestations and prognosis. Cancer 68, 1737-1741.

173. Niederau C., Fischer R., Purschel A., Stremmel W., Haussinger D. \& Strohmeyer G. (1996) Long-term survival in patients with hereditary hemochromatosis. Gastroenterology 110, 1107-1119. 
174. Nime F., Pickren J.W., Vana J., Aronoff B.L., Baker H.W. \& Murphy G.P. (1979) The histology of liver tumors in oral contraceptive users observed during a national survey by the American College of Surgeons Commission on Cancer. Cancer 44, 1481-1489.

175. Nishibori H., Matsuno Y., Iwaya M., Osada T., Kubomura N., Iwamatsu A., Kohno H., Sato S., Kitajima M. \& Hirohashi S. (1996) Human colorectal carcinomas specifically accumulate $\mathrm{Mr} 42,000$ ubiquitin-conjugated cytokeratin 8 fragments. Cancer Res. 56, 2752-2757.

176. Nishizawa T., Okamoto H., Konishi K., Yoshizawa H., Miyakawa Y. \& Mayumi M. (1997) A novel DNA virus (TTV) associated with elevated transaminase levels in posttransfusion hepatitis of unknown etiology. Biochem.Biophys.Res.Commun. 241, 92-97.

177. Nitsche E.M., Moquin A., Adams P.S., Guenette R.S., Lakins J.N., Sinnecker G.H., Kruse K. \& Tenniswood M.P. (1996) Differential display RT PCR of total RNA from human foreskin fibroblasts for investigation of androgen-dependent gene expression. Am.J.Med.Genet. 63, 231-238.

178. Nordmann R., Ribiere C. \& Rouach H. (1992) Implication of free radical mechanisms in ethanol-induced cellular injury. Free Radic.Biol.Med. 12, 219-240.

179. Ochman H., Gerber A.S. \& Hartl D.L. (1988) Genetic applications of an inverse polymerase chain reaction. Genetics $120,621-623$.

180. Ogunbiyi J.O. (2001) Hepatocellular carcinoma in the developing world.

Semin.Oncol. 28, 179-187. 
181. Oikawa T., Sasaki T., Nakamura M., Shimamura M., Tanahashi N., Omura S. \& Tanaka K. (1998) The proteasome is involved in angiogenesis. Biochem.Biophys.Res.Commun. 246, 243-248.

182. Oka H., Kurioka N., Kim K., Kanno T., Kuroki T., Mizoguchi Y. \& Kobayashi K. (1990) Prospective study of early detection of hepatocellular carcinoma in patients with cirrhosis. Hepatology 12, 680-687.

183. Okuda H., Nakanish T., Furukawa M., Yamagata H. \& Obata H. (1991) Abnormal prothrombin (PIVKA-II) and hepatocellular carcinoma. Trop.Gastroenterol. 12, 59-66.

184. Okuda H., Nakanishi T., Takatsu K., Saito A., Hayashi N., Takasaki K., Takenami K., Yamamoto M. \& Nakano M. (2000) Serum levels of des-gammacarboxy prothrombin measured using the revised enzyme immunoassay kit with increased sensitivity in relation to clinicopathologic features of solitary hepatocellular carcinoma. Cancer 88, 544-549.

185. Okuda H., Nakanishi T., Takatsu K., Saito A., Hayashi N., Watanabe K., Magario N., Yokoo T. \& Naraki T. (1999) Measurement of serum levels of desgamma-carboxy prothrombin in patients with hepatocellular carcinoma by a revised enzyme immunoassay kit with increased sensitivity. Cancer 85 , 812-818.

186. Okuda H., Obata H., Nakanishi T., Furukawa R. \& Hashimoto E. (1987) Production of abnormal prothrombin (des-gamma-carboxy prothrombin) by hepatocellular carcinoma. A clinical and experimental study. J.Hepatol. 4, 357-363. 
187. Okuda K. (1997) Hepatocellular carcinoma: clinicopathological aspects.

J.Gastroenterol.Hepatol. 12, S314-S318

188. Okuda K. (2000) Hepatocellular carcinoma. J.Hepatol. 32, 225-237.

189. Pain J.A., Gimson A.E., Williams R. \& Howard E.R. (1991) Focal nodular hyperplasia of the liver: results of treatment and options in management. Gut 32, 524-527.

190. Patel T., Roberts L.R., Jones B.A. \& Gores G.J. (1998) Dysregulation of apoptosis as a mechanism of liver disease: an overview. Semin.Liver Dis. 18, 105114.

191. Pianko S. \& Mchutchison J.G. (2000) Treatment of hepatitis C with interferon and ribavirin. J.Gastroenterol.Hepatol. 15, 581-586.

192. Pietrangelo A. (1998) Iron, oxidative stress and liver fibrogenesis. J.Hepatol. 28 Suppl 1, 8-13.

193. Pikaart M.J. \& Villeponteau B. (1993) Suppression of PCR amplification by high levels of RNA. Biotechniques 14, 24-25.

194. Pinna A.D., Iwatsuki S., Lee R.G., Todo S., Madariaga J.R., Marsh J.W., Casavilla A., Dvorchik I., Fung J.J. \& Starzl T.E. (1997) Treatment of fibrolamellar hepatoma with subtotal hepatectomy or transplantation. Hepatology 26, $877-883$.

195. Piperno A., Sampietro M., D'alba R., Roffi L., Fargion S., Parma S., Nicoli C., Corbetta N., Pozzi M., Arosio V., Boari G. \& Fiorelli G. (1996) Iron 
stores, response to alpha-interferon therapy, and effects of iron depletion in chronic hepatitis C. Liver 16, 248-254.

196. Poirier G.M., Pyati J., Wan J.S. \& Erlander M.G. (1997) Screening differentially expressed cDNA clones obtained by differential display using amplified RNA. Nucleic Acids Res. 25, 913-914.

197. Pombo F., Rodriguez E. \& Arnal-Monreal F. (1993) Multicystic fibrolamellar hepatocellular carcinoma. CT appearance. Clin.Imaging 17, 67-69.

198. Poyanli A., Rozanes I., Acunas B. \& Sencer S. (2001) Palliative treatment of hepatocellular carcinoma by chemoembolization. Acta Radiol. 42, 602607.

199. Ray R.B., Lagging L.M., Meyer K. \& Ray R. (1996a) Hepatitis C virus core protein cooperates with ras and transforms primary rat embryo fibroblasts to tumorigenic phenotype. J.Virol. 70, 4438-4443.

200. Ray R.B., Meyer K. \& Ray R. (1996b) Suppression of apoptotic cell death by hepatitis C virus core protein. Virology 226, 176-182.

201. Ray R.B., Meyer K., Steele R., Shrivastava A., Aggarwal B.B. \& Ray R. (1998) Inhibition of tumor necrosis factor (TNF-alpha)-mediated apoptosis by hepatitis C virus core protein. J.Biol.Chem. 273, 2256-2259.

202. Ray R.B., Steele R., Meyer K. \& Ray R. (1997) Transcriptional repression of p53 promoter by hepatitis C virus core protein. J.Biol.Chem. 272, 1098310986. 
203. Regev A. \& Schiff E.R. (2001) Drug therapy for hepatitis B. Adv.Intern.Med. 46, $107-135$

204. Risch N. (1997) Haemochromatosis, HFE and genetic complexity. Nat.Genet. 17, $375-376$.

205. Robert D. (1998) Textbook of radiology and imaging. Sixth Ed. New York, Edinburgh, London, Madrid, Melbourne, San Francisco, Tokyo: Churchill Livingstone. pp. 1000-1002.

206. Robinson W.S. (1994) Molecular events in the pathogenesis of hepadnavirusassociated hepatocellular carcinoma. Annu.Rev.Med. 45, 297-323.

207. Rogler C.E., Sherman M., Su C.Y., Shafritz D.A., Summers J., Shows T.B., Henderson A. \& Kew M. (1985) Deletion in chromosome 11p associated with a hepatitis B integration site in hepatocellular carcinoma. Science $230,319-322$.

208. Rose A.T., Rose D.M., Pinson C.W., Wright J.K., Blair T., Blanke C., Delbeke D., Debelak J.P. \& Chapman W.C. (1998) Hepatocellular carcinoma outcomes based on indicated treatment strategy. Am.Surg. 64, 1128-1134.

209. Ross R.K., Yu M.C., Henderson B.E., Yuan J.M., Qian G.S., Tu J.T., Gao Y.T., Wogan G.N. \& Groopman J.D. (1992a) Aflatoxin biomarkers. Lancet 340, 119

210. Ross R.K., Yuan J.M., Yu M.C., Wogan G.N., Qian G.S., Tu J.T., Groopman J.D., Gao Y.T. \& Henderson B.E. (1992b) Urinary aflatoxin biomarkers and risk of hepatocellular carcinoma. Lancet 339, 943-946. 
211. Ruggieri A., Harada T., Matsuura Y. \& Miyamura T. (1997) Sensitization to Fasmediated apoptosis by hepatitis C virus core protein. Virology 229, 68-76.

212. Ruiz J., Qian C., Drozdzik M. \& Prieto J. (1999) Gene therapy of viral hepatitis and hepatocellular carcinoma. J.Viral Hepat. 6, 17-34.

213. Rust C. \& Gores G.J. (2000) Apoptosis and liver disease. Am.J.Med. 108, 567574.

214. Sabelli P.A. \& Shewry P.R. (1995) Northern analysis and nucleic acid probes. Methods Mol.Biol. 49, 213-228.

215. Sakamuro D., Furukawa T. \& Takegami T. (1995) Hepatitis C virus nonstructural protein NS3 transforms NIH 3T3 cells. J.Virol. 69, 3893-3896.

216. Sambrook J., Fritch E.F. \& T.Maniatis. (1989) Molecular cloning. A laborarory manual. Second edn Ed. Cold spring Harbor laboratory press. pp. 11.7

217. Saxena R., Humphreys S., Williams R. \& Portmann B. (1994) Nodular hyperplasia surrounding fibrolamellar carcinoma: a zone of arterialized liver parenchyma. Histopathology 25, 275-278.

218. Scheffner M., Huibregtse J.M., Vierstra R.D. \& Howley P.M. (1993) The HPV-16 E6 and E6-AP complex functions as a ubiquitin-protein ligase in the ubiquitination of p53. Cell 75, 495-505.

219. Schotman S.N., De Man R.A., Stoker J., Zondervan P.E. \& Ijzermans J.N. (1999) Subcutaneous seeding of hepatocellular carcinoma after percutaneous needle biopsy. Gut 45, 626-627. 
220. Schwartz A.L. \& Ciechanover A. (1999) The ubiquitin-proteasome pathway and pathogenesis of human diseases. Annu.Rev.Med. 50, 57-74.

221. Scuric Z., Stain S.C., Anderson W.F. \& Hwang J.J. (1998) New member of aldose reductase family proteins overexpressed in human hepatocellular carcinoma. Hepatology 27, 943-950.

222. Severini A., Liu X.Y., Wilson J.S. \& Tyrrell D.L. (1995) Mechanism of inhibition of duck hepatitis B virus polymerase by (-)-beta-L-2',3'-dideoxy-3'thiacytidine. Antimicrob.Agents Chemother. 39, 1430-1435.

223. Sharara A.I. (1997) Chronic hepatitis C. South.Med.J. 90, 872-877.

224. Sherr C.J. (1993) Mammalian G1 cyclins. Cell 73, 1059-1065.

225. Shi Y., Zou M., Farid N.R. \& Paterson M.C. (2000) Association of FHIT (fragile histidine triad), a candidate tumour suppressor gene, with the ubiquitinconjugating enzyme hUBC9. Biochem.J. 352 Pt 2, 443-448.

226. Shiina S., Tagawa K., Unuma T., Fujino H., Uta Y., Niwa Y., Hata Y., Komatsu Y., Shiratori Y. \& Terano A. (1990) Percutaneous ethanol injection therapy of hepatocellular carcinoma: analysis of 77 patients. AJR Am.J.Roentgenol. 155, 1221-1226.

227. Shiina S., Tagawa K., Unuma T., Takanashi R., Yoshiura K., Komatsu Y., Hata Y., Niwa Y., Shiratori Y. \& Terano A. (1991) Percutaneous ethanol injection therapy for hepatocellular carcinoma. A histopathologic study. Cancer 68, $1524-1530$. 
228. Siddiqui M.T., HosseinSaboorian M.,Tunc Gokaslan S. \& Ashfaq R. (2002)

Diagnostic utility of the HepParl antibody to differentiate hepatocellular carcinoma from metastatic carcinoma in fine-needle aspiration samples. Cancer Cytopathology 96, 49-52.

229. Simons J.N., Pilot-Matias T.J., Leary T.P., Dawson G.J., Desai S.M., Schlauder G.G., Muerhoff A.S., Erker J.C., Buijk S.L. \& Chalmers M.L. (1995) Identification of two flavivirus-like genomes in the GB hepatitis agent. Proc.Natl.Acad.Sci.U.S.A 92, 3401-3405.

230. Smalley S.R., Moertel C.G., Hilton J.F., Weiland L.H., Weiand H.S., Adson M.A., Melton L.J., Iii \& Batts K. (1988) Hepatoma in the noncirrhotic liver. Cancer 62, 1414-1424.

231. Sompayrac L., Jane S., Burn T.C., Tenen D.G. \& Danna K.J. (1995) Overcoming limitations of the mRNA differential display technique. Nucleic Acids Res. 23, 4738-4739.

232. Songsivilai S., Dharakul T. \& Senawong S. (1995) Hepatit. Asian Pac.J.Allergy Immunol. 13, 167-171.

233. Soyer P., Bluemke D.A., Vissuzaine C., Beers B.V., Barge J. \& Levesque M. (1994) CT of hepatic tumors: prevalence and specificity of retraction of the adjacent liver capsule. AJR Am.J.Roentgenol. 162, 1119-1122.

234. Soyer P., Roche A. \& Levesque M. (1991) Fibrolamellar hepatocellular carcinoma presenting with obstructive jaundice. A report of two cases. Eur.J.Radiol. $13,196-198$. 
235. Spanakis E. \& Brouty-Boye D. (1997) Discrimination of fibroblast subtypes by multivariate analysis of gene expression. Int.J.Cancer 71, 402-409.

236. Stacey D.W. \& Allfrey V.G. (1976) Microinjection studies of duck globin messenger RNA translation in human and avian cells. Cell 9, 725-732.

237. Stauber R.E., Mischinger H.J., Trauner M. \& Pristautz H. (1993) [Indications for liver transplantation in neoplasms of the liver]. Acta Med.Austriaca 20, $57-60$

238. Stevens W.R., Johnson C.D., Stephens D.H. \& Nagorney D.M. (1995)

Fibrolamellar hepatocellular carcinoma: stage at presentation and results of aggressive surgical management. AJR Am.J.Roentgenol. 164, 1153-1158.

239. Strand S., Hofmann W.J., Hug H., Muller M., Otto G., Strand D., Mariani S.M., Stremmel W., Krammer P.H. \& Galle P.R. (1996) Lymphocyte apoptosis induced by CD95 (APO-1/Fas) ligand-expressing tumor cells--a mechanism of immune evasion?. Nat.Med. 2, 1361-1366.

240. Stuver S.O. (1998) Towards global control of liver cancer? Semin.Cancer Biol. 8, 299-306.

241. Sue S.R., Chari R.S., Kong F.M., Mills J.J., Fine R.L., Jirtle R.L. \& Meyers W.C. (1995) Transforming growth factor-beta receptors and mannose 6phosphate/insulin-like growth factor-II receptor expression in human hepatocellular carcinoma. Ann.Surg. 222, 171-178.

242. Sunday M.E. (1995) Differential display RT-PCR for identifying novel gene expression in the lung. Am.J.Physiol 269, L273-L284 
243. Sung Y.J. \& Denman R.B. (1997) Use of two reverse transcriptases eliminates false-positive results in differential display. Biotechniques 23, 462-4, 466, 468.

244. Syvanen A.C., Bengtstrom M., Tenhunen J. \& Soderlund H. (1988) Quantification of polymerase chain reaction products by affinity-based hybrid collection. Nucleic Acids Res. 16, 11327-11338.

245. Szmuness W. (1978) Hepatocellular carcinoma and the hepatitis B virus: evidence for a causal association. Prog.Med.Virol. 24, 40-69.

246. Tabor E. (1992) Hepatitis C virus and hepatocellular carcinoma. AIDS Res.Hum.Retroviruses 8, 793-796.

247. Takagi H., Uehara M., Kakizaki S., Takahashi H., Takezawa J., Kabeya K., Satoh K., Kojima A., Saito S., Matsumoto T., Hashimoto Y., Abe T., Yamada T., Konaka K., Shimoda R., Takayama H., Takehara K., Nagamine T. \& Mori M. (1998) Accidental transmission of HCV and treatment with interferon. J.Gastroenterol.Hepatol. 13, 238-243.

248. Takayasu K., Muramatsu Y., Moriyama N., Hasegawa H., Makuuchi M., Okazaki N., Hirohashi S. \& Tsugane S. (1989) Clinical and radiologic assessments of the results of hepatectomy for small hepatocellular carcinoma and therapeutic arterial embolization for postoperative recurrence. Cancer 64, 1848-1852.

249. Taketa K., Ichikawa E., Sato J., Taga H. \& Hirai H. (1989) Two-dimensional lectin affinity electrophoresis of alpha-fetoprotein: characterization of 
erythroagglutinating phytohemagglutinin-dependent microheterogeneity forms. Electrophoresis 10, 825-829.

250. Tanaka H., Shimada Y., Harada H., Shinoda M., Hatooka S., Imamura M. \& Ishizaki K. (1998) Methylation of the $5^{\prime} \mathrm{CpG}$ island of the FHIT gene is closely associated with transcriptional inactivation in esophageal squamous cell carcinomas. Cancer Res. 58, 3429-3434.

251. Tanaka H., Tsukuma H. \& Oshima A. (2001) [Epidemiology of primary liver cancer in Japan]. Gan To Kagaku Ryoho 28, 151-154.

252. Tanaka K., Hirohata T., Koga S., Sugimachi K., Kanematsu T., Ohryohji F., Nawata H., Ishibashi H., Maeda Y. \& Kiyokawa H. (1991a) Hepatitis C and hepatitis B in the etiology of hepatocellular carcinoma in the Japanese population. Cancer Res. 51, 2842-2847.

253. Tanaka K., Okazaki H., Nakamura S., Endo O., Inoue S., Takamura Y., Sugiyama M. \& Ohaki Y. (1991b) Hepatocellular carcinoma: treatment with a combination therapy of transcatheter arterial embolization and percutaneous ethanol injection. Radiology 179, 713-717.

254. Tangkijvanich P., Anukulkarnkusol N., Suwangool P., Lertmaharit S., Hanvivatvong O., Kullavanijaya P. \& Poovorawan Y. (2000) Clinical characteristics and prognosis of hepatocellular carcinoma: analysis based on serum alpha-fetoprotein levels. J.Clin.Gastroenterol. 31, 302-308.

255. Terkivatan T., De Wilt J.H., De Man R.A., Van Rijn R.R., Zondervan P.E., Tilanus H.W. \& Ijzermans J.N. (2001) Indications and long-term outcome of 
treatment for benign hepatic tumors: a critical appraisal. Arch.Surg. 136, 1033-1038.

256. Thomas P.S. (1980) Hybridization of denatured RNA and small DNA fragments transferred to nitrocellulose. Proc.Natl.Acad.Sci.U.S.A 77, 5201-5205.

257. Thomas P.S. (1983) Hybridization of denatured RNA transferred or dotted nitrocellulose paper. Methods Enzymol. 100, 255-266.

258. Thornberry N.A. (1998) Caspases: key mediators of apoptosis. Chem.Biol. 5, R97-103.

259. Thurman R.G. (1998) II. Alcoholic liver injury involves activation of Kupffer cells by endotoxin. Am.J.Physiol 275, G605-G611

260. Tillmann H.L., Trautwein C., Bock T., Boker K.H., Jackel E., Glowienka M., Oldhafer K., Bruns I., Gauthier J., Condreay L.D., Raab H.R. \& Manns M.P. (1999) Mutational pattern of hepatitis B virus on sequential therapy with famciclovir and lamivudine in patients with hepatitis B virus reinfection occurring under HBIg immunoglobulin after liver transplantation. Hepatology 30, 244-256.

261. Trayhurn P. (1996) Northern blotting. Proc.Nutr.Soc. 55, 583-589.

262. Tsai J.F., Chang W.Y., Jeng J.E., Ho M.S., Lin Z.Y. \& Tsai J.H. (1994) Effects of hepatitis $\mathrm{C}$ and $\mathrm{B}$ viruses infection on the development of hepatocellular carcinoma. J.Med.Virol. 44, 92-95. 
263. Tsuchihara K., Hijikata M., Fukuda K., Kuroki T., Yamamoto N. \& Shimotohno K. (1999) Hepatitis C virus core protein regulates cell growth and signal transduction pathway transmitting growth stimuli. Virology 258, 100-107.

264. Twu J.S., Lai M.Y., Chen D.S. \& Robinson W.S. (1993) Activation of protooncogene c-jun by the X protein of hepatitis B virus. Virology 192, 346-350.

265. Twu J.S. \& Schloemer R.H. (1987) Transcriptional trans-activating function of hepatitis B virus. J.Virol. 61, 3448-3453.

266. Ueda H., Ullrich S.J., Gangemi J.D., Kappel C.A., Ngo L., Feitelson M.A. \& Jay G. (1995) Functional inactivation but not structural mutation of p53 causes liver cancer. Nat.Genet. 9, 41-47.

267. Valla D.C. \& Degos F. (2001) Chemoprevention of hepatocellular carcinoma in hepatitis $\mathrm{C}$ virus-related cirrhosis: first, eliminate the virus. J.Hepatol. 34 , 606-609.

268. von Stein O.D., Thies W.G. \& Hofmann M. (1997) A high throughput screening for rarely transcribed differentially expressed genes. Nucleic Acids Res. $25,2598-2602$.

269. Wang J., Chenivesse X., Henglein B. \& Brechot C. (1990) Hepatitis B virus integration in a cyclin A gene in a hepatocellular carcinoma. Nature 343, $555-557$. 
270. Wang J., Sampath A., Raychaudhuri P. \& Bagchi S. (2001) Both Rb and E7 are regulated by the ubiquitin proteasome pathway in HPV-containing cervical tumor cells. Oncogene 20, 4740-4749.

271. Wang J., Zindy F., Chenivesse X., Lamas E., Henglein B. \& Brechot C. (1992) Modification of cyclin A expression by hepatitis B virus DNA integration in a hepatocellular carcinoma. Oncogene $7,1653-1656$.

272. Wang S.S., O'neill J.P., Qian G.S., Zhu Y.R., Wang J.B., Armenian H., Zarba A., Wang J.S., Kensler T.W., Cariello N.F., Groopman J.D. \& Swenberg J.A. (1999) Elevated HPRT mutation frequencies in aflatoxin-exposed residents of daxin, Qidong county, People's Republic of China. Carcinogenesis 20, 2181-2184.

273. Wang X.W., Forrester K., Yeh H., Feitelson M.A., Gu J.R. \& Harris C.C. (1994) Hepatitis B virus X protein inhibits p53 sequence-specific DNA binding, transcriptional activity, and association with transcription factor ERCC3. Proc.Natl.Acad.Sci.U.S.A 91, 2230-2234.

274. Wang X.W., Vermeulen W., Coursen J.D., Gibson M., Lupold S.E., Forrester K., Xu G., Elmore L., Yeh H., Hoeijmakers J.H. \& Harris C.C. (1996) The XPB and XPD DNA helicases are components of the p53-mediated apoptosis pathway. Genes Dev. 10, 1219-1232.

275. Wang Y.R., WU J.Y., Reaves S.K. \& Lei,K.Y. (1996) Enhanced expression of hepatic genes in copper-deficient rats detected by the messenger RNA differential display method. J.Nutr 126, 1772-1781. 
276. Wanless I.R., Albrecht S., Bilbao J., Frei J.V., Heathcote E.J., Roberts E.A. \& Chiasson D. (1989) Multiple focal nodular hyperplasia of the liver associated with vascular malformations of various organs and neoplasia of the brain: a new syndrome. Mod.Pathol. 2, 456-462.

277. Wells T.N. \& Peitsch M.C. (1997) The chemokine information source: identification and characterization of novel chemokines using the WorldWideWeb and expressed sequence tag databases. J.Leukoc.Biol. 61, 545-550.

278. Welsh J. \& Mcclelland M. (1990) Fingerprinting genomes using PCR with arbitrary primers. Nucleic Acids Res. 18, 7213-7218.

279. Wennerberg A.E., Nalesnik M.A. \& Coleman W.B. (1993) Hepatocyte paraffin 1: a monoclonal antibody that reacts with hepatocytes and can be used for differential diagnosis of hepatic tumors. Am.J.Pathol. 143, 1050-1054.

280. Wieland I., Bolger G., Asouline G. \& Wigler M. (1990) A method for difference cloning: gene amplification following subtractive hybridization. Proc.Natl.Acad.Sci.U.S.A 87, 2720-2724.

281. Wigler M., Pellicer A., Silverstein S. \& Axel R. (1978) Biochemical transfer of single-copy eucaryotic genes using total cellular DNA as donor. Cell 14, 724

282. Wiley S.R., Schooley K., Smolak P.J., Din W.S., Huang C.P., Nicholl J.K., Sutherland G.R., Smith T.D., Rauch C. \& Smith C.A. (1995) Identification and characterization of a new member of the TNF family that induces apoptosis. Immunity. 3, 673-682. 
283. Williams D.L. (1985) Molecular biology in arteriosclerosis research.

Arteriosclerosis 5, 213-227.

284. Wills K.N., Huang W.M., Harris M.P., Machemer T., Maneval D.C. \& Gregory R.J. (1995) Gene therapy for hepatocellular carcinoma: chemosensitivity conferred by adenovirus-mediated transfer of the HSV-1 thymidine kinase gene. Cancer Gene Ther. 2 , 191-197.

285. Winston C.B., Schwartz L.H., Fong Y., Blumgart L.H. \& Panicek D.M. (1999) Hepatocellular carcinoma: MR imaging findings in cirrhotic livers and noncirrhotic livers. Radiology 210, 75-79.

286. Woitach J.T., Zhang M., Niu C.H. \& Thorgeirsson S.S. (1998) A retinoblastomabinding protein that affects cell-cycle control and confers transforming ability. Nat.Genet. 19, 371-374.

287. Wolters L.M., Niesters H.G., Hansen B.E., Van Der Ende M.E., Kroon F.P., Richter C., Brinkman K., Meenhorst P.L. \& De Man R.A. (2002) Development of hepatitis B virus resistance for lamivudine in chronic hepatitis B patients co-infected with the human immunodeficiency virus in a Dutch cohort. J.Clin.Virol. 24, 173-181.

288. Wong N., Lai P., Pang E., Fung L.F., Sheng Z., Wong V., Wang W., Hayashi Y., Perlman E., Yuna S., Lau J.W. \& Johnson P.J. (2000) Genomic aberrations in human hepatocellular carcinomas of differing etiologies. Clin.Cancer Res. 6, 4000-4009.

289. Xu L., Hui L., Wang S., Gong J., Jin Y., Wang Y., Ji Y., Wu X., Han Z. \& Hu G. (2001) Expression profiling suggested a regulatory role of liver-enriched 
transcription factors in human hepatocellular carcinoma. Cancer Res. 61, $3176-3181$

290. Yamashita Y., Yoshimatsu S., Sumi M., Harada M. \& Takahashi M. (1993)

Dynamic MR imaging of hepatoma treated by transcatheter arterial embolization therapy. Assessment of treatment effect. Acta Radiol. 34, 303-308.

291. Ylikoski A., Sjoroos M., Lundwall A., Karp M., Lovgren T., Lilja H. \& Iitia A. (1999) Quantitative reverse transcription-PCR assay with an internal standard for the detection of prostate-specific antigen mRNA. Clin.Chem. $45,1397-1407$.

292. You L.R., Chen C.M., Yeh T.S., Tsai T.Y., Mai R.T., Lin C.H. \& Lee Y.H. (1999) Hepatitis $\mathrm{C}$ virus core protein interacts with cellular putative RNA helicase. J.Virol. 73, 2841-2853.

293. Yu M.C., Mack T., Hanisch R., Peters R.L., Henderson B.E. \& Pike M.C. (1983) Hepatitis, alcohol consumption, cigarette smoking, and hepatocellular carcinoma in Los Angeles. Cancer Res. 43, 6077-6079.

294. Zaman S.N., Johnson P.J. \& Williams R. (1990) Silent cirrhosis in patients with hepatocellular carcinoma. Implications for screening in high-incidence and low-incidence areas. Cancer 65, 1607-1610.

295. Zeng J., Gorski R.A. \& Hamer D. (1994) Differential cDNA cloning by enzymatic degrading subtraction (EDS). Nucleic Acids Res. 22, 4381-4385. 
296. Zhang W., Mi J., Li N., Sui L., Wan T., Zhang J., Chen T. \& Cao X. (2001) Identification and characterization of DPZF, a novel human BTB/POZ zinc finger protein sharing homology to BCL-6.

Biochem.Biophys.Res.Commun. 282, 1067-1073.

297. Zhu N., Khoshnan A., Schneider R., Matsumoto M., Dennert G., Ware C. \& Lai M.M. (1998) Hepatitis C virus core protein binds to the cytoplasmic domain of tumor necrosis factor (TNF) receptor 1 and enhances TNFinduced apoptosis. J.Virol. 72, 3691-3697.

298. Zimmerman R.L., Burke M., Young N.A., Solomides C.C.\& Bibbo M. (2002) Diagnostic utility og Glut-1 CA 15-3 in discriminating adenocarcinoma from hepatocellular carcinoma in liver tumors biopsied by fine-needle aspiration. Cancer Cytopathology 96, 53-57.

299. Zweiger G. \& Scott R.W. (1997) From expressed sequence tags to 'epigenomics': an understanding of disease processes. Curr.Opin.Biotechnol. 8, 684-687. 
List of abbreviations 
ADP

AFB1

AFP

APO

aRNA

Asp

ATP

BCL-6

BLAST

C2H2

CD

cDNA

CT

CTL

Cys

DCP

DD

DDRT-PCR

DEPC
Adenosine di-phosphate.

Aflatoxin B1.

Alpha feto protein.

Apolipoprotein.

Amplified RNA.

Aspartate

Adenosine tri-phosphate.

B-cell lymphoma-6.

Basic Local Alignment Search Tool.

zinc finger protein family.

Cluster of differentiation.

Complementary DNA.

Computed tomography.

Cytotoxic T-lymphocytes.

Cysteine.

Des- $\gamma$-carboxyprothrombin.

Differential display.

Differential display reverse transcriptase polymerase chain reaction

Diethyl pyrocarbonate. 
DMSO Dimethyl sulphoxide.

DNA Deoxy ribonucleic acid.

DPZF Dendritic cells derived zinc finger protein.

DSA Digital Subtraction Angiography.

EDS Enzyme degrading subtraction.

EST Expressed sequence tag.

FHIT Fragile histidine triad.

FNH Focal nodular hyperplasia.

GSP Gene specific primer.

HBV Hepatitis B virus.

HCC Hepatocellular carcinoma.

HCV Heaptitis C virus.

HFE Haemochromatosis gene.

HGMP Human genome mapping project.

HH Hereditary haemochromatosis.

His Histidine.

HPRT Hypoxanthine guanine phosphoribosyl transferase.

HKG House keeping gene.

HSP High-scoring segment pair.

HSV-tk Herpes simplex virus thymidine kinase. 
IFN

IS

Jak

MAP

MMLV

MPT

MR

mRNA

MTE

NGSP

NS

NUMP

OLB

ORF

P16INK4

PCK

PCR

PEI

PIVKA

RACE
Interferon.

Internal standard.

Janus kinase (protein tyrosine kinase).

Microtubule affinity-regulating kinase.

Moloney murine leukemia virus reverse transcriptase.

Mitochondrial permeability transition.

Magnetic resonance.

Messenger RNA.

Multiple tissue expression.

Nested gene specific primer.

Non-structural region.

Nested universal primer mix.

Oligonucleotide labelling buffer

Open reading frame.

Cyclin-dependent kinase inhibitor.

Phosphoenolpyruvate carboxykinase.

Polymarase chain reaction.

Percutaneous ethanol injection.

Protein induced by vitamin $\mathrm{K}$ absence.

Rapid amplification of cDNA ends. 
RDA Representational difference analysis.

RF Radiofrequency.

RNA Ribonucleic acid.

RNasin Ribonuclease inhibitor.

RT Reverse transcriptase.

SAP Shrimp alkaline phosphatase.

SMART Switching Mechanism At 5' end of RNA Transcript.

SSRNA Single strand RNA.

STAT Signal transducer and activator of transcription.

TACE Transcatheter Arterial Chemoembolisation.

TCA Tri chloacetic acid.

TGF Transforming growth factor.

TNF Tumour necrosis factor.

Tyr Tyrosine.

UBC Ubiquitin conjugating.

UMP Universal primer mix.

US Ultrasonography.

VEGF Vascular endothelial growth factor. 


\section{Appendix I}

\section{Raw data of RPAs}


Table RPA 1:

\begin{tabular}{|c|c|c|c|c|}
\hline Name & Type & Maximum OD & Adj Volume OD $\times \mathrm{mm}^{2}$ & OD ratio to G3PDH \\
\hline T1 G3PDH & Unknown & 1.64 & 16.91 & 1 \\
\hline NT1 G3PDH & Unknown & 0.63 & 0.63 & 1 \\
\hline T2 G3PDH & Unknown & 1.15 & 5.05 & 1 \\
\hline NT2 G3PDH & Unknown & 1.49 & 15.60 & 1 \\
\hline T3 G3PDH & Unknown & 1.28 & 12.50 & 1 \\
\hline NT3 G3PDH & Unknown & 1.15 & 11.19 & 1 \\
\hline FUL.H.G3PDH & Unknown & 1.87 & 26.34 & 1 \\
\hline ALC G3PDH & Unknown & 0.97 & 3.19 & 1 \\
\hline PBC G3PDH & Unknown & 0.70 & 1.31 & 1 \\
\hline NL G3PDH & Unknown & 1.13 & 6.54 & 1 \\
\hline T1 383 & Unknown & 1.19 & 14.97 & 0.89 \\
\hline NT1 383 & Unknown & 1.19 & 8.11 & 12.93 \\
\hline T2 383 & Unknown & 1.29 & 14.27 & 2.83 \\
\hline NT2 383 & Unknown & 1.38 & 20.99 & 1.35 \\
\hline T3 383 & Unknown & 1.26 & 13.37 & 1.07 \\
\hline NT3 383 & Unknown & 0.93 & 9.70 & 0.87 \\
\hline FUL.H.383 & Unknown & 0.39 & 1.29 & 0.05 \\
\hline ALC 383 & Unknown & 0.38 & 0.30 & 0.09 \\
\hline PBC 383 & Unknown & 0.41 & 0.03 & 0.03 \\
\hline NL.383 & Unknown & 0.29 & 0.10 & 0.02 \\
\hline T1 403 & Unknown & 1.87 & 22.72 & 1.34 \\
\hline NT1 403 & Unknown & 1.97 & 20.88 & 33.25 \\
\hline T2 403 & Unknown & 1.87 & 21.20 & 4.20 \\
\hline NT2 403 & Unknown & 1.87 & 21.736 & 4.31 \\
\hline T3 403 & Unknown & 1.79 & 19.59 & 1.57 \\
\hline NT3 403 & Unknown & 1.64 & 17.91 & 1.60 \\
\hline FUL.H.403 & Unknown & 0.51 & 1.93 & 0.07 \\
\hline
\end{tabular}




\begin{tabular}{|lllll|}
\hline ALC.403 & Unknown & 0.58 & 1.53 & 0.48 \\
PBC 403 & Unknown & 0.38 & 0.60 & 0.45 \\
NL 403 & Unknown & 0.35 & 0.34 & 0.05 \\
Background 1 & Background & 0.89 & 0 & \\
Background 2 & Background & 0.63 & 0 & \\
Background 3 & Background & 0.46 & 0 & \\
Background 4 & Background & 0.42 & 0 & \\
\hline
\end{tabular}

Table RPA 2a:

\begin{tabular}{|c|c|c|c|c|}
\hline Name & Type & Maximum OD & Adj Volume OD $\times \mathrm{mm}^{2}$ & OD ratio to G3PDH \\
\hline T1-G3PDH & Unknown & 0.97 & 6.52 & 1 \\
\hline T2-G3PDH & Unknown & 0.88 & 4.93 & 1 \\
\hline T3-G3PDH & Unknown & 1.53 & 14.23 & 1 \\
\hline NT1-G3PDH & Unknown & 0.35 & 0.35 & 1 \\
\hline $\mathrm{T} 1-333$ & Unknown & 0.27 & 0.39 & 0.06 \\
\hline $\mathrm{T} 2-333$ & Unknown & 0.51 & 2.99 & 0.61 \\
\hline $\mathrm{T} 3-333$ & Unknown & 0.28 & 0.42 & 0.03 \\
\hline NT1-333 & Unknown & 0.30 & 0.87 & 2.46 \\
\hline $\mathrm{T} 1-385 \mathrm{~b}$ & Unknown & 0.70 & 5.78 & 0.89 \\
\hline T2-385 & Unknown & 0.96 & 26.23 & 5.32 \\
\hline T3-385 & Unknown & 0.43 & 4.33 & 0.30 \\
\hline NT1-385 & Unknown & 0.41 & 4.33 & 12.30 \\
\hline $\mathrm{T} 1-361$ & Unknown & 0.67 & 10.468 & 1.61 \\
\hline $\mathrm{T} 2-361$ & Unknown & 1.49 & 37.51 & 7.60 \\
\hline T3-361 & Unknown & 0.49 & 6.13 & 0.43 \\
\hline NT1-361 & Unknown & 0.77 & 10.66 & 30.28 \\
\hline Background 1 & Background & 0.28 & 0 & \\
\hline Background 2 & Background & 0.25 & 0 & \\
\hline
\end{tabular}


Table RPA 2b:

\begin{tabular}{|lllll|}
\hline Name & Type & Maximum OD & Adj Volume OD x mm & OD ratio to G3PDH \\
\hline NT2-G3PDH & Unknown & 1.67 & 45.80 & 1 \\
NT2-333 & Unknown & 0.95 & 3.49 & 0.08 \\
NT2-385 & Unknown & 0.98 & 7.07 & 0.15 \\
NT2-361 & Unknown & 2.04 & 52.27 & 1.14 \\
Background & Background & & 0 & \\
\hline
\end{tabular}

Table RPA 2c:

\begin{tabular}{|lllll|}
\hline Name & Type & Maximum OD & Adj Volume OD x mm ${ }^{2}$ & OD ratio to G3PDH \\
\hline NT3-G3PDH & Unknown & 1.53 & 17.21 & 1 \\
C1-G3PDH & Unknown & 2.09 & 90.99 & 1 \\
C2-G3PDH & Unknown & 1.87 & 40.64 & 1 \\
C3-G3PDH & Unknown & 1.78 & 24.02 & 1 \\
NL-G3PDH & Unknown & 1.87 & 58.30 & 1 \\
NT3-385 & Unknown & 0.34 & 1.76 & 0.10 \\
C1-385 & Unknown & 0.57 & 5.68 & 0.06 \\
C2-385 & Unknown & 1.87 & 67.47 & 1.66 \\
C3-385 & Unknown & 1.45 & 14.09 & 0.58 \\
NL-385 & Unknown & 1.23 & 18.61 & 0.32 \\
NT3-361 & Unknown & 0.90 & 16.59 & 0.96 \\
C1-361 & Unknown & 1.53 & 24.19 & 0.27 \\
C2-361 & Unknown & 1.78 & 47.30 & 1.16 \\
C3-361 & Unknown & 1.34 & 19.36 & 0.80 \\
NL-361 & Unknown & 1.37 & 11.47 & 0.20 \\
Background 1 & Background & 0.23 & 0 & \\
Background 2 & Background & 0.18 & 0 & \\
& & & & \\
\hline
\end{tabular}


RPA3a:

\begin{tabular}{|lllll|}
\hline Name & Type & Maximum OD & Adj Volume OD x mm ${ }^{2}$ & OD ratio to G3PDH \\
\hline T1-G3PDG & Unknown & 316.155 & 221.02 & 1 \\
T2-G3PDH & Unknown & 147.748 & 90.47 & 1 \\
T3-G3PDH & Unknown & 194.355 & 119.19 & 1 \\
NT1-G3PDH & Unknown & 88.863 & 43.24 & 1 \\
NT2-G3PDH & Unknown & 118.1 & 59.79 & 1 \\
NT3-G3PDH & Unknown & 248.487 & 184.87 & 1 \\
T1-373 & Unknown & 161.92 & 110.86 & 0.50 \\
T2-373 & Unknown & 101.591 & 62.97 & 0.70 \\
T3-373 & Unknown & 67.303 & 39.01 & 0.33 \\
NT1-373 & Unknown & 40.106 & 22.71 & 0.53 \\
NT2-373 & Unknown & 31.919 & 7.63 & 0.13 \\
NT3-373 & Unknown & 89.548 & 57.96 & 0.31 \\
T1-299 & Unknown & 62.916 & 34.94 & 0.16 \\
T2-299 & Unknown & 143.422 & 108.27 & 1.20 \\
T3-299 & Unknown & 196.967 & 151.02 & 0.75 \\
NT1-299 & Unknown & 204.156 & 159.12 & \\
NT2-299 & Unknown & 58.494 & 26.65 & 1.27 \\
NT3-299 & Unknown & 189.906 & 138.93 & 0.45 \\
Background 1 & Background & 49.957 & 0 & 1.27 \\
\hline
\end{tabular}


RPA3b:

\begin{tabular}{|lllll|}
\hline Name & Type & Maximum OD & Adj Volume OD x mm² & OD ratio to G3PDH \\
\hline C1-G3PDH & Unknown & 2.36 & 64.27 & 1 \\
C2-G3PDH & Unknown & 1.97 & 37.01 & 1 \\
C3-G3PDH & Unknown & 2.22 & 104.77 & 1 \\
NL-G3PDH & Unknown & 2.21 & 124.75 & 1 \\
C1-373 & Unknown & 1.71 & 25.28 & 0.39 \\
C2-373 & Unknown & 1.70 & 14.56 & 0.39 \\
C3-373 & Unknown & 2.09 & 57.49 & 0.55 \\
NL-373 & Unknown & 2.22 & 87.20 & 0.70 \\
C1-299 & Unknown & 0.59 & 3.17 & 0.05 \\
C2-299 & Unknown & 0.76 & 3.34 & 0.09 \\
C3-299 & Unknown & 0.83 & 4.37 & 0.04 \\
NL-299 & Unknown & 0.80 & 4.05 & 0.03 \\
BG2 & Background & 0.48 & 0 & \\
\hline
\end{tabular}

RPA4:

\begin{tabular}{|lllll|}
\hline Name & Type & Maximum OD & Adj Volume OD x mm² & OD ratio to G3PDH \\
\hline T1-G3PDH & Unknown & 0.37 & 2.19 & 1 \\
T2-G3PDH & Unknown & 0.53 & 6.41 & 1 \\
T3-G3PDH & Unknown & 0.80 & 13.75 & 1 \\
NT1-G3PDH & Unknown & 2.09 & 82.00 & 1 \\
NT2-G3PDH & Unknown & 1.03 & 14.86 & 1 \\
NT3-G3PDH & Unknown & 1.07 & 15.99 & 1 \\
C1-G3PDH & Unknown & 1.09 & 17.61 & 1 \\
C2-G3PDH & Unknown & 1.45 & 27.42 & 1 \\
C3-G3PDH & Unknown & 1.78 & 76.81 & 1 \\
\hline
\end{tabular}




\begin{tabular}{|lllll|}
\hline NL-G3PDH & Unknown & 0.99 & 21.42 & 1 \\
T1-389 & Unknown & 0.36 & 0.08 & 0.01 \\
T2-389 & Unknown & 0.37 & 5.50 & 0.15 \\
T3-389 & Unknown & 0.70 & 12.56 & 0.19 \\
NT1-389 & Unknown & 1.64 & 29.24 & 0.36 \\
NT2-389 & Unknown & 0.53 & 15.59 & 0.19 \\
NT3-389 & Unknown & 0.55 & 9.66 & 0.11 \\
C1-389 & Unknown & 0.37 & 4.11 & 0.23 \\
C2-389 & Unknown & 0.38 & 2.54 & 0.09 \\
C3-389 & Unknown & 1.06 & 11.68 & 0.15 \\
NL-389 & Unknown & 0.36 & 2.21 & 0.10 \\
T1-397 & Unknown & 1.41 & 31.30 & 14.31 \\
T2-397 & Unknown & 1.45 & 32.60 & 5.09 \\
T3-397 & Unknown & 1.41 & 28.32 & 2.06 \\
NT1-397 & Unknown & 1.87 & 79.80 & 0.97 \\
NT2-397 & Unknown & 1.58 & 22.60 & 1.52 \\
NT3-397 & Unknown & 0.77 & 12.04 & 0.75 \\
C1-397 & Unknown & 0.96 & 24.21 & 1.16 \\
C2-397 & Unknown & 0.54 & 8.17 & \\
C3-397 & Unknown & 0.91 & 22.90 & \\
NL-397 & Unknown & 1.04 & 24.76 & 0.30 \\
BG2 & Background & 0.35 & 0 & 0.30 \\
\hline
\end{tabular}


RPA5a:

\begin{tabular}{|c|c|c|c|c|}
\hline Name & Type & Maximum OD & Adj Volume OD $\times \mathrm{mm}^{2}$ & OD ratio to G3PDH \\
\hline T1-G3PDH & Unknown & 0.54 & 3.83 & 1 \\
\hline NT1-G3PDH & Unknown & 2.087 & 79.05 & 1 \\
\hline NT2-G3PDH & Unknown & 1.782 & 29.61 & 1 \\
\hline NT3-G3PDH & Unknown & 0.699 & 4.98 & 1 \\
\hline FH-G3PDH & Unknown & 1.642 & 28.36 & 1 \\
\hline ALC-G3PDH & Unknown & 1.106 & 8.32 & 1 \\
\hline T1-311 & Unknown & 0.363 & 0.19 & 0.05 \\
\hline NT1-311 & Unknown & 1.487 & 15.26 & 0.19 \\
\hline NT2-311 & Unknown & 0.374 & 0.59 & 0.02 \\
\hline NT3-311 & Unknown & 0.334 & 0.11 & 0.02 \\
\hline FH-311 & Unknown & 0.409 & 0.69 & 0.02 \\
\hline ALC-311 & Unknown & 0.401 & 0.35 & 0.04 \\
\hline T1-287 & Unknown & 0.588 & 7.38 & 1.93 \\
\hline NT1-287 & Unknown & 0.735 & 4.39 & 0.06 \\
\hline NT2-287 & Unknown & 0.647 & 3.99 & 0.14 \\
\hline NT3-287 & Unknown & 0.505 & 1.94 & 0.39 \\
\hline FH-287 & Unknown & 0.459 & 1.18 & 0.04 \\
\hline ALC-287 & Unknown & 0.51 & 1.09 & 0.13 \\
\hline T1-281 & Unknown & 1.09 & 18.93 & 4.94 \\
\hline NT1-281 & Unknown & 1.583 & 24.95 & 0.32 \\
\hline NT2-281 & Unknown & 1.583 & 34.38 & 1.16 \\
\hline NT3-281 & Unknown & 1.187 & 16.59 & 3.33 \\
\hline FH-281 & Unknown & 0.653 & 5.757 & 0.20 \\
\hline ALC-281 & Unknown & 0.593 & 3.18 & 0.38 \\
\hline BG1 & Background & 0.463 & 0 & \\
\hline BG2 & Background & 0.401 & 0 & \\
\hline
\end{tabular}




\section{RPA5b:}

\begin{tabular}{|lllll|}
\hline Name & Type & Maximum OD & Adj Volume OD x mm ${ }^{2}$ & OD ratio to G3PDH \\
\hline NL-G3PDH & Unknown & 0.33 & 2.45 & 1 \\
NL-281 & Unknown & 0.65 & 5.99 & 2.44 \\
NL-287 & Unknown & 0.29 & 1.75 & 0.71 \\
NL-311 & Unknown & 0.482 & 0 & 0 \\
BG & Background & 0.27 & 0 & \\
\hline
\end{tabular}

\section{RPA5c:}

\begin{tabular}{|lllll|}
\hline Name & Type & Maximum OD & Adj Volume OD x mm² & OD ratio to G3PDH \\
\hline T3-G3PDH & Unknown & 1.64 & 14.66 & 1 \\
T3-311 & Unknown & 0.44 & 1.03 & 0.07 \\
T3-287 & Unknown & 0.88 & 10.70 & 0.73 \\
T3-281 & Unknown & 1.97 & 35.14 & 2.40 \\
BG & Background & 0.24 & 0 & \\
\hline
\end{tabular}




\section{Appendix II}

Constitution of buffers and solutions 


\section{$10 \times$ blunt-end ligation buffer:}

0.66 M Tris- $\mathrm{HCl}$ (pH 7.6), $50 \mathrm{mM} \mathrm{MgCl} 2,50 \mathrm{mM}$ DTT, $1 \mathrm{mg} / \mathrm{ml}$ bovine serum albumin (optional), $10 \mathrm{mM}$ hexamminecobalt chloride (optional), $5 \mathrm{mM}$ spermidine $\mathrm{HCl}$ (optional), The buffer is stored in small aliquots at $-20^{\circ}$.

\section{0x Ligation buffer:}

0.5 M Tris- $\mathrm{HCl}$ (pH 7.6), $100 \mathrm{mM} \mathrm{MgCl2,} 100 \mathrm{mM}$ dithiothreitol, $500 \mu \mathrm{g} / \mathrm{ml}$ bovine serum albumin (BSA).

\section{$10 \%$ SDS (sodium dodecyl sulphate):}

$100 \mathrm{~g}$ of electrophoresis-grade SDS are dissolved in $900 \mathrm{ml}$ of $\mathrm{H}_{2} \mathrm{O}$. The solution is heated to $68^{\circ} \mathrm{C}$ to assist dissolution. $\mathrm{pH}$ is adjusted to 7.2 by adding a few drops of concentrated $\mathrm{HCl}$. The volume is adjusted to 1 liter with $\mathrm{H}_{2} \mathrm{O}$.

\section{0x T4 DNA ligase buffer:}

$200 \mathrm{mM}$ Tris- $\mathrm{HCl}$ (pH 7.6), $50 \mathrm{mM} \mathrm{HgCl}, 50 \mathrm{mM}$ dithiothreitol, $500 \mu \mathrm{g} / \mathrm{ml}$ bovine serum albumin.

This buffer must be kept in aliquots at $-20^{\circ} \mathrm{C}$ and ATP should be added at the time of setting up the reaction.

\section{$10 \times$ T4 polynucleotide kinase buffer:}

0.5 M Tris- $\mathrm{HCl}(\mathrm{pH} 7.6), 0.1 \mathrm{M} \mathrm{HgCl}_{2}, 50 \mathrm{mM}$ dithiothreitol, $1 \mathrm{mM}$ spermidine $\mathrm{HCl}$, 1 mM EDTA (pH 8.0). 


\section{0 x SSPE:}

175.3 $\mathrm{g}$ of $\mathrm{NaCl}, 27.6 \mathrm{~g}$ of $\mathrm{NaH}_{2} \mathrm{PO} 4$ and $7.4 \mathrm{~g}$ EDTA are dissolved in $800 \mathrm{ml}$ of $\mathrm{H}_{2} \mathrm{O}$. $\mathrm{pH}$ is adjusted to 7.4 with $\mathrm{NaOH}(\sim 6.5 \mathrm{ml}$ of a $10 \mathrm{~N}$ solution). The volume is adjusted to 1 liter with $\mathrm{H}_{2} \mathrm{O}$. The solution is sterilised by autoclaving.

\section{Ampicillin agar plates:}

Per liter the following reagents were added to $950 \mathrm{ml}$ deionised water: 10 gm bactotryptone, 5 gm bacto-yeast extract, $10 \mathrm{gm} \mathrm{NaCl}$ and $15 \mathrm{gm}$ bacto-agar. The solution was shaken until the solutes were dissolved. The $\mathrm{pH}$ was adjusted to 7.0 with $5{ }_{\mathrm{N}} \mathrm{NaOH}$. The volume of the solution was adjusted to 1 liter with deionised water and sterilised by autoclaving for 20 minutes at $15 \mathrm{lb} / \mathrm{sq}$. in. on liquid cycle. The solution was left to cool down to $50^{\circ} \mathrm{C}$ then ampicillin was added at $50 \mu \mathrm{g} / \mathrm{ml}$. The solution was mixed by swirling and plates were poured from the flask allowing 30-35 $\mathrm{ml}$ of medium per 90mm plate.

\section{Denhardt's reagent:}

$50 \mathrm{x}$ stock solution contains $5 \mathrm{~g}$ of Ficoll (Type 400, Pharmacia), $5 \mathrm{~g}$ of polyvinylpyrrolidone, $5 \mathrm{~g}$ of bovine serum albumin (Fraction V; Sigma), and water to $500 \mathrm{ml}$.

\section{DEPC (Diethyl pyrocarbonate) treated water:}

Water is treated with $0.1 \% \mathrm{DEPC}$ for at least 12 hours at $37^{\circ} \mathrm{C}$ then heated to $100^{\circ} \mathrm{C}$ for 15 minutes or autoclaved for 15 minutes at $15 \mathrm{Ib} / \mathrm{sq}$.in.on liquid cycle.

\section{Differential display loading dye:}

$2 \mathrm{ml}$ glycerol, $18 \mathrm{ml}$ water, $0.01 \mathrm{gm}$ xylene cyanol, $0.01 \mathrm{gm}$ bromophenol blue.

\section{DTT (1M Dithiothreitol):}


Dissolve $3.09 \mathrm{~g}$ of DTT in $20 \mathrm{ml}$ of $0.01 \mathrm{M}$ sodium acetate $(\mathrm{pH} 5.2)$. The solution is sterilised by filtration, dispensed into $1 \mathrm{ml}$ aliquots and stored at $-20^{\circ} \mathrm{C}$.

\section{Glyoxal gel loading dye:}

$50 \%$ Glycerol, $10 \mathrm{mM}$ sodium phosphate $(\mathrm{pH} 7.0), 0.25 \%$ bromophenol blue, $0.25 \%$ xylene cyarol FF.

\section{I.ysis buffer:}

$15 \mathrm{ml}$ stock buffer and $300 \mu \mathrm{l}$ RNase protein degrader, Invitrogen mRNA extraction kit.

\section{TNE buffer:}

Tris $10 \mathrm{mM}$ (pH 7.5- 8), $\mathrm{NaCl} 100 \mathrm{mM}$, EDTA 1mM.

\section{OLB (Oligo-labelling buffer):}

Solution O: $1.25 \mathrm{M}$ Tris- $\mathrm{HCl}$ and $0.125 \mathrm{M} \mathrm{MgCl} 2$ at $\mathrm{pH}$ 8.0. The solution is stored at $4^{\circ} \mathrm{C}$.

Solution A: $1 \mathrm{ml}$ solution $\mathrm{O}, 18 \mu \mathrm{l} 2$-mercaptoethanol and $5 \mu 1$ of dATP, $5 \mu 1$ of dTTP and $5 \mu$ l of dGTP (each previously dissolved in TE [3mM Tris- $\mathrm{HCl}, 0.2 \mathrm{mEDTA}, \mathrm{pH}$ 7.0] at concentration of $0.1 \mathrm{M}$ )

Solution B: $2 \mathrm{M}$ HEPES titrated to $\mathrm{pH} 6.6$ with $4 \mathrm{M} \mathrm{NaOH}$ and stored at $4^{\circ} \mathrm{C}$.

Solution C: Hexadeoxyribonucleotides evenly suspended in $\mathrm{TE}$ at $90 \mathrm{OD}_{260} \mathrm{u} / \mathrm{ml}$ and stored at $-20^{\circ} \mathrm{C}$.

OLB is prepared by mixing solutions $\mathrm{A}, \mathrm{B}$ and $\mathrm{C}$ at $100: 250: 150$ then stored at $-20^{\circ} \mathrm{C}$.

\section{React 3:}

50mM Tris $\mathrm{Hcl} \mathrm{pH} 8.0,6 \mathrm{mM} \mathrm{MgCl} 2,50 \mathrm{mM} \mathrm{KCl}, 50 \mathrm{mM} \mathrm{NaCl}$ 


\section{React 4:}

$20 \mathrm{mM}$ Tris-Hcl (pH7.4), $5 \mathrm{mM} \mathrm{MgCl}_{2}, 50 \mathrm{mMKCl}$.

\section{React 6:}

$50 \mathrm{mM}$ Tris $\mathrm{Hcl} \mathrm{pH} \mathrm{7.4,6mM} \mathrm{MgCl2,} \mathrm{50mM} \mathrm{KCl,} \mathrm{50mM} \mathrm{NaCl.}$

SAP (Shrimp alkaline phosphatase) buffer:

200mM Tris- $\mathrm{HCl}, \mathrm{pH} 8.0,100 \mathrm{mM} \mathrm{MgCl} 2$.

\section{Sephadex:}

Sephadex resin is added to distilled sterile water in a $500 \mathrm{ml}$ beaker $(10 \mathrm{~g}$ of Sephadex G-50 [medium] yields $160 \mathrm{ml}$ of slurry). The swollen resin is washed is washed with distilled sterile water several times to remove double dextran.

The resin is equilibrated in TE (pH 7.6) and autoclaved at $10 \mathrm{Ib} / \mathrm{sq}$. in. for 15 minutes and stored at room temperature.

\section{TBE (Tris-borate) 5x:}

$54 \mathrm{~g}$ Tris base, $27.5 \mathrm{~g}$ boric acid, $20 \mathrm{ml} \mathrm{0.5} \mathrm{M} \mathrm{EDTA} \mathrm{(pH} \mathrm{8.0).}$

TNE buffer:

Tris $10 \mathrm{mM}(\mathrm{pH} 7.5-8), \mathrm{NaCl} 100 \mathrm{mM}$ and EDTA $1 \mathrm{mM}$.

\section{TTE:}

$215 \mathrm{~g}$ of Tris base, $71.3 \mathrm{~g}$ of Taurine, $20 \mathrm{ml}$ of $0.5 \mathrm{M}$ EDTA and made up to 1 litre with water.

\section{X-gal (5-Bromo-4-chloro-3-indolyl- $\beta$-D-galactoside):}


A stock solution is made by dissolving X-gal in dimethylformamide to make a 20 $\mathrm{mg} / \mathrm{ml}$ solution. Polypropylene or glass tubes can be used. The tube containing the solution should be wrapped in aluminium foil to avoid damage by light and stored at $20^{\circ} \mathrm{C}$. It is not necessary to sterilise $\mathrm{X}$-gal by filtration. 
Appendix III

Abstract presented in EASL, 2001 meeting 
on cell-to-cell contact. Despite this potent bystander cell killing, gene therapy using prodrug activating systems remains a locoregional therapeutic approach unless it results in the induction of a systemic antitumor immunity. Such immunomodulatory effects have been observed for the HSV-tk/GCV system in a murine melanoma model, which were dependend on the induction of necrtotic cell death and the upregulation of heat shock proteins (hsp70). Apoptotic tumor cell death did not result in detectable antitumor immunity in this model.

Methods: To characterize the molecular mechanisms involved in PNP and HSV-tk mediated cell death in human hepatocellular carcinoma (HCC) cells with respect to potential immunomodulatory effects, we transduced the HCC cell lines HepG2 and Hep3B with PNP or HSV-tk using adenoviral vectors followed by prodrug incubation. Apoptosis was dtermined by PARP cleavage, DNA fragmentation and AnnexinV-FACS. Expression of hsp70, p53, Fas and FasL were determined by Western blot, flow cytometrie and RT-PCR.

Results and Discussion: In p53 positive (HepG2) and p53 negative (Hep3B) cells, cell death induced by both prodrug activating systems was identified as apoptosis. In HepG2 cells apoptosis occurred earlier and was preceded by $\mathrm{p} 53$ accumulation: HSV-tk/GCV, but not PNP/fludarabine, induced the expression of Fas and FasL in HepG2 cells. Furthermore, cell death induced by both prodrug activating systems did not result in detectable upregulation of cellular heat shock protein 70 in human HCC cells, which might indicate potential limitations for immunomodulatory effects induced by prodrug activating systems in human gene therapy of HCC.

1592 GENE EXPRESSION IN HCV-ASSOCIATED HCC IDENTIFICATION OF AN UPREGULATED GENE ENCODING A PROTEIN RELATED TO UBIQUITIN CONJUGATING ENZYME

G.M. El-Nady, R. Ling, T.J. Harrison. Centre for Hepatology, Department of Medicine, Royal Free and University College Medical School, UCL, London, UK

Objective: To understand better the cellular changes in HCV-induced human hepatocellular carcinoma by identifying up- or down-regulated genes.

Methods: Differential display RT-PCR was used to compare levels of gene expression in tumour and non-tumour tissue from the same livers. The differentially expressed gene fragments were sequenced and compared to the nucleotide sequence database. Differential expression was confirmed using a ribonuclease protection assay (RPA). The relative expression levels of one candidate gene were studied in various normal tissues and some malignant cell lines using multiple tissue expression (MTE) arrays and further characterisation of the gene was carried out using programmes available at the UK Human Genome Mapping Project website.

Results: 52 differentially expressed cDNA fragments were identified, of which 47 were up-regulated and 5 down-regulated in the tumour tissue, and 22 were cloned and sequenced. RPA analysis confirmed reproducibly that one particular CDNA was up-regulated in the tumour cells. MTE revealed that this gene is expressed at high levels in various cell lines derived from human tumours. Sequence analysis revealed that this gene lies on chromosome 17 end encodes a protein related to ubiquitin conjugating enzyme. The precise length of this gene is still unknown.

Conclusion: There seems to be a novel gene on chromosome 17 which is expressed at higher levels in tumour than in adjacent non-tumour tissue in $\mathrm{HCV}$ associated $\mathrm{HCC}$.

\section{P05 Category 5: Viral hepatitis: basic aspects}

\section{EFFECT OF CHRONIC B HEPATITIS ACTIVITY ON PLASMA TRANSFORMING GROWTH FACTOR-BETA 1 CONCENTRATION}

Robert Flisiak, Danuta Prokopowicz, Jerzy Jaroszewicz, Anatol Panasiuk. Department of Infectious Diseases, Medical Academy, Bialystok, Poland

Transforming growth factor-beta 1 (TGF-b1) plays a principal role in induction of hepatic fibrosis, and is considedered as a possible biomarker of liver function impairment. Our previous research demonstrated correlation between liver insufficiency in cirrhotics and TGF-bl plasma levels. Aim of this study was to evaluate a possible effect of chronic HBV infection activity on plasma TGF-b1 concentration.

TGF-b1 was measured with an EIA in plasma of 26 patients with chronic B hepatitis. Normal values were obtained from 13 healthy voluteers. Results were analysed in respect to biochemical indices of liver injury, serum HBV load (Quantiplex HBV-DNA assay) and morphological changes in liver biopsy specimens.

Mean plasma concentration of TGF-b1 $(27.4 \pm 4.2 \mathrm{ng} / \mathrm{ml})$ was higher than normal values $(18.3 \pm 1.6 \mathrm{ng} / \mathrm{ml})$. Comparison of TGF-b1 concentration with values of biochemical indices of liver injury revealed significant correlation with bilirubin concentration $(r=0.427)$, activities of aminotransferases (ALT: $r=0.536$, AST: $r=0.606$ ), alkaline phosphatase $(r=0.395)$ and gamma-glutamyltranspeptidase $(r=0.598)$. There was no association between plasma TGF-b1 and serum HBV-DNA level. Analysis performed in comparison with histologic picture showed significant correlation $(r=0.643)$ with plasma TGF-b1 only in respect to degree of fibrosis, but not in respect to inflammatory activity.

These results indicate possible use of plasma TGF-b1 measurement as an early marker of liver fibrosis. Follow-up of patients involved in this study can evaluate its prognostic value during progression to liver cirrhosis.

\section{SERUM TUMOR NECROSIS FACTOR LEVEL IN CHRONIC HEPATITIS C}

M.G. Neuman, J. Benhamou, R. Akremi, T. Asselah, M. Martinot, N. Boyer, P. Marcellin. Sunnybrook \& Women's College Health Sciences Centre., Sunnybrook WCHSC, Canada; Hospital Beaujon, France

Aims: to measure tumor necrosis alpha (TNF $\beta$ ) as marker of liver inflammation in chronic hepatitis $\mathrm{C}(\mathrm{HCV})$-patients.

Methods: 96 patients received I-CT: IFN $\beta 2 \mathrm{~b}(3 \mathrm{MU}$ TIW for 24 weeks) + ribavirin R-1200 mg/day versus MT: IFN $\beta$ 2b and II-CTP1: pegilated (PEG) IFN $\beta 2 \mathrm{~b} 1.5 \mathrm{mcg}+800 \mathrm{mg} /$ day for 48 weeks and CTP2 PEG-IFN $\beta 2 \mathrm{~b} 1.5 \mathrm{mcg}$ and R $1200 \mathrm{mg} /$ day for 4 weeks followed by PEG-IFN $\beta 2 \mathrm{~b} 0.5 \mathrm{mcg} / \mathrm{kg}$ and R $1200 \mathrm{mg} /$ day additional 44 weeks vs. MTP: PEG-IFN $\beta 2 \mathrm{~b} 1.5 \mathrm{mcg} Q W$ alone.

\begin{tabular}{lccccc}
\hline Time & MT (18) & CT (36) & MTP (26) & CTP 1 (11) & CTP2 (5) \\
\hline 0 & $355 \pm 29$ & $331 \pm 29$ & $457 \pm 61^{* *}$ & $437 \pm 86^{*}$ & $408 \pm 79^{*}$ \\
1 & $324 \pm 16$ & $302 \pm 15$ & $278 \pm 48^{*}$ & $338 \pm 73^{\wedge}$ & $166 \pm 29^{*}$ \\
2 & $254 \pm 19^{*}$ & $277 \pm 14^{*}$ & $330 \pm 37^{*}$ & $364 \pm 29^{* *}$ & $193 \pm 66^{*}$ \\
3 & $286 \pm 20^{*}$ & $273 \pm 22^{*}$ & $447 \pm 50^{* *}$ & $373 \pm 79^{* *}$ & $223 \pm 61^{*}$ \\
\hline "p 0.001 lower than the basal value; p < 0.05 lower than the basal value; *p \\
< 0.05 higher than standard therapy at the same time; **p < 0.001 higher than \\
standard therapy at the same point in time; ${ }^{*}$ lower than the values of CTP1 at \\
same time.
\end{tabular}

